FHWA/IN/JTRP-2006/29

Final Report

RISK ASSESSMENT OF VARIOUS MEDIAN TREATMENTS OF RURAL INTERSTATES

Natalie Villwock

Nicolas Blond

Andrew Tarko

August 2008 


\section{TECHNICAL Summary}

INDOT Research

Technology Transfer and Project Implementation Information

TRB Subject Code: 34-9 Guardrail and Barriers

Publication No.: FHWA/IN/JTRP-2006/29, SPR-2950

August 2008

Final Report

\section{Risk Assessment of Various Median Treatments of Rural Interstates}

\section{Introduction}

The majority of the rural interstates in Indiana are four-lane roadways and the Indiana Department of Transportation (INDOT) is planning to expand many of them to six-lane facilities to accommodate the increasing traffic. These expansions will occur over the next twenty to thirty years and INDOT must decide where to locate the additional lanes in cross-sections of the widened rural freeways: inside by reducing the median width or outside by widening the right of way. This consideration requires comparing the safety impacts of narrowing the medians with the economic engineering aspects of widening the roadway and the bridge structures. The safety impacts of narrowing medians and installing barriers on them are mostly unknown.

Until recently, Indiana only had two dominant median treatments in practice: a depressed median without barriers and a flush median with a concrete barrier. INDOT would like to investigate other median treatments used in other states to determine if these median treatments should be considered in Indiana conditions on medians with reduced widths.

A complete set of equations for predicting crash frequencies on rural freeway sections with alternative median treatments is needed to allow designers and planners include safety consideration to economic analysis of alternative rural freeway designs. This research report is aimed to fill the gap in the existing knowledge of safety effects of various median solutions including both the ones recommended by AASHTO and additional ones used by states.

\section{Findings}

Negative binomial models were developed to predict the frequency of crashes in three categories: single vehicle (SV), multiple vehicles same direction (MVSD), and multiple vehicles opposite directions (MVOD). Logit models were developed to split the frequency of crashes into two severity categories: fatal/injury crashes and property damage crashes. It has been found that different median treatments affect different types of crashes differently. Aggregating crashes when modeling safety impact of median treatments may lead to less effective prediction of crash frequency and severity. The obtained results support the findings of previous research that narrowing a freeway median increases both the frequency and severity of the cross-over crashes. Furthermore, the frequency of MVSD crashes and SV crashes increase on segments with berm median treatments. Sloped median treatments are also attributed with an increase in the SV crashes. Reducing medians and installing concrete barriers seem to eliminate cross-over crashes but increase the frequency and severity of SV and MVSD crashes. The majority of the developed crash frequency models include variables that represent the road curvature; it is primarily the average horizontal curvature. Curvature, predominately the presence of horizontal curves, also had a significant negative effect on the severity of crashes. 


\section{Implementation}

Obtained equations can be used by designers and planners to predict the frequency and severity of crashes for alternative median solutions on rural freeways in the states that had contributed the research data. The results of this study help designers and planners select better median treatments on modernized rural freeways that often involve adding traffic lanes, narrowing medians, and installing barriers. The developed equations can be used as part of economic analysis of safety, construction, and maintenance costs.

The report includes a chapter where all the equations are presented in an organized and uniform manner. There is also a table which summarized the obtained equations. Nevertheless, the multiplicity and complexity of the equations call for a computer based application such as a programmed spreadsheet.

\section{Contacts}

For more information:

Prof. Andrew P. Tarko

Principal Investigator

School of Civil Engineering

Purdue University

West Lafayette IN 47907

Phone: (765) 494-5027

Fax: (765) 496-7996

E-mail: tarko@purdue.edu

\section{Indiana Department of Transportation}

Division of Research

1205 Montgomery Street

P.O. Box 2279

West Lafayette, IN 47906

Phone: (765) 463-1521

Fax: (765) 497-1665

\section{Purdue University}

Joint Transportation Research Program

School of Civil Engineering

West Lafayette, IN 47907-1284

Phone: (765) 494-9310

Fax: (765) 496-7996

E:mail: jtrp@ecn.purdue.edu 
Final Report

FHWA/IN/JTRP-2006/29

\title{
RISK ASSESSMENT OF VARIOUS MEDIAN TREATMENTS OF RURAL INTERSTATES
}

\author{
By \\ Natalie M. Villwock \\ Graduate Research Assistant \\ Nicolas Blond \\ Graduate Research Assistant \\ Andrew P. Tarko \\ Professor of Civil Engineering \\ School of Civil Engineering \\ Purdue University \\ Joint Transportation Research Program \\ Project No. C-36-59QQ \\ File No. 8-5-43 \\ SPR-2950 \\ Conducted in Cooperation with the \\ Indiana Department of Transportation \\ and the U.S. Department of Transportation \\ Federal Highway Administration
}

The contents of this report reflect the views of the authors who are responsible for the facts and accuracy of the data presented herein. The contents do not necessarily reflect the official views or policies of the Indiana Department of Transportation and the Federal Highway Administration. This report does not constitute a standard, specification, or regulation.

Purdue University

West Lafayette, IN

August 2008 


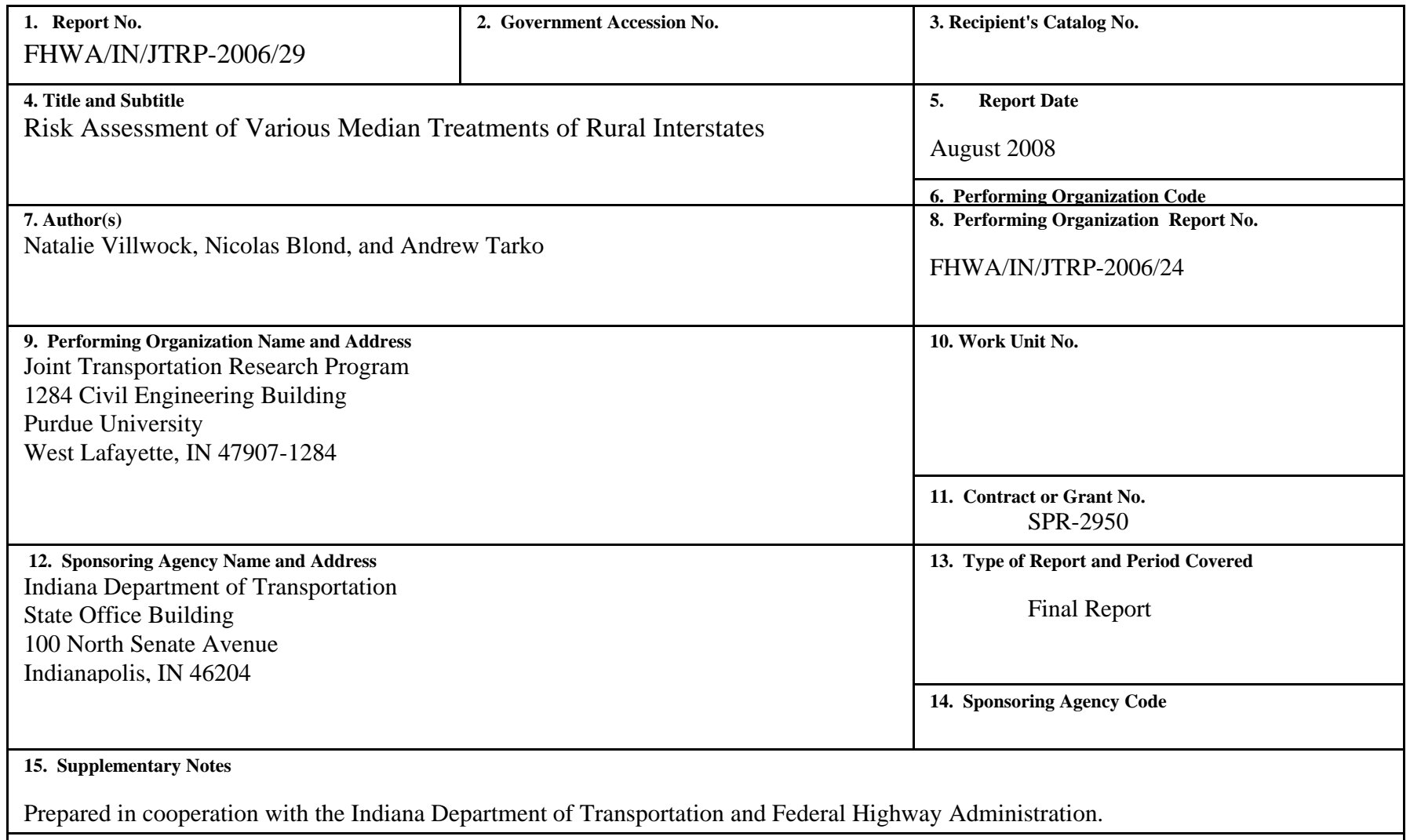

\section{Abstract}

This report presents results of a comprehensive study that evaluates the safety impacts of alternative median treatments on rural freeways. Extensive data were obtained from Indiana, Colorado, Illinois, Iowa, Missouri, New York, Ohio, Oregon, Washington, and Wisconsin. The studied median treatments include AASHTO-recommended treatments: depressed medians, depressed medians with high and lowtensioned cable barriers, and flush medians with concrete barriers. Other treatments used in the freeway design were also studied: medians with berms, sloped medians, and depressed medians with berms.

Negative binomial models were developed to predict the frequency of crashes in three categories: single vehicle (SV), multiple vehicles same direction (MVSD), and multiple vehicles opposite directions (MVOD). Logit models were developed to split the frequency of crashes into two severity categories: fatal/injury crashes and property damage crashes. The obtained results support the findings of previous research that narrowing a freeway median increases the frequency of cross-median crashes. Furthermore, the frequency of MVSD crashes and SV crashes increase on segments with berm median treatments. Sloped median treatments are also attributed with an increase in the SV crashes. The majority of the developed frequency equations have a variable that represents the road curvature; it was primarily the average horizontal curvature. Freeway segments with medians with reduced width tend to experience more severe crashes than segments with wide medians. Curvature, predominately the presence of horizontal curves, also had a significant negative effect on the severity of crashes.

Obtained equations can be used by designers and planners to predict the frequency and severity of crashes for alternative median solutions on rural freeways in the states that had contributed the research data. The results of this study help designers and planners select better median treatments on modernized rural freeways that often involve adding traffic lanes, narrowing medians, and installing barriers. The developed equations can be used as part of economic analysis of safety, construction, and maintenance costs.

\section{Key Words}

Freeway, safety, median, median treatments, median barriers, crash frequency, crash severity, regression analysis, logit model.

\section{Distribution Statement}

No restrictions. This document is available to the public through the National Technical Information Service, Springfield, VA 22161



Form DOT F 1700.7 (8-69) 


\title{
ACKNOWLEDGEMENTS
}

We would like to express our gratitude to the following departments of transportations for providing us with the necessary data to include the respective state in this research:

\author{
Indiana Department of Transportation \\ Colorado Department of Transportation \\ Illinois Department of Transportation \\ Iowa Department of Transportation \\ Missouri Department of Transportation \\ New York Department of Transportation \\ Ohio Department of Transportation \\ Oregon Department of Transportation \\ Washington Department of Transportation \\ Wisconsin Department of Transportation
}


TABLE OF CONTENTS

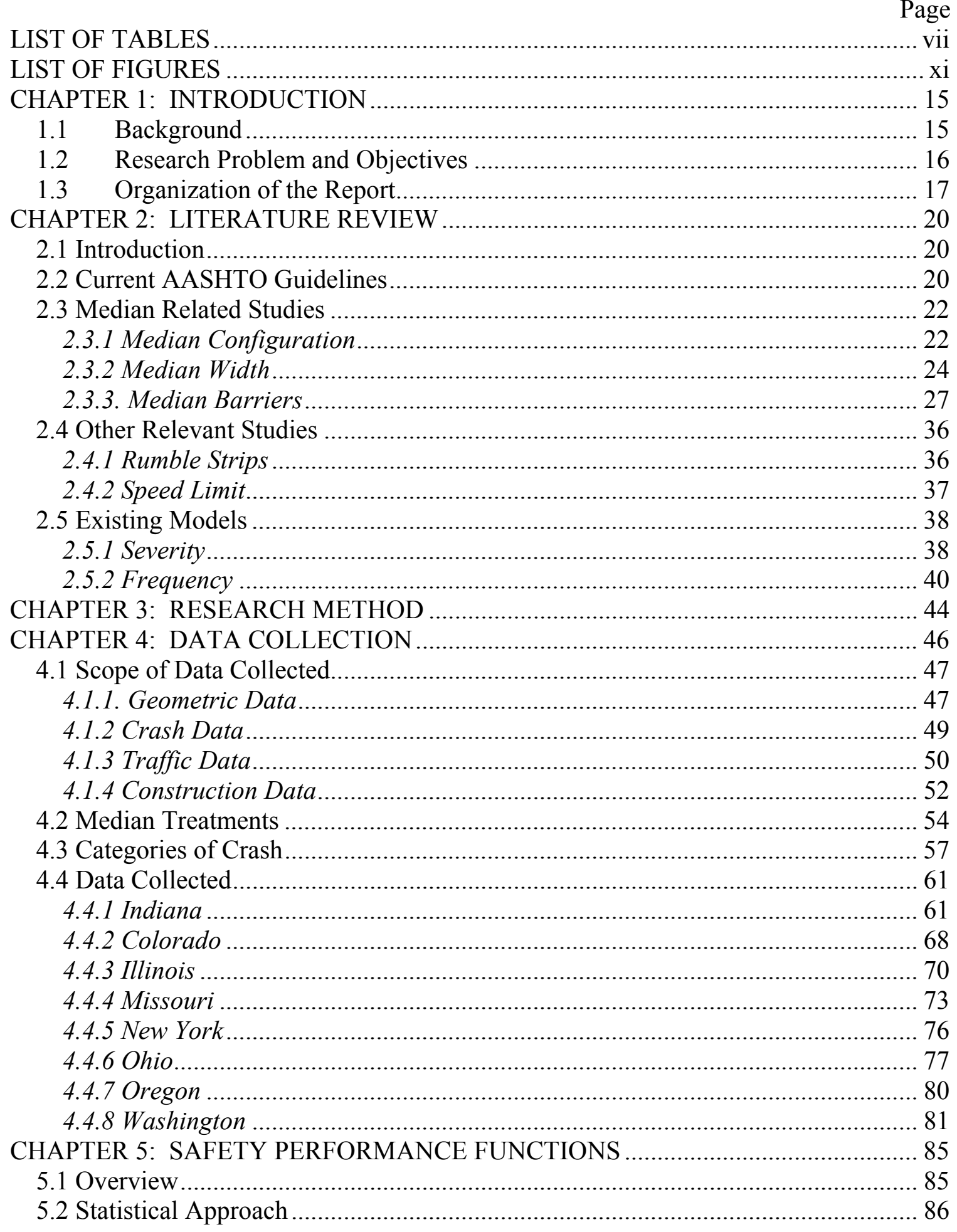






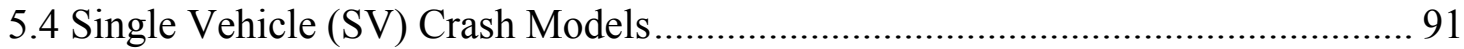

5.4.1 Depressed Without a Median Barrier, .......................................................... 93



5.4.2 Depressed Without a Median Barrier, .......................................................... 95

Median Width Greater Than or Equal to 50 feet (D3N)........................................ 95

5.4.3 Depressed With Berms Without a Median Barrier, ........................................ 97

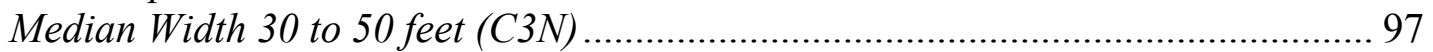

5.4.4 Berms Without a Median Barrier, ............................................................. 99

Median Width Greater Than or Equal to 50 feet $(B 3 N)$......................................... 99

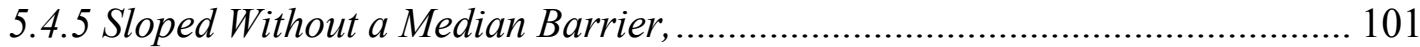

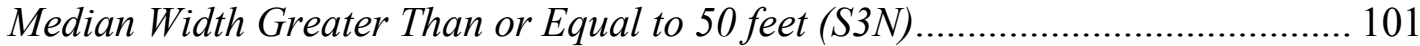

5.5 Multiple Vehicle - Same Direction (MVSD) Crash Models................................ 102

5.5.1 Depressed Without a Median Barrier, ......................................................... 104

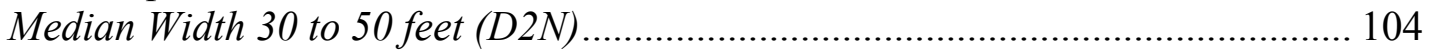

5.5.2 Depressed Without a Median Barrier, ..................................................... 105

Median Width Greater Than or Equal to 50 feet (D3N)....................................... 105

5.5.3 Depressed With Berms Without a Median Barrier, ...................................... 107

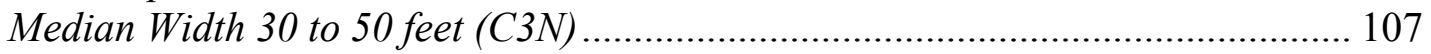

5.5.4 Berms Without a Median Barrier, ............................................................... 109

Median Width Greater Than or Equal to 50 feet (B3N) ...................................... 109

5.5.5 Sloped Without a Median Barrier, .......................................................... 110

Median Width Greater Than or Equal to 50 feet $(S 3 N)$......................................... 110

5.6 Multiple Vehicle - Opposite Direction (MVOD) Crash Models............................. 112

5.7 Overall Modeling Results ................................................................................ 115

5.7.1 Overall Results for Single Vehicle Crash Models........................................ 116

5.7.2 Overall Results for Multiple Vehicle - Same Direction Crash Models ......... 117

5.7.3 Multiple Vehicle - Opposite Direction Crash Models.................................... 119

CHAPTER 6: CRASH MODIFICATION FACTORS................................................ 121

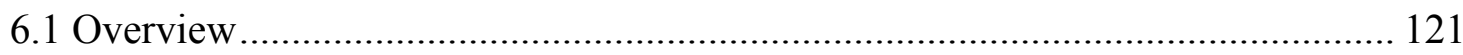

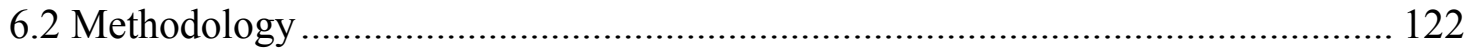

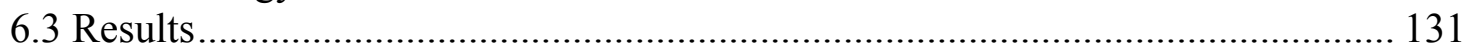

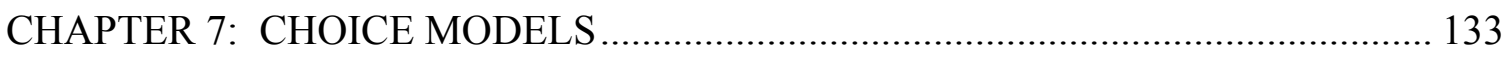

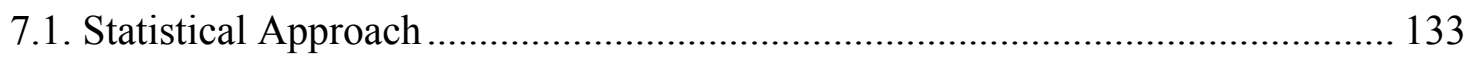

7.2 Equations of likelihood of severity …………….................................................. 137

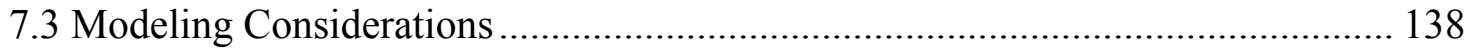

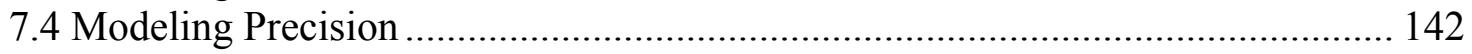

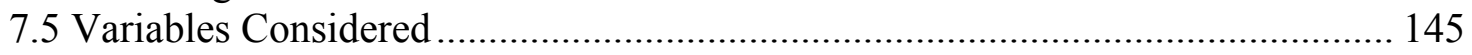

7.6 Single Vehicle (SV) Crash Model ......................................................................... 146

7.7 Multiple Vehicle - Same Direction (MVSD) Crash Model .................................. 149

7.8 Multiple Vehicle - Opposite Direction (MVOD) Crash Model ............................ 152

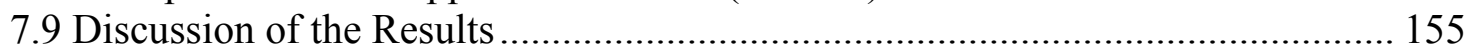

7.9.1 Single Vehicle (SV) Crashes ................................................................... 155

7.9.2 Multiple Vehicle - Same Direction (MVSD) Crashes..................................... 161

7.9.3 Multiple Vehicle - Opposite Direction (MVOD) Crash Model ...................... 162 
7.10 Likelihood of Severity and Median Treatments ............................................. 165


CHAPTER 8: PREDICTING CRASHES FOR VARIOUS MEDIAN TREATMENTS

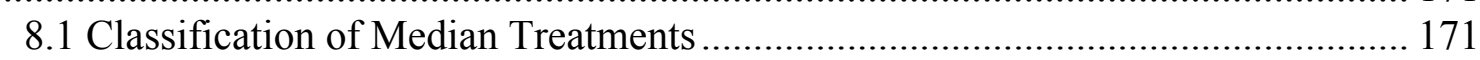

8.1.1 Depressed, Intermediate Median, No Barrier (D2N) .................................. 172

8.1.2 Depressed, Wide Median, No Median Barrier (D3N) ................................. 173

8.1.3 Depressed with Berms, Wide Median, No Median Barrier (C3N) ................. 174

8.1.4 Berms, Wide Median, No Median Barrier (B3N) ........................................ 175

8.1.5 Sloped, Wide Median, No Median Barrier (S3N) ........................................ 176

8.1.6 Depressed, Intermediate Median, Low-Tensioned Cable Median Barrier (D2L)

177

8.1.7 Depressed, Wide Median, Low-Tensioned Cable Median Barrier (D3L) .... 178

8.1.8 Depressed, Wide Median, High-Tensioned Cable Median Barrier (D3H) ... 179

8.1.9 Flush, Narrow Median, Concrete Median Barrier (F1C) ............................ 180

8.1.10 Flush, Intermediate Median, Concrete Median Barrier (F2C) ................... 181

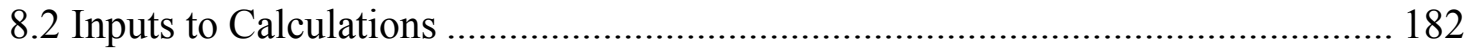

8.2.1 Homogeneous Segments............................................................................ 182

8.2.2 Preparing Input Data ............................................................................. 182

8.3 Predictive Equations ...................................................................................... 188

8.3.1 Depressed, Intermediate Median, No Median Barrier (D2N) ...................... 192

8.3.2 Depressed, Wide Median, No Median Barrier (D3N) .................................. 195

8.3.3 Depressed with Berms, Wide Median, No Median Barrier (C3N) ................ 198

8.3.4 Berms, Wide Median, No Median Barrier (B3N) ........................................ 201

8.3.5 Sloped, Wide Median, No Median Barrier (S3N) ........................................ 204

8.3.6 Depressed, Intermediate Median, Low-Tensioned Cable Median Barrier (D2L)

208

8.3.7 Depressed, Wide Median, Low-Tensioned Cable Median Barrier (D3L) .... 210

8.3.8 Depressed, Wide Median, High-Tensioned Cable Median Barrier (D3H) ... 213

8.3.9 Flush, Narrow Median, Concrete Median Barrier (F1C) ........................... 216

8.3.10 Flush, Intermediate Median, Concrete Median Barrier (F2C) .................. 218

CHAPTER 9: OTHER STATES EXPERIENCE WITH CABLE BARRIERS............. 220

9.1 Low-Tensioned Cable Barriers ........................................................................ 220

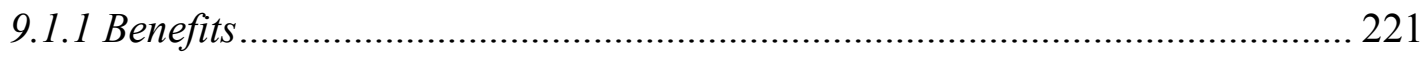

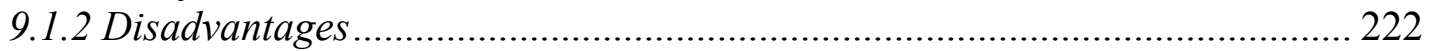

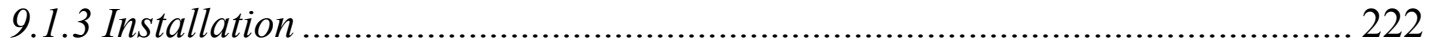

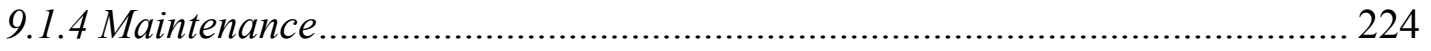

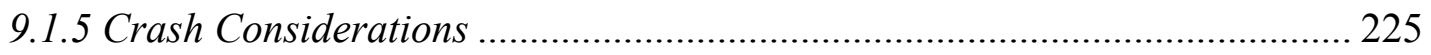

9.2 High-Tensioned Cable Barriers ..................................................................... 226

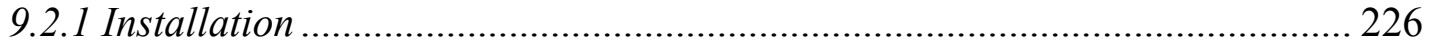

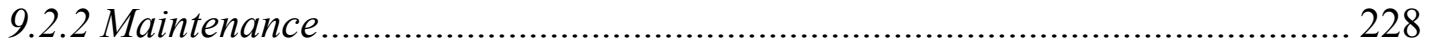

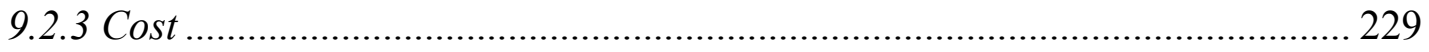

9.2.4 Causes of Vehicles Breaking Through the Cables ........................................ 230

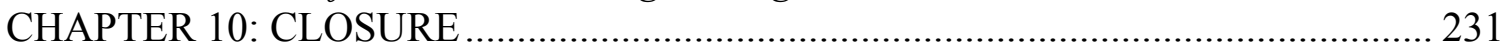

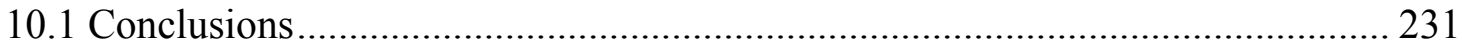


10.2 Future Research Needs ........................................................................ 235

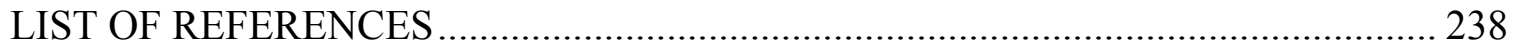

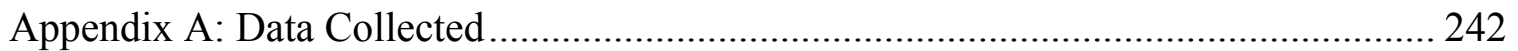

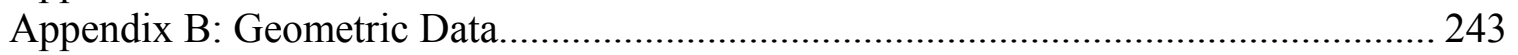

Appendix C: Images of the Median Treatments .................................................... 250

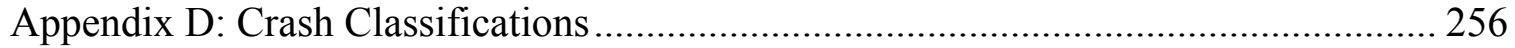

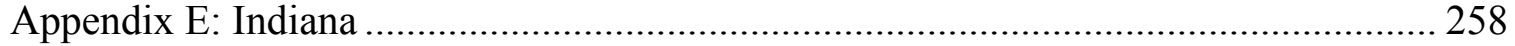

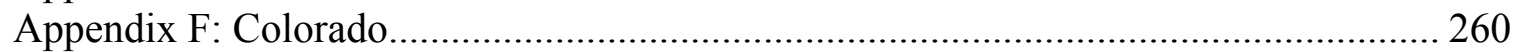

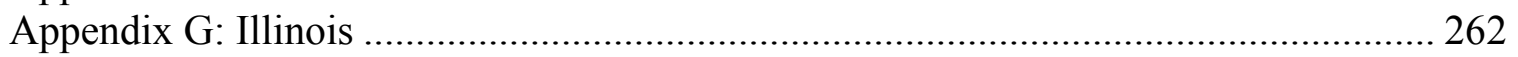

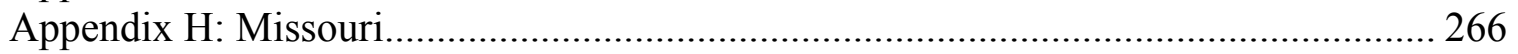



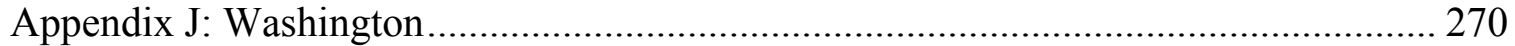

Appendix K: Pearson Coefficient of Correlation........................................................ 271 


\section{LIST OF TABLES}

Table

Page

Table 2.1 Median Barrier Characteristics $\quad 28$

Table 2.2 AASHTO Installation Recommendations 29

Table 4.1 Crash Data Information, State By State 49

Table 4.2 Years of AADT, State By State 50

Table 4.3 Median Treatment Categories $\quad 55$

Table 4.4 Number and Percentage of Total Crashes Per County 64

Table 4.5 Number and Percentage of Unassigned Crashes 65

Table 5.1 Number of Miles Per Median Treatment Per State 85

Table 5.2 Variables Used in Frequency Analysis $\quad 89$

Table 5.3 Number of Single Vehicle Crashes Per Median Treatment Per State 90

Table 5.4 Single Vehicle Crash Rates 91

Table 5.5 Single Vehicle Crash Model for D2N 92

Table 5.6 Single Vehicle Crash Model for D3N 94

Table 5.7 Single Vehicle Crash Model for C3N 96

Table 5.8 Single Vehicle Crash Model for B3N 98

$\begin{array}{ll}\text { Table 5.9 Single Vehicle Crash Model for S3N } & 100\end{array}$

Table 5.10 Number of Multiple Vehicle - Same Direction Crashes

Per Median Treatment Per State 101

Table 5.11 Multiple Vehicle - Same Direction Crash Rates 102

Table 5.12 Multiple Vehicle - Same Direction Crash Model for D2N 103

Table 5.13 Multiple Vehicle - Same Direction Crash Model for D3N 105 
Table

Table 5.14 Multiple Vehicle - Same Direction Crash Model for C3N 106

Table 5.15 Multiple Vehicle - Same Direction Crash Model for B3N 108

Table 5.16 Multiple Vehicle - Same Direction Crash Model for S3N 109

Table 5.17 Multiple Vehicle - Opposite Direction Crash Rates 112

Table 5.18 MVOD Model Results $\quad 113$

Table 6.1 Before and After Analysis Period with Available Crash Data $\quad 120$

Table 6.2 Without Control, $\mathrm{CMF}=\theta_{\mathrm{t}} \quad 127$

Table 6.3 With Control, $\mathrm{CMF}=\theta_{\mathrm{t}} / \theta_{\mathrm{c}} \quad 128$

$\begin{array}{lr}\text { Table } 6.4 \text { Control Values } & 128\end{array}$

Table 6.5 With Grouped Control, CMF $=\theta_{\mathrm{t}} / \theta_{\mathrm{c}}{ }^{\prime} \quad 130$

Table 7.1 Example of High Correlation Between a Median Treatment and $\begin{array}{ll}\text { a First-Order Interaction } & 138\end{array}$

Table 7.2 Variables Used in Severity Analysis 145

Table 7.3 Binary Logit Model for Single Vehicle Crash Model 146

Table 7.4 Goodness-of-fit Statistics for the Single Vehicle Crash Model 147

Table 7.5 Binary Logit Model for Multiple Vehicle - Same Direction

Crashes

Table 7.6 Goodness-of-fit Statistics for the Multiple Vehicle - Same

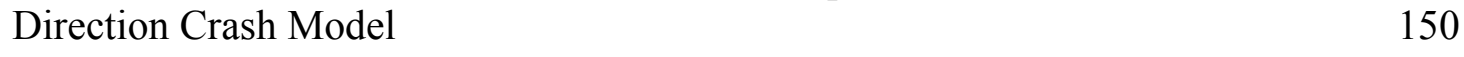

Table 7.7 Binary Logit Model for Multiple Vehicle - Opposite

Direction Crashes 152

Table 7.8 Goodness-of-fit Statistics for the Multiple Vehicle - Opposite Direction Crash Model $\quad 153$

Table 7.9 Likelihood of Severity for Single Vehicle Crashes 165 
Table

Table 7.10 Likelihood of Severity for Multiple Vehicle - Same

Direction Crashes

166

Table 7.11 Likelihood of Severity for Multiple Vehicle - Opposite

Direction Crashes

166

Table 8.1 Classification of Median Treatments

171

Table 8.2: Equations for Predicting Crash Frequency and Severity

by Median Treatment

188

Table 9.1 Barrier Installation Costs

Table A.1 Summary of Data Collected, By State

Table D.1 Accuracy of First Crash Classification

Table D.2 Accuracy of Second Crash Classification 256

Table E.1 Indiana Barrier Installation Dates

Table F.1 With Constant, Predicting Average Horizontal Curvature

Table F.2 Without Constant, Predicting Average Horizontal Curvature

Table F.3 Installation Dates of High-Tensioned Cable Barriers

260

Table G.1 Multiple Vehicle - Opposite Direction Crash Explanations

Table G.2 Illinois Barrier Installation Dates

264

Table H.1 Missouri Barrier Installation Dates 266

Table I.1 Ohio Barrier Installation Dates

Table I.2 Ohio: Explanation for Crossover Crashes on Segments with Cable Barrier

Table K.1 Pearson Coefficients of Correlation Between the Median Treatments and Traffic and Geometric Variables

Table K.2 Pearson Coefficients of Correlation Between the Median Treatments and the First- Order Interaction Between the Corresponding 
Table K.3 Pearson Coefficients of Correlation Between the Traffic and Geometric Variables and the First-order Interaction Between the

Table L. 1 Equations for Predicting Crash Frequency and Severity by Median Treatment 


\section{LIST OF FIGURES}

Figure $\quad$ Page

Figure 2.1 AASHTO Median Barrier Warrants $\quad 21$

Figure 2.2 Mound Median Treatment 22

Figure 4.1 States Where Data Was Collected 45

Figure 4.2 Concrete Barrier Post-Crossover Crash 52

Figure 5.1 Effect of AADT on Median Treatments for Single

$\begin{array}{ll}\text { Vehicle Crashes } & 115\end{array}$

Figure 5.2 Effect of AADT on Median Treatments for Multiple

$\begin{array}{ll}\text { Vehicle - Same Direction Crashes } & 117\end{array}$

Figure 8.1 Depressed, Intermediate Median, No Median Barrier $\quad 172$

Figure 8.2 Cross-Section of a Depressed Median 172

Figure 8.3 Depressed Wide Median, No Median Barrier 173

$\begin{array}{ll}\text { Figure 8.4 Cross-Section of a Depressed Median } & 173\end{array}$

Figure 8.5 Depressed with Berms, Wide Median, No Median Barrier 174

Figure 8.6 Cross-Section of a Depressed with Berms Median Treatment $\quad 174$

Figure 8.7 Berms, Wide Median, No Median Barrier $\quad 175$

$\begin{array}{ll}\text { Figure 8.8 Berm Cross-Section } & 175\end{array}$

Figure 8.9 Sloped, Wide Median, No Barrier 176

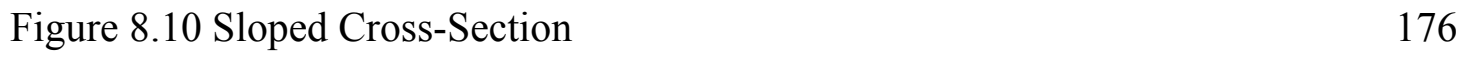

Figure 8.11 Depressed, Intermediate Median, Low-Tensioned Cable

$\begin{array}{ll}\text { Median Barrier } & 177\end{array}$

Figure 8.12 Depressed, Wide Median, Low-Tensioned Cable Median Barrier 179

Figure 8.13 Depressed, Wide Median, High-Tensioned Cable Median Barrier $\quad 180$ 
$\begin{array}{lll}\text { Figure } & \text { Page }\end{array}$

Figure 8.14 Flush, Narrow Median, Concrete Median Barrier 181

Figure 8.15 Flush, Intermediate, Concrete Median Barrier 181

Figure 10.1 Truck on Concrete Barrier 236

Figure C.1 Depressed Without A Median Barrier, Median Width 30 to 50 feet (D2N) 249

Figure C.2 Cross-Section of A Depressed Median 249

Figure C.3 Depressed With Berms, Median Width Greater Than or Equal to 50 feet $(\mathrm{C} 3 \mathrm{~N})$

Figure C.4 Cross-Section of A Depressed Median With Berms 250

Figure C.5 Berms Without A Median Barrier, Median Width Greater Than or Equal to 50 feet (B3N) 250

Figure C.6 Cross-Section of A Berms Median Without Median Barrier 250

Figure C.7 Sloped Without A Median Barrier, Median Width Greater Than or Equal to 50 feet (S3N) 251

Figure C.8 Cross-Section of A Sloped Median Without Median Barrier 251

Figure C.9 Depressed Median With High-Tensioned Cable Barrier 252

Figure C.10 Depressed Median With Low-Tensioned Cable Barrier 253

Figure C.11 Flush With Concrete Median Barrier, Median Width Less Than or Equal to 30 feet (F1C) 253

Figure C.12 Flush With Concrete Median Barrier, Median Width 30 to 50 feet (F2C) 254

Figure E.1 Indiana Sample Video Log Image 257

Figure E.2 Indiana Data for An Image $\quad 257$

$\begin{array}{ll}\text { Figure G.1 Illinois Sample Video Log Image } & 261\end{array}$

Figure G.2 Illinois Data for An Image 261 
Figure $\quad$ Page

Figure G.3 Illinois Location of Data Collection 262

Figure H.1 Missouri Sample Video Log Image 265

Figure I.1 Ohio Sample Video Log Image $\quad 267$

Figure J.1 Sample Washington State Video Log Image 269 


\begin{abstract}
This report presents results of a comprehensive study evaluating alternative median solutions on rural freeways from the safety standpoint. Extensive datasets have been collected from several states: Indiana, Colorado, Illinois, Iowa, Missouri, New York, Ohio, Oregon, Washington, and Wisconsin. The studies solutions include AASHTOrecommended treatments: depressed medians, depressed medians with high and lowtensioned cable barriers, and flush medians with concrete barriers. Other treatments used in the freeway design were also included: medians with berms, sloped medians, and depressed medians with berms. Obtained equations can be used by designers and planners to predict frequency and severity of crashes for alternative median solutions on rural medians in the regions determined by the states that had contributed the research data.
\end{abstract}

Negative binomial models were developed to estimate the frequency of crashes of a given segment in three categories: single vehicle, multiple vehicles same direction, and multiple vehicles opposite direction. The developed choice models could then be used to split the frequency of crashes into the frequencies of fatal/injury and property damage only crashes. The obtained results support the findings of previous research that narrowing the median increases the frequency of cross-median crashes. Furthermore, the frequency of multiple vehicle - same direction crashes and single vehicle crashes increase on segments with berm median treatments. Sloped median treatments are also attributed with an increase in the single vehicle crashes. The majority of the developed frequency equations have a variable that represents the road curvature; it was primarily the average horizontal curvature. 
A reduction in median width is also associated with an increase in the crash severity. Curvature, predominately the presence of horizontal curves, also tended to result in a higher proportion of severe crashes.

The results of this study will help designers and planners select better median treatment solutions for modernized rural freeways, often involving adding traffic lanes and narrowing medians. The developed equations can be used as part of the economic analysis of safety, construction, and maintenance costs.

\section{CHAPTER 1: INTRODUCTION}

\subsection{Background}

The majority of the rural interstates in Indiana are four-lane roadways and the Indiana Department of Transportation (INDOT) is planning to expand many of them to six-lane facilities to accommodate the increasing average annual daily traffic (AADT). These expansions will occur over the next twenty to thirty years, as described in INDOT's 2000-2025 Long Range Plan. INDOT has to decide where to locate the additional lanes in cross-sections of the widened rural freeways: inside by reducing the median width or outside by widening the right of way. This consideration requires comparing the safety impacts of narrowing the medians with the economic engineering aspects of widening the roadway and the bridge structures. The safety impacts of narrowing medians and installing barriers on them are mostly unknown. 
Until recently, Indiana only had two dominant median treatments in practice: a depressed median without barriers and a flush median with a concrete barrier. INDOT would like to investigate other median treatments used in other states to determine if these median treatments should be considered in Indiana conditions on medians with reduced widths.

A better understanding of the safety impacts of various median treatments is needed, as the current median barrier warrants developed by the American Association of State and Highway Transportation Officials (AASHTO) in the 1960's do not always warrant median barriers in locations that have seen a high frequency of crossover crashes. As a result, states such as California, Washington and North Carolina, have created their own median barrier warrants. Furthermore, the median treatments identified in the AASHTO guidelines do not include some of the median treatments encountered in practice.

\subsection{Research Problem and Objectives}

Adding new lanes to existing freeways should be decided while considering safety and costs. Presently, the safety impacts of various median treatments on freeways are mostly unknown. Research thus far has primarily been focused on how median barriers affect crossover crashes; no information is available on how changes to the median treatment affect other crash types such as sideswipe or single vehicle crashes. Although it is generally accepted that narrowing medians increases the probability of 
crossover crashes, little is understood about the impact of narrowing a median on the frequency and severity of crashes.

This research is aimed to fill the gap in the existing knowledge of safety effects of various median solutions including both the ones recommended by AASHTO and additional ones used by states. A comprehensive set of equations will be developed for predicting crash frequencies on rural freeway sections with alternative median treatments. These equations should allow designers and planners include safety consideration to economic analysis of alternative rural freeway designs.

\subsection{Organization of the Report}

This report is divided into ten chapters, covering the main aspects of the study conducted on median treatment design and explaining the development of the crash frequency and severity equations.

The first chapter provides the background of the study, the problem, proposed solution, and the organization of the report.

The second chapter presents a review of the past studies conducted to evaluate the safety impact of median treatments and median barriers. It also provides a summary of the current practices of transportation agencies in relation to median design, and more importantly, the guidelines followed by departments of transportation for the installation of median barriers.

The third chapter elucidates the research process. 
The fourth chapter describes the data collection process. The types of data collected are discussed in detail. The chapter also addresses the overall quality of the data, a crucial issue given the substantial amount of data collected.

The fifth chapter presents the developed safety performance functions. The statistical approach to developing the frequency models is discussed. The single vehicle, multiple vehicle - same direction, and multiple vehicle - opposite direction models of frequency are presented. The chapter concludes with a discussion of the modeling results.

The sixth chapter presents the crash modification factors (CMF) that were developed to be applied to safety performance functions for some median treatments. The chapter begins with an overview of the significance of crash modification factors. Then, the methodology used to develop crash modification factors is presented. The last section presents the results.

The seventh chapter presents the choice models. The chapter begins with a description of the statistical approach. Aspects of the modeling process are then discussed. The chapter then presents the single vehicle, multiple vehicle - same direction, and multiple vehicle - opposite direction models. The chapter concludes with a discussion of the results.

The eighth chapter begins by discussing the classification of the median treatment. It then discusses the input data that may be needed, and how to calculate the value if necessary, when predicting the frequency and severity of crashes for a given median treatment. Then, the prediction of accident frequency and severity is described, 
step-by-step. The last section of this chapter provides and example of applying the equations to an example problem.

The ninth chapter provides information gathered on the experiences of other states with low and high-tensioned cable barriers.

The tenth chapter discusses the outcomes of the research, suggestions for future research, and discusses the applicability of the results for design. 


\section{CHAPTER 2: LITERATURE REVIEW}

\section{$\underline{2.1 \text { Introduction }}$}

This chapter is organized into four sections. The first section summarizes the existing guidelines provided by the American Association of State Highway and Transportation Officials (AASHTO) that concern median treatments and barriers. The second section provides an overview of past studies that are related to the median. Within this section are three additional subsections which cover median configuration, median width, and median barriers. The third section discusses other relevant studies. The final section discusses previous modeling attempts for crash frequency and severity.

\subsection{Current AASHTO Guidelines}

The majority of the state departments of transportation use the AASHTO guidelines as a policy for the design of median width, median side slopes, median barrier types, and median placement. As such, a short overview of the guidance recommended by AASHTO concerning median treatments on rural freeways is presented.

The AASHTO Design Guidelines (AASHTO, 2002) generally recommend depressed medians as the most favorable solutions for freeways. AASHTO suggests side slopes of 6:1 (6H:1V) for depressed medians; however, steeper slopes (4:1) may also be 
adequate. When a longitudinal median barrier is present on a slope, flatter slopes (flatter than 6:1) are recommended.

Medians between 50 and 100 feet are the most common on rural freeways, especially when the terrain is level and there are few or no right-of-way restrictions. In the case of rolling terrain, independent profiles are often used. Narrow medians (10 to 30 feet) are often employed in mountainous terrain.

Where right-of-way restrictions exist and the median section must be narrowed to a width less than or equal to 50 feet, the probability of crossover median crashes increases (AASHTO, 2002). In such a situation, a median barrier might be installed as mitigation. The AASHTO Design Guidelines provide installation guidelines for median barriers on high-speed roadways, dependent on the median width and the average daily traffic (ADT). Figure 2.1 presents the AASHTO median barrier warrants included in these guidelines. The thresholds used by AASHTO (30 ft and $50 \mathrm{ft})$ were determined from a study of crossover accidents (AASHTO, 2002). 


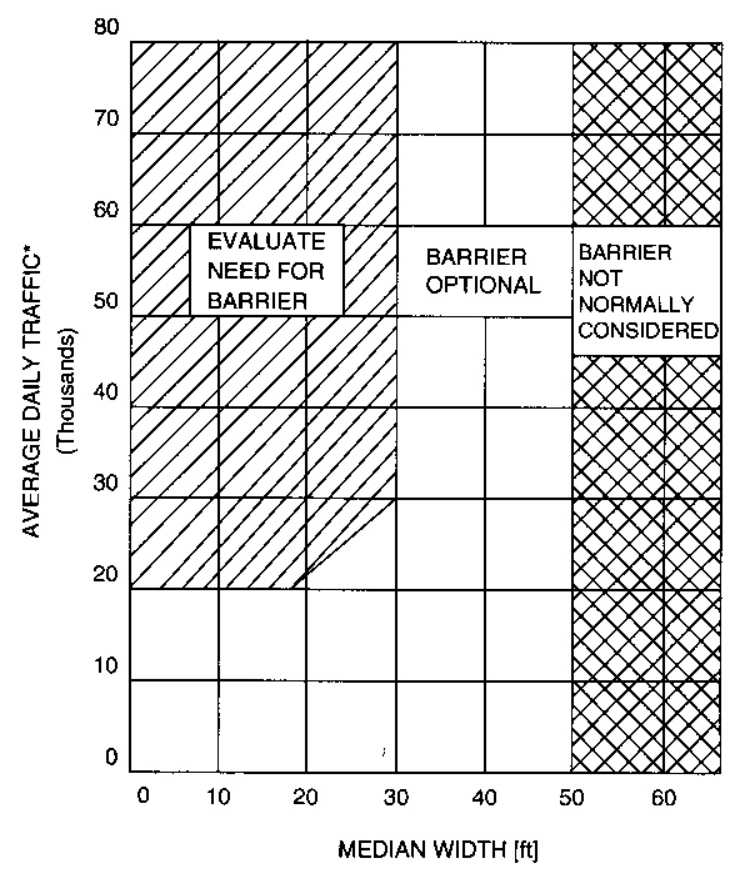

Figure 2.1 AASHTO Median Barrier Warrants (AASHTO, 2002)

\section{$\underline{2.3 \text { Median Related Studies }}$}

\subsubsection{Median Configuration}

The safety effects of the median shape on crash severity have not been studied extensively, particularly for rural freeways. Foody and Culp (1974) studied the safety effects of depressed versus mound median sections using data from Ohio. A mound median section is a depressed median with a slightly raised middle, as shown in Figure 2.1 . 


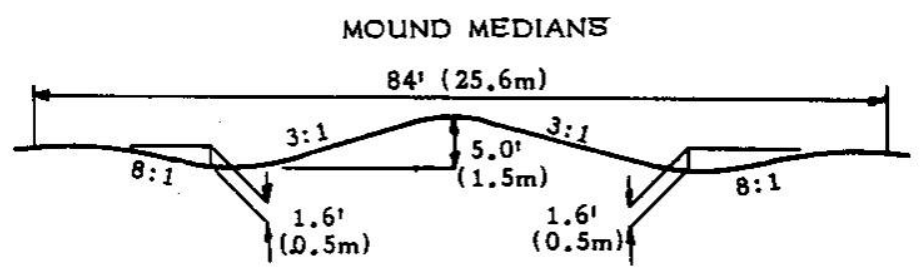

Figure 2.2 Mound Median Treatment

Their study included 125 miles of interstate with an 84-foot mound median, and 135 miles with an 84-foot depressed median. Three years of crash data were analyzed. This study assumed that the number of accidents was proportional to the AADT since all other design features, except the median, were similar. The primary focus of this study was on single vehicle accidents involving the median section. With respect to the severity issue, they concluded that there was no significant difference between the two median designs in the number of injury-producing accidents. When considering the frequency of crashes, Foody and Culp (1974) concluded that the accident rate was higher for the mound median design.

The median-related crashes were then classified into three categories dependent upon the path of the vehicle involved in the accident: "crossover," "median," and "redirect." Foody and Culp (1974) concluded again that there was no significant difference between the two median designs in the number of accidents. When considering the number of injury-producing accidents, for the redirect and median path, there was no difference. Yet, when considering crossover crashes, there were a disproportionately greater number of injury-producing accidents for the swale (depressed) design. 
Hadi et al. (1995) studied the impact of several median types for nine classes of roads. A significant relationship was only found between the median type and the crashes that occurred on four-lane divided urban highways. The safety of the median type decreased in the following order: flush unpaved median (grass), raised curb, crossover resistance, and Two-Way Left Turn Lane (TWLTL). It was not possible to draw conclusions as to whether the type of median affected the severity of crashes for four-and six-lane divided rural highways.

More studies have been performed on urban and suburban conditions, especially on TWLTL and raised medians. However, these issues are not the purpose of this study and therefore will not be discussed here.

\subsubsection{Median Width}

Telford and Israel (1953) studied the safety effect of median width for three median categories: traversable, deterring, and non-traversable. A traversable median is described as a flat hard surface. A deterring median is paved as well, but it is also double striped, curbed, and has earth slopes less than 4:1. The non-traversable median is restrictive as a result of large slopes or a median barrier. They used California data to estimate the effects of the three types of median section widths on accident frequency and severity. Accident frequency was found to be lower in the case of the traversable median section, but no proof was found that the rate of injury crashes decreased as the width of a traversable median section increased. The median width was also found not to have an effect on the rate of injury crashes in the case of deterring medians. However, for a non- 
traversable median section, there was some indication that the rate of injury crashes increased with the increase of the median width. These conclusions are to be carefully considered since the difference in accident rates might be due to other traits such as larger average annual daily traffic (AADT) values rather than whether or not the median is traversable.

Knuiman et al. (1993) used data from Utah and Illinois to conduct a study on the effects of median widths on accident frequency and severity on homogeneous highway sections with a traversable (non-barrier) median. The sample only included two-way, four-lane, rural and urban interstates, freeways, and major highway road sections in Utah and Illinois of a length exceeding $0.07 \mathrm{mi}$. The posted speed limit was at least $35 \mathrm{mi} / \mathrm{h}$, with no median, or an unprotected median less than or equal to $110 \mathrm{ft}$. To account for external influences, other variables were included, such as functional classification, speed limit, right shoulder width, access control, Average Daily Traffic (ADT) and section length. A log-linear regression model assuming a negative-binomial variance function was used to determine the effects of the median width. The total accident rate was found to decrease steadily as the median width increased from 0 to $110 \mathrm{ft}$. Over this range of median widths, as the median width increased, the relative accident rates of serious injury, all injury, and Property Damage Only (PDO) crashes also generally declined. They concluded that the total accident rates and rates for specific types and severity decline rapidly when the median width exceeds 25 feet $(7.6 \mathrm{~m})$. The relative accident rates were also found to be approximately the same for different severities at the same median width, which differs from the usual assumptions that wider medians decrease the frequency of severe crossover accidents. 
Noland and Oh (2003) studied the effect of various infrastructures and geometric design on traffic-related fatalities. Four years of Illinois crash data were used to estimate fixed-effect negative binomial models for total fatalities. Demographic variables were included in the models to account for the influence of demographic changes. AADT was not used due to data inconsistencies. In the final models for fatalities, the median width was not found to be statistically significant. Therefore, no statistical association with changes in the severity of accidents was found for the median width.

Wang et al. (1998) investigated rural, multi-lane, non-freeway sections using data from Minnesota. They modeled accident frequency using a Poisson model. According to the model presented in the paper, the number of annual accidents decreases with an increase in the median width.

Hadi et al. (1995) studied the impact of median width on the frequency and severity of accidents. They used four years of Florida crash data (1988-1991) for the analysis. Negative binomial regression was used to model the effects of cross-section design elements for total, fatal and injury crash rates for rural and urban highways. The roadway samples were classified into nine categories for model development, depending on the location (urban or rural), the access type, and the number of lanes. The model for the total number of crashes, for four-and six-lane rural freeways, indicated that an increase in the median width reduced these types of crashes.

In conclusion, various results have been found regarding the effect of the median width on crash severity and frequency. All of the studies reviewed showed that an increase in median width generally decreased accident frequency. Similarly, an increase in the median width generally decreases the frequency of severe accidents. In the case of 
a crossover accident, a wider median appears to help reduce the frequency of these types of accidents. However, all the studies reviewed were conducted only on the frequency of injury accidents, and very few studies directly considered the effect of the median width on the proportion of severe crashes in the total number of crashes.

\subsubsection{Median Barriers}

Several types of median barriers can be used as a protection against crossover crashes. Median barriers can be broken into three general categories: flexible barriers, semi-rigid barriers, and rigid barriers. The flexible barriers absorb more energy during impact. Consequently, energy is dissipated and the forces applied on the vehicle are lower. Rigid barriers, on the other hand, absorb less energy and the forces applied on the vehicle are greater, which may lead to a more severe accident. A drawback of flexible barriers is that they tend to experience higher distortion and deflection at impact than semi-rigid and rigid barriers, which requires more maintenance.

The performance level of a barrier can be assessed based on its test level value. A test level value is a standardized indicator used by the Federal Highway Administration (FHWA) to help designers compare the safety performance of roadside and median barriers. There are six tests levels (TLs) for longitudinal barriers. The tests evaluate the occupant risk, the structural integrity of the barrier, and the post-impact behavior of the vehicle for a variety of vehicle masses at varying speeds and angles of impact. Consequently, if a barrier is found to have a test-level TL-2, it means that it has 
successfully passed the series of standard crash tests required for this level. The standards crash tests for the different test levels are as follows:

- $\quad$ For TL-1, TL-2 and TL-3: The barrier must successfully pass the test of an $820 \mathrm{~kg}$ car impacting a barrier at an angle of 20 degrees and a 2,000 kg pickup truck impacting a barrier at an angle of 25 degrees, at speeds of $50 \mathrm{~km} / \mathrm{h}$ (TL1), $70 \mathrm{~km} / \mathrm{h}$ (TL2), and 100 $\mathrm{km} / \mathrm{h}(\mathrm{TL} 3)$.

- For TL-4: In addition to the TL-3 tests, the barrier must also pass the test of an $8,000 \mathrm{~kg}$ single-unit truck at an impact angle of 15 degrees and $80 \mathrm{~km} / \mathrm{h}$.

- For TL-5 and TL-6: The single-unit truck used for TL-4 is substituted by a 36,000 $\mathrm{kg}$ tractor trailer (van) for TL5 and by a 36,000 $\mathrm{kg}$ tractor trailer (tanker) for TL-6. The Roadside Design Guide by AASHTO (2002) provides the descriptions and features of the barriers which passed the NCHRP Report 350 tests and were accepted by the FHWA as median barriers. Table 2.1 (AASHTO, 2002) summarizes the available median barriers and their test levels, depending on the results of the NCHRP Report 350 tests. 
Table 2.1 Median Barrier Characteristics

\begin{tabular}{|c|c|c|c|c|c|c|}
\hline Description & Beam & Posts & Blocks & $\begin{array}{c}\text { Maximum Barrier } \\
\text { Height (in) }\end{array}$ & Test Level & $\begin{array}{c}\text { Maximum } \\
\text { Deflection (in) }\end{array}$ \\
\hline Low-tensioned Cable & Three Steel Cables & Steel & No & 30 & TL-3 & 138 \\
\hline \multicolumn{7}{|l|}{ High-tensioned Cable } \\
\hline Brifen WRSF & Four Steel Cables & Steel & No & 40 & TL-3, TL-4* & 94 \\
\hline Trinity CASS & Three Steel Cables & Steel & No & 56 & TL-3, TL-4* & 92 \\
\hline Marion Steel Wire Rope Barrier & Three Steel Cables & Steel & No & 30 & TL-3 & 91 \\
\hline Safence Wire Rope Barrier (350 4RI) & Four Steel Cables & Steel & No & 31 & TL-3 & 106 \\
\hline Gibraltar Cable Barrier System & Three Steel Cables & Steel & No & 42 & TL-3, TI-4* & 112 \\
\hline Weak-Post, W-Beam & Two Steel W sections & Steel & No & $30-33$ & TL-2 & 84 \\
\hline Weak-Post, Box-Beam & Steel Tube & Steel & No & 30 & TL-3 & 66 \\
\hline \multicolumn{7}{|l|}{ Strong-Post, Blocked-Out W-Beam } \\
\hline Wood Posts, Plastic Blocks & Two Steel W sections & Wood & Plastic & 27 & TL-3 & 24 \\
\hline Wood Posts, Wood Blocks & Two Steel W sections & Wood & Wood & 27 & TL-3 & 24 \\
\hline Steel Posts, Plastic Blocks & Two Steel W sections & Steel & Plastic & 27 & TL-3 & 24 \\
\hline Steel Posts, Wood Blocks & Two Steel W sections & Steel & Wood & 27 & TL-3 & 24 \\
\hline Steel Posts, Steel Blocks & Two Steel W sections & Steel & Steel & 27 & TL-2 & 24 \\
\hline \multicolumn{7}{|l|}{ Strong-Post, Thrie-Beam } \\
\hline Wood Posts, Plastic Blocks & Two Thrie-Beams & Wood & Plastic & 32 & TL-3 & 20 \\
\hline Wood Posts, Wood Blocks & Two Thrie-Beams & Wood & Wood & 32 & TL-3 & 20 \\
\hline Steel Posts, Plastic Blocks & Two Thrie-Beams & Steel & Plastic & 32 & TL-3 & 20 \\
\hline Steel Posts, Wood Blocks & Two Thrie-Beams & Steel & Wood & 32 & TL-3 & 20 \\
\hline Strong-Post, Modified Thrie-Beam & Two Thrie-Beams & Steel & Steel & 32 & TL-4 & 20 \\
\hline \multicolumn{7}{|l|}{ Concrete Safety Shape } \\
\hline NJ-Shape, 32 in. & No & No & No & 32 & TL-4 & 0 \\
\hline NJ-Shape, 42 in. & No & No & No & 42 & TL-5 & 0 \\
\hline F-Shape, 32 in. & No & No & No & 32 & TL-4 & 0 \\
\hline F-Shape, 42 in. & No & No & No & 42 & TL-5 & 0 \\
\hline \multicolumn{7}{|l|}{ Tall Wall Concrete Safety Shape } \\
\hline Reinforced, 32 in. & No & No & No & 32 & TL-4 & 0 \\
\hline Reinforced, 42 in. & No & No & No & 42 & TL-5 & 0 \\
\hline Non-reinforced, 32 in. & No & No & No & 32 & TL-4 & 0 \\
\hline Non-reinforced, 42 in. & No & No & No & 42 & TL-5 & 0 \\
\hline \multicolumn{7}{|l|}{ Single-Slope Concrete Barrier } \\
\hline 32 in. & No & No & No & 32 & TL-4 & 0 \\
\hline 42 in. & No & No & No & 42 & TL-5 & 0 \\
\hline
\end{tabular}

The Roadside Design Guide (2002) also provides recommendations on what type

of barrier should be used dependent on the median section. These guidelines are

summarized in Table 2.2. 
Table 2.2 AASHTO Installation Recommendations

\begin{tabular}{|c|c|c|}
\hline Barrier Type & Median Width (ft) & Recommended Terrain \\
\hline Weak-post W-beam & $23 \mathrm{ft}$ or greater & $\begin{array}{c}\text { Flat, regular, traversable slopes, straight } \\
\text { median }\end{array}$ \\
\hline Three-strand cable & $23 \mathrm{ft}$ or greater & Flat, regular, traversable slopes \\
\hline Box-beam & $10 \mathrm{ft}$ or greater & Flat, regular, traversable slopes \\
\hline Blocked-out W-beam (strong post) & $10 \mathrm{ft}$ or greater & $\begin{array}{c}\text { Flat, regular, median width of } 10 \mathrm{ft} \text { or } \\
\text { greater }\end{array}$ \\
\hline Blocked-out Thrie-beam (strong post) & $10 \mathrm{ft}$ or greater & $\begin{array}{c}\text { Flat, regular, requires effective barrier } \\
\text { height }\end{array}$ \\
\hline Modified Thrie-beam & $10 \mathrm{ft}$ or greater & $\begin{array}{c}\text { Flat, regular, requires effective barrier } \\
\text { height }\end{array}$ \\
\hline Concrete median barrier & Lower than $10 \mathrm{ft}$ & Use in narrow, symmetric medians \\
\hline
\end{tabular}

BMI Engineers (2003) conducted a survey of state departments of transportation.

There were trying to determine three things. First, they sought to identify if the state departments of transportation diverged from AASHTO guidelines. Next, if the state departments of transportation did indeed diverge from AASHTO guidelines, the researchers wanted to determine how. Finally, they wanted to identify the types of median barriers that each state used. California was identified as diverging from the AASHTO standards. Missouri and New York identified seven barrier types in use; Washington five; Ohio and Colorado, four; and Indiana only had two. Illinois and Oregon did not respond to this survey.

Johnson (1964) directed a before and after study on median barriers using California data. He compared the safety aspects of cable barriers and metal beam barriers on freeways. The cable barriers were installed on medians wider than 16 feet, whereas the beam barriers were installed on narrower medians. From this study, it appears that the installation of the median barriers resulted in an increase in the number of PDO and injury crashes compared to before the installation. Still, the number of fatal accidents did 
not change significantly between before and after. With respect to the median barrier type, the metal beam seems to result in more severe accidents than the cable barrier, which can be explained by the more rigid structure of the metal beam barrier as compared to the flexible nature of the cable barrier. An attempt was also made to study the statewide fatal accident rates for freeways with and without barriers and to relate them to the ADT. However, the number of fatal accidents was too small to conclusively identify any systematic trends in the data.

Elvik (1995) conducted a meta-analysis using 32 research studies about the effects of median barriers on safety. His analysis concluded that median barriers induced a $30 \%$ increase in accident rate, a $20 \%$ reduction in the chance of sustaining a fatal injury, and a $10 \%$ reduction in the chance of sustaining a personal injury. According to this study, placing a barrier in the median would increase the accident rate by $30 \%$, increase the number of fatal accidents by $4 \%$, and increase the number of injury accidents by $17 \%$.

Hauer (2000) reviewed the study of Nystrom et al. (1997) on median barrier warrants. The study by Nystrom et al. used California crash data from 1991 to 1995. Four categories of crashes were defined:

- Type A: the vehicle crosses the median section but is not hit by a vehicle - Type B: the vehicle leaves the road to the left, penetrates the median and has an accident anywhere in the median or has an accident when it veers back into the original travel lanes or even beyond them to the right

- $\quad$ Cross-median crashes

- Hit barrier accidents 
Accident rates (accidents/100MVM ) were computed for several median widths and ADT ranges for roads with and without barriers. In the case of roads without median barriers, the rate was calculated using "Type A + Type B + Cross-median crash;" and in the case of roads with a median barrier, the rate was calculated for "Type B + Hit barrier accidents." A comparison of the rate of crashes on roads without a median barrier and the rate of crashes on roads with a median barrier showed that, in almost all cases, for the same median width and the same ADT range, the rates of Injury crashes and PDO crashes were smaller on roads without a barrier than on roads with a barrier. The opposite was observed for fatal accidents.

The Washington State Department of Transportation analyzed 11,457 median barrier collisions on Washington State highways from 1999 to 2004 (WSDOT, 2006, p.2). It was found that occupants striking the cable barrier were less likely to be injured or killed than those striking the concrete or guardrail barrier. More interestingly, they concluded that this is because the cable barrier is less likely to redirect vehicles into another vehicle.

It appears from previous research that the presence of a median barrier tends to increase the rates of PDO and Injury accidents but at the same time decreases the rates of fatal accidents. These results, however, cannot be interpreted alone and have to be compared with the findings on crash frequency in order to understand the complete impact of median barriers on safety. 


\subsubsection{Cable Barriers}

Recent studies have been conducted on the safety impact of cable barriers. There are two general categorizations of cable barriers: low and high-tensioned. Lowtensioned, 3-strand cable systems began to be installed in the 1960's (McClanahan et al., 2003). High-tensioned cable systems, such as Brifen Wire Safety Fence, Trinity and SafeRoads, have only been recently introduced into the U.S., although they have been used internationally for many years. Since their introduction in the U.S. and acceptance by the Federal Highway Administration, the states where high-tensioned cables were installed have conducted in-service evaluations of the system. Colorado, Iowa, Ohio, Oklahoma, Texas, Utah, and Washington are some of the states known to have hightensioned cable systems in place. Many other states are presently in the process of installing high-tensioned cable barriers, including Indiana. Ohio was the only state found to have three high-tensioned cable systems installed: Brifen WRSF, Marion Steel SafeRoads, and Trinity CASS (Focke, 2005). However, only the Brifen WRSF is installed on an interstate. The primary advantage of high-tensioned cable barrier systems is that they "hold their height after an impact" (Focke, 2005); and, therefore, they can withstand another impact without immediate repair. Of all the reports and research on cable barriers that have been found, little information is provided about the effect of hightensioned cable barriers on motorcyclists. Only a study in Washington State referenced motorcycle accidents by noting that no cable barrier accidents involved motorcycles (McClanahan et al, 2003). 
In a study on the potential effectiveness of cable barriers on preventing crossmedian crashes, Davis and Pei (2005) showed that the impact severity in five reconstructed cases was lower than stated in the National Cooperative Highway Research Program (NCHRP) 350 Test Level 3, which would allow a "range of barrier designs" to be utilized as a means to prevent cross-median crashes. In addition, they simulated the cases in which the cable median barrier was placed in the center and off the shoulder. The results indicated that cable barriers at both placements would be effective in preventing cross-median crashes.

Several states have performed in-service evaluations of high-tensioned cable systems. Although the implementation phase to date has been short, the presented results are promising considering that crossover crashes have been reduced to almost zero. When crossover crashes have occurred, the failure was attributed to the faulty placement of the system. In Colorado, a vehicle was able to slide under the cable because the barrier was installed at a level higher than recommended by that standards (Outcalt, 2004). The state of Utah witnessed a similar occurrence, and the investigators suggested that the system should be "placed on the high side of the median slope" (Sharp, 2005). These results highlight the importance of the proper placement of cable barriers.

The Ohio Department of Transportation conducted an in-service performance evaluation of a 14.5 mile section installed of the Brifen WRSF (high-tensioned) cable barriers installed in July 2003. The barriers were installed after 11 cross-median fatal accidents occurred on this segment within a 14-month period (Focke, 2005). A review of the crash data from the first year revealed that after the installation of the high-tensioned cable barrier, only 9 of the 87 crashes that occurred on this section resulted in injuries. 
None of these crashes were crossover fatal crashes. In addition, when the vehicle was able to penetrate the cable barrier, it never entered the opposing lanes of traffic. The study also pointed out that 25 of the 87 crashes occurred after a vehicle crossed the ditch. This implies that the vehicle was heading into the opposing direction of traffic, but was stopped by the cable barrier.

An in-service evaluation was performed by Hunter et al. (2001) who compared crash rates in the before and after periods associated with a low-tensioned cable barrier installations at a high-hazard location in North Carolina. The results indicated that injury and fatal crashes were "significantly lower than the pretreatment level" and that there was an increase in "ran-off-road-left, hit fixed object" due to the proximity of the cable barrier to the roadway

The Washington Department of Transportation, after conducting an inperformance study of 24.4 miles of low-tensioned cable barriers, found that on sections where the cable barriers had been installed, the frequency of accidents was found to increase while the number of severe accidents decreased significantly (McClanahan et al., 2003). These results imply that the low-tensioned cable barrier was able to contain the vehicles while absorbing the energy of a crash, rather than applying the energy to the vehicle. They concluded that cable barrier is a cost-effective solution to prevent crossover accidents.

The Washington Department of Transportation studied the cable barrier performance in eight other states (WSDOT, 2006, p.10). It was found that in the five states included in the study (New York, North Carolina, South Carolina, Utah and 
Oregon), the average severity and number of crossover median crashes decreased after the installation of the cable barrier.

To conclude, the in-performance studies conducted by the department of transportation after the installation of cable barriers appear to show that the number of severe accidents was reduced after the installation of the cable barriers. On the other hand, the frequency of crashes appears to increase.

\subsection{Other Relevant Studies}

The Noland and Oh (2003) study described previously also investigated the relationship between fatalities and road cross-sectional elements. The models for fatalities produced the following results: an increase in the number of lanes appeared to be associated with an increase in the number of fatalities, and an increase in lane width also appeared to be associated with increased fatalities. However, outside shoulder width, inside shoulder width, and horizontal and vertical curvatures were not found to be correlated with the number of fatal accidents.

\subsubsection{Rumble Strips}

Rumble strips are designed to alert inattentive drivers through vibrations and sound that their vehicles have left the travel lane (FHWA, 2001). Rumble strips have only recently begun to be applied to rural interstates. This component is included as one of the geometric characteristics and thus literature on it is presented herein. 
A study by Carrasco, McFadden and Chandhok (Carrasco et al., 2004) showed, using data from Minnesota, that there was a reduction in crashes for rural multi-lane highways as a result of shoulder rumble strips. However, the values that were obtained were not as large as those found in freeway literature.

Cheng et al. (2000) used data from Utah to compare continuous rumble strips with those that were disjointed. They concluded that the rumble strips installed on asphaltic pavement were more effective than rumble strips on concrete as a result of the discontinuous nature of the latter.

\subsubsection{Speed Limit}

The National Highway System Designation Act of 1995 eliminated the Federal mandate for a National Maximum Speed Limit (NYSDOT, 1999). New York later raised the speed limits of some of its rural interstates and rural interstate "look-a-likes." A study was then performed in New York, as required by in-state legislation, to evaluate the effect that the speed limit change had on accident frequency and rates. It was found that the total accident rate (total accidents per million vehicle-miles) decreased. The frequency of total accidents, on the other hand, increased (NYSDOT, 1999). 


\section{$\underline{2.5 \text { Existing Models }}$}

\subsubsection{Severity}

Several types of models may be used to predict the expected severity of crashes: logit models, probit models, ordered and unordered models, and nested structures. This section provides an overview of the different statistical approaches used for the estimation of crash severity.

Ulfarsson and Mannering (2002) developed several multinomial logit (MNL) models to study the differences between male and female injury severities for several types of vehicles. They distinguished four levels of injury severity (no injury, possible injury, evident injury, and fatal or disabling injury) and developed a total of 14 models (separate models were estimated for male and female in each of the seven vehicle categories). Maximum likelihood estimation was used to estimate the coefficients. The results showed significant differences, and even sometimes opposite effects, between males and females with respect to how certain factors such as the road condition or the type of crash affect injury severity.

Khorashadi, Niemeier, Shankar, and Mannering (2005) used a classic MNL model to estimate the differences in rural and urban driver-injury severities in accidents involving large trucks. The standard MNL model with four outcomes corresponding to the four levels of severities was chosen over an ordered logit model which can restrict the influence of explanatory variables on the severity outcomes. Therefore, the ordered model is not able to handle the possibility of an increase in the likelihood of mid-level 
severities. The study also tested whether a nested logit model would be more appropriate than the standard logit formulation (if the various injury categories share unobserved effects, the multinomial logit assumption of the independence of the unobserved effects across the discrete outcome categories is violated). To solve this issue, four nested logit structures were estimated for rural and urban areas, combining the severity outcomes in different nest structures. For all of the nested structures, the validity of the simple multinomial logit model could not be rejected with a reasonable level of confidence (i.e., the log-sum coefficient estimated for the nested models was not significantly different from 1 , the value for which the nested model reduces to a simple multinomial logit model).

Lee and Mannering (2000) considered a nested logit model structure to analyze the impact of roadside features on the severity of run-off-roadway accidents using three years of crash data from Washington State (1994 to 1996). Four levels of severity were distinguished: PDO, possible injury, evident injury, and disabling injury / fatality. A nested structure was chosen to cancel out the shared unobserved effects in each nest. Different nested structures were considered in order to determine statistically the one that best captured the correlation among the various severity levels. The nested structure eventually chosen had evident injury and disabling injury/fatality as outcomes alone, and PDO and possible injury in a single nest (the assumption was that the two low-injury outcomes share unobserved effects). The study had various results concerning the effects of roadside features on the severity of crashes; some of the roadside features contributed to a higher severity as a result of the impact or mitigated the severity, probably due to the driver modifying his behavior on the road. 
O’Donnell and Connor (1996) used two multiple choice models, the ordered probit and the ordered logit, to estimate the effects of various attributes of road users on the severity of accidents. Four levels of severity were considered: non-treated injury, treated injury, admitted injury, and death. The final subset of variables chosen for the model was selected according to the Schwarz Bayesian Information Criterion (SBIC). No attempt was made to check for shared unobserved effects between the levels of severities.

In conclusion, the logit formulation seems to be widely accepted over the probit models when the dependent variable presents more than two outcomes. Although they were used in past studies on accident severity, the ordered choice models no longer appear appropriate since they can restrict the influence of explanatory variables on severity outcomes. With respect to the nested models, the studies were divided: some of the past research on accident severity concluded that nested structures are useful due to the presence of correlation among the unobserved effects, whereas other research did not consider the distinction as necessary.

\subsubsection{Frequency}

The following section first describes the development of frequency modeling. It then presents frequency models developed during previous research. Finally, a study is presented which had interesting variables in the resulting models, although it was case specific. Since the literature related to the development of frequency models is extensive, 
the studies included here are those that show the progression of frequency models over time, as well as studies that more closely tie to the scope of this research.

Originally, traditional regression analysis was used to model the frequency of crashes. This model fails to represent crash data well as a result of two assumptions: the dependent variable is assumed to be continuous and normally distributed with constant variance. Crash data, in contrast, is discrete and non-negative. Negative binomial regression was able to account for these considerations, and as a result, it is the typical model used when analyzing the frequency of crashes. In cases where the mean and variance are equal (i.e., the overdispersion parameter is not statistically significant), the Poisson model may be employed.

The Hadi et al. (1995) study, as previously described, investigated the safety impacts of several cross-section elements using negative binomial models and four years of Florida crash data. For four and six-lane rural freeways, they found that an increase in the inside paved shoulder width decreased the frequency of injury crashes, whereas an increase in the number of interchanges increased this frequency. This is shown in the model that follows for total crashes on four and six-lane rural freeways:

$$
Y=\exp \left(\begin{array}{l}
-12.14+0.8533 \times \text { Llen }+0.9032 \times \text { Laadt }-0.0252 \times I p \\
+0.4679 \times I c-0.0472 \times S m
\end{array}\right)
$$

where:

Llen is the logarithm of (1000xSection Length) (in miles), Laadt is the logarithm of the AADT, Ip denotes the inside paved shoulder, Ic is the number of interchanges, $\mathrm{Sm}$ is the (Median Width) $)^{0.5}$. 
Notice that the coefficient of the length of the segment is relatively close to 1 . It is also interesting to note that the number of interchanges is a significant component. In addition, the independent variable percentage of commercial vehicles was included in the modeling analysis, yet it was not present in the final model.

Wang et al. (1998) investigated rural, multi-lane, non-freeway sections using data from Minnesota. Geometric data was primarily obtained from road inventory files which contained segments that were described as "homogeneous highway sections." Minnesota data was utilized because of the videodisc photo logs that were available. The photo logs were utilized in conjunction with a Photolog Laser Video disc system to estimate median widths because some of the median widths in the original dataset were described as "varies." Six years of accident data were utilized in the analysis. A Poisson model was developed as follows:

$$
Y=0.0002 \times(D V M T)^{1.073} \times \exp \left(\begin{array}{l}
0.131 \times X_{1}-0.151 \times X_{2}+0.034 \times X_{3}+ \\
0.163 \times X_{4}+0.052 \times X_{5}-0.572 \times X_{6}+ \\
-0.094 \times X_{7}-0.003 \times X_{8}+0.429 \times X_{9}
\end{array}\right) \text {, }
$$

where:

$\mathrm{Y}$ is the predicted annual accidents, DVMT is the average daily vehicle miles of travel, $\mathrm{X}_{1}$ is the average roadside hazard rating,

$\mathrm{X}_{2}$ is the access control ( partial control $=1$, no control $=0$ ),

$\mathrm{X}_{3}$ is the frequency of driveways (Driveways/mi),

$\mathrm{X}_{4}$ is the frequency of intersections with turn lanes (Intersections with turn lanes/mi), $\mathrm{X}_{5}$ is the frequency of intersections without turn lanes (Intersections without turn lanes/mi), $\mathrm{X}_{6}$ is the road functional class (rural principal arterial $=1$, rural others $=0$ ), $\mathrm{X}_{7}$ is the shoulder width (in feet), 
$\mathrm{X}_{8}$ is the median width (in feet),

$\mathrm{X}_{9}$ is the area location type (rural municipal $=1$, rural non-municipal $=0$ ).

Similar to the Hadi et al. study above, although the information was collected on percent commercial vehicles, it was not a significant variable in the model.

Shankar et al. (1995) investigated the effects of geometry and weather on accident frequency. Interstate 90, from which the data was obtained, exhibits extreme weather and geometric characteristics; and therefore, the model is likely to be case specific. Several models were developed, including one for total frequency of crashes. The significant variables in this model were related to the number of horizontal curves, grade, weather, and interactions between geometric components and weather. 


\section{CHAPTER 3: RESEARCH METHOD}

This research study investigates the safety impacts of alternative median treatments on rural interstates. The research approach applied in this study is mostly statistical modeling of frequency and severity of crashes by fitting statistical models to data. Data are collected in four categories: geometric, traffic, crash and road construction. Data from other states was included in addition to Indiana so that alternative median treatments could be considered in the analysis. This became challenging at times, particularly for high-tensioned cable barriers that typically had short history.

A new element of this study is analyzing the safety impacts for various crash categories rather than the overall effect on all crashes. The presumption is that various median solutions may affect different types of crashes differently. An original categorization was proposed to differentiate various ways in which a median may influence crash progress: preventing crossover (involved vehicle contained in the median), failing prevent crossover (crossover crash), vehicle returning to the traveled way (same direction crashes), or crashes not related to the median (other crashes). This categorization has been abandoned due to unreliable identification of crash categories that had to be done automatically. A new categorization was less oriented towards median but sufficiently supported with existing crash records from multiple states. The final categorization included: single vehicle crashes, multiple vehicles same direction, 
and multiple vehicles opposite direction. There was a small group of crashes that could not be classified to none of the three categories.

The safety impacts of the various median treatments were then analyzed using a combination of econometric modeling and before-and-after analyses. Safety performance functions were developed to analyze the frequency of crashes. Negative binomial models were utilized to relate segments of homogeneous cross-sections to the frequency of crashes for the development of the safety performance functions. For some median treatments, particularly those with barriers, the sample size was too small to obtain confident regression equations. Yet, it was desirable to analyze the effect of these treatments on safety. A before-and-after analysis was performed for these median treatments to develop crash modification factors.

The crash severity was modeled using a discrete choice model to predict the probability of severity outcomes. The severity estimated is a discrete variable; every observation is constituted by a crash. The severity analysis was first modeled with a multinomial logistic regression model with three outcomes: property damage only, injury, and fatality. This model was later reduced to a binary logit model because the results using the multinomial logit model implied that the two severity categories injury and fatal were sharing some unobserved effects; the sample size of the fatal crashes was too small.

The development of a set of crash prediction equations is accompanied with an extensive study of the existing state-of-the-art and state-of-the-practice to provide the transportation agencies with additional guidance related to the to-date experience of other agencies with novel median treatments. 


\section{CHAPTER 4: DATA COLLECTION}

This chapter begins by identifying the states that were used in the analysis. Then, an overview is provided for the four categories of data that have been collected. The final section describes the experience of each state with these four categories of data.

Of the original sixteen states targeted for inclusion in the study, data was collected for ten. The ten states include Colorado, Illinois, Indiana, Iowa, Missouri, New York, Ohio, Oregon, Washington State and Wisconsin. The states are shaded in orange in Figure 4.1. The data from Wisconsin and Iowa were not used in the final modeling due to incomplete data.

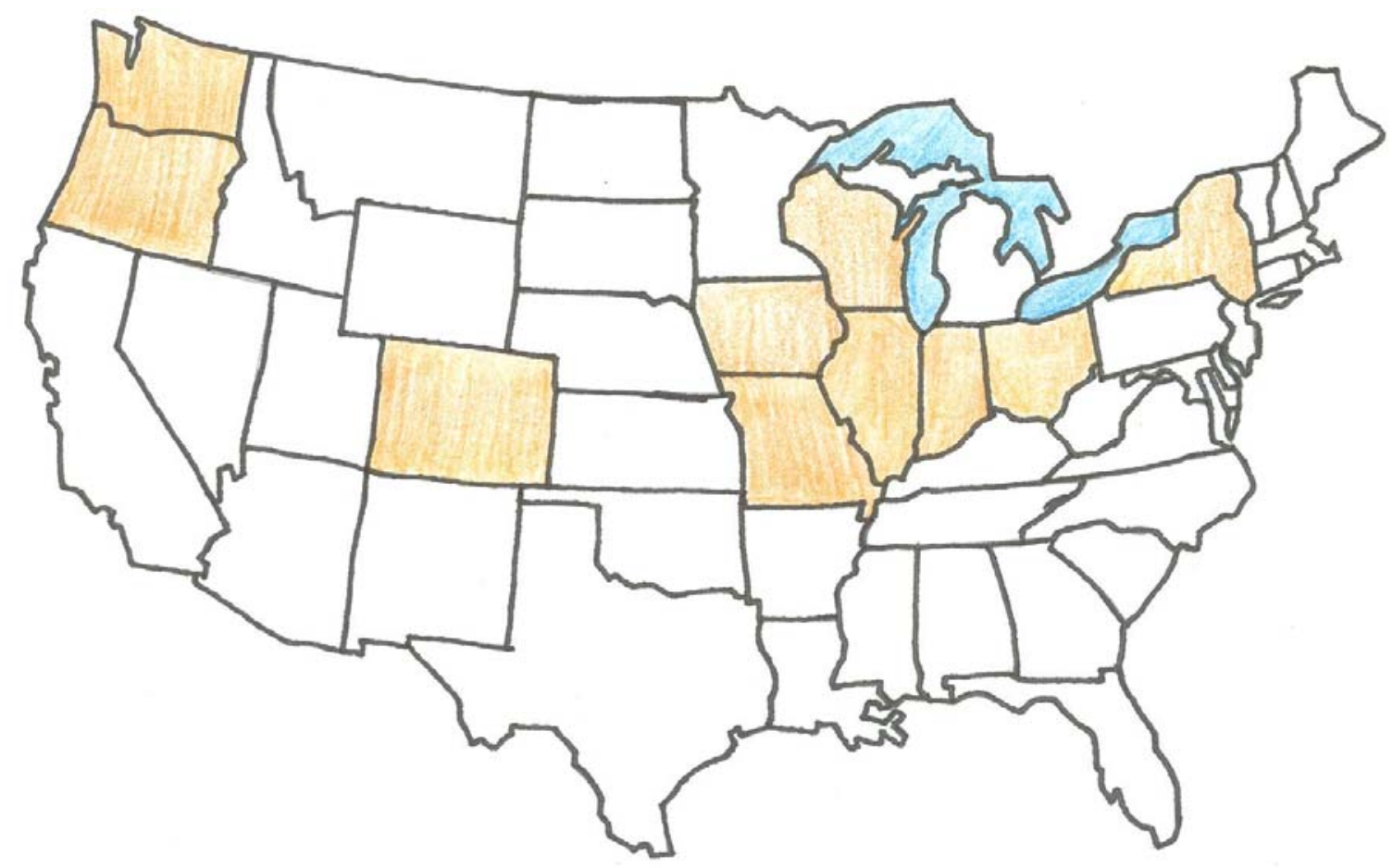

Figure 4.1 States Where Data Was Collected 


\subsection{Scope of Data Collected}

The data collected for this study can be divided into four general categories: geometric, crash, traffic, and construction. Geometric data was often the most difficult to obtain. Examples of geometric data include the number of vertical and horizontal curves, the widths of the median, type of median barriers and so forth. This type of data was typically collected using video logs or a combination of photo logs and databases. Crash data, on the other hand, was relatively easy to collect. Every state contacted had a crash database, but the contents of the database varied. In some states, the raw data for a set of years was obtained, whereas in others, a portion of the data was provided. Traffic data was accessible from every state. Types of traffic data that were collected include: average annual daily traffic (AADT), percentage of trucks, posted speed limit, and the statewide speed limits. One of the most crucial pieces of data that was the most difficult to obtain is construction data. The desired construction data is the installation year of a barrier. It would have been preferable to have had absolute knowledge of any major alignment changes and additions or subtractions to the number of lanes, but the difficulty related to obtaining this data caused our study to focus on median barrier installation dates.

\subsubsection{Geometric Data}

A segment is defined as a homogeneous cross-section of a rural interstate. This means that within a segment, the barrier type, median width, number of lanes, roadway 
pavement, inside and outside shoulder widths, speed limit, and the presence of interior and exterior rumble strips does not change. A segment was not terminated based upon the exterior components because the focus of this study was the median. Therefore, the presence of an exterior barrier was often neglected unless it was present in a significant portion of the segment.

The geometric data used for this study were usually collected using either video or photo images of the interstates. The video log software, which displays video images of the roads, is generally used by the departments of transportation to help manage pavement; however, the video log system has a measuring tool that allows the user to collect lateral freeway dimensions, such as median widths, shoulder widths, and the offset of barriers from the inside lane line.

Video logs were not always available in each state. In place of a video log, a geometric database was used in combination with photo log images to define segments. It was important that the databases match up with the photo log images with regards to how they were referenced, whether it was through mileposts or reference marker-posts.

The final geometric database obtained is a table where each observation represents a given segment of an interstate, with all its associated geometric characteristics. Each segment also has its corresponding traffic information, such as AADT, percentage of trucks, and statewide speed limit, attached.

If the AADT is not similar throughout the segment, then a weighted AADT (as well as a weighted average percentage of trucks) was computed according to the following formula: 


$$
A A D T_{\text {segment }}=\frac{\sum_{i=1}^{n} A A D T_{i}\left(L_{i}\right)}{L},
$$

where:

$\mathrm{n}$ is the total number of AADT values provided for the geometric segment, $\mathrm{AADT}_{\mathrm{i}}$ is the daily traffic provided for subsegment $\mathrm{i}_{\mathrm{i}}$ $\mathrm{AADT}_{\text {segment }}$ is the AADT for the geometric segment, $\mathrm{L}_{\mathrm{i}}$ is the length of subsegment $i$ with $\mathrm{AADT}_{\mathrm{i}}$,

$\mathrm{L}$ is the length of the geometric segment.

A description of all the variables present in the geometric database can be found in Appendix B.

\subsubsection{Crash Data}

The crash data were obtained through the state departments of transportation. The type of crash information provided and the manner in which it was coded varies from state to state. Five years of crash data were typically requested from each state, but more were obtained when possible. Obtaining a minimum of five years of crash data helps to ensure that the problem of regression to the mean is taken care of. Table 4.1 identifies the years of data that were collected for each state. More recent years of crash data were obtained for some states to ensure that data was available for the after period since the installation of some of the barriers were only in the last few years. Furthermore, some of the crash data collected was from more historical years due to changes in the coding of crashes, which was the case in Indiana. Crash data was originally obtained for Washington from 1993 to 2001. The years 1997 and 1998 were removed because a 
WSDOT study (McClanahan et al, 2003) indicated that these years were transition years between an old crash database format and a new crash database format. The authors of that study had concerns about the completeness of the crash data for these two years.

Table 4.1 Crash Data Information, State By State

\begin{tabular}{|c|c|c|}
\hline STATE & $\begin{array}{c}\text { Years From Which Crash } \\
\text { Data Was Taken }\end{array}$ & $\begin{array}{c}\text { Number Of Years Of Crash } \\
\text { Data }\end{array}$ \\
\hline Colorado & $1999-2005$ & 7 \\
\hline Illinois & $1999-2003$ & 5 \\
\hline Indiana & $1995-1999 ; 2003-2005$ & 8 \\
\hline Missouri & $2001-2005$ & 5 \\
\hline New York & $1992-2003$ & 5 \\
\hline Ohio & $2001-2005$ & 10 \\
\hline Oregon & $1995-2004$ & 7 \\
\hline Washington & $1993-1996 \& 1999-2001$ & \\
\hline
\end{tabular}

\subsubsection{Traffic Data}

Average annual daily traffic, percentage of trucks, statewide and posted speed limit are the traffic data collected in this study.

Different statistical models require different average annual daily traffic information. For the frequency model, it was desirable to obtain the average annual daily traffic for the median year of the crash data period. For the severity model, average annual daily traffic was desired for each year so that a crash could be related to the AADT for the year of the crash.

In some cases, AADT values were available for several years. This information could then be used to develop an equation that computes AADT for any desired year. The AADT was assumed to vary over the years at some location according to the 
compound factor model. The AADT values at some location were computed by adjusting the AADT for the base year at the same location using the compound factor model with a growth factor of $2.6 \%$. Equation (4) details the compound factor model:

$$
A A D T_{n+m}=(1+i)^{m} \times A A D T_{n},
$$

where:

" $i$ " is the growth factor, $\mathrm{AADT}_{n+m}$ is the AADT for the year $\mathrm{n}+\mathrm{m}$, $\mathrm{AADT}_{n}$ is the AADT for the year $n$.

Table 4.2 provides the years of from which AADT was taken for each state.

Table 4.2 Years of AADT, State By State

\begin{tabular}{|c|c|}
\hline STATE & Years of AADT \\
\hline Colorado & 2005 \\
\hline Illinois & 2004 \\
\hline Indiana & $1998,2000,2002$ \\
\hline Missouri & 2003 \\
\hline New York & 2003 \\
\hline Ohio & $2000-2003$ \\
\hline Oregon & $1995-2004$ \\
\hline Washington & 1997 \\
\hline
\end{tabular}

Two types of data related to speed limit were collected: the posted and statewide speed limit. The posted speed limit was taken from a database or recorded as viewed in the video or photo log. The statewide speed limit is the maximum speed limit allowed in each state on rural interstates (IIHS, 2006). For Washington and New York, the 
statewide speed limits changed within the years of crash data that were obtained. As a result, for the frequency models, a weighted average statewide speed limit was computed.

\subsubsection{Construction Data}

When analyzing the data it was found that barrier information and crash data were inconsistent in several instances. In several cases, crossover crashes occurred on segments where barriers were indicated as being present at the time of the crash. In such cases, the construction data, specifically the dates when the barriers were installed or changed, were requested. In a few instances, the correctness of the barrier information was confirmed. The crossover crashes occurred even under the presence of barriers. Only one case was specifically identified for concrete barriers. Figure 4.2 presents a case where a concrete barrier failed to prevent a vehicle from penetrating into the opposing traffic stream. 




Figure 4.2 Concrete Barrier Post-Crossover Crash

It should be highlighted that this crash was an anomaly, but all cases were addressed to ensure that crashes were removed from analysis only if justified. For example, there were several instances in which debris traveled from one traveled way to the opposing traveled way thereby causing a crash which was reported as occurring between two vehicles traveling in the opposite direction. Yet, our definition requires that two vehicles traveling in opposite directions initially collide in order for the crash to be categorized as a multiple vehicle - opposite direction crash. In several other cases, the barriers were installed during the period with crash data. In these cases, the original period was divided into two periods: with and without median barriers. The year when the barrier was installed was excluded from consideration. 


\section{$\underline{4.2 \text { Median Treatments }}$}

A classification of median treatments is proposed to account for the effects of the median features in the models. Instead of assessing the impact of different median attributes independently, segments were classified into appropriate median treatments dependent upon their characteristics. Evaluating the effect of two median attributes on the frequency and severity of accidents separately is less useful to the designers than knowing the collective impact of a particular median treatment. For instance, evaluating the effect of the median width and the effect of a paved flush median individually is not useful since it is unlikely that a large median width will accompany a paved, flush median section. The classification system devised identifies median treatments depending on the configuration of the median, the type of barrier installed, and the median width category.

Three categories of median widths were considered: median sections narrower or equal to 30 feet, median sections whose widths were between 30 and 50 feet, and median sections wider than or equal to 50 feet. These divisions correspond to the limits considered by AASHTO guidelines for the installation of a median barrier (AASHTO, 2002): for a median section greater than 50 feet, a median barrier is usually not considered; for the medians between 30 and 50 feet, the barrier is optional; and for medians narrower than 30 feet, the need for a barrier must be evaluated. In addition to following the current divisions established by AASHTO guidelines, grouping the median section into ranges of widths helps to account for any possibility of imprecision in the measurements of the median widths that were taken with the video log system. 
The median treatments studied in this research were usually in accordance with the specifications of the AASHTO Roadside Design Guide. However, a limited number of median treatments found in the field did not appear to meet the design standards. These median treatments involved particular situations on the road, such as a rock wall, and they did not constitute sufficiently large and consistent groups that should be included in this study. It was decided to remove these incidental median treatments and the corresponding crashes from the sample in order to keep for consideration only classifiable solutions.

Thirteen categories of median treatments were distinguished, depending on the median configuration, the median width, and the type of barrier installed. Their impact on safety will be evaluated through the use of a binary variable which takes the value 1 if the crash occurred on a segment where the corresponding median treatment is installed and 0 otherwise. The categories and their abbreviation are listed in Table 4.3 below. Sample images of a depressed median, a depressed median with high-tensioned cable, a depressed median with low-tensioned cable, a depressed median with a berm, a berm median, a sloped median, and both median treatments with concrete barriers can be found in Appendix C. In addition, cross-sections can be found in Appendix $\mathrm{C}$ for a depressed median, a depressed median with a berm, a berm median, and a sloped median. 
Table 4.3 Median Treatment Categories

\begin{tabular}{|l|c|}
\hline \multicolumn{1}{|c|}{ Median Treatment } & Abbreviation \\
\hline Depressed median, no barrier, width $<30 \mathrm{ft}$. & D1N \\
\hline Depressed median, no barrier, $30 \mathrm{ft} . \leq$ width $\leq 50 \mathrm{ft}$. & D2N \\
\hline Depressed median, no barrier, width $>50 \mathrm{ft}$. & D3N \\
\hline Depressed median, high-tensioned cable barrier, $30 \mathrm{ft} . \leq$ width $\leq 50 \mathrm{ft}$. & D2H \\
\hline Depressed median, high-tensioned cable barrier, $>50 \mathrm{ft}$. & D3H \\
\hline Depressed median, low-tensioned cable barrier, $30 \mathrm{ft} . \leq$ width $\leq 50 \mathrm{ft}$. & D2L \\
\hline Depressed median, low-tensioned cable barrier, $>50 \mathrm{ft.}$ & D3L \\
\hline Depressed w/berms, no barrier, width $>50 \mathrm{ft}$. & C3N \\
\hline Berm median, no barrier, width $>50 \mathrm{ft}$. & B3N \\
\hline Flush median, w-beam, width $<30 \mathrm{ft.}$ & F1W \\
\hline Flush median, concrete barrier, width $<30 \mathrm{ft.}$ & F1C \\
\hline Flush median, concrete barrier, $30 \mathrm{ft.} \leq$ width $\leq 50 \mathrm{ft.}$ & F2C \\
\hline Sloped median, no barrier, width $>50 \mathrm{ft}$. & S3N \\
\hline
\end{tabular}

The abbreviations in Table 4.3 were constructed based upon the median configuration, the median width category and the type of barrier present, if any, on the segment. The median configuration can be defined as depressed (D), depressed with berms $(\mathrm{C})$, berms (B), flush (F), and sloped (S). There are three median width categories: 1 stands for less than 30 feet, 2 stands for greater than or equal to 30 feet and less than or equal to 50 feet, and 3 stands for greater than 50 feet. The third character relates to the barrier type present on the median. No barrier is signified by $(\mathrm{N})$. Concrete is abbreviated with $(\mathrm{C})$. High-tensioned cable barrier is indicated by $(\mathrm{H})$. Low-tensioned cable barrier is signified by (L) and w-beam with (W).

The models for severity were able to provide safety impacts on more median treatments than those for frequency as a result of the exclusion of the New York data from the statistical sample for crash frequency modeling. At the same time, the New 
York data could be used to analyze the impact on crash severity. Data from New York was not included in the frequency models because of the under-representation of crashes, which could severely affect the estimation of the model parameters. The underrepresentation occurred because mileposts were not provided for all of the reference markers. The median treatments that were not included in the frequency models are F1W and D1N.

Although initially considered for frequency and severity, the median treatment D2H had to be removed from the frequency models. Originally the total sample for this treatment was 9.48 miles. As a result of the elimination of several segments from analysis because of correcting the installation date, the sample size was reduced to 5.484 miles. The sample size is too small. This is compounded by the short period with crash data; only crashes from 2005 can be used in the analysis for the remaining segments where the barrier was installed in 2004.

\subsection{Categories of Crash}

One goal of this study was to study the effect of the median design on different types of crashes. Even if all types of crashes might be affected by the median design, it is believed that the median section characteristics particularly affect "median-related" crashes since those types of accidents are directly in contact with the median section. Consequently, a first attempt was made to classify the crashes into the four following categories: crossover, stopped in the median, redirected and other. A crossover crash is 
defined as at least one vehicle crosses the median section completely and enters the opposing direction of traffic. A stopped in the median crash is defined as a vehicle leaving the traveled way and entering the median section, but the vehicle does not enter the opposing traveled way. A redirected crash is defined as one vehicle leaves the traveled way into the median but is subsequently redirected into the original traveled way. Other crashes are those which do not fall into the previous three categories.

These categories were not directly available from the entries in crash records and a means was needed to classify the crashes as accurately as possible. The best way to reliably determine the categories was through the use of the crash reports. The crash reports include a description of the crash and a sketch showing the succession of events. Using this information, the exact path of the vehicles as interpreted by the police officer and whether or not the median was involved can be determined. The downfall of this method is that it is time-consuming and obtaining the crash reports from other states is often difficult due to privacy issues; therefore, a different method was attempted.

An attempt was made to classify the crashes by utilizing several different entries from the crash databases. The codes available in these crash databases made it difficult to determine whether a crash was "median-related." The paths of the vehicles involved in the crash were not always described or obvious to deduce using the fields entered in the crash databases. In addition, the information provided in the crash databases was not always the same within the states. The entries for a similar variable might change between two states. Information was usually available about the type of collision, the location of the first damage or injury, the action of the vehicle prior to the crash, the contributing circumstances, and the objects involved in the crash. An attempt was made 
to determine the category of each crash by combining those entries, using the crash database for the state of Indiana. The categorization of crashes using this method was verified by inspecting a subset of reports obtained from INDOT. From the sample of 42 crash reports obtained, only 23 crashes were correctly classified; 17 crashes were misclassified, and in the case of two crashes, the reports were difficult to interpret. The percentage of redirected crashes correctly classified was particularly low; only four crashes were correctly classified in this category. Nine crashes were misclassified. These results are summarized in Table D.1.

As a consequence of the problems of misclassification, a new categorization was established which was believed to be more robust as it was based on more reliable entries, namely the number of vehicles involved in the crash and the direction of travel of each vehicle prior to the crash. Three categories were developed: a single vehicle (SV) crash, a multiple vehicle - same direction (MVSD) crash, and a multiple vehicle opposite direction (MVOD) crash. A single vehicle crash is a crash that only involves one vehicle. For this case, even if the initial direction of the vehicle is unknown, the crash can still be included. A multiple vehicle crash - same direction involves two or more vehicles all with the same initial direction of travel prior to the occurrence of the crash. A multiple vehicle-opposite direction crash involves two or more vehicles where at least one of the vehicles was traveling in a direction opposite of the other vehicle or vehicles prior to the crash. As an example, in this case, it was required that if one of the vehicles was originally traveling west, the other vehicle had to be traveling east. Two additional categories were established due to incomplete or inconsistent data entries. If the directions of travel were not opposite in their original direction of travel, the crash 
was categorized as multiple vehicle crash - unclear. When one of the directions of travel for a vehicle was missing, the crash was categorized as multiple vehicle - unknown.

Classifying the crashes in this manner avoided the problems related to the previous classification because it is totally objective, whereas the previous classification was mainly an interpretation of the entries in the crash database. However, this classification presents one disadvantage. First, if the directions of the vehicles were contradictory (but not opposite), the events could not be interpreted. The crash was then reassigned to the multiple vehicle - unclear category. This leads to an underestimation of the other categories; the crashes that were classified as unclear could probably be classified in the other categories using the crash reports. This issue becomes a concern with the frequency models, but does not affect the estimation of the likelihood of a severity level using the multinomial logit model.

The crash reports obtained from INDOT were used again to determine the quality of this classification. This time, only one crash was misclassified. An additional 36 reports were obtained from INDOT to confirm the previous results. Two crashes were misclassified in this sample. See Table D.2 for the summary. Overall, the classification was correct in more than $96 \%$ of the cases. Consequently, it was concluded that this classification based on coded entries provided consistent results with crash reports. It could be applied automatically to a large number of crash records. 


\subsection{Data Collected}

Trying to combine data from several states was challenging. The data was often obtained in alternate formats dependent upon the state. For example, some states had video log, whereas others only had photo logs and databases. This section describes the data collection experiences for each state.

\subsubsection{Indiana}

Indiana was the first state where data was collected and was therefore used as a benchmark to which future data collection results were compared.

\section{Geometric Data}

The geometric data were collected using the Pathview II video log system located at the INDOT Office of Research and Technology in West Lafayette, Indiana. Data were acquired using images from 2002, which was the most recent year in which data was available for all of the interstates at the time of study. Figure E.1 provides an example of the images that were viewed. The video log system used by INDOT includes a measuring tool that allows the user to measure real-world distances on the still images displayed on a computer monitor. The measuring tool was instrumental in collecting freeway lateral dimensions, such as median widths, shoulders widths, and the location of barriers. Every image in the screen had a corresponding data screen, as shown in Figure 
E.2. This screen provided two important pieces of information: heading and grade. The heading was used to compute the radius for horizontal curves. The grade was used to deduce $\mathrm{K}$ for vertical curves. The radius is computed as follows:

$$
\text { Radius }=\frac{180}{\pi} \frac{\mid \text { Beginning Milepost }- \text { End Milepost } \mid}{\mid \text { Beginning Heading }- \text { End Heading } \mid}
$$

The units for the radius are miles. The beginning and end mileposts are given in miles; the headings are in degrees. $\mathrm{K}$ is computed as follows:

$$
K=\frac{\mid \text { Beginning Milepost }- \text { End Milepost } \mid}{\mid \text { Beginning Grade }- \text { End Grade } \mid}
$$

The units of $\mathrm{K}$ are miles $/ \%$ and the grades are in percent.

\section{Crash Data}

The crash data used for Indiana was obtained in raw format. It was acquired from the crash database maintained by the Indiana State Police and was obtained through INDOT. This crash database includes records for all the crashes reported in Indiana. For model significance, it was necessary to obtain as many observations as possible. The crash data used to develop safety models included the five-year period of 1995-1999. 
Crash modification factors were developed using the 1995-1999 data for the before period and 2003-2005 data for the after period. Data from 2000 through 2002 was not utilized because the crash data was unreliable due to a transition period between two methods of crash coding which created concerns about the accuracy of the data.

A problem with the 1995-1999 crash database stems from the coding used to locate a crash. Three variables are used: a reference point, the direction from which the crash was located from the reference point, and the distance from the reference point. The crashes were not always located properly for several reasons. First, the distance from the reference point might be was missing. Secondly, the direction from which the crash was located from the reference point may not be provided. Thirdly, a milepost was not always provided for each reference point. Consequently, for a large proportion of the sample, the exact crash location was not known.

Using the data from 1995 as an example, the original database contains around 10,000 crashes recorded on an interstate. Yet, only $40 \%$ of those crashes or 4,000 crashes were located precisely. The exact location is a pivotal issue since the geometric database contains several short segments. Consequently, when assigning a crash to specific geometric segments, if the crash location is not known precisely, the crash may be assigned to the wrong segment.

Since the number of observations (i.e. number of crashes) was a concern, it was desirable to save some of the crash records which only had the distance from the reference point missing. The following describes how this was done.

The reference posts used to code crash locations are one mile apart. When a police officer has to estimate the distance to the reference post, it is assumed that the 
officer selects the closest reference post. Consequently, the distance from the reference point should be limited to 0.5 mile and the mean distance should be 0.25 mile. This assumption was checked; the mean distance from the reference point was determined to be very close to 0.25 mile for the sample. Thus, the following was assumed: if the reference point used to locate a crash was included in a specific geometric segment and if the distances from this reference point to the beginning and the end of the geometric segments were greater or equal to 0.5 mile, then the corresponding crash was assigned to this specific geometric segment. This rule helped to locate some crashes which had missing information, thus increasing the number of observations in the sample.

Segments were originally separated when a bridge was present. In order to attach more crashes that were missing information about distance, direction or both, attempts were made to lengthen the segments. Lengthening the segments allowed for the retention of more crashes. It also eliminated the bias brought by ending and starting the majority of the segments where overpasses or underpasses were present. Segments with similar characteristics that were only separated by a bridge were combined. As a result, the number of bridges within a segment was subsequently recorded.

The crash data from Indiana used to develop the crash modification factor for concrete was from 1997 to 1999 for the before period and 2003 to 2005 for the after period. Between these two periods, changes were made to the crash database. As such, further investigation was made into the percentage of unassigned crashes for each period. To perform this investigation, only the counties where the concrete stretched through on I-65 in Indian were investigated. The counties under investigation were Jasper, Newton and Lake County. 
A total of 10,395 crashes were found on I-65 from 2003 to 2005 . This is about a $10 \%$ increase from the total from 1997 to 1999 of 9,491 crashes. The following table provides the number of crashes that occurred in each county and the percentage of crashes in each county as compared to the total crashes occurring on the interstate.

Table 4.4 Number and Percentage of Total Crashes Per County

\begin{tabular}{|c|c|c|c|c|}
\hline & \multicolumn{2}{|c|}{$1997-1999$} & \multicolumn{2}{c|}{$2003-2005$} \\
\hline Lake & 1068 & $11.25 \%$ & 1881 & $18.10 \%$ \\
\hline Jasper & 385 & $4.06 \%$ & 765 & $7.36 \%$ \\
\hline Newton & 37 & $0.39 \%$ & 80 & $0.77 \%$ \\
\hline
\end{tabular}

The crash data from 1997 to 1999 had pseudo codes associated with every crash which were tied to reference points. The direction from which the crash was located from the reference point and the distance was also provided with each crash. As such, three pieces of information, the reference point, the direction and the distance was needed to locate every crash. In many cases, not all three components were provided. As such, a crash could still be assigned to a segment by the process described in Chapter 4 if at least the reference point information was provided. Therefore, although many crashes did not contain complete information, assumptions were made to locate as many crashes as possible.

The crash data from 2003 to 2005 had mileposts directly provided. As such, if the milepost was not provided then the crash could not be located in each county.

The following table summarized the number of crashes that could not be assigned for each period as related to each county, and it also provides the percentage of unassigned crashes as compared to the number of crashes that occurred in the county 
during the given time period. It is important to note that the numbers would be much greater for the 1997 to 1999 period had the assumptions described in Chapter 4 not been made.

Table 4.5 Number and Percentage of Unassigned Crashes

\begin{tabular}{|c|c|c|c|c|}
\hline & \multicolumn{2}{|c|}{$1997-1999$} & \multicolumn{2}{c|}{$2003-2005$} \\
\hline Lake & 31 & $2.90 \%$ & 192 & $10.21 \%$ \\
\hline Jasper & 4 & $1.04 \%$ & 23 & $3.01 \%$ \\
\hline Newton & 2 & $5.41 \%$ & 1 & $1.25 \%$ \\
\hline TOTAL & 37 & $2.48 \%$ & 216 & $7.92 \%$ \\
\hline
\end{tabular}

\section{Traffic Data}

AADT values were available for years 1998, 2000, and 2002 for Indiana, whereas the crash data used to develop the safety models includes the five-year period of 1995 1999. The AADT for these years therefore had to be obtained by adjusting the AADT for 1998 with a growth factor of $2.6 \%$. This growth factor was inferred from 822 interstate AADT values for the years 1998, 2000, and 2002 by matching the following compound factor model to the AADT data:

$$
A A D T_{c+d}=(1+i)^{d} \times A A D T_{c}
$$

Taking the logarithm of this equation, so that it takes the form $Y=m^{*} x+b$, it becomes:

$$
\log \left[\frac{A A D T_{c+d}}{A A D T_{c}}\right]=d \times \log (1+i),
$$


where:

$$
\begin{aligned}
& Y=\log \left(\frac{A A D T_{c+d}}{A A D T_{c}}\right), \\
& X=d, \\
& m=\log (1+i) .
\end{aligned}
$$

Using Limdep, (1995), $m=0.01099139037$. In this computation, it should be noted that $b$ was forced to equal zero. Solving for $i, i=0.026$. Therefore, to compute the AADT for the years 1995 to 1997 and 1999, the following equation was utilized:

$$
A A D T_{i}=(1+0.026)^{i-1998} \times A A D T_{1998}
$$

The percentages of trucks - both the single unit trucks percentage and the combination trucks percentage - were obtained from the Indiana Travel Demand Model database in TransCAD (TransCAD).

\section{Construction Data}

Barrier installation dates were obtained after geometric data was collected. Therefore, segments in which the installation year was during or subsequent to the last year of crash data had to be eliminated. Not all barrier installation dates were obtained because of the time intensive nature of collecting this information. Barrier installation dates for segments in which crossover (multiple vehicle - opposite direction) crashes had been observed were requested. Table E.3 shows the installation dates of segments with barrier for which information was obtained. 


\subsubsection{Colorado}

The geometric data collected from Colorado was only from Interstate 25 where there was a stretch of high-tensioned cable barrier. Two types of median treatments were collected: those with high-tensioned cable barriers and depressed median sections without barriers. The depressed median sections without barriers were collected for use as a reference.

Photo log images were used in coordination with the online database provided by Colorado to develop the geometric database. To access the data from the Colorado Department of Transportation, go to the web site (CODOT, 2007), click on "Stats and Data," then click on "Highway Data." Once in "Highway Data," chose "Geometrics List." The data obtained from the web page had rounded numbers with little variation which indicates that the data has likely been aggregated. The lack of variation made it difficult to develop the models.

Although Colorado provided a wealth of data, there was no information available on the average horizontal curvature of the roadways. The use of photo logs did allow for information to be collected on the number of horizontal curves. They also enabled the percentage of horizontal curvature to be computed. Information was collected for the vertical curvature, percentage of vertical curvature and number of vertical curves.

One model was developed using simple linear regression to predict the average horizontal curvature. The variables that were used to develop the models are: length of the segment (miles), average horizontal curvature, percentage of horizontal curvature, 
and number of horizontal curves. Data was used from the six other states used in the development of the safety performance functions (Illinois, Indiana, Missouri, Ohio, Oregon, Washington). The following model was developed:

$$
\text { Average Horizontal Curvature }=(1.273168(P H C)) \text {, }
$$

where:

$\mathrm{PHC}=$ percentage of horizontal curvature.

For a further discussion on the development of this equation, see Appendix F.

\section{Crash Data}

Crash data was collected from Colorado for seven years, from 1999 to 2005 . It was necessary to have recent crash data in order to include the segments with hightensioned cable barrier in the analysis as a result of their recent installation dates.

The data was not obtained in a raw format; only the crash data for I-25 was obtained.

\section{Traffic Data}

Average annual daily traffic and percentage truck information was obtained through the web site, as described previously. 


\section{Construction Data}

The barrier installation dates were easy to obtain for Colorado because the cable barrier was recently installed. No other segments were collected that had barriers on them. Refer to Table F.3 for the barrier installation dates of the high-tensioned cable barriers.

\subsubsection{Illinois}

Geometric Data

The geometric data for Illinois were collected using their video log system. The video log system was utilized on-site in Springfield, Illinois. Data were collected using images from 2004. Figure G.1 is an example of the images that were viewed. The images provided through the video log software are comprised of images from a total of six cameras. Three of the images were taken from the front of the data collection vehicle, similar to Indiana. An additional camera directed to the rear interior provides the bottom left image. The other two images are from cameras directed toward the pavement. Although the data displayed along with the images are not identical to the data provided by the Indiana video log, the heading and grade were provided. Figure G.2 displays the type of data provided for each image in Illinois. Having this data shown in Figure G.2 provided in conjunction with the images was a major advantage for this project as many states lack information on vertical and horizontal curves. Variables related to vertical and horizontal curves have shown to be significant for some safety models developed in past 
research; therefore, every effort was made to collect this information for the included states.

To provide a conceptual idea of how representative the sample for Illinois was of the interstates throughout Illinois, Figure G.3 shows the areas where segments were collected. It took a week to collect this amount of data due to the time intensive nature of the process.

\section{Crash Data}

The crash data for Illinois was obtained in a raw format. Four years of crash data, from 1999 to 2003 were provided for Illinois. As crashes were attached to segments, it was determined that 34 crashes classified as MVOD occurred on segments in which a median barrier, w-beam or concrete, was present. The first suspicion was that the barrier was installed at some point within or after the time period that the crash data spanned. This is a possibility considering that the video log images were taken on a more recent date than the years the crash data comes from. The barrier installation dates explained 8 of the 34 crashes. The remaining 25 crash reports were then requested from Illinois. Privacy laws within Illinois disallowed us access to the actual crash reports, but the Manager of the Traffic Statistics Unit within the Illinois Department of Transportation identified what caused the coding of these crashes as "Multiple-vehicle crash - opposite direction." The predominant explanation was that debris flew over the barrier, striking an opposing vehicle. The results are recorded in Table G.1. 
Two of the crashes could not be explained by either of the alternatives presented above. One of these two crashes occurred where a w-beam was viewed, but the record indicated that no barrier was present. There are several possible explanations for this discrepancy. First, it may have occurred at the end of the barrier segment but was coded within where the barrier was identified. Second, there may have been some error in the recording of the report. The second crash occurred where a concrete barrier was present. Following up on this abnormality, it was confirmed that the report identified the vehicle as penetrating the concrete barrier.

All 34 of the questionable crashes were removed from the sample for the model development. The Illinois crash data showed that crossover crashes where a barrier was present could usually be explained by two typical scenarios: the barrier was installed within a year of the crash data or debris crossed from one direction of traffic to the other causing a collision. Therefore, again, it was concluded that there was no misunderstanding of the meaning of the SV, MVSD, and MVOD crash classification utilized.

Traffic Data

AADT and percentage of trucks information was obtained through the IRIS Program. This is a database utilized by the Illinois Department of Transportation. The AADT was taken was 2004; this is not the median year. The percentage of truck information was collaboratively taken from years 2003, 2004 and 2005, although the majority of the information was from 2004. 


\section{Construction Data}

Table G.2 presents the barrier installation dates obtained. The lack of information as can be seen through this table exemplifies the difficulties in obtaining this type of information.

\subsubsection{Missouri}

\section{Geometric Data}

Video log was obtained from the Missouri Department of Transportation (MODOT) for I-70 using Aran Video. The images are from 2005; an example is provided in Figure H.1. These images were utilized to establish segments. The measurements, such as median width and shoulder width, were primarily taken from the provided database. Some of the median width values were edited using a scaling technique after observing that the values provided in the database did not resemble the median widths shown in the video log images. These differences were attributed to an aggregation of the data. Using the video log images allowed the data collected for this research to be more accurate.

Interstate 70 was selected in order to obtain segments with low-tensioned cable barrier. Data again collected for depressed segments to serve as a reference. A few 
additional median treatments were identified, but those with barriers which were not cable barriers had to be removed because barrier installation dates were unavailable.

The horizontal and curve information was computed using GPS coordinates, which were provided for every image along the interstate. The following equation was used to determine the radius of a horizontal curve using the GPS coordinates:

$$
R=\frac{L}{|\beta-\alpha|},
$$

where:

$$
\begin{aligned}
& R=\text { radius of the curve }(m i), \\
& L=\text { length of the curve }(m i), \\
& \beta=\operatorname{Arcsin}\left(\frac{-\left(X_{4}-X_{3}\right)}{\sqrt{\left(X_{4}-X_{3}\right)^{2}+\left(Y_{4}-Y_{3}\right)^{2}}}\right), \\
& \alpha=\operatorname{Arcsin}\left(\frac{-\left(X_{2}-X_{1}\right)}{\sqrt{\left(X_{2}-X_{1}\right)^{2}+\left(Y_{2}-Y_{1}\right)^{2}}}\right) .
\end{aligned}
$$

and:

$\left(\mathrm{X}_{1}, \mathrm{Y}_{1}\right)$ are coordinates of a point on the tangent prior to the beginning of the curve, $\left(\mathrm{X}_{2}, \mathrm{Y}_{2}\right)$ are coordinates of the beginning of the curve, $\left(\mathrm{X}_{3}, \mathrm{Y}_{3}\right)$ are coordinates of the end of the curve, $\left(\mathrm{X}_{4}, \mathrm{Y}_{4}\right)$ are coordinates of a point on the tangent after the end of the curve. 
Since the process of computing the radius in this manner was originally developed for Ohio, a check of the accuracy of the process will be presented under the Ohio data section.

Crash Data

The crash data provided was not raw. Five years of crash data, from 2001 to 2005, were provided specifically for I-70 within the range of miles included in the video log. An additional three years of crash data, from 1998 to 2000, were obtained for use in the development of crash modification factors.

\section{Traffic Data}

Traffic data was taken from 2003. This is the median year for which crash data was provided.

\section{Construction Data}

Table H.1 shows the barrier installation dates as provided by MODOT. These years were available because the barrier has only recently been installed. In fact, several segments within Missouri had to be eliminated as a result of the installation of the cable barrier on some segments in 2005 , since no crash data was available for the after period at the time of the analysis. 


\subsubsection{New York}

\section{Geometric Data}

The geometric data for New York was collected using the photo log images and a scaling technique. A wide variety of median treatments were collected in this state including median treatments with box-beam, w-beam and low-tensioned cable barriers. Unfortunately, the box-beam segments could not be included in the final sample as a result of limited observations. Since this barrier type was not of particular interest to INDOT, it was not pursued in other states, which may have allowed its inclusion.

\section{Crash Data}

Twelve years of crash data was collected for New York in a raw format. Similar to Indiana, New York used reference markers to locate the crashes. Unfortunately, not all of the reference markers had associated mileposts. As such, although there were 12 years of crash data from New York, the total number of crashes in New York was fewer than that in states where only five years of crash data was collected. Therefore, data from New York was only included in the severity modeling. Under-representation of crashes does not affect the logit models because the analysis is performed knowing that the crash happened. 


\section{Traffic Data}

Average annual daily traffic and percentage truck data was obtained using a database provided by the New York Department of Transportation.

\section{Construction Data}

As a result of the numerous barrier types in New York, a large request to obtain the years of the installation of the median barriers was made. Although NYDOT assisted this research in every way possible, only a limit number of barrier installation dates were provided. Many barriers in New York have been in place since the 1960's. As such, some of the barrier installation dates can no longer be deduced by asking employees, which is the typical procedure used to obtain this information.

\subsubsection{Ohio}

\section{Geometric Data}

The geometric data were collected using a video log system with a Mandli Communications, Inc. interface (Roadview Player) in combination with a GIS database of the interstates. The video images were provided from 2004. Figure I.1 provides an example of the video images. Since the video log system used does not include any measurement tool, the median and shoulder widths were retrieved using the data available in the GIS database. The horizontal and vertical curves information (radius and 
K-parameter) were computed using the GPS coordinates and the altitude at the point of the road displayed on the image. GPS coordinates and the altitude were provided for every image. The same equation used for computing the horizontal curvature for Missouri was used in Ohio.

The accuracy of the computations was checked using several satellite images of the roadway (GlobeXplorer, 2006). In most of the cases, the calculated values were found to be reasonably close to the values observed using the satellite images.

The K-parameter of the vertical curves was determined using the altitude and the milepost of the beginning, the midpoint, and the end of the curve. A vertical curve is parabolic in nature. As such, it is known that:

$$
Y=a \times x^{2}+b \times x+c
$$

In this case, $Y$ is the altitude, $x$ is the milepost, and $\mathrm{a}, \mathrm{b}$ and $\mathrm{c}$ are unknowns. Since three points were taken, the three unknowns can be found.

The beginning and end mileposts are known. Taking the derivative of (12), the following is obtained:

$$
Y^{\prime}=2 \times a \times x+b
$$

The beginning grade is then found by inserting the beginning milepost as $x$ and the parameters obtained using the three points and (12) in order to obtain $Y^{\prime}{ }_{\text {beg. }}$. A similar procedure is followed to obtain the end grade. 
Two types of median treatments were of particular interest in Ohio: a mound median section (depressed with a slight berm in the center) and a depressed median section with a high-tensioned cable as the median barrier. The geometric data were collected on three interstates (I-70, I-71, I-75) which had the desired median treatments.

\section{Crash Data}

Five years of crash data, from 2001 to 2005, were collected from Ohio.

Traffic Data

Information was taken from the GIS data to determine average annual daily traffic and percentage of trucks for every segment.

\section{Construction Data}

As the data collected from Ohio was only a subset of the total rural interstate system, barrier installation dates were only needed for the high-tensioned cable system. These barriers were installed in 2003. See Table I.1 for a summary.

Six crashes occurred where high-tensioned cable barriers are present. Even though it is possible to cross a median section protected by a cable barrier, more information was requested from the Ohio Department of Transportation (ODOT) on these specific crashes. Table I.2 provides the explanation associated with each crash. Out of the six crashes, only one was an actual crossover. The other crashes were the result of 
debris, vehicles backing on the shoulder, and a vehicle that was traveling down the interstate in the wrong direction. Only the crossover crash was kept for the final analysis; the five other crashes were removed.

\subsubsection{Oregon}

Geometric Data

The database for Oregon was established using a combination of video log images and the database that was provided on-line. The video log images are provided on-line, but technological limitations made the process tedious; therefore, the images were requested.

Crash Data

Ten years of crash data were collected from Oregon. The crash data was provided for all of the interstates from 1995 to 2004 in a raw format. Oregon's crash database contains extensive information. Similar to other states, crash reports were requested where crossover crashes were identified with a barrier present. Looking at the requested crash reports indicated that crashes on the frontage roads had been included. The problem was corrected. 


\section{Traffic Data}

Traffic data for Oregon was obtained through the databases that were provided on-line.

\section{Construction Data}

Construction data drastically reduced the initial database that was collected. Originally, numerous median treatments that contained concrete barriers were collected, but they had to be eliminated from the final sample because the Oregon DOT was unable to provide these installation dates. Crash data was collected for a wide span of years, and as such, obtaining the installation date of barriers was imperative.

\subsubsection{Washington}

\section{Geometric Data}

The database for Washington State was first collected using only the "State Highway Log," as a result of the bountiful information presented. Yet, the median configuration information was not provided from this source in several instances, so photo log images were requested. After viewing these photo images, it was realized that that data for Washington State was aggregated in comparison to how data was collected 
for this research. Therefore, the data collection process for Washington State had to be redone using the photo log images and database together.

Washington State has a video log system. Figure J.1 is a sample image from the video $\log$ system. The video log system was not utilized because the database and photo log images provided the information at a more reasonable cost. The video log system could only be used on-site.

Geometric data were obtained by combining the information retrieved from the photo log images and data taken from the State Highway Log for 2005 for three interstates (I-5, I-82 and I-90). The State Highway Log for Washington State is available on their web site. The State Highway Log contains information about vertical and horizontal curves in addition to providing the widths of many required variables.

Several components could not be determined from using the database and photo images. First, information about the presence of rumble strips was not provided in the database. The presence of rumble strips on the exterior could only be determined through the video log images. The presence of rumble strips on the interior could not be determined from the photo log images because the cameras only take images of the outside lanes. At the time of this research, a Washington Department of Transportation employee indicated that a database which would provide information on where rumble strips had been installed was under construction. It was not available by the time of analysis. Since a glimpse of the median is allowed in the images, the type of barrier could still be deduced from the images. Cable barriers were an exception as a result of the aesthetically pleasing element of the cable barriers. Cable barriers are not as intrusive as the concrete or w-beam barriers. The quality of the images and direction of the camera 
made it difficult to observe the presence of the cable barriers. Using information provided by the Washington State DOT, the data collector could take a closer look at the images in locations where cable barriers were installed. Finally, the database did not provide information about the median barrier location, and it could not be scaled from the images.

Some data were collected from semi-urbanized areas to try to collect a wider variety of data. For example, segments with two to four lanes of traffic per direction were collected. INDOT indicated that collecting data with a range of the number of lanes to be desirable. Including this information was an attempt to fulfill this request.

\section{Crash Data}

Crash data was originally provided from 1993 to 2001. As mentioned above, crash data from 1997 and 1998 were removed due to data accuracy concerns. The data was provided as raw databases specific to the requested interstates.

\section{Traffic Data}

The AADT and percentage of trucks were obtained from the Annual Traffic Report from year 1997. 1997 is the median year for the provided span of crash data. 


\section{Construction Data}

Due to the richness of the data provided by the Washington State DOT, a lot of segments were collected from this state. Yet, as in Oregon, many segments were eliminated due to the inability to obtain the barrier installation dates. 


\section{CHAPTER 5: SAFETY PERFORMANCE FUNCTIONS}

\section{$\underline{5.1 \text { Overview }}$}

Originally, a single model was going to be developed for each crash type: single vehicle (SV), multiple vehicle - same direction (MVSD), and multiple vehicle - opposite direction (MVOD). Although a large amount of data was collected, there was too much or not enough variability when trying to compare all of the median treatments in a single model for each crash type. For example, although the total mileage collected for segments with high-tensioned cable barriers should have been sufficient for analysis, there was not enough variability within the average annual daily traffic for this median treatment. As such, for SV and MVSD crashes, models were developed for each median treatment if a barrier was not present on the median treatment (i.e. for median treatments D2N, D3N, C3N, B3N, and S3N). For treatments with barriers, crash modification factors (CMF) were developed, which could then be applied to the appropriate SV and MVSD model. The development of crash modification factors are discussed in the next chapter. For MVOD crashes, a single model was developed for all median treatments without barriers; a table with crash rates is also presented.

Table 5.1 shows the total miles associated with each median treatment and state. 
Table 5.1 Number of Miles Per Median Treatment Per State

\begin{tabular}{|l|c|c|c|c|c|c|c|c|}
\hline & CO & IL & IN & MO & OH & OR & WA & TOTAL \\
\hline D2N & 3.605 & 58.815 & 184.678 & 0.142 & 0 & 0 & 79.7 & 326.94 \\
\hline D3N & 22.212 & 163.475 & 48.577 & 1.347 & 36.239 & 34.08 & 175.65 & 481.58 \\
\hline C3N & 0 & 1.337 & 0.283 & 0 & 41.431 & 0 & 32.88 & 75.931 \\
\hline B3N & 0 & 7.863 & 29.153 & 0.35 & 1.14 & 0 & 13.98 & 52.486 \\
\hline S3N & 0 & 0.088 & 5.166 & 0 & 0 & 0 & 34.3 & 39.554 \\
\hline D3H & 17.2 & 0 & 0 & 0 & 12.29 & 0 & 0 & 29.49 \\
\hline D2L & 0 & 0 & 0 & 34.029 & 0 & 0 & 9.22 & 43.249 \\
\hline D3L & 0 & 0 & 0 & 0 & 0 & 9.7 & 0 & 9.7 \\
\hline F1C & 0 & 9.914 & 3.992 & 5.315 & 0 & 27.3 & 9.37 & 55.891 \\
\hline F2C & 0 & 4.673 & 0.558 & 0 & 0 & 0.85 & 8.02 & 14.101 \\
\hline TOTAL & 43.017 & 246.165 & 272.407 & 41.183 & 91.1 & 71.93 & 363.12 & 1128.922 \\
\hline
\end{tabular}

Table 5.1 shows that the majority of the data was collected from Indiana, Illinois and Washington State. Notice that mileage was collected from every state for the median treatment D3N. This was used as the base case for median treatments when there was more than one median treatment in the model (i.e. for the MVOD model).

\section{$\underline{5.2 \text { Statistical Approach }}$}

Crashes are non-negative integer values. As such, a count data model is appropriate when modeling the frequency of crashes. Two types of models are typically used for count data: the Poisson regression model and the negative binomial regression model. The primary difference between the two model structures is that the Poisson regression model restricts the mean to be equal to the variance: 


$$
E\left[y_{i}\right]=\operatorname{VAR}\left[y_{i}\right]
$$

whereas the negative binomial model does not.

When the variance is not equal to the mean, the data are overdispersed $\left[\mathrm{E}\left[\mathrm{y}_{\mathrm{i}}\right]<\right.$ $\left.\operatorname{VAR}\left[\mathrm{y}_{\mathrm{i}}\right]\right)$ or under dispersed $\left(\mathrm{E}\left[\mathrm{y}_{\mathrm{i}}\right]>\operatorname{VAR}\left[\mathrm{y}_{\mathrm{i}}\right]\right)$ (Washington et al, 2003). The negative binomial model allows for the overdispersion of the data. The overdispersion parameter is signified by the variable $\alpha$. As such, the variances can differ from the mean as follows:

$$
\operatorname{VAR}\left[y_{i}\right]=E\left[y_{i}\right]\left[1+\alpha E\left[y_{i}\right]\right]=E\left[y_{i}\right]+\alpha E\left[y_{i}\right]^{2}
$$

Variables were included or excluded from the model dependent upon their Pvalue. If the P-value was smaller than 0.1 , the variable remained in the model. Furthermore, when the variable was on the border, if the magnitude and sign of the coefficient aligned with results from previous research and with expectations, the variables was retained. If not, the variable was removed.

For each model, the number of observations, n, the log likelihood function, the restricted log likelihood function, and the Chi-Squared value are provided. All of these outputs help convey the fit of the model to the data.

More observations are preferred to fewer observations. Yet, fewer observations of higher quality are preferred to more observations of lower quality. For every model, the number of observations, $\mathrm{n}$, is provided. As many observations as possible were included while maintaining the quality of the data. 
The log likelihood function and restricted log likelihood function can be used to compute the corrected $\rho^{2}$ statistic and the likelihood ratio test statistic. The corrected $\rho^{2}$ statistic is computed as follows:

$$
\text { corrected } \rho^{2}=1-\frac{L L(\beta)-K}{L L(0)} \text {. }
$$

A perfect model would have a corrected $\rho^{2}$ statistic of 1 . As such, the fit of the model is improved as the corrected $\rho^{2}$ statistic approaches 1 . The corrected $\rho^{2}$ statistic is preferred to the $\rho^{2}$ statistic because the latter does not take into account the number of parameters in the model; the $\rho^{2}$ statistic will always increase as parameters are added. The $\rho^{2}$ statistic is similar to $R^{2}$ in this regard.

The likelihood ratio test statistic is used to compare the log-likelihoods of two competing models. The likelihood ratio test statistics is computed as follows:

$$
-2\left[L L\left(\beta_{R}\right)-L L\left(\beta_{U}\right)\right]
$$

Since the log likelihood and the restricted log likelihood are being compared, this test indicates whether or not the developed model is superior to a model with only the intercept. The result of equation (17) is then compared with the $\chi^{2}$ statistic.

The Chi-Squared test is used to determine how well the sample distribution supports and assumption about the population distribution (Washington et al., 2003). The presented value is the sum of the squared difference between the observed count and the 
expected count divided by the expected count. As such, the closer the value is to 0 the better. A drawback about this test is that it does not accurately convey the fit when the sample sizes are small or the expected frequencies are small.

\section{$\underline{5.3 \text { Variables Considered }}$}

Table 5.2 provides a list of the variables that, not including the median treatments, were used when developing the frequency models. 
Table 5.2 Variables Used in Frequency Analysis

\begin{tabular}{|c|c|c|}
\hline Description & Symbol & Units \\
\hline Colorado & $\mathrm{CO}$ & $\mathrm{n} / \mathrm{a}$ \\
\hline Illinois & IL & $\mathrm{n} / \mathrm{a}$ \\
\hline Missouri & MO & $\mathrm{n} / \mathrm{a}$ \\
\hline Ohio & $\mathrm{OH}$ & $\mathrm{n} / \mathrm{a}$ \\
\hline Oregon & OR & $\mathrm{n} / \mathrm{a}$ \\
\hline Washington & WA & $\mathrm{n} / \mathrm{a}$ \\
\hline Number of Years of Data & $\mathrm{Y}$ & years \\
\hline Segment Length & $\mathrm{L}$ & miles \\
\hline Average Vertical Curvature & VK & $\% /$ mile \\
\hline$\%$ Vertical Curvature & VP & $\% / 100$ \\
\hline Frequency of Vertical Curves & $\mathrm{VF}$ & \#/mile \\
\hline Average Horizontal Curvature & HR & $1 /$ mile \\
\hline$\%$ Horizontal Curvature & HP & $\% / 100$ \\
\hline Frequency of Horizontal Curves & $\mathrm{HF}$ & $\# /$ mile \\
\hline Frequency of On-ramps & RON & $\# /$ mile \\
\hline Frequency of Off-ramps & ROF & $\# /$ mile \\
\hline Frequency of On and Off-ramps & RAL & $\# /$ mile \\
\hline Inside Shoulder Width & ISW & feet \\
\hline Outside Shoulder Width & OSW & feet \\
\hline Number of Lanes in One-Direction * 2 & LNS & $\mathrm{n} / \mathrm{a}$ \\
\hline Posted Speed Limit & PSL & $\mathrm{mph}$ \\
\hline Statewide Speed Limit & SSL & mph \\
\hline Average Annual Daily Traffic & AADT & vehicles/day \\
\hline Percentage of Trucks & PT & $\%$ \\
\hline Frequency of Bridges & BRG & $\# /$ mile \\
\hline
\end{tabular}

Notice that Indiana is not included in the list of state variables used in the analysis. This is because Indiana was considered to be the "base case," which is the state that all other states were compared to. Therefore, when state variables are significant, the 
coefficient indicates if there is an increase or decrease in the type of crash being analyzed when compared with Indiana.

\subsection{Single Vehicle (SV) Crash Models}

Table 5.3 provides the number of single vehicle crashes associated with each median treatment and each state. Totals are provided as well.

Table 5.3 Number of Single Vehicle Crashes Per Median Treatment Per State

\begin{tabular}{|c|c|c|c|c|c|c|c|c|}
\hline & CO & IL & IN & MO & OH & OR & WA & TOTAL \\
\hline D2N & 94 & 1101 & 2701 & 6 & - & - & 1563 & 5465 \\
\hline D3N & 428 & 2327 & 728 & 24 & 1101 & 197 & 3686 & 8491 \\
\hline C3N & - & 32 & 4 & - & 940 & - & 777 & 1753 \\
\hline B3N & - & 188 & 363 & 6 & 112 & - & 360 & 1029 \\
\hline S3N & - & 1 & 37 & - & - & - & 947 & 985 \\
\hline D3H & 157 & - & - & - & 306 & - & - & 463 \\
\hline D2L & - & - & - & 134 & - & - & 83 & 217 \\
\hline D3L & - & - & - & - & - & 83 & - & 83 \\
\hline F1C & - & 414 & 14 & 9 & - & 221 & 24 & 682 \\
\hline F2C & - & 174 & 5 & - & - & 1 & 143 & 323 \\
\hline TOTAL & 679 & 4237 & 3852 & 179 & 2459 & 502 & 7583 & 19491 \\
\hline
\end{tabular}

Notice in Table 5.3 that there are approximately the same numbers of single vehicle crashes for Indiana and Illinois. These states had almost the same mileage and the same number of years of crash data used for modeling the frequency of crashes. An additional 3 years of data was used from Indiana for the development of crash modification factors. These crashes were not used to develop the models in this chapter. 
Also, notice for Washington State, that although approximately the same mileage was collected as Indiana and Illinois, there were substantially more single vehicle crashes because more years of crash data were used from Washington State. These observations built confidence towards the quality of the data.

Table 5.4 provides the single vehicle crash rates for each median treatment and state.

Table 5.4 Single Vehicle Crash Rates (crashes/100,000,000 VMT)

\begin{tabular}{|c|c|c|c|c|c|c|c|c|}
\hline \multirow{2}{*}{ Treatment } & \multicolumn{7}{|c|}{ State } & Overall \\
\cline { 2 - 9 } & CO & IL & IN & MO & OH & OR & WA & \\
\hline D2N & 27.51 & 41.09 & 37.93 & 73.21 & - & - & 23.59 & 32.58 \\
\hline D3N & 35.37 & 39.46 & 37.41 & 31.83 & 35.56 & 7.74 & 36.51 & 34.15 \\
\hline C3N & - & 55.96 & 32.59 & - & 38.03 & - & 41.54 & 39.73 \\
\hline B3N & - & 59.15 & 35.66 & 32.06 & 45.30 & - & 49.33 & 44.13 \\
\hline S3N & - & 28.69 & 27.96 & - & - & - & 36.23 & 35.82 \\
\hline D3H & 39.01 & - & - & - & 40.48 & - & - & 39.97 \\
\hline D2L & - & - & - & 16.08 & - & - & 3.47 & 6.72 \\
\hline D3L & - & - & - & - & - & 7.05 & - & 7.05 \\
\hline F1C & - & 26.44 & 0 & 1.85 & - & 16.13 & 1.90 & 12.31 \\
\hline F2C & - & 44.34 & 6.18 & - & - & 5.42 & 13.36 & 20.68 \\
\hline
\end{tabular}

Models for five (D2N, D3N, C3N, B3N, S3N) of the eleven median treatments are presented. All models were developed using Limdep 7.0 (LIMDEP). Table 5.5 displays the statistical output for D2N. Table 5.6 contains the statistical output for D3N. Table 5.7 displays the statistical output for $\mathrm{C} 3 \mathrm{~N}$. Table 5.8 provides the statistical output for B3N, and Table 5.9 contains the statistical output for $\mathrm{S} 3 \mathrm{~N}$. 


\subsubsection{Depressed Without a Median Barrier, Median Width 30 to 50 feet (D2N)}

Table 5.5 presents the output for the model of D2N.

Table 5.5 Single Vehicle Crash Model for D2N

\begin{tabular}{|l|c|}
\hline Number of Observations & 215 \\
\hline Log Likelihood Function & -730.0381 \\
\hline Restricted Log Likelihood Function & -952.578 \\
\hline Chi-Squared & 450.5938 \\
\hline
\end{tabular}

\begin{tabular}{|c|c|c|c|c|c|}
\hline Variable & Coefficient & Standard Error & b/St. Er. & $\mathrm{P}[|\mathrm{Z}|>\mathrm{Z}]$ & Mean of $X$ \\
\hline Constant & -4.134021 & 0.827730 & -4.994 & 0.0000 & \\
\hline $\log (Y)$ & 1.000000 & \multicolumn{3}{|c|}{ Fixed Parameter } & 1.724677 \\
\hline $\log (L)$ & 1.000000 & \multicolumn{3}{|c|}{ Fixed Parameter } & 0.254399 \\
\hline Log(AADT) & 0.577157 & 0.080012 & 7.213 & 0.0000 & 10.120631 \\
\hline $\mathrm{HR}$ & 0.149610 & 0.067882 & 2.204 & 0.0275 & 0.369089 \\
\hline ROF & 0.070253 & 0.019995 & 3.513 & 0.0004 & 0.631132 \\
\hline ISW & -0.166394 & 0.045685 & -3.642 & 0.0003 & 4.591526 \\
\hline IL & 0.388809 & 0.095869 & 4.056 & 0.0001 & 0.237209 \\
\hline \multicolumn{6}{|c|}{ Dverdispersion paramater for negative binomial $\mathrm{m}$} \\
\hline Alpha & 0.214057 & 0.030372 & 7.048 & 0.0000 & \\
\hline
\end{tabular}

\section{Model fit and predictive power:}

There are eight total parameters in the model. The likelihood ratio test statistic was 445.0798 with a p-value of $<0.001$; therefore, this model performs superior to the model with only the constant. The corrected $\rho^{2}$ value was determined as 0.2252 . Compared to the other developed models, this value is high.

For the median treatment D2N, the equation for the frequency of single vehicle crashes is as follows: 


$$
S V_{D 2 N}=Y L(A A D T)^{0.57716} \exp \left[\begin{array}{l}
-4.13402+0.14961(H R)+0.07025(R O F)+ \\
-0.16639(I S W)+0.38881(I L)
\end{array}\right]
$$

The signs of the variables are as expected. As the AADT, average horizontal curvature (HR), and frequency of off ramps (ROF) increase, so do the frequency of single vehicle crashes on the median treatment $\mathrm{D} 2 \mathrm{~N}$. In addition, an increase in the inside shoulder width (ISW) is associated with a decrease in the frequency of single vehicle crashes. The state indicator variable for Illinois is also present. An interpretation of these results follows.

An increase in the frequency of single vehicle crashes with an increase in the AADT is expected because more vehicles provide more possibilities for errors in driving, which may result in single vehicle crashes.

Horizontal curvature provides an indication of the sharpness of the horizontal curves on a segment. As the average horizontal curvature increases, it would be expected that the frequency of single vehicle crashes increases. Sharper curves leave room for more driver errors; and hence, sharper curves create the possibility for more single vehicle crashes.

Indecision can cause accidents when considering an off-ramp. Unlike an onramp, where a person has already committed to entering a highway, motorists may make the last minute decision to exit using an off-ramp. The erratic maneuver associated with such a decision can cause the motorists to subsequently loose control of their own vehicle, which may result in a single vehicle crash. 
As the shoulder width increases, the frequency of single vehicle crashes

decreases. A larger inside shoulder width provides a stable surface for an out-of-control vehicle to recover on.

One binary variable related to states was significant: Illinois (IL). Illinois had a positive coefficient which indicates that there was a higher frequency of single vehicle crashes for this median treatment type in Illinois as compared to Indiana, the base case. The significance of this variable indicates that there is something specific to this state with regards to this particular median treatment that causes a higher frequency of single vehicle crashes. It could be the result of the reporting scheme or possibly the quality of the shoulder or any number of other explanations for which variables were not considered.

5.4.2 Depressed Without a Median Barrier, Median Width Greater Than or Equal to 50 feet (D3N)

Table 5.6 presents the output for the model of D3N.

Table 5.6 Single Vehicle Crash Model for D3N

\begin{tabular}{|l|c|}
\hline Number of Observations & 428 \\
\hline Log Likelihood Function & -1358.9 \\
\hline Restricted Log Likelihood Function & -1670.541 \\
\hline Chi-Squared & 623.2825 \\
\hline
\end{tabular}

\begin{tabular}{|l|c|c|c|c|c|}
\hline Variable & Coefficient & Standard Error & b/St. Er. & $\mathrm{P}[|\mathrm{Z}|>\mathrm{Z}]$ & Mean of X \\
\hline Constant & -2.202377 & 0.422594 & -5.212 & 0.0000 & \\
\hline Log(Y) & 1.000000 & \multicolumn{3}{|c|}{ Fixed Parameter } & 1.756297 \\
\hline Log(L) & 1.000000 & \multicolumn{2}{|c|}{ Fixed Parameter } & 0.528025 \\
\hline Log(AADT) & 0.337503 & 0.042748 & 7.895 & 0.0000 & 9.944555 \\
\hline HF & -0.026618 & 0.012120 & -2.196 & 0.0281 & 1.810355 \\
\hline $\mathrm{OH}$ & 0.414807 & 0.099795 & 4.157 & 0.0000 & 0.095794 \\
\hline $\mathrm{OR}$ & -1.736339 & 0.536352 & -3.237 & 0.0012 & 0.007009 \\
\hline \multicolumn{7}{|c|}{ Overdispersion paramater for negative binomial model } \\
\begin{tabular}{|l|l|l|l|l|}
\hline Alpha & 0.181604 & 0.015132 & 12.001 & 0.0000 \\
\hline
\end{tabular}
\end{tabular}


Model fit and predictive power:

There are seven total parameters in the model. The likelihood ratio test statistic was 623.282 with a p-value of $<0.001$; therefore, this model performs superior to the model with only the constant. The corrected $\rho^{2}$ value was determined as 0.1824 . Compared to the other developed models, this value is fairly high.

For the median treatment D3N, the equation for the frequency of single vehicle crashes is as follows:

$$
S V_{D 3 N}=Y L(A A D T)^{0.33750} \exp \left[\begin{array}{l}
-2.20238+0.41481(O H)+ \\
-1.73633(O R)-0.02662(H F)
\end{array}\right]
$$

Several variables were significant in this model. AADT again had a positive value associated with it. Two indicator variables for states were present as well: one for Ohio $(\mathrm{OH})$ and one for Oregon $(\mathrm{OR})$. The frequency of horizontal curvature $(\mathrm{HF})$ was also significant.

An increase in the frequency of single vehicle crashes with an increase in the AADT is expected because more vehicles provide more possibilities for errors in driving, which may result in single vehicle crashes.

Two variables related to states that were significant for this model. For this model, the coefficient for the Oregon state indicator variable was slightly larger than it was for the D2N model; it was still negative. The state indicator variable for Ohio was 
also present with a positive coefficient. The significance of these variables may be the result of differences in crash reporting or other unobserved factors.

The variable for the frequency of horizontal curves is significant as well. The sign is somewhat unexpected, but it can be justified. First, the coefficient is small. Therefore, the affect that this variable has on the model is minimal. Second, gradual horizontal curves may actually help to maintain a driver's attention. It would normally be expected that horizontal curves would increase the frequency of curves, but this expectation assumes that the curves are sharp. This variable could be picking up on the small benefit, as indicated by the small coefficient, that gradual horizontal curves may bring in maintaining a driver's attention when compared to a straight continuous road.

\subsubsection{Depressed With Berms Without a Median Barrier, Median Width 30 to 50 feet (C3N)}

Table 5.7 presents the output for the model of C3N.

Table 5.7 Single Vehicle Crash Model for C3N

\begin{tabular}{|l|c|}
\hline Number of Observations & 73 \\
\hline Log Likelihood Function & -242.2107 \\
\hline Restricted Log Likelihood Function & -277.2625 \\
\hline Chi-Squared & 70.10353 \\
\hline
\end{tabular}

\begin{tabular}{|c|c|c|c|c|c|}
\hline 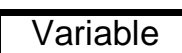 & Coefficient & Standard Error & b/St. Er. & $\bar{P}[|\mathrm{Z}|>\mathrm{Z}]$ & Mean of $X$ \\
\hline Constant & -0.898660 & 1.248934 & -0.720 & 0.4718 & \\
\hline $\log (Y)$ & 1.000000 & \multicolumn{3}{|c|}{ Fixed Parameter } & 1.763960 \\
\hline $\log (\mathrm{L})$ & 1.000000 & \multicolumn{3}{|c|}{ Fixed Parameter } & 0.425330 \\
\hline Log(AADT) & 0.196346 & 0.127480 & 1.540 & 0.1235 & 10.147680 \\
\hline $\mathrm{OH}$ & 0.361770 & 0.127858 & 2.829 & 0.0047 & 0.547945 \\
\hline $\mathrm{HR}$ & 0.278872 & 0.062021 & 4.496 & 0.0000 & 0.273458 \\
\hline & \multicolumn{5}{|c|}{ Overdispersion paramater for negative binomial model } \\
\hline Alpha & 0.116727 & 0.032608 & 3.580 & 0.0003 & \\
\hline
\end{tabular}




\section{Model fit and predictive power:}

There are six total parameters in the model. The likelihood ratio test statistic was 70.1036 with a p-value of $0.389 \mathrm{E} 10^{-12}$; therefore, this model performs superior to the model with only the constant. The corrected $\rho^{2}$ value was determined as 0.1048 .

For the median treatment $\mathrm{C} 3 \mathrm{~N}$, the equation for the frequency of single vehicle crashes is as follows:

$$
S V_{C 3 N}=Y L(A A D T)^{0.19635} \exp [-0.89866+0.36177(O H)+0.27887(H R)]
$$

Three variables are present in the model in addition to $\mathrm{Y}$ and $\mathrm{L}$ : AADT, $\mathrm{OH}$, and HR. AADT and the average horizontal curvature (HR) were associated with an increase in the frequency of single vehicle crashes for this median treatment. The implication of both of these variables was discussed previously. The state variable for Ohio was also associated with an increase in single vehicle crashes for this median treatment.

Only one of the binary variables related to states was significant: Ohio (OH).

Ohio was associated with an increase in the frequency of single vehicle crashes for this median treatment as compared to the base case, Indiana. The berms in this type of median treatment are more pronounced than those observed in Indiana. This is a possible explanation for a higher frequency of single vehicle crashes for this median treatment in Ohio. 


\subsubsection{Berms Without a Median Barrier, Median Width Greater Than or Equal to 50 feet (B3N)}

Table 5.8 presents the output for the model of B3N.

Table 5.8 Single Vehicle Crash Model for B3N

\begin{tabular}{|c|c|c|c|c|c|}
\hline \multicolumn{4}{|c|}{ Number of Observations } & \multicolumn{2}{|c|}{125} \\
\hline \multicolumn{4}{|c|}{ Log Likelihood Function } & \multicolumn{2}{|c|}{-322.9135} \\
\hline \multicolumn{4}{|c|}{ Restricted Log Likelihood Function } & \multicolumn{2}{|c|}{-364.6171} \\
\hline \multicolumn{4}{|c|}{ Chi-Squared } & \multicolumn{2}{|c|}{83.40732} \\
\hline Variable & Coefficient & Standard Error & b/St. Er. & $\mathrm{P}[|\mathrm{Z}|>\mathrm{Z}$ & Mean of $X$ \\
\hline Constant & -5.127100 & 0.999949 & -5.127 & 0.0000 & \\
\hline $\log (Y)$ & 1.000000 & \multicolumn{3}{|c|}{ Fixed Parameter } & 1.741039 \\
\hline $\log (\mathrm{L})$ & 1.000000 & \multicolumn{3}{|c|}{ Fixed Parameter } & 1.246614 \\
\hline Log(AADT) & 0.619796 & 0.101719 & 6.093 & 0.0000 & 9.835872 \\
\hline IL & 0.489148 & 0.160083 & 3.056 & 0.0022 & 0.216000 \\
\hline \multirow[t]{2}{*}{$\mathrm{VK}$} & 0.062267 & 0.027844 & 2.236 & 0.0253 & 1.345176 \\
\hline & \multicolumn{5}{|c|}{ Overdispersion paramater for negative binomial model } \\
\hline Alpha & 0.223986 & 0.068040 & 3.292 & 0.0010 & \\
\hline
\end{tabular}

\section{Model fit and predictive power:}

There are six total parameters in the model. The likelihood ratio test statistic was 83.4072 with a $\mathrm{p}$-value of $0.666 \mathrm{E} 10^{-15}$; therefore, this model performs superior to the model with only the constant. The corrected $\rho^{2}$ value was determined as 0.0979 .

For the median treatment $\mathrm{B} 3 \mathrm{~N}$, the equation for the frequency of single vehicle crashes is as follows:

$$
S V_{B 3 N}=Y L(A A D T)^{0.61980} \exp [-5.12710+0.48914(I L)+0.06227(V K)]
$$


In addition to the presence of the $\mathrm{Y}$ and $\mathrm{L}$ variables, $\mathrm{AADT}$, IL and $\mathrm{VK}$ were all present in the model. AADT and the average vertical curvature (VK) were associated with an increase in the frequency of single vehicle crashes for this median treatment. The state indicator variable for Illinois (IL) was also associated with an increase in single vehicle crashes for this median treatment.

The coefficient for $\mathrm{Q}$ for this median treatment was 0.62 . This value is larger in magnitude than all of the treatments which makes sense because berms are essentially a rigid object. Therefore, as the probability to hit a berm increases because AADT is increasing, the possibility that a single vehicle accident will occur on this median treatment increases.

An increase in the average vertical curvature was associated with an increase in the frequency of single vehicle accidents on this median treatment. The more sharp the vertical curve, the larger the average vertical curvature. Sharp vertical curves will increase the chances that a driver may loose control of their vehicle.

The binary variable for Illinois (IL) was the only state variable that was significant in this model with Indiana as the base case. Illinois saw an increase in the frequency of single vehicle accidents on this median treatment as compared to Indiana. The higher rate of accidents in Illinois could be related to the distance from the toe of the berm to the traveled way edge or other factors not included in the model that are state specific. 


\subsubsection{Sloped Without a Median Barrier, Median Width Greater Than or Equal to 50 feet (S3N)}

Table 5.9 presents the output for the model of S3N.

Table 5.9 Single Vehicle Crash Model for S3N

\begin{tabular}{|l|c|}
\hline Number of Observations & 69 \\
\hline Log Likelihood Function & -201.7529 \\
\hline Restricted Log Likelihood Function & -225.0191 \\
\hline Chi-Squared & 46.53241 \\
\hline
\end{tabular}

\begin{tabular}{|l|c|c|c|c|c|}
\hline Variable & Coefficient & Standard Error & b/St. Er. & $\mathrm{P}[|\mathrm{Z}|>\mathrm{Z}]$ & Mean of X \\
\hline Constant & -4.960491 & 1.161170 & -4.272 & 0.0000 & \\
\hline Log(Y) & 1.000000 & \multicolumn{2}{|c|}{ Fixed Parameter } & 2.004513 \\
\hline Log(L) & 1.000000 & \multicolumn{2}{|c|}{ Fixed Parameter } & 0.929179 \\
\hline Log(AADT) & 0.596096 & 0.115359 & 5.167 & 0.0000 & 9.912712 \\
\hline HR & 0.332606 & 0.146414 & 2.272 & 0.0231 & 0.559213 \\
\hline \multicolumn{5}{|c|}{ Overdispersion paramater for negative binomial model } \\
\hline
\end{tabular}

\section{Model fit and predictive power:}

There are five total parameters in the model. The likelihood ratio test statistic was 106.5324 with a p-value of $<0.001$; therefore, this model performs superior to the model with only the constant. The corrected $\rho^{2}$ value was determined as 0.0812 .

For the median treatment S3N, the equation for the frequency of single vehicle crashes is as follows:

$$
S V_{S 3 N}=Y L(A A D T)^{0.59610} \exp [-4.96049+0.33261(H R)]
$$




\subsection{Multiple Vehicle - Same Direction (MVSD) Crash Models}

Table 5.10 provides the number of crashes that were used in developing the multiple vehicle - same direction models. They are shown state by state, treatment by treatment, and as totals.

Table 5.10 Number of Multiple Vehicle - Same Direction Crashes Per Median Treatment Per State

\begin{tabular}{|c|c|c|c|c|c|c|c|c|}
\hline & CO & IL & IN & MO & OH & OR & WA & TOTAL \\
\hline D2N & 42 & 458 & 1203 & 1 & - & - & 1049 & 2753 \\
\hline D3N & 151 & 790 & 283 & 14 & 865 & 282 & 1460 & 3845 \\
\hline C3N & - & 14 & 0 & - & 472 & - & 222 & 708 \\
\hline B3N & - & 53 & 95 & 3 & 262 & - & 147 & 560 \\
\hline S3N & - & 1 & 6 & - & - & - & 719 & 726 \\
\hline D3H & 180 & - & - & - & 296 & - & - & 476 \\
\hline D2L & - & - & - & 92 & - & - & 92 & 184 \\
\hline D3L & - & - & - & - & - & 146 & - & 146 \\
\hline F1C & - & 836 & 16 & 24 & - & 185 & 25 & 1086 \\
\hline F2C & - & 176 & 6 & - & - & 6 & 89 & 277 \\
\hline TOTAL & 373 & 2328 & 1609 & 134 & 1895 & 619 & 3803 & 10761 \\
\hline
\end{tabular}

Table 5.11 provides the multiple vehicle - same direction crash rates for each median treatment and each state. 
Table 5.11 Multiple Vehicle - Same Direction Crash Rates (crashes/100,000,000 VMT)

\begin{tabular}{|c|c|c|c|c|c|c|c|c|}
\hline \multirow{2}{*}{ Treatment } & \multicolumn{7}{|c|}{ State } & Overall \\
\cline { 2 - 9 } & CO & IL & IN & MO & OH & OR & WA & \\
\hline D2N & 12.29 & 17.09 & 16.89 & 12.20 & - & - & 15.84 & 16.41 \\
\hline D3N & 12.48 & 13.40 & 14.54 & 18.57 & 27.94 & 11.09 & 14.46 & 15.46 \\
\hline C3N & - & 24.48 & 0 & - & 19.09 & - & 11.87 & 16.05 \\
\hline B3N & - & 16.67 & 9.33 & 16.03 & 105.96 & - & 20.14 & 24.02 \\
\hline S3N & - & 28.69 & 4.53 & - & - & - & 27.50 & 26.40 \\
\hline D3H & 44.73 & - & - & - & 39.16 & - & - & 41.09 \\
\hline D2L & - & - & - & 11.04 & - & - & 3.84 & 5.70 \\
\hline D3L & - & - & - & - & - & 12.41 & - & 12.41 \\
\hline F1C & - & 53.40 & 0 & 4.93 & - & 13.50 & 1.98 & 19.72 \\
\hline F2C & - & 44.85 & 7.42 & - & - & 32.50 & 8.31 & 17.73 \\
\hline
\end{tabular}

Models for five (D2N, D3N, C3N, B3N, S3N) of the eleven median treatments are presented. All of the models were developed using Limdep 7.0. Table 5.12 displays the statistical output for D2N. Table 5.13 contains the statistical output for D3N. Table 5.14 displays the statistical output for $\mathrm{C} 3 \mathrm{~N}$. Table 5.15 provides the statistical output for $\mathrm{B} 3 \mathrm{~N}$, and Table 5.16 contains the statistical output for $\mathrm{S} 3 \mathrm{~N}$. 


\subsubsection{Depressed Without a Median Barrier, Median Width 30 to 50 feet (D2N)}

Table 5.12 presents the output for the model of D2N.

Table 5.12 Multiple Vehicle - Same Direction Crash Model for D2N

\begin{tabular}{|l|c|}
\hline Number of Observations & 215 \\
\hline Log Likelihood Function & -584.097 \\
\hline Restricted Log Likelihood Function & -689.1004 \\
\hline Chi-Squared & 210.0063 \\
\hline
\end{tabular}

\begin{tabular}{|l|c|c|c|c|c|}
\hline \multicolumn{1}{|c|}{ Variable } & Coefficient & Standard Error & b/St. Er. & $P[|\mathrm{Z}|>\mathrm{Z}]$ & Mean of X \\
\hline Constant & -12.746582 & 0.928667 & -13.726 & 0.0000 & \\
\hline Log(Y) & 1.000000 & \multicolumn{3}{|c|}{ Fixed Parameter } & 1.724677 \\
\hline Log(L) & 1.000000 & \multicolumn{3}{|c|}{ Fixed Parameter } & 0.254399 \\
\hline Log(AADT) & 1.254144 & 0.092784 & 13.517 & 0.0000 & 10.120631 \\
\hline BRG & 0.020004 & 0.002610 & 7.664 & 0.0000 & 19.216953 \\
\hline CO & -0.578030 & 0.329102 & -1.756 & 0.0790 & 0.032558 \\
\hline \multicolumn{7}{|c|}{ Overdispersion paramater for negative binomial model } \\
\hline Alpha & 0.219915 & 0.035257 & 6.237 & 0.0000 \\
\hline
\end{tabular}

\section{Model fit and predictive power:}

There are six total parameters in the model. The likelihood ratio test statistic was 210.0064 with a $\mathrm{p}$-value of $<0.001$; therefore, this model performs superior to the model with only the constant. The corrected $\rho^{2}$ value was determined as 0.1437 . This value is high compared to the other models for multiple vehicle - same direction crashes.

For the median treatment D2N, the equation for the frequency of multiple vehicle - same direction crashes is as follows: 


$$
M V S D_{D 2 N}=Y L(A A D T)^{1.25414} \exp \left[\begin{array}{l}
-12.74658+0.02000(B R G)+ \\
-0.57803(C O)
\end{array}\right]
$$

Three variables were present in the model in addition to $\mathrm{Y}$ and $\mathrm{L}$ : AADT, CO, and BRG. AADT and BRG are associated with an increase in multiple vehicle - same direction crashes for this median treatment. The state variables that was present, $\mathrm{CO}$ and was associated with a decrease in the frequency of multiple vehicle - same direction crashes for this median treatment.

$\mathrm{BRG}$ is representative of the frequency of bridges on a segment. A bridge is a physical obstruction. As such, if a vehicle crashes into the bridge pier, it may be redirected into traffic cause a multiple vehicle - same direction crash. Therefore, the result, which indicates an increase in this crash type as the frequency of bridges increases, is expected.

The state indicator variable for Colorado (CO) implies a decrease in the frequency of multiple vehicle - same direction crashes for this median treatment. The significance of this variable indicates the likelihood that state specific factors are playing a role.

5.5.2 Depressed Without a Median Barrier, Median Width Greater Than or Equal to 50 feet (D3N)

Table 5.13 presents the output for the model of D3N. 
Table 5.13 Multiple Vehicle - Same Direction Crash Model for D3N

\begin{tabular}{|l|c|}
\hline Number of Observations & 428 \\
\hline Log Likelihood Function & -1034.616 \\
\hline Restricted Log Likelihood Function & -1283.517 \\
\hline Chi-Squared & 497.8026 \\
\hline
\end{tabular}

\begin{tabular}{|c|c|c|c|c|c|}
\hline Variable & Coefficient & Standard Error & b/St. Er. & $\mathrm{P}[|\mathrm{Z}|>\mathrm{Z}$ & Mean of $X$ \\
\hline Constant & -12.303864 & 0.473721 & -25.973 & 0.0000 & \\
\hline$\overline{\log (Y)}$ & 1.000000 & \multicolumn{3}{|c|}{ Fixed Parameter } & 1.756297 \\
\hline $\log (\mathrm{L})$ & 1.000000 & \multicolumn{3}{|c|}{ Fixed Parameter } & 0.528025 \\
\hline Log(AADT) & 1.239510 & 0.047917 & 25.868 & 0.0000 & 9.944555 \\
\hline $\mathrm{OH}$ & 0.450144 & 0.130730 & 3.443 & 0.0006 & 0.095794 \\
\hline RAL & 0.033058 & 0.015751 & 2.099 & 0.0358 & 1.075653 \\
\hline \multicolumn{6}{|c|}{ Overdispersion paramater for negative binomial model } \\
\hline Alpha & 0.273354 & 0.028082 & 9.734 & 0.0000 & \\
\hline
\end{tabular}

\section{Model fit and predictive power:}

There are six total parameters in the model. The likelihood ratio test statistic was 497.802 with a p-value of $<0.001$; therefore, this model performs superior to the model with only the constant. The corrected $\rho^{2}$ value was determined as 0.1892 . This value is the highest compared to the other models for multiple vehicle - same direction crashes.

For the median treatment D3N, the equation for the frequency of multiple vehicle - same direction crashes is as follows:

$$
M V S D_{D 3 N}=Y L(A A D T)^{1.23951} \exp [-12.30386+0.45014(O H)+0.03306(R A L)]
$$

In addition to $\mathrm{Y}$ and $\mathrm{L}$ in this model, three other variables are present in the model for multiple vehicle - same direction crashes for D3N: AADT, OH, and RAL. The state indicator variable for Ohio was associated with an increase in the frequency of this type of crash as compared to Indiana (IN). RAL, which is the frequency of on and off-ramps, 
was also associated with an increase in the frequency of this crash type for this median treatment.

The coefficient for Q in this model was smaller than that of the D2N model (1.25 vs. 1.58).

Both $\mathrm{OH}$ and RAL have been discussed previously.

\subsubsection{Depressed With Berms Without a Median Barrier, Median Width 30 to 50 feet (C3N)}

Table 5.14 presents the output for the model of C3N.

Table 5.14 Multiple Vehicle - Same Direction Crash Model for C3N

\begin{tabular}{|l|c|}
\hline Number of Observations & 73 \\
\hline Log Likelihood Function & -187.5498 \\
\hline Restricted Log Likelihood Function & -193.3774 \\
\hline Chi-Squared & 11.65522 \\
\hline
\end{tabular}

\begin{tabular}{|c|c|c|c|c|c|}
\hline Variable & Coefficient & Standard Error & b/St. Er. & $\mathrm{P}[|\mathrm{Z}|>\mathrm{Z}]$ & Mean of $X$ \\
\hline Constant & -12.034512 & 1.016631 & -11.838 & 0.0000 & \\
\hline $\log (Y)$ & 1.000000 & \multicolumn{3}{|c|}{ Fixed Parameter } & 1.763960 \\
\hline $\log (\mathrm{L})$ & 1.000000 & \multicolumn{3}{|c|}{ Fixed Parameter } & 0.425330 \\
\hline Log(AADT) & 1.193643 & 0.099334 & 12.016 & 0.0000 & 10.147680 \\
\hline $\mathrm{OH}$ & 0.362134 & 0.134880 & 2.685 & 0.0073 & 0.547945 \\
\hline RON & 0.223894 & 0.070771 & 3.164 & 0.0016 & 0.327165 \\
\hline $\mathrm{HR}$ & 0.209860 & 0.099091 & 2.118 & 0.0342 & 0.273458 \\
\hline \multicolumn{6}{|c|}{ Overdispersion paramater for negative binomial model } \\
\hline Alpha & 0.099411 & 0.033466 & $\overline{2.971}$ & 0.0030 & \\
\hline
\end{tabular}

\section{Model fit and predictive power:}

There are seven total parameters in the model. The likelihood ratio test statistic was 11.6552 with a p-value of 0.112 ; therefore, this model does not perform very well. Even so, these measures of model fit can perform poorly when the sample sizes are smaller. The variables in the model that are significant behave as expected, as such, the 
model is retained. The corrected $\rho^{2}$ value was determined as -0.0061 . Again, this is probably the result of a smaller sample size where the corrected $\rho^{2}$ measure can perform poorly. Again, the variables included in the model behave as expected and are statistically significant; therefore, the model is retained.

For the median treatment $\mathrm{C} 3 \mathrm{~N}$, the equation for the frequency of multiple vehicle - same direction crashes is as follows:

$$
\operatorname{MVSD}_{C 3 N}=Y L(A A D T)^{1.19364} \exp \left[\begin{array}{l}
-12.03451+0.36213(O H)+0.22389(R O N)+ \\
0.20986(H R)
\end{array}\right]
$$

In addition to $\mathrm{Y}$ and $\mathrm{L}$, four variables are present in this model: AADT, $\mathrm{OH}, \mathrm{RON}$ and HR. The frequency of on-ramps (RON) and the average horizontal curvature (HR) were associated with an increase in the frequency of multiple vehicle - same direction crashes for this median treatment.

The frequency of on-ramps was associated with an increase in this crash type for this median treatment. This is expected for this particular crash type because when a motorist tries to merge from an on-ramp into the main stream traffic they have the possibility of crashing into another vehicle already in the main traffic stream.

An increase in the average curvature is associated with an increase in the frequency of MVSD direction crashes for this median treatment. A sharp curve creates the opportunity for a vehicle to stray into an adjacent lane, thereby creating the possibility for a MVSD crash. 
The state indicator variable that was significant was for Ohio $(\mathrm{OH})$. This indicates that the frequency of MVSD crashes for this crash type is larger in Ohio than in Indiana, the base case. As previously discussed, it may be the result of differences between the reporting schemes of Ohio and Indiana.

\subsubsection{Berms Without a Median Barrier, Median Width Greater Than or Equal to 50 feet (B3N)}

Table 5.15 presents the output for the model of B3N.

Table 5.15 Multiple Vehicle - Same Direction Crash Model for B3N

\begin{tabular}{|l|c|}
\hline Number of Observations & 125 \\
\hline Log Likelihood Function & -223.3312 \\
\hline Restricted Log Likelihood Function & -275.597 \\
\hline Chi-Squared & 104.5317 \\
\hline
\end{tabular}

\begin{tabular}{|c|c|c|c|c|c|}
\hline Variable & Coefficient & Standard Error & b/St. Er. & $\mathrm{P}[|\mathrm{Z}|>\mathrm{Z}]$ & Mean of $X$ \\
\hline Constant & -16.072260 & 1.405945 & -11.432 & 0.0000 & \\
\hline $\log (Y)$ & 1.000000 & \multicolumn{3}{|c|}{ Fixed Parameter } & 1.741039 \\
\hline Log(L) & 1.000000 & \multicolumn{3}{|c|}{ Fixed Parameter } & 1.246614 \\
\hline Log(AADT) & 1.618572 & 0.140445 & 11.525 & 0.0000 & 9.835872 \\
\hline RON & 0.144463 & 0.059712 & 2.419 & 0.0155 & 0.439903 \\
\hline \multicolumn{6}{|c|}{ Overdispersion paramater for negative binomial model } \\
\hline Alpha & 0.562261 & 0.146317 & 3.843 & 0.0001 & \\
\hline
\end{tabular}

\section{Model fit and predictive power:}

There are five total parameters in the model. The likelihood ratio test statistic was 104.5316 with a p-value of $<0.001$; therefore, this model performs superior to the model with only the constant. The corrected $\rho^{2}$ value was determined as 0.1715 . This value is the fairly high compared to the other models for multiple vehicle - same direction crashes. 
For the median treatment B3N, the equation for the frequency of multiple vehicle - same direction crashes is as follows:

$$
\operatorname{MVSD}_{B 3 N}=Y L(A A D T)^{1.61857} \exp [-16.07226+0.14446(R O N)]
$$

In addition to the presence of $\mathrm{Y}$ and $\mathrm{L}$ in this model, $\mathrm{AADT}$ and $\mathrm{RON}$ were statistically significant. An increase in the frequency of on-ramps (RON) and AADT was associated with an increase in the frequency of MVSD crashes. The explanation is the same as previously provided.

The coefficient of $\mathrm{Q}$ for this treatment was 1.62. This is larger than the coefficient of Q in the D2N model.

\subsubsection{Sloped Without a Median Barrier,} Median Width Greater Than or Equal to 50 feet (S3N)

Table 5.16 presents the output for the model of S3N.

Table 5.16 Multiple Vehicle - Same Direction Crash Model for S3N

\begin{tabular}{|l|c|}
\hline Number of Observations & 69 \\
\hline Log Likelihood Function & -151.7966 \\
\hline Restricted Log Likelihood Function & - \\
\hline Chi-Squared & - \\
\hline
\end{tabular}

\begin{tabular}{|c|c|c|c|c|c|}
\hline Variable & Coefficient & Standard Error & b/St. Er. & $\mathrm{P}[|\mathrm{Z}|>\mathrm{Z}$ & Mean of $X$ \\
\hline Constant & -13.231178 & 1.157925 & -11.427 & 0.0000 & \\
\hline $\log (Y)$ & 1.000000 & \multicolumn{3}{|c|}{ Fixed Parameter } & 45 \\
\hline $\log (\mathrm{L})$ & 1.0 & \multicolumn{3}{|c|}{ Fixed Parameter } & 0.92 \\
\hline Log(AADT) & 1.3 & 5026 & 11.455 & $\overline{0.0}$ & 9.91271 \\
\hline RON & 0.094950 & 0.039855 & 2.382 & 0.0172 & 1.375 \\
\hline & \multirow{2}{*}{\multicolumn{5}{|c|}{ Overdispersion paramater for negative binomial model }} \\
\hline pha & & & & & \\
\hline
\end{tabular}




\section{Model fit and predictive power:}

There are five total parameters in the model. The likelihood ratio test statistic and the corrected $\rho^{2}$ value cannot be determined because there was no output for the restricted $\log$ likelihood. The number of observations is few. Even so, the resulting variables that are present and the signs behave as expected, as such the model is retained.

For the median treatment S3N, the equation for the frequency of multiple vehicle - same direction crashes is as follows:

$$
M V S D_{S 3 N}=Y L(A A D T)^{1.32904} \exp [-13.23118+0.09495(R O N)]
$$

In addition to the presence of $\mathrm{Y}$ and $\mathrm{L}$ in this model, the variables $\mathrm{Q}$ and $\mathrm{HR}$ are statistically significant. An increase in the AADT and average horizontal curvature (HR) are associated with an increase in the frequency of single vehicle crashes for this median treatment. No state indicator variables are significant for the $\mathrm{S} 3 \mathrm{~N}$ median treatment. For $\mathrm{S} 3 \mathrm{~N}, \mathrm{AADT}$ is raised to the power of 0.6. This value is lower than the coefficient for B3N but higher than the other three median treatments (D2N, D3N and $\mathrm{C} 3 \mathrm{~N})$. The configuration of the $\mathrm{S} 3 \mathrm{~N}$ has some similarities to $\mathrm{B} 3 \mathrm{~N}$. The low side of the slope of an S3N median treatment would act like a berm. The high side would act like a 
depressed median. Based on this comparison, it would then make sense that the value for the coefficient of $\mathrm{Q}$ for $\mathrm{B} 3 \mathrm{~N}$ is similar to that of $\mathrm{S} 3 \mathrm{~N}$.

Again, as described above, an increase in the average horizontal curvature indicates a sharper curve, which may cause increase the probability that a vehicle may loose control and result in a single vehicle crash.

In addition to the presence of $\mathrm{Y}$ and $\mathrm{L}$ in this model, $\mathrm{AADT}$ and $\mathrm{RON}$ were statistically significant. An increase in the frequency of on-ramps (RON) and AADT was associated with an increase in the frequency of MVSD crashes. The explanation is the same as previously provided.

The coefficient of $\mathrm{Q}$ for this treatment was 1.33 . This is only slightly smaller than the coefficient of Q in the B3N model. Also notice that the B3N and S3N model have the same variables present.

\subsection{Multiple Vehicle - Opposite Direction (MVOD) Crash Models}

Multiple vehicle - opposite direction (MVOD) crashes are assumed to be zero for any treatments with a barrier. Table 5.17 demonstrates the validity of this assumption: all of the median treatments with barriers have 2 or fewer crashes. Each MVOD crash that occurred on a segment with a barrier was individually investigated. Where multiple vehicle - opposite direction crashes did occur on segments with barriers, the crash rate is very small. 
Table 5.17 Multiple Vehicle - Opposite Direction Crash Rates

\begin{tabular}{|c|c|c|c|c|}
\hline $\begin{array}{c}\text { Median } \\
\text { Treatment }\end{array}$ & $\begin{array}{c}\text { Total Length } \\
\text { Represented } \\
(\mathrm{mi})\end{array}$ & $\begin{array}{c}\text { VMT } \\
\text { (per 100,000,000) }\end{array}$ & $\begin{array}{c}\text { Total } \\
\text { Number of } \\
\text { Crashes }\end{array}$ & $\begin{array}{c}\text { Crash Rate } \\
\text { (crashes/100,000,000 } \\
\text { VMT) }\end{array}$ \\
\hline D2N & 333.040 & 167.755 & 215 & 1.282 \\
\hline D3N & 481.580 & 248.651 & 173 & 0.696 \\
\hline C3N & 75.931 & 44.118 & 29 & 0.657 \\
\hline B3N & 52.486 & 23.315 & 13 & 0.558 \\
\hline S3N & 39.554 & 27.500 & 18 & 0.655 \\
\hline D3H & 21.428 & 9.610 & 1 & 0.104 \\
\hline D2L & 43.249 & 32.275 & 2 & 0.062 \\
\hline D3L & 9.700 & 11.766 & 0 & 0.000 \\
\hline F1C & 55.612 & 54.261 & 0 & 0.000 \\
\hline F2C & 14.101 & 15.622 & 0 & 0.000 \\
\hline
\end{tabular}

A single model was developed for MVOD for all median treatments without barriers. The results are as follows: 
Table 5.18 MVOD Model Results

\begin{tabular}{|l|c|}
\hline Number of Observations & 911 \\
\hline Log Likelihood Function & -587.5164 \\
\hline Restricted Log Likelihood Function & -592.8185 \\
\hline Chi-Squared & 10.60408 \\
\hline
\end{tabular}

\begin{tabular}{|c|c|c|c|c|c|}
\hline Variable & Coefficient & Standard Error & b/St. Er. & $\mathrm{P}[|\mathrm{Z}|>\mathrm{Z}]$ & Mean of $X$ \\
\hline Constant & -18.991257 & 1.748160 & -10.864 & 0.0000 & \\
\hline $\log (Y)$ & 1.000000 & \multicolumn{3}{|c|}{ Fixed Parameter } & 1.766755 \\
\hline $\log (\mathrm{L})$ & 1.000000 & \multicolumn{3}{|c|}{ Fixed Parameter } & 0.581637 \\
\hline$\overline{L o g(A A D T)}$ & 1.383801 & 0.115048 & 12.028 & 0.0000 & 9.984532 \\
\hline$\widehat{\mathrm{OH}}$ & 0.363653 & 0.177505 & 2.049 & 0.0405 & 0.091109 \\
\hline PSL & 0.030421 & 0.016536 & 1.840 & 0.0658 & 65.982437 \\
\hline $\mathrm{D} 2 \mathrm{~N}$ & 0.758848 & 0.129769 & 5.848 & 0.0000 & 0.237102 \\
\hline \multicolumn{6}{|c|}{ Overdispersion paramater for negative binomial model } \\
\hline Alpha & 0.229213 & 0.090696 & 2.527 & 0.0115 & \\
\hline
\end{tabular}

\section{Model fit and predictive power:}

There are seven total parameters in the model. The likelihood ratio test statistic was 10.6042 with a p-value of 0.1568 ; therefore, this model does not perform very well. Even so, these measures of model fit can perform poorly when the sample sizes are small. The variables in the model that are significant behave as expected, as such, the model is retained. The corrected $\rho^{2}$ value was determined as -0.002864 . The low value is probably the result of a smaller sample size which can result in the corrected $\rho^{2}$ measure performing poorly. The variables included in the model behave as expected and are statistically significant; therefore, the model is retained.

This equates to the following model:

$$
M V O D=Y L(A A D T)^{1.384} \exp \left(\begin{array}{l}
-18.99+0.3637(O H)+ \\
0.03042(P S L)+0.7588(D 2 N)+
\end{array}\right)
$$




\subsection{Overall Modeling Results}

There are some commonalities among all of the models. All of the variables included in the models are statistically significant; all insignificant variables were removed. The results coincide with existing knowledge.

All of the models had the following variables: the number of years of crash data $(\mathrm{Y})$, the length of the segment (L) and the average annual daily traffic (AADT).

$\mathrm{Y}$ and $\mathrm{L}$ have coefficients fixed to 1 because the length of the segment and the number of years of crash data should be directly proportional to the frequency of crashes. Before the variables were fixed to 1 , the coefficients in most of the models were observed to be relatively close to the fixed value of 1 . The coefficients for $\mathrm{L}$ and $\mathrm{Y}$ were taken as 1 because when considering the length of the segment, if it was divided into two halves, there should be half the frequency of crashes on one segment and half the frequency of the crashes on the other segment. Similarly, if you double the number of years of crash data collected, the frequency of crashes should be doubled as well. This assumption is based on the consideration that the models were developed with enough data to regress to the mean. A minimum of five years of crash data was obtained from each state department of transportation to try to accomplish this. Using this amount of data has shown to produce consistent results from previous studies. 


\subsubsection{Overall Results for Single Vehicle Crash Models}

All of the single vehicle models that were developed had coefficients of Q that are less than 1. Q is the natural logarithm of AADT. This implies that as the AADT increases, the frequency of crashes will continue to increase, but the rate at which single vehicle crashes increases will be reduced. This behavior can be observed in Figure 5.1.

\section{Single Vehicle}

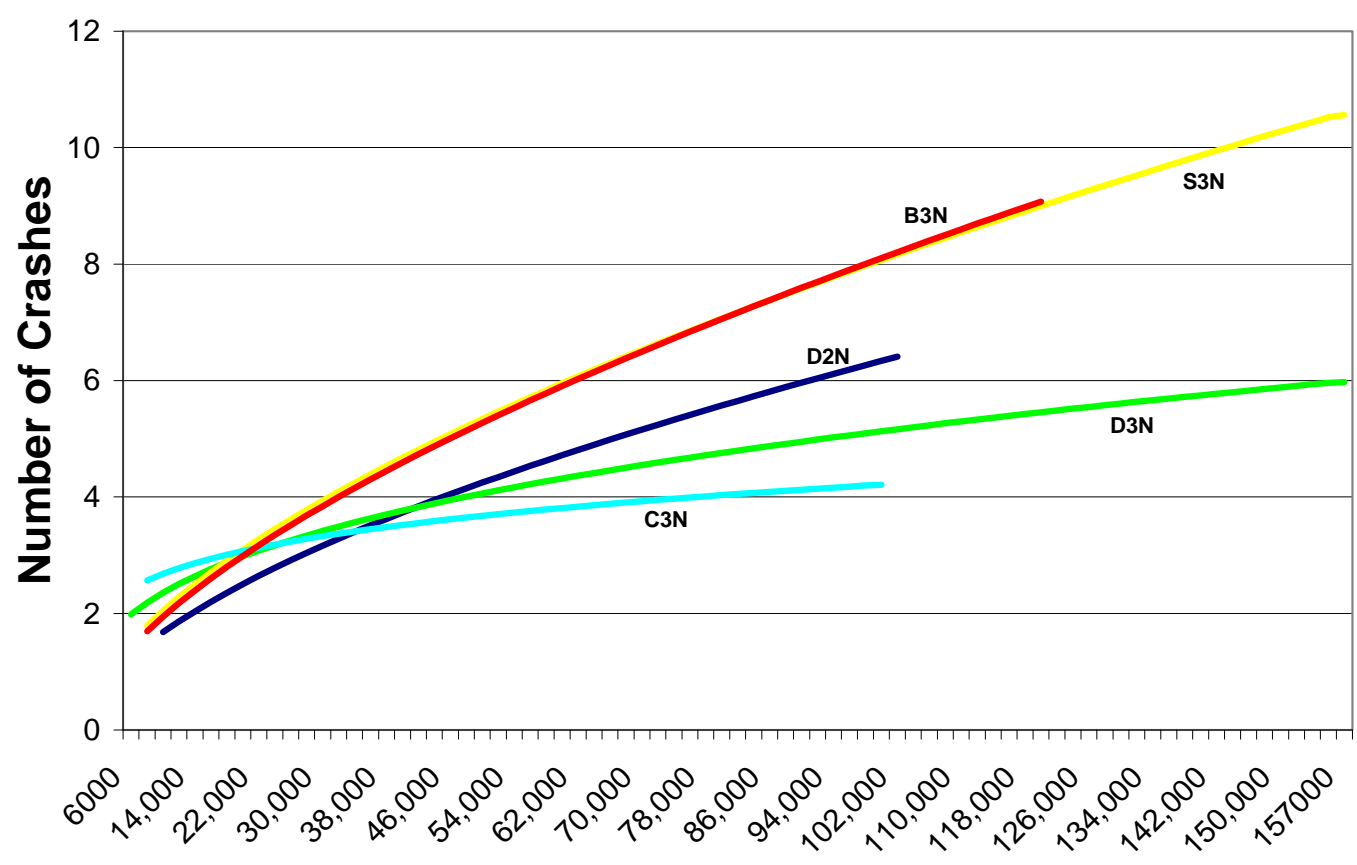

AADT

Figure 5.1 Effect of AADT on Median Treatments for Single Vehicle Crashes

Figure 5.1 also shows that an increase in AADT has a more significant affect on the median treatments $\mathrm{S} 3 \mathrm{~N}$ and $\mathrm{B} 3 \mathrm{~N}$; the frequency of single vehicle crashes for these median treatments dramatically increases beyond an AADT of 42,000. Also notice that 
the curves for $\mathrm{D} 2 \mathrm{~N}, \mathrm{D} 3 \mathrm{~N}$ and $\mathrm{C} 3 \mathrm{~N}$ are similar. These three median treatments are very similar in configuration with the exception of median width or the presence of a slight berm in the middle.

The alpha parameter, which serves as an indicator as to whether or not there is overdispersion in the data, is statistically significant in every model developed for single vehicle crashes; hence, there is overdispersion in the data. As such, the negative binomial model, which was used, is appropriate.

All of the models for single vehicles had some measure of curvature significant in the model. For the D2N, D3N, C3N, and S3N median treatments, it was related to the horizontal curvature. For the B3N median treatment, a variable related to vertical curvature was significant.

Almost every model had a state indicator variable that was significant; the median treatment $\mathrm{S} 3 \mathrm{~N}$ was the only exception. This could imply that there are differences amongst the states with insurance or some other factor that would affect the reporting of single vehicle crashes.

\subsubsection{Overall Results for Multiple Vehicle - Same Direction Crash Models}

For single vehicle crashes, the coefficient for Q, which represents the natural logarithm of AADT, was less than 1. For the models for multiple vehicle - same direction crashes, the coefficient is always greater than 1 . Therefore, the frequency of multiple vehicle - same direction crashes will increase exponentially. Figure 5.2 is a graph that demonstrates the effect of an increasing AADT with all other variables held 
constant. Similar to the plot for single vehicle crashes, the B3N median treatment is most significantly affected by an increase in AADT for this crash type. This indicates that this median treatment performs poorly when considering single vehicle and multiple vehicle same direction crashes. Figure 5.2 shows that when holding all variables constant while increasing the AADT that the median treatments D2N and B3N and the median treatments $\mathrm{S} 3 \mathrm{~N}, \mathrm{C} 3 \mathrm{~N}$ and D3N exhibit similarities for this crash type.

\section{Multiple Vehicle - Same Direction Crashes}

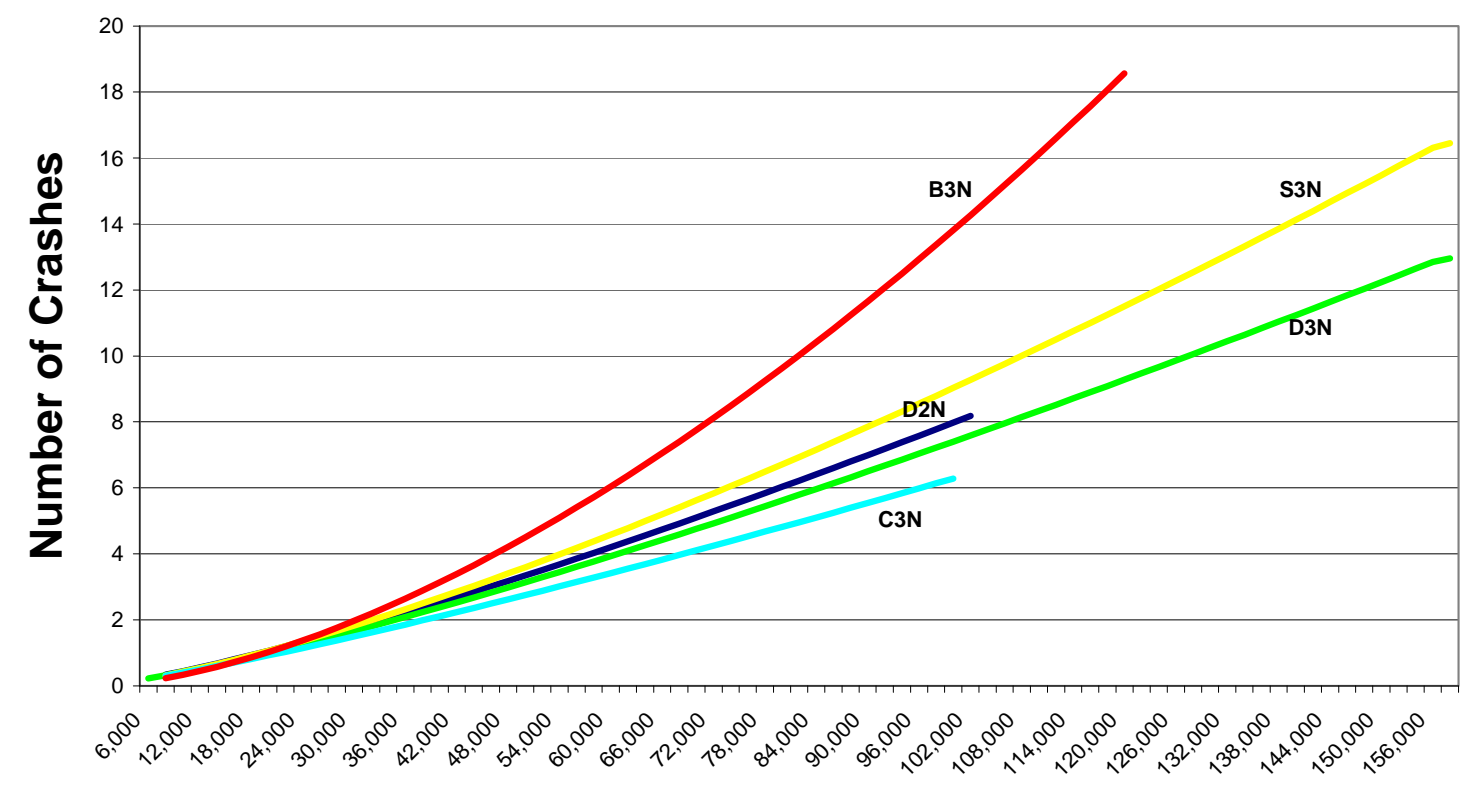

AADT

Figure 5.2 Effect of AADT on Median Treatments for Multiple Vehicle - Same Direction Crashes

Every model for multiple vehicle - same direction crashes had a significant variable related to the presence of ramps. In most cases, the variable was representative of on-ramps, $(\mathrm{RON})$ which would be expected. When a vehicle is merging, the driver is 
trying to establish their place in the flow of traffic. As such, there is always the possibility that this type of crash may occur while one is trying to merge with traffic. In the models where the RON variable was not present, the variable was present for the total frequency of on and off-ramps (RAL).

State indicator variables were present in three of the five models. This implies that the reporting of this type of crash is different in these states when compared with Indiana.

\subsubsection{Multiple Vehicle - Opposite Direction Crash Models}

Seven total variables were present in the single model for multiple vehicle opposite direction crashes (MVOD). One of these variables was a state indicator variable. An increase in the posted speed limit was associated with an increase in the frequency of MVOD crashes. One variable for median treatment was significant: D2N.

The variable that was statistically significant for a state indicator variable was for Ohio $(\mathrm{OH})$. Ohio was associated with an increase in MVOD crashes as compared to Indiana. This variable may be picking up on variables not considered such as differences in crash reporting.

Increasing the posted speed limit was associated with an increase in multiple vehicle - opposite direction crashes. When the speed limit increases, it is likely that motorists will increase their average speed. Higher speeds increase the likelihood that motorists may loose control and subsequently result in a crash. 
Notice that only the median treatment D2N was present in the model for multiple vehicle - opposite direction crashes. Initially, all median treatments except D3N, which was taken as the base case, were included in the model. The variables for C3N, S3N and $\mathrm{B} 3 \mathrm{~N}$ proved to be statistically insignificant. Therefore, they were removed from the model and the base case became D3N, B3N, C3N and S3N. 


\section{CHAPTER 6: CRASH MODIFICATION FACTORS}

\section{$\underline{6.1 \text { Overview }}$}

Data available for several median treatments were insufficient to develop frequency models for these median treatments. The median treatments with insufficient data included D3H, D2L, D3L, F1C and F2C. As a result, an alternative method of before-and-after analysis was utilized to estimate the safety impact of high-tensioned cable barriers $(\mathrm{D} 3 \mathrm{H})$, low-tensioned cable barriers (D2L, D3L), and concrete barriers (F1C, F2C). Table 6.1 below provides the periods with available data used in the analysis. These periods were location-dependent and vary even for the same state and median treatment.

Table 6.1 Before and After Analysis Period with Available Crash Data

\begin{tabular}{|c|c|c|c|c|}
\hline State & $\begin{array}{c}\text { Median } \\
\text { Treatment }\end{array}$ & $\begin{array}{c}\text { Before Period } \\
\text { Crash Years }\end{array}$ & $\begin{array}{c}\text { Installation } \\
\text { Year }\end{array}$ & $\begin{array}{c}\text { After Period } \\
\text { Crash Years }\end{array}$ \\
\hline Colorado & D3H & $2001-2002$ & 2003 & $2004-2005$ \\
\hline Ohio & D3H & $2001-2002$ & 2003 & $2004-2005$ \\
\hline Missouri & D2L & $1998-2001$ & 2002 & $2003-2005$ \\
\cline { 2 - 5 } & D2L & $1998-2003$ & 2004 & 2005 \\
\hline Washington & D2L & $1993-1996$, & 2000 & 2001 \\
\cline { 2 - 5 } & D2L & $1993-1994$ & 1995 & $1996,1999-$ \\
\hline Oregon & D3L & 1995 & $1996-1997$ & $1998-2004$ \\
\hline Indiana & CONC & $1995-1998$ & $1999-2000$ & $2003-2005$ \\
\hline
\end{tabular}


CONC was the aggregation of the treatments F1C and F2C. There was a time gap between the installation year and the after periods for these aggregated treatments from 2001 to 2002. These years of crash data were not utilized for the after period because changes were made to the manner in which the crash database was coded in 2000 . In Chapter 4, the percentages of unassigned crashes for each crash coding system were discussed. The difference was found to be small (about $3 \%$ as compared to about $7 \%$ ), and as such, it was neglected when deriving the crash modification factors.

\section{$\underline{6.2 \text { Methodology }}$}

The method for estimating the crash modification factors was adapted from "Guidelines for Road Safety Improvements" (Tarko et al, 2006).

To begin, crashes were divided into either the before or after category for each segment. For example, the high-tensioned cable barrier in Ohio was installed in 2003, and crash data was available from 2001 to 2005 . As such, the before period was from 2001 to 2002, and the after period was from 2004 to 2005. Dividing the crashes into periods define $\mathrm{Y}_{\mathrm{A}}$ and $\mathrm{Y}_{\mathrm{B}}$. Variable $\mathrm{Y}_{\mathrm{A}}$ was defined as the total number of years of crash data in the after period. Variable $Y_{B}$ was defined as the total number of years of crash data in the before period. As described above for Ohio, $\mathrm{Y}_{\mathrm{A}}$ and $\mathrm{Y}_{\mathrm{B}}$ are both 2. The sums of the crashes for each segment for the before and after case are the values for $A_{B}$ and $A_{A}$, respectively. After $Y_{A}, Y_{B}, A_{A}$, and $A_{B}$ were determined, $a_{0 A}$ and $a_{1 A}$ were computed. 
Variable $\mathrm{a}_{0 \mathrm{~A}}$ was the best estimate of crash frequency in the period after

implementation of the safety project, had the safety project not been implemented. It was computed for each segment as follows:

$$
a_{0 A}=\frac{\frac{1}{D}+A_{B}}{\frac{1}{D \times a_{B}}+Y_{B}} \times\left(\frac{a_{A}}{a_{B}}\right),
$$

where:

$\mathrm{D}$ was the overdispersion coefficient taken from the safety performance function utilized for $\mathrm{a}_{\mathrm{B}}$,

$A_{B}$ was the sums of the crashes for each segment for the before case, $Y_{B}$ was defined as the total number of years of crash data in the before period, $a_{A}$ was the crash frequency calculated with the safety performance function for the traffic representing the after-implementation period,

$a_{B}$ was the crash frequency calculated with the safety performance function for the traffic representing the before-implementation period.

The ratio of $a_{A}$ and $a_{B}$ was taken as one because it is assumed that control cases

will account for the effect of the change in volume. The assumption was considered to be valid because the control cases were typically taken from the same interstate as the treated cases. Therefore, equation (29) simplified to:

$$
a_{04}=\frac{\frac{1}{D}+A_{B}}{\frac{1}{D \times a_{B}}+Y_{B}},
$$

where:

D was the overdispersion coefficient taken from the safety performance function utilized for $\mathrm{a}_{\mathrm{B}}$,

$A_{B}$ was the sums of the crashes for each segment for the before case, $Y_{B}$ was defined as the total number of years of crash data in the before period, 
$\mathrm{a}_{\mathrm{A}}$ was the crash frequency calculated with the safety performance function for the traffic representing the after-implementation period,

$a_{B}$ was the crash frequency calculated with the safety performance function for the traffic representing the before-implementation period.

Variable $\mathrm{a}_{1 \mathrm{~A}}$ was the crash frequency estimate for the period after implementation.

It was based on crashes that occurred where the median barrier was installed. It was

computed as follows:

$$
a_{1 A}=\frac{A_{A}}{Y_{A}},
$$

where:

$\mathrm{A}_{\mathrm{A}}$ was the number of reported crashes that occurred during the period after the installation of the median barrier, $\mathrm{Y}_{\mathrm{A}}$ was previously defined as the number of after-implementation years with crash data.

Next, the variances of $\mathrm{a}_{0 \mathrm{~A}}$ and $\mathrm{a}_{1 \mathrm{~A}}$, defined as $\operatorname{Var}\left(\mathrm{a}_{0 \mathrm{~A}}\right)$ and $\operatorname{Var}\left(\mathrm{a}_{1 \mathrm{~A}}\right)$, respectively, were computed.

The $\operatorname{Var}\left(\mathrm{a}_{0 \mathrm{~A}}\right)$ was computed as follows:

$$
\operatorname{Var}\left(a_{0 A}\right)=\frac{\frac{1}{D}+A_{B}}{\left(\frac{1}{D \times a_{B}}+Y_{B}\right)^{2}} \times\left(\frac{a_{A}}{a_{B}}\right)^{2},
$$

where:

$\mathrm{D}$ was the overdispersion coefficient taken from the safety performance function utilized for $\mathrm{a}_{\mathrm{B}}$,

$A_{B}$ was the sums of the crashes for each segment for the before case, $Y_{B}$ was defined as the total number of years of crash data in the before period, $a_{A}$ was the crash frequency calculated with the safety performance function for the traffic representing the after-implementation period,

$a_{B}$ was the crash frequency calculated with the safety performance function for the traffic representing the before-implementation period. 
Again, based on the previously stipulated assumption that the ratio of $\mathrm{a}_{\mathrm{A}}$ to $\mathrm{a}_{\mathrm{B}}$ will be 1 , equation (32) simplified to:

$$
\operatorname{Var}\left(a_{0 A}\right)=\frac{\frac{1}{D}+A_{B}}{\left(\frac{1}{D \times a_{B}}+Y_{B}\right)^{2}},
$$

where:

$\mathrm{D}$ was the overdispersion coefficient taken from the safety performance function utilized for $\mathrm{a}_{\mathrm{B}}$,

$A_{B}$ was the sums of the crashes for each segment for the before case, $Y_{B}$ was defined as the total number of years of crash data in the before period, $a_{B}$ was the crash frequency calculated with the safety performance function for the traffic representing the before-implementation period.

The $\operatorname{Var}\left(\mathrm{a}_{1 \mathrm{~A}}\right)$ was computed as follows:

$$
\operatorname{Var}\left(a_{1 A}\right)=\frac{A_{A}}{Y_{A}^{2}}
$$

where:

$\mathrm{A}_{\mathrm{A}}$ was the number of reported crashes that occurred during the period after the installation of the median barrier,

$\mathrm{Y}_{\mathrm{A}}$ was previously defined as the number of after-implementation years with crash data.

Next, since there are multiple treated segments, the results needed to be aggregated. This was done by summing the individual result for each treated segment as follows to create one final value for $\mathrm{a}_{1 \mathrm{~A}}, \operatorname{Var}\left(\mathrm{a}_{1 \mathrm{~A}}\right), \mathrm{a}_{0 \mathrm{~A}}$, and $\operatorname{Var}\left(\mathrm{a}_{0 \mathrm{~A}}\right)$.

$$
\begin{gathered}
a_{1 A}=\sum_{i} a_{A i} \\
\operatorname{Var}\left(a_{1 A}\right)=\sum_{i} \operatorname{Var}\left(a_{1 A i}\right)
\end{gathered}
$$




$$
\begin{gathered}
a_{0 A}=\sum_{i} a_{0 A i} \\
\operatorname{Var}\left(a_{0 A}\right)=\sum_{i} \operatorname{Var}\left(a_{0 A i}\right)
\end{gathered}
$$

Similarly, the values for the control sites were summed as follows:

$$
\begin{aligned}
a_{1 A}^{\prime} & =\sum_{i} a_{A i}^{\prime} \\
\operatorname{Var}\left(a_{1 A}^{\prime}\right) & =\sum_{i} \operatorname{Var}\left(a_{1 A i}^{\prime}\right) \\
a_{0 A}^{\prime} & =\sum_{i} a_{0 A i}^{\prime} \\
\operatorname{Var}\left(a_{0 A}^{\prime}\right) & =\sum_{i} \operatorname{Var}\left(a_{0 A i}^{\prime}\right)
\end{aligned}
$$

Then, the crash reduction for the treated $\left(\theta_{t}\right)$ and control $\left(\theta_{c}\right)$ sites were computed, respectively, as follows:

$$
\begin{gathered}
\theta_{t}=\frac{a_{1 A}}{a_{0 A}} \\
\theta_{c}=\frac{a_{1 A}^{\prime}}{a_{0 A}^{\prime}}
\end{gathered}
$$

The variance for the treated $\left[\operatorname{Var}\left(\theta_{t}\right)\right]$ and control $\left[\operatorname{Var}\left(\theta_{\mathrm{c}}\right)\right]$ sites were computed, respectively, as follows:

$$
\begin{aligned}
& \operatorname{Var}\left(\theta_{t}\right)=\left(\frac{1}{a_{0 A}}\right)^{2} \times \operatorname{Var}\left(a_{1 A}\right)+\left(\frac{a_{1 A}}{a_{0 A}{ }^{2}}\right) \times \operatorname{Var}\left(a_{0 A}\right) \\
& \operatorname{Var}\left(\theta_{c}\right)=\left(\frac{1}{a_{0 A}^{\prime}}\right)^{2} \times \operatorname{Var}\left(a_{1 A}^{\prime}\right)+\left(\frac{a_{1 A}^{\prime}}{a_{0 A}^{\prime 2}}\right) \times \operatorname{Var}\left(a_{0 A}^{\prime}\right)
\end{aligned}
$$


Then, the crash modification factor (CMF) and the variance of the CMF were computed. This result incorporated the information from the adjusted control group with the treatment information.

$$
\begin{gathered}
C M F=\frac{\theta_{t}}{\theta_{c}} \\
\operatorname{Var}(C M F)=\left(\frac{1}{\theta_{c}}\right)^{2} \times \operatorname{Var}\left(\theta_{t}\right)+\left(\frac{\theta_{t}}{\theta_{c}^{2}}\right)^{2} \times \operatorname{Var}\left(\theta_{c}\right)
\end{gathered}
$$

Finally, the statistical significance of the CMF was computed as follows:

$$
Z=\frac{1-C M F}{\sqrt{V \operatorname{ar}(C M F)}}
$$

When a median treatment occurred in more than one state, the CMF and $\operatorname{Var}(\mathrm{CMF})$ for each state were combined, which resulted in $\mathrm{CMF}_{\text {OVERALL }}$ and $\operatorname{Var}\left(\mathrm{CMF}_{\text {OVERALL }}\right) . \mathrm{CMF}_{\text {OVERALL }}$ and $\operatorname{Var}\left(\mathrm{CMF}_{\text {OVERALL }}\right)$ were computed as follows:

$$
\begin{gathered}
C M F_{\text {OVERALL }}=\frac{\operatorname{Var}(C M F)_{1} \times C M F_{2}+\operatorname{Var}(C M F)_{2} \times C M F_{1}}{\operatorname{Var}(C M F)_{1}+\operatorname{Var}(C M F)_{2}} \\
\operatorname{Var}\left(C M F_{\text {OVERALL }}\right)=\frac{\left(\operatorname{Var}(C M F)_{2}\right)^{2} \times \operatorname{Var}(C M F)_{1}+\left(\operatorname{Var}(C M F)_{1}\right)^{2} \times \operatorname{Var}(C M F)_{2}}{\left(\operatorname{Var}(C M F)_{1}+\operatorname{Var}(C M F)_{2}\right)^{2}}
\end{gathered}
$$

The statistical significance of $\mathrm{CMF}_{\text {OVERALL }}$ was computed as follows:

$$
Z\left(C M F_{\text {OVERALL }}\right)=\frac{\left(C M F_{\text {OVERALL }}-1\right)}{S Q R T\left(\operatorname{Var}\left(C M F_{\text {OVERALL }}\right)\right)}
$$


It was observed in the results of this analysis that the variance of the overall crash modification factor which incorporated control information was large in comparison to the treated variance. As such, the combined treated crash modification factor, $\theta_{\mathfrak{t}}, \operatorname{Var}\left(\theta_{\mathrm{t}}\right)$, and $Z_{t}$ were computed as follows:

$$
\begin{gathered}
\left(\theta_{t}\right)_{\text {OVERALL }}=\frac{\operatorname{Var}\left(\theta_{t}\right)_{1} \times\left(\theta_{t}\right)_{2}+\operatorname{Var}\left(\theta_{t}\right)_{2} \times\left(\theta_{t}\right)_{1}}{\operatorname{Var}\left(\theta_{t}\right)_{1}+\operatorname{Var}\left(\theta_{t}\right)_{2}} \\
\operatorname{Var}\left(\left(\theta_{t}\right)_{\text {OVERALL }}\right)=\frac{\left(\operatorname{Var}\left(\theta_{t}\right)_{2}\right)^{2} \times \operatorname{Var}\left(\theta_{t}\right)_{1}+\left(\operatorname{Var}\left(\theta_{t}\right)_{1}\right)^{2} \times \operatorname{Var}\left(\theta_{t}\right)_{2}}{\left(\operatorname{Var}\left(\theta_{t}\right)_{1}+\operatorname{Var}\left(\theta_{t}\right)_{2}\right)^{2}}
\end{gathered}
$$

The statistical significance of $\left(\theta_{\mathrm{t}}\right)_{\text {OVERALL }}$ was computed as follows:

$$
Z_{t}=\frac{\left(\left(\theta_{t}\right)_{\text {OVERALL }}-1\right)}{\operatorname{SQRT}\left(\operatorname{Var}\left(\left(\theta_{t}\right)_{\text {OVERALL }}\right)\right)}
$$

Table 6.2 and Table 6.3 presented the crash modification factors without using the control crash reduction and with using the control crash reduction, respectively.

Table 6.2 Without Control, $\mathrm{CMF}=\theta_{\mathrm{t}}$

\begin{tabular}{|c|c|c|c|c|c|c|}
\hline \multirow{2}{*}{$\begin{array}{c}\text { Median } \\
\text { Treatment }\end{array}$} & \multicolumn{3}{|c|}{ Single Vehicle } & \multicolumn{3}{c|}{ Multiple Vehicle - Same Direction } \\
\cline { 2 - 7 } & $\theta_{\mathrm{t}}$ & $\operatorname{Var}\left(\theta_{\mathrm{t}}\right)$ & $\mathrm{Z}_{\mathrm{t}}$ & $\theta_{\mathrm{t}}$ & $\operatorname{Var}\left(\theta_{\mathrm{t}}\right)$ & $\mathrm{Z}_{\mathrm{t}}$ \\
\hline $\mathrm{D} 3 \mathrm{H}$ & 1.65 & 0.53 & 0.89 & 1.25 & 0.42 & 0.39 \\
\hline $\mathrm{D} 2 \mathrm{~L}$ & 0.72 & 0.25 & -0.56 & 0.86 & 0.32 & -0.25 \\
\hline $\mathrm{D} 3 \mathrm{~L}$ & 1.79 & 0.19 & 1.84 & 0.91 & 0.13 & -0.24 \\
\hline CONC & 2.18 & 0.29 & 2.20 & 0.80 & 0.14 & -0.53 \\
\hline
\end{tabular}


Table 6.3 With Control, $\mathrm{CMF}=\theta_{\mathrm{t}} / \theta_{\mathrm{c}}$

\begin{tabular}{|c|c|c|c|c|c|c|}
\hline \multirow{2}{*}{$\begin{array}{c}\text { Median } \\
\text { Treatment }\end{array}$} & \multicolumn{3}{|c|}{ Single Vehicle } & \multicolumn{3}{c|}{ Multiple Vehicle - Same Direction } \\
\cline { 2 - 7 } & CMF & $\operatorname{Var}(\mathrm{CMF})$ & $\mathrm{Z}$ & $\mathrm{CMF}$ & $\operatorname{Var}(\mathrm{CMF})$ & $\mathrm{Z}$ \\
\hline D3H & 1.64 & 1.25 & 0.57 & 1.13 & 0.73 & 0.15 \\
\hline D2L & 0.81 & 0.59 & -0.24 & 0.94 & 0.64 & -0.07 \\
\hline D3L & 1.83 & 2.31 & 0.55 & 0.70 & 0.16 & -0.77 \\
\hline CONC & 2.20 & 1.28 & 1.06 & 0.79 & 0.23 & -0.43 \\
\hline
\end{tabular}

With only two exceptions, the values of the crash modification factor did not change by more than $10 \%$ when incorporating the control site information: the single vehicle crash modification factor for D2L and the multiple vehicle - same direction crash modification factor for D3L were the only exceptions. Yet, notice the significant changes in the variances. This implied that the control sites bring more variability than explanatory power, possibly because the sample sizes in some cases were small. As such, in order to use the control site information, the control sites were grouped.

Table 6.4 below listed the control values and variances determined by state and crash type.

Table 6.4 Control Values

\begin{tabular}{|c|c|c|c|c|c|}
\hline \multirow{2}{*}{ State } & \multirow{2}{*}{\begin{tabular}{c} 
Median \\
\cline { 3 - 6 }
\end{tabular}} & \multicolumn{2}{|c|}{ Single Vehicle } & \multicolumn{2}{c|}{ Multiple Vehicle - Same Direction } \\
\cline { 3 - 6 } & & $\theta_{\mathrm{c}}$ & $\operatorname{Var}\left(\theta_{\mathrm{c}}\right)$ & $\theta_{\mathrm{c}}$ & $\operatorname{Var}\left(\theta_{\mathrm{c}}\right)$ \\
\hline WA & D2L & 1.14 & 1.14 & 1.20 & 0.74 \\
\hline MO & D2L & $0.85^{*}$ & $0.58^{*}$ & $0.85^{*}$ & $0.58^{*}$ \\
\hline OR & D3L & 0.98 & 0.60 & 1.31 & 0.27 \\
\hline OH & D3H & 1.03 & 0.36 & 1.00 & 0.51 \\
\hline CO & D3H & 0.82 & 0.67 & 1.55 & 1.58 \\
\hline IN & CONC & 0.99 & 0.20 & 1.02 & 0.17 \\
\hline
\end{tabular}


The $\left(^{*}\right)$ indicates that this value was computed using information from both multiple vehicle - same direction and single vehicle control information. This was done because the control sample from this state, which was originally smaller in size, was further reduced because there were two installation dates for the same median treatment, D2L. One was installed in 2002 and the other in 2004. The same control group could not be used for both installations because of concerns of endogeneity.

To begin grouping the values, first, it was determine whether or not an aggregated value could be used when combining all of the control values. The resulting F-statistic was 2.78 . Using a $95 \%$ confidence level, the null hypothesis, that the values are statistically significantly different from each other cannot be rejected: $2.78<5.12$. As such, the control values were grouped to develop one control value. The resulting control crash modification factor was found to be 1.05 with a variance of 0.04 .

Variable $\mathrm{CMF}_{\text {OVERALL }}$ and $\operatorname{Var}\left(\mathrm{CMF}_{\text {OVERALL }}\right)$ and $\mathrm{Z}\left(\mathrm{CMF}_{\text {OVERALL }}\right)$ were then recomputed using the grouped $\theta_{\mathrm{c}}{ }^{\prime}$ as follows:

$$
\begin{gathered}
C M F_{\text {OVERALL }}=\frac{\theta_{t}}{\theta_{c}{ }^{\prime}} \\
\operatorname{Var}\left(C M F_{\text {OVERALL }}\right)=\left(\frac{1}{\theta_{c}{ }^{\prime}}\right)^{2} \times \operatorname{Var}\left(\theta_{t}\right)+\left(\frac{\theta_{t}}{\theta_{c}{ }^{\prime 2}}\right)^{2} \times \operatorname{Var}\left(\theta_{c}{ }^{\prime}\right) \\
Z\left(C M F_{\text {OVERALL }}\right)=\frac{1-C M F_{\text {OVERALL }}}{\sqrt{\operatorname{Var}\left(C M F_{\text {OVERALL }}\right)}}
\end{gathered}
$$

Table 6.5 shows the updated results. 
Table 6.5 With Grouped Control, $\mathrm{CMF}=\theta_{\mathrm{t}} / \theta_{\mathrm{c}}{ }^{\prime}$

\begin{tabular}{|c|c|c|c|c|c|c|}
\hline \multirow{2}{*}{$\begin{array}{c}\text { Median } \\
\text { Treatment }\end{array}$} & \multicolumn{3}{|c|}{ Single Vehicle } & \multicolumn{2}{c|}{ Multiple Vehicle - Same Direction } \\
\cline { 2 - 7 } & CMF & Var(CMF) & Z & CMF & Var(CMF) & Z \\
\hline D3H & 1.57 & 0.54 & 0.78 & 1.19 & 0.41 & 0.30 \\
\hline D2L & 0.68 & 0.23 & -0.65 & 0.81 & 0.30 & -0.34 \\
\hline D3L & 1.70 & 0.26 & 1.36 & 0.86 & 0.15 & -0.35 \\
\hline CONC & 2.07 & 0.40 & 1.69 & 0.76 & 0.14 & -0.63 \\
\hline
\end{tabular}

\section{$\underline{6.3 \text { Results }}$}

Expectations were that both single vehicle crashes and multiple vehicle - same direction crashes would increase with the addition of a barrier in the median. When considering the results presented in Table 6.5 , the crash modification factors that were found for single vehicle crashes tended to show an increase. For multiple vehicle - same direction crashes, on the other hand, there appeared to be a decrease. In addition to installing a concrete barrier in the median, the crash modification factor for CONC also accounts for an additional lane that was added. Yet, when considering the resulting safety performance functions developed, none of them had the variable for the number of lanes significant. Therefore, the crash modification factors for all barrier-types were grouped to develop one crash modification value for single vehicle crashes and multiple vehicle - same direction crashes, respectively. For single vehicle crashes, the crash modification factor was determined to be 1.405 with a variance of 0.080 and a significance level of 1.428. For multiple vehicle - same direction crashes, the crash 
modification factor was determined to be 0.860 with a variance of 0.051 and a significance level of -0.620 . 


\section{CHAPTER 7: CHOICE MODELS}

\subsection{Statistical Approach}

The statistical equations to determine the probability of the severity outcomes were determined using a discrete choice model. The dependent variable was a discrete variable with three crash severity outcomes: property damage only (PDO), non-fatal injury, and fatal crashes. Given this discrete variable to measure the severity, a standard multinomial logit model was deemed appropriate for the study.

A categorical analysis (using an unordered model) is preferable here as compared to an ordinal analysis (using an ordered model). Ordered probability models "restrict variables to either increase the highest severity category and decrease the lowest severity category or increase the lowest severity category and decrease the highest severity category (Khorashadi et al., 2005). Consequently, this type of model cannot handle situations where there is a middle category. This restriction was not applied since no evidence was found that the independent variables would not increase the likelihood of non-fatal injury crashes and reduce the probability of PDO and fatal crashes.

If $P_{n}(i)$ is considered as the probability of an observation $n$ (i.e., the accident $n$ ) to end up in the severity category $i$, such that:

$$
P_{n}(i)=P\left(\beta_{i} X_{\text {in }}+\varepsilon_{\text {in }} \geq \beta_{I} X_{I n}+\varepsilon_{\text {in }}\right) \forall I \neq i,
$$


where:

$I$ is a set of all possible crash outcomes (PDO, injury, and fatal),

$\mathbf{X}_{\text {in }}$ is a vector of measurable characteristics (median and road features, traffic conditions, etc.) for the observation $n$,

$\boldsymbol{\beta}_{\text {in }}$ is a vector of estimated coefficients,

$\varepsilon_{i n}$ is an error term accounting for unobserved effects influencing the severity of crash $n$.

If the $\varepsilon_{i n}$ are extreme values distributed (the important property of this distribution is that the maximums of randomly drawn values from the distribution have the same distribution as the values from which they were drawn), then the standard multinomial formulation follows:

$$
P_{n}(i)=\frac{\exp \left(\beta_{i} X_{i n}\right)}{\sum_{\forall I} \exp \left(\beta_{I} X_{I n}\right)},
$$

where:

$P n(i)$ is the probability of an observation $n$ to end up in the severity category $I$, $i$ is a set of all possible outcomes (PDO, injury, and fatal), $\mathbf{X}_{\text {in }}$ is a vector of measurable characteristics (median and road features, traffic conditions, etc.) for the observation $n$, $\boldsymbol{\beta}_{\text {in }}$ is a vector of estimated coefficients.

The coefficients of the multinomial logit model were estimated using the maximum likelihood method. This estimation chooses parameter estimates in order to maximize the likelihood of observing the given data. The coefficients are chosen in order to maximize the likelihood function. The following gives an example of the maximum likelihood function in the case of a dependent variable with two outcomes: 


$$
\log (L)=\sum_{i} y_{i} \log \left(\frac{p_{i}}{1-p_{i}}\right)-\sum_{i} \log \left(1-p_{i}\right)
$$

where:

$L$ is the likelihood function, $i$ denotes the observation $I$,

$y_{i}$ is the outcome for observation $i$,

$p_{i}$ is the probability to have outcome 1 for the observation $i$ and is a function of the vector of measurable characteristics.

A possible issue may arise when using a standard multinomial logit model if the severity categories are not independent from each other and share unobserved effects. In such a case, the assumption of Independence of Irrelevant Alternatives (IIA) is violated: the disturbance terms are not independently and identically distributed. IIA is one critical assumption of the multinomial logit model. Consequently, the multinomial logit model will have specification error. If necessary, this problem may be overcome by using a nested logit model where the categories that share unobserved effects are grouped in the same nest.

The first attempt was to estimate the severity of crashes using a multinomial logit model with the three different outcomes:

- Property Damage Only (PDO) crashes: the crash does not result in any injuries or deaths, only property damage.

- Injury crashes: the crash results in any type of injury, except a fatal injury.

- Fatality crashes: the crash results in the death of at least one person involved in the crash. 
The standard multinomial logit formulation applied to this case gives the following set of severity equations:

$$
P_{n}(I N J)=\frac{\exp \left(\beta_{I N J} X_{I N J n}\right)}{\exp \left(\beta_{P D O} X_{P D O n}\right)+\exp \left(\beta_{I N J} X_{I N J n}\right)+\exp \left(\beta_{F A T} X_{F A T n}\right)},
$$

where:

$P_{n}(I N J)$ is the probability that observation $n$ is an injury crash.

$$
P_{n}(F A T)=\frac{\exp \left(\beta_{F A T} X_{F A T n}\right)}{\exp \left(\beta_{P D O} X_{P D O n}\right)+\exp \left(\beta_{I N J} X_{I N J n}\right)+\exp \left(\beta_{F A T} X_{F A T n}\right)}
$$

where:

$P_{n}(F A T)$ is the probability that observation $n$ is a fatal crash.

$$
P_{n}(P D O)=1-P_{n}(I N J)-P_{n}(F A T)
$$

where:

$P_{n}(P D O)$ is the probability that observation $n$ is a PDO crash.

The attempt to develop a multinomial logit model that returns both the probability of injury crashes and the probability of fatal crashes was not successful. The number of fatal crashes in the sample was too small when divided into the different crash types. Furthermore, the parameters estimated with the multinomial logit model were not reliable; the results obtained might not reflect the actual effect of the variable and may only be due to an unfortunate variation among a small number of observations. In 
addition, several variables were found to be insignificant for fatal crashes but significant for injury crashes. It was then decided to create a joint category of severe crashes that includes injury and fatal crashes together for the single vehicle, multiple vehicle - same direction, and multiple vehicle - opposite direction crash types. The modification converted the multinomial model into a binomial model with only two levels of severity: fatal + injury crashes and PDO crashes for the single vehicle, multiple vehicle - same direction, and multiple vehicle - opposite direction crash types.

\subsection{Equations of likelihood of severity}

Using the coefficients determined in the standard multinomial logit formulation, a set of equations predicting the likelihood of a crash for the severity was obtained:

$$
\begin{aligned}
& P_{n}(F A T-I N J)=\frac{\exp \left(\beta_{F A T-I N J} X_{F A T-I N J n}\right)}{\exp \left(\beta_{P D O} X_{P D O n}\right)+\exp \left(\beta_{F A T-I N J} X_{F A T-I N J n}\right)}, \\
& P_{n}(F A T-I N J)=\frac{1}{1+\exp \left(\beta_{P D O} X_{P D O n}-\beta_{F A T-I N J} X_{F A T-I N J n}\right)},
\end{aligned}
$$

where:

$P_{n}(F A T-I N J)$ is the probability of observation $n$ to be a fatal or injury crash.

$$
P_{n}(P D O)=1-P_{n}(F A T-I N J)
$$

where: 
$P_{n}(P D O)$ is the probability of observation $n$ to be a PDO crash.

$P_{n}(F A T-I N J)$ is the probability of observation $n$ to be a fatal or injury crash

SAS sets up the coefficients for the outcome PDO to zero and models the

probability for the severity injury-fatal crashes. So we have:

$$
P_{n}(F A T-I N J)=\frac{1}{1+\exp \left(-\beta_{F A T-I N J} X_{F A T-I N J n}\right)},
$$

where:

$P_{n}(F A T-I N J)$ is the probability of observation $n$ to be a fatal or injury crash, $\boldsymbol{\beta}_{F A T-I N J}$ is the vector of coefficients estimated by SAS.

\section{$\underline{7.3 \text { Modeling Considerations }}$}

A single statistical model was developed for each crash type (SV, MVSD, and MVOD). The models developed for severity were complicated by the inclusion of interactions between the median treatments and traffic or geometric variables.

\section{Interactions}

Some variables might have a different effect on severity depending on the median treatment. For instance, the AADT or the presence of a horizontal curve might have a different effect on severity if the median section is a wide depressed median, without any barrier when compared to a narrow flush median section with a concrete barrier. To account for these effects, it was necessary to include first-order interactions between 
median treatments and the other variables in the model. However, the inclusion of these interactions must be done with caution. If there is too much correlation between the initial variable and the first-order interaction variables, it might lead to problems of multicollinearity and large standard errors of the estimated coefficients. High correlation is possible if the variable considered in the interaction with the binary variable associated to the median treatment does not vary a lot. Table 7.1 illustrates this.

Table 7.1 Example of High Correlation Between a Median Treatment and a First-Order Interaction

\begin{tabular}{|c|c|c|}
\hline Median Treatment & Speed Limit & Interaction \\
\hline 0 & 65 & 0 \\
\hline 0 & 65 & 0 \\
\hline 0 & 55 & 0 \\
\hline 0 & 65 & 0 \\
\hline 1 & 65 & 65 \\
\hline 1 & 65 & 65 \\
\hline 0 & 55 & 0 \\
\hline 1 & 65 & 65 \\
\hline 0 & 65 & 0 \\
\hline 1 & 65 & 65 \\
\hline 1 & 65 & 65 \\
\hline 0 & 65 & 0 \\
\hline 1 & 65 & 65 \\
\hline 0 & 65 & 0 \\
\hline 0 & 55 & 0 \\
\hline 0 & 55 & 0 \\
\hline 0 & 55 & 0 \\
\hline
\end{tabular}

In this case, the variable associated with the median treatment is not correlated with the speed limit, but the interaction variable is highly correlated to the binary variable corresponding to the median treatment.

Therefore, the Pearson coefficients of correlation were run for the variables to verify the actual level of correlation (Refer to Appendix K). The coefficients sometimes 
show very high correlation between the first-order interaction variable and the binary variable associated with the median treatment. As a rule, it was decided to remove all of the interaction variables from the model where the coefficient of correlation was greater than or equal to 0.7 .

\section{Model fit and predictive power}

Several statistics were calculated to assess the overall fit and the power of prediction of the model: the likelihood ratio, the generalized $\mathrm{R}^{2}$, the Akaike's information criterion (AIC), the Schwarz criterion (SC), and the Hosmer and Lemeshow (HL) Goodness-of-fit test.

The first test, the likelihood ratio chi-square is obtained by comparing the loglikelihood for the fitted model with the log-likelihood for a model with no explanatory variables. It was calculated using the following equation:

$$
\chi^{2}=-2\left[L L\left(\beta_{R}\right)-L L\left(\beta_{U}\right)\right],
$$

where:

$L L\left(\beta_{R}\right)$ is the log-likelihood at the convergence of the "restricted" model, $L L\left(\beta_{U}\right)$ is the log-likelihood at the convergence of the "unrestricted" model.

This statistic is $\mathrm{X}^{2}$ distributed with degrees of freedom equal to the difference in the number of parameters between the restricted and unrestricted model (the difference in the number of parameters in the $\beta_{\mathrm{R}}$ and the $\beta_{\mathrm{U}}$ parameter vectors). This statistic typically 
tests the null hypothesis that all the explanatory variables have coefficients of 0 . Therefore, it gives information on how well the model performs compared to a model without any variables.

The generalized $\mathrm{R}^{2}$ describes how well one can predict the dependent variable based on the value of the independent variables. Therefore, it is not a goodness-of-fit measure, but rather a measure of the predictive power. The generalized $\mathrm{R}^{2}$ for the logit analysis is computed using the likelihood ratio chi-square for testing the null hypothesis that all the coefficients are 0 . It is calculated as follows:

$$
R^{2}=1-\exp \left[-\frac{L^{2}}{n}\right]
$$

where:

$R^{2}$ is the generalized $R^{2}$, $L$ is the log-likelihood ratio chi-square, $n$ is the sample size.

The Akaike's information criterion (AIC) and the Schwarz criterion (SC) were also computed for each model. These two statistics are useful in comparing the relative fit of different models as well as the models fitted within each category of crash. The AIC and SC penalize the log-likelihood for estimating more parameters and the lower values of these statistics correspond to more desirable models.

$$
\begin{aligned}
& A I C=-2 L+2 k, \\
& S C=-2 L+k \log (n),
\end{aligned}
$$


where:

AIC is the Akaike's information criterion, $S C$ is the Schwarz criterion.

The last statistic, the Hosmer and Lemeshow (HL) Goodness-of-fit test, attempts to compare the model fitted with a "maximal" model that always fits better than the model of interest in order to answer the question: "Is there a model better than this one?" The HL statistic is calculated using the following procedure. Based on the estimated model, predicted probabilities are generated for all observations. These are sorted by size, and then grouped into approximately 10 intervals. Within each interval, the expected frequency is obtained by adding up the predicted probabilities. The expected frequencies are compared with the observed frequencies by the conventional Pearson chisquare statistic. The degrees of freedom are the number of intervals minus 2. Caution has to be taken when concluding that a model is good because the HL test is not significant. Some simulations suggest that it is not a powerful test.

\subsection{Modeling Precision}

Three models were estimated: a single-vehicle (SV) crash model, a multiple vehicle - opposite direction (MVOD) crash model, and a multiple vehicle - same direction (MVSD) crash model. Models were not estimated for the categories of "multiple-vehicle unclear" and "multiple-vehicle unknown" due to the expected difficulties in interpreting such models. 
The median treatment $\mathrm{D} 3 \mathrm{~N}$ was selected as a base case for modeling purposes. Other median treatments were represented in the models through corresponding binary variables. A binary variable takes the value 1 if a given crash occurred on a segment with the given median treatment and zero otherwise.

For each type of crash, first a binary logit model was fit with SAS 9.1 including all the binary variables representing the median treatments (except the base case, since the variable selected as base case is a linear combination of all the other binary variables representing the remaining median treatments). The traffic and design variables expected to have an impact on the severity of accidents, as well as the first-order interaction variables, were also inserted. Then, the "Wald chi-squares" test-statistics computed by SAS 9.1 were used to determine the significance of the variables entered. This statistic is calculated by dividing each coefficient by its standard error and squaring the result. It operates as a classic t-statistic and gives a test-statistic for the null hypotheses that each coefficient is equal to 0 . If a variable representing a median treatment was not significant, an attempt was made to combine this variable with another variable representing a median treatment. To do so, engineering judgment combined with rational statistical analysis of the coefficients was used. First, it was only attempted to combine variables corresponding to median treatments that share similarities and can be considered as having the same effects on accident severity. Then, two tests were performed to check if the coefficients associated with the two variables to be combined were "close enough to each other." The first test, the percent difference, determines if the coefficients are close to each other in relative value. If the percent difference was higher than $20 \%$, the variables were not combined. 


$$
\text { Percent Difference }=\frac{\left|b_{2}-b_{1}\right|}{\max \left(\left|b_{1}\right|,\left|b_{2}\right|\right)},
$$

where:

$b_{1}$ is the coefficient associated with the first variable, $b_{2}$ is the coefficient associated with the second variable.

If the percent difference was lower than $20 \%$, then, a statistic test was conducted to check if the coefficients were significantly different from 0 , as follows (a level of significance of $\alpha=0.05$ was used):

$$
t=\frac{b_{1}-b_{2}}{\sqrt{\sigma_{1}^{2}+\sigma_{2}^{2}}},
$$

where:

$t$ is the statistic test,

$b_{1}$ is the coefficient associated with the first variable,

$b_{2}$ is the coefficient associated with the second variable, $\sigma_{1}$ is the standard error of the first variable, $\sigma_{2}$ is the standard error of the second variable.

If both of these tests conclude that the coefficients are not significantly different from each other, it means that the effects of the two median treatments on the severity were close enough. Thus, there was no need to consider those median treatments separately. The variables could then be combined. All the variables not presenting significant coefficients - and which could not be combined - were dropped from the model. 
In the case of the binary variables representing the median treatments, caution was taken during interpretation, particularly when a median treatment was not significant. If the coefficient associated with the variable representing a median treatment was not significantly different from zero, it means either that the impact of this particular median treatment on accident severity was not significantly different from the impact of the base case (i.e., D3N) on crash severity, or that there was not sufficient data for the median treatment.

Binary variables representing the states were also included in the model (the variable is equal to 1 if the observation comes from the corresponding state, 0 otherwise). The binary variable corresponding to the state of Indiana was taken as a base case; and, therefore it was not included in the model.

\section{$\underline{7.5 \text { Variables Considered }}$}

The logit models are developed on the assumption that the crash happened. As such, variables such as the length of the segment and number of years of crash data used in analysis are not considered. Variables that are point specific, rather than spatially specific are considered. Therefore, instead of having variables for the average horizontal curvature as was used in the frequency models, variables are used for the presence of horizontal and vertical curves, which will be abbreviated as PHC and PVC, respectively. Furthermore, a variable related to the presence of an exterior barrier was also included, and it is abbreviated as PO. As such, Table 7.2 lists the variables that may be found in the severity models. 
Table 7.2 Variables Used in Severity Analysis

\begin{tabular}{|l|c|c|}
\hline \multicolumn{1}{|c|}{ Description } & Symbol & Units \\
\hline Colorado & $\mathrm{CO}$ & $\mathrm{n} / \mathrm{a}$ \\
\hline Illinois & $\mathrm{IL}$ & $\mathrm{n} / \mathrm{a}$ \\
\hline Missouri & $\mathrm{MO}$ & $\mathrm{n} / \mathrm{a}$ \\
\hline Ohio & $\mathrm{OH}$ & $\mathrm{n} / \mathrm{a}$ \\
\hline Oregon & $\mathrm{OR}$ & $\mathrm{n} / \mathrm{a}$ \\
\hline Washington & $\mathrm{WA}$ & $\mathrm{n} / \mathrm{a}$ \\
\hline New York & $\mathrm{NY}$ & $\mathrm{n} / \mathrm{a}$ \\
\hline Presence of an Outside Barrier & $\mathrm{PO}$ & $\mathrm{n} / \mathrm{a}$ \\
\hline Presence of Horizontal Curves & $\mathrm{PHC}$ & $\mathrm{n} / \mathrm{a}$ \\
\hline Presence of Vertical Curves & $\mathrm{PVC}$ & $\mathrm{n} / \mathrm{a}$ \\
\hline Frequency of On-ramps & $\mathrm{RON}$ & $\# / \mathrm{mile}$ \\
\hline Frequency of Off-ramps & $\mathrm{ROF}$ & $\# / \mathrm{mile}$ \\
\hline Frequency of On and Off-ramps & $\mathrm{RAL}$ & $\# / \mathrm{mile}$ \\
\hline Inside Shoulder Width & $\mathrm{ISW}$ & $\mathrm{feet}$ \\
\hline Outside Shoulder Width & $\mathrm{OSW}$ & $\mathrm{feet}$ \\
\hline Number of Lanes in One Direction ${ }^{*} 2$ & $\mathrm{LNS}$ & $\mathrm{n} / \mathrm{a}$ \\
\hline Posted Speed Limit & $\mathrm{PSL}$ & $\mathrm{mph}$ \\
\hline Statewide Speed Limit & $\mathrm{SSL}$ & $\mathrm{mph}$ \\
\hline Average Annual Daily Traffic & $\mathrm{AADT}$ & vehicles/day \\
\hline Percentage of Trucks & $\mathrm{PT}$ & $\% / 100$ \\
\hline Frequency of Bridges & $\mathrm{BRG}$ & $\# / \mathrm{mile}$ \\
\hline
\end{tabular}

\subsection{Single Vehicle (SV) Crash Model}

Table 7.3 shows the results of the binary logit model with single vehicle crashes only. The coefficients are set to 0 for the outcome PDO and the probability modeled here is for the outcome "Injury and Fatal" crashes. Thus, the coefficients shown in the table correspond to the outcome "Injury and Fatal" crashes. Twenty-three variables were included in the model (eight of which represent the effect of median treatments). The median treatment D3N was considered as a base case here (and is not included in the model). All the insignificant median treatments (not significantly different from the base case) were removed from the model. 
Table 7.3 Binary Logit Model for the Single Vehicle Crash Model

\begin{tabular}{|l|c|c|c|c|}
\hline Variable & Coefficient & Standard Error & Wald Chi- & Pr $>$ ChiSq \\
\hline \multicolumn{4}{|c|}{ Characteristics in numerator of Prob[Y=Injury-Fatal] } \\
\hline Intercept & -1.5462 & 0.0501 & 950.6735 & $<.0001$ \\
D2H & -0.6843 & 0.3799 & 3.2443 & 0.0717 \\
D2L & -0.5575 & 0.2933 & 3.6127 & 0.0573 \\
D3L & -0.4578 & 0.3286 & 1.9406 & 0.1636 \\
C3N & 0.2056 & 0.0696 & 8.7324 & 0.0031 \\
F1C & 0.3305 & 0.0877 & 14.2038 & 0.0002 \\
S3N & -0.1738 & 0.0712 & 5.9537 & 0.0147 \\
D2N & 0.0792 & 0.0387 & 4.1981 & 0.0405 \\
D1N & -0.3206 & 0.1865 & 2.9553 & 0.0856 \\
IL & 0.2460 & 0.0591 & 17.3244 & $<.0001$ \\
WA & 1.1906 & 0.0534 & 497.3175 & $<.0001$ \\
OH & -0.2386 & 0.0788 & 9.1700 & 0.0025 \\
MO & 0.6798 & 0.2485 & 7.4853 & 0.0062 \\
NY & 1.0159 & 0.0645 & 248.3928 & $<.0001$ \\
OR & 1.2591 & 0.1089 & 133.7608 & $<.0001$ \\
CO & 0.7674 & 0.0979 & 61.4174 & $<.0001$ \\
ROF & -0.0191 & 0.0198 & 0.9325 & 0.3342 \\
RON & -0.0330 & 0.0155 & 4.5424 & 0.0331 \\
PHC & 0.1606 & 0.0385 & 17.4375 & $<.0001$ \\
ROF•D2L & -0.9029 & 0.5815 & 2.4106 & 0.1205 \\
RON•D2L & 0.9147 & 0.5899 & 2.4042 & 0.1210 \\
PVC•D3L & 0.6938 & 0.4683 & 2.1949 & 0.1385 \\
PHC•D3L & 1.2773 & 1.2647 & 1.0201 & 0.3125 \\
PHC•C3N & -0.3326 & 0.1454 & 5.2305 & 0.0222 \\
\hline
\end{tabular}

Model fit and predictive power:

Table 7.4 presents the values for the statistics calculated to evaluate the overall fit of the model: 
Table 7.4 Goodness-of-fit Statistics for the Single Vehicle Crash Model

Model Fit Statistics

\begin{tabular}{|ccc|}
\hline Criterion & Intercept only & $\begin{array}{c}\text { Intercept and } \\
\text { Covariates }\end{array}$ \\
\hline AIC & 26497.838 & 25234.958 \\
SIC & 26505.825 & 25426.636 \\
-2 Log Likelihood & 26495.838 & 25186.958 \\
\hline
\end{tabular}

Testing Global Null Hypothesis: BETA=0

\begin{tabular}{|cccc|}
\hline Test & Chi-Square & DF & Pr $>$ ChiSq \\
\hline $\begin{array}{c}\text { Likelihood Ratio } \\
\text { HL test }\end{array}$ & 1308.88 & 23 & $<0.0001$ \\
& 14.4202 & 8 & 0.0714 \\
\hline & & & \\
\hline & 0.0584 & &
\end{tabular}

The resulting p-value of the likelihood ratio is very low: the model is significantly better than a model without any variables. The value for the generalized $\mathrm{R}^{2}$ is not very high so the predictive power of the model is not very good. The AIC and SC values are lower for the models with an intercept and covariates, which is in accordance with the conclusion from the likelihood ratio. The HL test ( $p$-value $=0.0714$ ) is not conclusive with respect to the fitness of this model compared with a "maximal" model.

Consequently, the following utility function was developed for single vehicle crashes where:

$\boldsymbol{\beta}_{\text {FAT-INJ }}$ is the vector of coefficients estimated by SAS

$\mathbf{X}_{F A T-I N J}$ is the vector of measurable characteristics 


$$
\beta_{F A T-I N J} X_{F A T-I N J}=\left(\begin{array}{l}
-1.5426-0.6843(D 2 H)-0.5575(D 2 L)-0.4578(D 3 L)+ \\
0.2056(C 3 N)+0.3305(F 1 C)-0.1738(S 3 N)+ \\
0.0792(D 2 N)-0.3206(D 1 N)+0.2460(I L)+ \\
1.1906(W A)-0.2386(O H)+0.6798(M O)+1.0159(N Y)+ \\
1.2591(O R)+0.7674(C O)-0.0191(R O F)+ \\
-0.0330(R O N)+0.1606(P H C)-0.9029(R O F \bullet D 2 L)+ \\
0.9147(R O N \bullet D 2 L)+0.6938(P V C \bullet D 3 L)+ \\
1.2773(P H C \bullet D 3 L)-0.3326(P H C \bullet C 3 N)
\end{array}\right)
$$

\subsection{Multiple Vehicle - Same Direction (MVSD) Crash Model}

Table 7.5 shows the result of the binary logit model with multiple vehicle - same direction crashes only. The coefficients are set to 0 for the outcome PDO and the probability modeled here is for the outcome "Injury and Fatal" crashes. Thus, the coefficients shown in the table correspond to the outcome "Injury and Fatal" crashes. Twenty-five variables were included in the model (five of which represent the effects of median treatments). The median treatment $\mathrm{D} 3 \mathrm{~N}$ was considered as a base case, and as such, it is not included in the model. All the insignificant median treatments (not significantly different from the base case) were removed from the model. 
Table 7.5 Binary Logit Model for the Multiple Vehicle - Same Direction Crash Model

\begin{tabular}{|c|c|c|c|c|}
\hline Variable & Coefficient & Standard Error & Wald Chi- & Pr > ChiSq \\
\hline \multicolumn{5}{|c|}{ Characteristics in numerator of Prob[Y=Injury-Fatal] } \\
\hline Intercept & -0.5647 & 0.4497 & 1.5770 & 0.2092 \\
\hline D2L & 0.4187 & 0.2702 & 2.4015 & 0.1212 \\
\hline D3L & -0.2500 & 0.2052 & 1.4845 & 0.2231 \\
\hline F2C & 0.5129 & 0.1422 & 13.0090 & 0.0003 \\
\hline S3N & 0.1996 & 0.0987 & 4.0871 & 0.0432 \\
\hline D1N & -0.3645 & 0.2312 & 2.4864 & 0.1148 \\
\hline IL & 0.1508 & 0.0672 & 5.0319 & 0.0249 \\
\hline WA & 0.9392 & 0.0695 & 182.8257 & $<.0001$ \\
\hline NY & 1.4965 & 0.1024 & 213.5164 & $<.0001$ \\
\hline OR & 0.9534 & 0.0994 & 91.9191 & $<.0001$ \\
\hline Co & 0.8180 & 0.1555 & 27.6922 & $<.0001$ \\
\hline LNS & 0.0542 & 0.0371 & 2.1350 & 0.1440 \\
\hline PO & -0.1583 & 0.0926 & 2.9215 & 0.0874 \\
\hline AADT & $-2.43 E-06$ & $1.23 \mathrm{E}-06$ & 3.8841 & 0.0487 \\
\hline PSL & -0.0128 & 0.00647 & 3.9428 & 0.0471 \\
\hline PT & -0.4034 & 0.3104 & 1.6891 & 0.1937 \\
\hline BRG & 0.0494 & 0.0203 & 5.9187 & 0.0150 \\
\hline ROF & -0.0264 & 0.0232 & 1.3037 & 0.2535 \\
\hline PVC & 0.1070 & 0.0485 & 4.8605 & 0.0275 \\
\hline PHC & -0.1151 & 0.0538 & 4.5856 & 0.0322 \\
\hline BRG•D2L & -0.9856 & 0.3642 & 7.3222 & 0.0068 \\
\hline PVC•D2L & 0.8588 & 0.3560 & 5.8191 & 0.0159 \\
\hline$P V C \cdot C 3 N$ & 0.3565 & 0.1761 & 4.0986 & 0.0429 \\
\hline ROF•B3N & 0.1121 & 0.0653 & 2.9469 & 0.0860 \\
\hline RON•B3N & -0.0865 & 0.0727 & 1.4154 & 0.2342 \\
\hline $\mathrm{PHC} \cdot \mathrm{F} 2 \mathrm{C}$ & -0.5372 & 0.3503 & 2.3516 & 0.1252 \\
\hline
\end{tabular}

Model fit and predictive power:

Table 7.6 presents the values for the statistics calculated to evaluate the overall fit of the model: 
Table 7.6 Goodness-of-fit for the Multiple Vehicle - Same Direction Crash Model

Model Fit Statistics

\begin{tabular}{|ccc|}
\hline Criterion & Intercept only & $\begin{array}{c}\text { Intercept and } \\
\text { Covariates }\end{array}$ \\
\hline AIC & 14494.846 & 13838.194 \\
SIC & 14502.201 & 14029.423 \\
-2 Log Likelihood & 14492.846 & 13786.194 \\
\hline
\end{tabular}

Testing Global Null Hypothesis: BETA=0

\begin{tabular}{|cccc|}
\hline Test & Chi-Square & DF & Pr $>$ ChiSq \\
\hline Likelihood Ratio & 706.6525 & 25 & $<0.0001$ \\
HL test & 8.3832 & 8 & 0.397 \\
\hline \multicolumn{4}{r}{} \\
\hline Generalized R ${ }^{2}$ & 0.0593 & & \\
\hline
\end{tabular}

The resulting p-value of the likelihood ratio is low; the model is definitely better than a model without any variables. Again the AIC and SC values are lower for the models with an intercept and covariates, which is in accordance with the conclusion from the likelihood ratio. The value for the generalized $\mathrm{R}^{2}$ is not very high so the predictive power of the model is not very good. The HL test ( $p$-value $=0.3762$ ) is again not conclusive with respect to the fitness of this model compared with a "maximal" model.

Consequently, the following utility function was developed for multiple vehicle same direction crashes where:

$\boldsymbol{\beta}_{F A T-I N J}$ is the vector of coefficients estimated by SAS, $\mathbf{X}_{F A T-I N J}$ is the vector of measurable characteristics. 


$$
\beta_{F A T-I N J} X_{F A T-I N J}=\left(\begin{array}{l}
-0.5647+0.4187(D 2 L)-0.2500(D 3 L)+ \\
0.5129(F 1 C)+0.1996(S 3 N)-0.3645(D 1 N)+ \\
0.1508(I L)+0.9392(W A)+1.4965(N Y)+0.9534(O R)+ \\
0.8180(C O)+0.0542(L N S)-0.1583(P O)+ \\
-0.00000243(A A D T)-0.0128(P S L)-0.4034(P T)+ \\
0.0494(B R G)-0.0264(R O F)+0.1070(P V C)+ \\
-0.1151(P H C)-0.9856(B R G \bullet D 2 L)+ \\
0.8588(P V C \bullet D 2 L)+0.3565(P V C \bullet C 3 N)+ \\
0.1121(R O F \bullet B 3 N)-0.0865(R O N \bullet B 3 N)+ \\
-0.5372(P H C \bullet F 2 C)
\end{array}\right)
$$

\subsection{Multiple Vehicle - Opposite Direction (MVOD) Crash Model}

Table 7.7 shows the results of the binary logit model with multiple vehicle opposite direction crashes. The coefficients are set to 0 for the outcome PDO and the probability modeled here is for the outcome "Injury and Fatal" crashes. Thus, the coefficients shown in the table correspond to the outcome "Injury and Fatal" crashes. Eleven variables were included in the model (two of which represent the effect of median treatments). The median treatment "Depressed median without barrier, with a width greater than $50 \mathrm{ft}$." was used as the base case (and is not included in the model). All the insignificant median treatments (not significantly different from the base case) were removed from the model.

As noted in Chapter 5, there were several MVOD crashes that occurred on segments with barriers. These crashes were removed from the model and their severity was addressed independently. There were 3 MVOD crashes on segments with barriers: 2 
were from Missouri and 1 was from Ohio. Not one of the 3 crashes was a fatal crash. One of the two crashes in the Missouri data was PDO; the other was an injury crash. These crashes were both on segments with the D2L median treatment. The crash from Ohio was an injury crash. This crash was on the D3H median treatment. As such, it is expected that if a MVOD crash occurred on a D2L segment, it has a $50 \%$ chance of being a PDO and a 50\% chance of being and injury crash. Furthermore, it is expected that if a crash does occur on a D3H segment, it will be an injury crash.

Table 7.7 Binary Logit Model for Multiple Vehicle - Opposite Direction Crashes

\begin{tabular}{|l|c|c|c|c|}
\hline Variable & Coefficient & Standard Error & Wald Chi- & Pr > ChiSq \\
\hline \multicolumn{4}{|c|}{ Characteristics in numerator of Prob[Y=Injury-Fatal] } \\
\hline Intercept & -0.6691 & 0.6483 & 1.0654 & 0.3020 \\
D2N & 0.5446 & 0.2566 & 4.5034 & 0.0338 \\
D1N & 1.3416 & 1.173 & 1.3082 & 0.2527 \\
OH & -0.7532 & 0.3253 & 5.3604 & 0.0206 \\
OR & 0.6875 & 0.6223 & 1.2202 & 0.2693 \\
CO & 0.4969 & 0.492 & 1.0200 & 0.3125 \\
LNS & 0.1836 & 0.1688 & 1.1827 & 0.2768 \\
PO & -0.8433 & 0.4791 & 3.0992 & 0.0783 \\
AADT & $-6.79 E-06$ & $5.49 E-06$ & 1.5290 & 0.2163 \\
PVC & 0.3346 & 0.2363 & 2.0047 & 0.1568 \\
ROF•D2N & -1.0808 & 0.4710 & 5.2652 & 0.0218 \\
RON·D2N & 0.9680 & 0.4416 & 4.8050 & 0.0284 \\
\hline
\end{tabular}

\section{Model fit and predictive power:}

Table 7.8 presents the values for the statistics calculated to evaluate the overall fit of the model: 
Table 7.8 Goodness-of-fit Statistics for the Multiple Vehicle - Opposite Direction Crash Model

Model Fit Statistics

\begin{tabular}{|ccc|}
\hline Criterion & Intercept only & $\begin{array}{c}\text { Intercept and } \\
\text { Covariates }\end{array}$ \\
\hline AIC & 663.760 & 651.004 \\
SIC & 667.931 & 701.064 \\
-2 Log Likelihood & 661.760 & 627.004 \\
\hline
\end{tabular}

Testing Global Null Hypothesis: $B E T A=0$

\begin{tabular}{|cccc|}
\hline Test & Chi-Square & DF & Pr $>$ ChiSq \\
\hline Likelihood Ratio & 34.7557 & 11 & 0.0003 \\
HL test & 1.758 & 8 & 0.9876 \\
\hline
\end{tabular}

Generalized R $^{2} \quad 0.0700$

The resulting $\mathrm{p}$-value of the likelihood ratio is low so the model is definitely better than a model without any variables. The value for the generalized $\mathrm{R}^{2}$ is not very high so the predictive power of the model is not very good. The HL test ( $p$-value = 0.9876) is high and suggests that the model fits well. However, this result must be taken with caution since the HL test is not very powerful.

Consequently, the following utility function was developed for multiple vehicle opposite direction crashes where:

$\boldsymbol{\beta}_{F A T-I N J}$ is the vector of coefficients estimated by SAS, $\mathbf{X}_{\text {FAT-INJ }}$ is the vector of measurable characteristics. 


$$
\beta_{F A T-I N J} X_{F A T-I N J}=\left(\begin{array}{l}
-0.6691+0.5446(D 2 N)+1.3416(D 1 N)+ \\
-0.7532(O H)+0.6875(O R)+ \\
0.4969(C O)+0.1836(L N S)-0.8433(P O)+ \\
0.00000679(A A D T)+0.3346(P V C)+ \\
-1.0808(R O F \bullet D 2 N)+0.9680(R O N \bullet D 2 N)
\end{array}\right)
$$

\section{$\underline{7.9 \text { Discussion of the Results }}$}

Most of the coefficients, signs, and magnitudes obtained through the modeling process were consistent with the expectations. This section discusses the coefficient estimates and their effects on the accident severity and provides an explanation for their signs. For each of the models presented in the previous section $[(73),(74),(75)]$, the effect of the variables included are discussed.

\subsubsection{Single Vehicle (SV) Crashes}

The implications of the coefficients in the single vehicle crash model are discussed below.

\section{Variable: D2H}

Finding: Lower probability of injury-fatal severity relative to PDO severity compared with the median treatment D3N.

The median treatment decreases the likelihood of severe crashes compared with the base case. The cable barriers are flexible barriers; and therefore, they absorb a 
portion of the energy due to the crash, leading to less severe accidents. This suggests that cable barriers could be a safer solution when the median is large enough to contain the maximum deflection of the barrier after impact.

\section{Variable: D2L}

Finding: Lower probability of injury-fatal severity relative to PDO severity compared with the median treatment $\mathrm{D} 3 \mathrm{~N}$.

The median treatment decreases the likelihood of severe crashes compared with the base case. This result is in accordance with the previous one, obtained for hightensioned cables. The magnitude of the coefficient associated with this median treatment is higher than the magnitude of the coefficient associated to the median treatment $\mathrm{D} 2 \mathrm{H}$, suggesting that low-tensioned cables reduce the likelihood of severe crashes more than high-tensioned cables. This difference could reflect the differences between the two types of cables: low-tensioned cables do not have any tensioning in them, high-tensioned cables do. Therefore, low-tensioned cable barriers might not be nearly as invasive. However, this result has to be taken carefully due to the low number of segments with high-tensioned cable barriers in the sample.

\section{Variable: D3L}

Finding: Lower probability of injury-fatal severity relative to PDO severity compared with the median treatment $\mathrm{D} 3 \mathrm{~N}$

This finding is consistent with the coefficient found for the category D2L. 


\section{Variable: $\mathrm{C} 3 \mathrm{~N}$}

Finding: Greater probability of injury-fatal severity relative to PDO severity compared with the median treatment D3N.

This median treatment increases the likelihood of more severe crashes compared with the median treatment D3N. This makes sense when considering that these two median treatments have very similar design with the exception of the berm installed in the middle. The berm acts as an obstacle inside the median. This probably explains why it is implied that accidents are more severe on the $\mathrm{C} 3 \mathrm{~N}$ median treatment as compared to the D3N median treatment.

\section{Variable: F1C}

Finding: Greater probability of injury-fatal severity relative to PDO severity compared with the median treatment D3N.

This median treatment appeared to increase the severity compared with the base case. A median barrier is expected to decrease the frequency of crossover accidents, but it might increase the severity of a crash. In particular, concrete barriers are rigid barriers which do not absorb the energy of the crash during the impact. As a consequence, the severity is expected to be greater when impacting a concrete barrier when compared with a more flexible one.

For this model, the variable "Flush median, concrete barrier, $30 \mathrm{ft}$. $\leq$ width $\leq 50$ ft." was not found to be significant

\section{Variable: S3N}


Finding: Lower probability of injury-fatal severity relative to PDO severity compared with the median treatment $\mathrm{D} 3 \mathrm{~N}$.

The sloped median treatment was found to decrease the likelihood of severe crashes compared with the base case. This median treatment is quite similar to the base case; however, the difficult terrain transforms the depressed shape into a sloped shape. An explanation for this result might be the fact that the difficult terrain incites drivers to drive more carefully than on a flat straight segment. As a consequence of the apparent shift in driving behavior, less severe crashes are experienced on these portions of the roadway.

Variables: D2N

D1N

Finding: Greater probability of injury-fatal severity relative to PDO severity for the category of width between $30 \mathrm{ft}$. and $50 \mathrm{ft}$., but lower probability of injury-fatal severity relative to PDO severity for the category of width lower than $30 \mathrm{ft}$. compared to the median treatment: D3N.

These median treatments are similar to the base case in their overall design, with the exception of the median width. Consequently, these variables should capture the effect of median width on the severity of crashes. The coefficient is positive for the category D2N but negative for the category D1N. The positive coefficient was expected and is in accordance with previous studies on the median width (a decrease in the median width increases the probability of more severe crashes). However, the negative coefficient for D1N is surprising. A positive coefficient, greater than the one associated 
to the median treatment $\mathrm{D} 2 \mathrm{~N}$ would have been expected. The significance of the variable D1N is not extremely high (Wald Chi-square statistic lower than 1.6), so the corresponding coefficient must be considered with caution. In addition, almost all the segments that fall in the D1N category come from the state of New York. This trend might be due to some specific characteristics of the state New York and not to the actual effect of the median treatment. In addition, this median treatment is not expected: generally, when the median width is very narrow, a median barrier is installed.

Variables: IL
WA
$\mathrm{OH}$
MO
NY
OR
$\mathrm{CO}$

Finding: Greater probability of injury-fatal severity relative to PDO severity for Illinois, Washington, Missouri, New York, Oregon, and Colorado (compared with Indiana); lower probability of injury-fatal severity relative to PDO severity for Ohio (compared with Indiana).

These variables primarily capture the differences between the states with respect to the severity.

Variables: ROF 


\section{RON}

Finding: Lower probability of injury-fatal severity relative to PDO severity with increasing on and off-ramp frequency.

It appears that a high frequency of on and off-ramps decreases the likelihood of severe accident. Even though a contrary result might be expected, it is possible that a high concentration of on and off-ramps modifies the behavior of drivers and incites them to drive more carefully; ramps zones are known as being more dangerous and drivers are likely to pay more attention than usual in their proximity. No major difference was found between the impact of off-ramps and on-ramps on severity. However, the percent difference between these two variables is $27.5 \%$. As such, the variables cannot be combined.

\section{Variable: $\mathrm{PHC}$}

Finding: Greater probability of injury-fatal severity relative to PDO severity with the presence of a horizontal curve.

The presence of a horizontal curve represents an additional hazard for the driver (reduces the sight distance on sharp curves, tendency of the vehicle to be driven out of the travel way by the centrifugal force). This variable captures the effect of the terrain: the presence of a horizontal curve was found to increase the likelihood of high severity accidents.

\section{Interaction variables: $\quad \mathrm{PHC} \cdot \mathrm{D} 3 \mathrm{~L}$}

\section{$\mathrm{PHC} \cdot \mathrm{C} 3 \mathrm{~N}$}


Finding: Greater probability of injury-fatal severity relative to PDO severity for the interaction variable with $\mathrm{D} 3 \mathrm{~L}$ and lower probability for the interaction variable with C3N.

Interaction variable: $\mathrm{PVC} \cdot \mathrm{D} 3 \mathrm{~L}$

Finding: Greater probability of injury-fatal severity relative to PDO severity for the interaction variable

The presence of a vertical curve increases the likelihood of severe crashes when the vertical curve is installed on a D3L.

\section{Interaction variables: $\quad \mathrm{RON} \cdot \mathrm{D} 2 \mathrm{~L}$ \\ $\mathrm{ROF} \cdot \mathrm{D} 2 \mathrm{~L}$}

Finding: Greater probability of injury-fatal severity relative to PDO severity with increasing on-ramp frequency for the corresponding median treatment; lower probability of injury-fatal severity relative to PDO severity with increasing off-ramp frequency for the corresponding median treatment

\subsubsection{Multiple Vehicle - Same Direction (MVSD) Crashes}

The interpretation of the coefficients found in this model was not straightforward: some signs were consistent, whereas some results were unexpected. The inner nature of the sample of observations made the interpretation far more difficult. The MVSD category includes all the crashes that happened between at least two vehicles traveling in 
the same direction prior to the crash. Consequently, what happened during the crash is not easy to determine. A rear-end crash may have occurred between two vehicles. In this case, it may be concluded that the crash has nothing to do with the median section. If, on the other hand, the crash was a sideswipe between two vehicles where one of them was redirected on the median section, the crash may be considered "median related." The combination of crashes affected by the median treatment in various ways might explain the difficulties in interpreting some of the results.

\subsubsection{Multiple Vehicle - Opposite Direction (MVOD) Crash Model}

Implication of the coefficients:

The implication of the coefficients in the model MVOD will be discussed below.

Variables: D1N

D2N

Finding: Greater probability of injury-fatal severity relative to PDO severity compared with the median treatment D3N.

These median treatments are similar to the base case when overlooking their median widths. Consequently, these variables captured the effect of median width on the severity of crashes. It appears that a decrease in the median width increased the probability of more severe crashes (the coefficients are positive and increased when the category of width increased). Since crossover crashes typically happen only when no 
median barrier is present, it is normal that the impact of the median treatments on severity is only represented by the "Depressed median, no barrier" treatments. Several explanations may be found to justify this impact of the median width on the severity of crossover crashes. First, an increase in the median width may allow the vehicle crossing the median section to lose some speed, leading to a less severe impact after the crossover. In addition, the vehicles driving in the opposite direction have more time to react to the vehicle coming from the opposing direction.

\section{Variables: $\mathrm{OH}$}

OR

$\mathrm{CO}$

Finding: Lower probability of injury-fatal severity relative to PDO severity for Ohio (compared with Indiana); higher probability of injury-fatal severity relative to PDO severity for Oregon and Colorado (compared with Indiana).

This variable primarily captures the differences between the states with respect to the severity.

\section{Variable: LNS}

Finding: Greater probability of injury-fatal severity relative to PDO severity with an increase in the number of lanes.

It seems that increasing the number of lanes increases the likelihood of severe crashes relative to PDO accidents. An increase in the number of lanes allows more vehicles on the road which may result in an increase in traffic; and therefore, a greater 
risk for interaction between vehicles is created, thereby contributing to more severe accidents. The significance of the variable is not extremely high, so the result must be considered with caution.

\section{Variable: $\mathrm{PO}$}

Finding: Lower probability of injury-fatal severity relative to PDO severity with the presence of an outside barrier.

Outside barriers are typically installed to protect the drivers from hazards next to the outside edge of the road (for instance, a difficult steep terrain or the presence of an obstacle). This variable might capture the positive effect of these barriers in helping to avoid the severe crashes that would happen if an outside barrier was not present. However, it is surprising to see such a high significance of this variable in the case of crossover crashes.

Variable: AADT

Finding: Lower probability of injury-fatal severity relative to PDO severity with increasing AADT.

This result is unexpected: the likelihood of more severe accidents decrease with the increase in traffic. This result is surprising but the presence of the variable LNS, which also picks up the effect of the traffic in a certain way, might also have impacted the result.

\section{Variable: PVC}


Finding: Greater probability of injury-fatal severity relative to PDO severity with the presence of a vertical curve (PVC).

The presence of a vertical curve represents an additional hazard for the driver (reduces the sight distance on the uphill portion, increases the speed of the vehicle on the downhill portion). This variable captures the effect of the terrain: the presence of a vertical curve was found to increase the likelihood of high severity accidents.

\section{Interaction variables: $\quad \mathrm{ROF} \cdot \mathrm{D} 2 \mathrm{~N}$}

\section{$\mathrm{RON} \cdot \mathrm{D} 2 \mathrm{~N}$}

Finding: Greater probability of injury-fatal severity relative to PDO severity with increasing on-ramp frequency for the corresponding median treatment; lower probability of injury-fatal severity relative to PDO severity with increasing off-ramp frequency for the corresponding median treatment

\subsection{Likelihood of Severity and Median Treatments}

To evaluate how the types of median treatments influence the likelihood to obtain severe crashes, it is interesting to calculate the probability to obtain a certain severity given the type of median treatment. To do so, the likelihood of accident severity was calculated using the single vehicle, multiple vehicle - same direction and multiple vehicle - opposite direction models with the following values for the variables:

- The binary variable corresponding to the median treatment of concern takes the value 1 
- All the binary variables representing the other median treatments take the value 0

- The variables representing the state take the value 0 (Indiana is the base case and the likelihood will be computed for this state)

- The other variables take their average value over all the observations in the sample

- If the interaction variable is calculated using the median treatment of concern, it takes its average value over all the observations occurring on the corresponding median treatment; otherwise, it takes the value 0 .

Using this procedure helped to assess how well a median treatment performs compared with another in reducing the severity. The following results were obtained.

Table 7.9 Likelihood of Severity for Single Vehicle Crashes

\begin{tabular}{|c|c|c|}
\hline Median Treatment & P(FAT-INJ) & P(PDO) \\
\hline D2H & 0.097 & 0.903 \\
D3H & 0.176 & 0.824 \\
D2L & 0.096 & 0.904 \\
D3L & 0.157 & 0.843 \\
C3N & 0.196 & 0.804 \\
B3N & 0.176 & 0.824 \\
F1C & 0.229 & 0.771 \\
F2C & 0.176 & 0.824 \\
S3N & 0.152 & 0.848 \\
D2N & 0.188 & 0.812 \\
D1N & 0.134 & 0.866 \\
D3N & 0.176 & 0.824 \\
\hline
\end{tabular}


Table 7.10 Likelihood of Severity for Multiple Vehicle - Same Direction Crashes

\begin{tabular}{|c|c|c|}
\hline Median Treatment & P(FAT-INJ) & P(PDO) \\
\hline D2H & 0.237 & 0.763 \\
D3H & 0.237 & 0.763 \\
D2L & 0.272 & 0.728 \\
D3L & 0.195 & 0.805 \\
C3N & 0.254 & 0.746 \\
B3N & 0.242 & 0.758 \\
F1C & 0.237 & 0.763 \\
F2C & 0.319 & 0.681 \\
S3N & 0.275 & 0.725 \\
D2N & 0.237 & 0.763 \\
D1N & 0.178 & 0.822 \\
D3N & 0.237 & 0.763 \\
\hline
\end{tabular}

Table 7.11 Likelihood of Severity for Multiple Vehicle - Opposite Direction Crashes

\begin{tabular}{|c|c|c|}
\hline Median Treatment & P(FAT-INJ) & P(PDO) \\
\hline C3N & 0.502 & 0.498 \\
B3N & 0.502 & 0.498 \\
S3N & 0.502 & 0.498 \\
D2N & 0.637 & 0.363 \\
D1N & 0.794 & 0.206 \\
D3N & 0.502 & 0.498 \\
\hline
\end{tabular}

Even though the median treatments affect the likelihood of accident severity, their effect does not appear to significantly modify the final probabilities. For the first two models, the likelihood of a PDO crash is always within $76.29 \%$ to $90.28 \%$, no matter which median treatment is specified. However, the median treatments with lowtensioned cables and high-tensioned cables appear to reduce significantly the likelihood of injury-fatal crashes compared with the other median treatments (the median treatment D2L in particular presents good results: $\mathrm{P}(\mathrm{PDO})=0.9042$ for the single vehicle crash model and $\mathrm{P}(\mathrm{PDO})=0.7281$ for the multiple vehicle - same direction crash model). Therefore, this median treatment seems to be one of the best candidates to reduce the severity of crashes if the median section is wide enough to contain the potential 
deflection of the barrier. The flush median treatments with a concrete barrier appear to increase the likelihood of severe crashes much more than the other median treatments, especially if the median section is between $30 \mathrm{ft}$. and $50 \mathrm{ft}$. As for the median width, it seems to impact the likelihood to experience severe crossover crashes (see model "multiple vehicle - opposite direction"): the likelihood of an injury-fatal crossover accident decreases when the median section width increases.

\subsection{Implications of the Results}

Most of the results obtained through the modeling were consistent with the current standards and were expected. The low-tensioned cable appears to work well and help to reduce the likelihood of severe accidents. The installation of cable barriers might be a good solution to mitigate severe accidents if the median section has to be reduced, as a consequence of widening the travel ways. However, designers must be careful as the maximum dynamic deflection of low-tensioned cable barriers was evaluated to be around 138 in. (11.5 ft.). Therefore, this barrier should not be installed on median sections narrower than twice this maximum deflection ( $23 \mathrm{ft}$.). Let us consider the case where it is decided to widen four-lane freeways into six-lanes and the additional lanes are to be installed in the median section. If the original median treatment was a wide depressed median section (width greater than $50 \mathrm{ft}$.), as suggested by the AASHTO design standards, the creation of two 12 -ft. lanes inside the median section will reduce its width to a minimum value of $26 \mathrm{ft}$. This value is higher than twice the maximum deflection of 
cable barriers, and the cables therefore appear to be a good candidate to prevent crossover crashes.

In the case of narrow median sections (narrower than $23 \mathrm{ft}$.), another solution has to be found; the current design usually involves the installation of a concrete median barrier. This barrier is evidently the best solution in preventing crossover crashes as its rigid structure stops essentially all the crashes from crossing the median. If the median width is very small, the likelihood of severe crossover crashes increases. In such a situation, the concrete median barrier is effective. However, the models show an obvious tendency of the "Flush median section with concrete barrier" to increase the likelihood of severe accidents. Even if this median treatment helps to prevent severe crossover crashes, it also represents a rigid obstacle for the vehicles entering the median section and consequently increases the severity of a vehicle hitting the median barrier. In addition, one can notice that an increase in median width for this particular median treatment also tends to increase the likelihood of severe crashes. As a consequence, if a concrete median barrier is to be installed in the median section, the median section should be kept within reasonable widths (less than or equal to $30 \mathrm{ft}$.).

Another solution presents an interesting compromise for relatively narrow median sections: the high-tensioned cable barriers. The results found in these models with respect to the high-tensioned cable barriers were not really significant, which was probably due to the small sample available. When the median treatment was significant, it seemed to reduce the likelihood to obtain more severe crashes in most of the cases (refer to the model for single vehicle crashes). The relatively recent introduction and acceptance of this median barrier in the U.S. makes it difficult to obtain a large enough 
sample of data on this barrier. Furthermore, several high-tensioned cable barrier designs are available and it is desirable to compare their performances when more data is available. The lack of variability in our sample does not help to provide significant results. However, high-tensioned cable barriers were found to prevent crossover crashes quite well (high-tensioned cable barriers are NCHRP Report 350 TL-3 or TL-4 depending on the model) with a lower maximum deflection than classic low-tensioned cable barriers (ranging from 91 in. to 112 in., depending on the models). In addition, the structure of this barrier is highly similar to the one for low-tensioned cable barriers so it presents the advantages of low-tensioned cable barriers in reducing the severity. Therefore, their use could be extended to median section between $19 \mathrm{ft}$. (twice the maximum deflection) or wider. Still, the actual effect of high-tensioned cables on severity needs to be assessed before considering their installation on narrow median section.

To get a full estimation of the effect of these median treatments; however, the results found here have to be analyzed and compared with the findings from frequency models.

Concerning the median width, the models generally show that an increase in the median width tends to correspond to a reduction in the likelihood of severe crashes. The model of crossover crashes especially highlights this tendency. However, if a concrete barrier is installed in the middle of the median section, the contrary seems to occur (higher likelihood of severe crashes when the median width increases). 
CHAPTER 8: PREDICTING CRASHES FOR VARIOUS MEDIAN TREATMENTS

\section{$\underline{\text { 8.1 Classification of Median Treatments }}$}

Median treatments have been classified based on their width, surface, and presence of barrier. Table 8.1 provides an overview of the median treatments. A description, including schematic drawings and pictures of these treatments, follows.

Table 8.1 Classification of Median Treatments

\begin{tabular}{|c|c|c|c|c|}
\hline Name & Symbol & Width & Surface & Barrier \\
\hline $\begin{array}{l}\text { Depressed, intermediate } \\
\text { median, no median barrier }\end{array}$ & $\mathrm{D} 2 \mathrm{~N}$ & $30-50$ & Depressed, turf & No \\
\hline $\begin{array}{l}\text { Depressed, wide median, no } \\
\text { median barrier }\end{array}$ & D3N & $>50$ & $\begin{array}{l}\text { Depressed, turf, } \\
\text { possibly trees and } \\
\text { brush }\end{array}$ & No \\
\hline $\begin{array}{l}\text { Depressed with berms, wide } \\
\text { median, no median barrier }\end{array}$ & $\mathrm{C} 3 \mathrm{~N}$ & $>50$ & Depressed, turf & No \\
\hline $\begin{array}{l}\text { Berms, wide median, no median } \\
\text { barrier }\end{array}$ & $\mathrm{B} 3 \mathrm{~N}$ & $>50$ & $\begin{array}{l}\text { Berms, turf, } \\
\text { possibly trees and } \\
\text { brush }\end{array}$ & No \\
\hline $\begin{array}{l}\text { Sloped, wide median, no } \\
\text { median barrier }\end{array}$ & S3N & $>50$ & $\begin{array}{c}\text { Sloped, turf, } \\
\text { possibly trees and } \\
\text { brush }\end{array}$ & No \\
\hline $\begin{array}{l}\text { Depressed, intermediate } \\
\text { median, low-tensioned cable } \\
\text { median barrier }\end{array}$ & D2L & $30-50$ & Depressed, turf & $\begin{array}{c}\text { Low- } \\
\text { tensioned } \\
\text { cable barrier }\end{array}$ \\
\hline $\begin{array}{l}\text { Depressed, wide median, low- } \\
\text { tensioned cable median barrier }\end{array}$ & D3L & $>50$ & Depressed, turf & $\begin{array}{c}\text { Low- } \\
\text { tensioned } \\
\text { cable barrier }\end{array}$ \\
\hline $\begin{array}{l}\text { Depressed, wide median, high- } \\
\text { tensioned cable median barrier }\end{array}$ & $\mathrm{D} 3 \mathrm{H}$ & $>50$ & Depressed, turf & $\begin{array}{c}\text { High- } \\
\text { tensioned } \\
\text { cable barrier }\end{array}$ \\
\hline
\end{tabular}




\begin{tabular}{|l|c|c|c|c|}
\hline $\begin{array}{l}\text { Flush, narrow median, concrete } \\
\text { median barrier }\end{array}$ & F1C & $<30$ & Flush, paved & Concrete \\
\hline $\begin{array}{l}\text { Flush, intermediate median, } \\
\text { concrete median barrier }\end{array}$ & F2C & $30-50$ & Flush, paved & Concrete \\
\hline
\end{tabular}

\subsubsection{Depressed, Intermediate Median, No Barrier (D2N)}

A depressed median of intermediate width (30-50 ft) is one of the more common median treatments found on rural interstates. It is essentially a swale between the two traveled way directions, as seen in Figure 8.2. The swale allows for drainage. Figure 8.3 shows what a cross-section of a typical swale would look like.

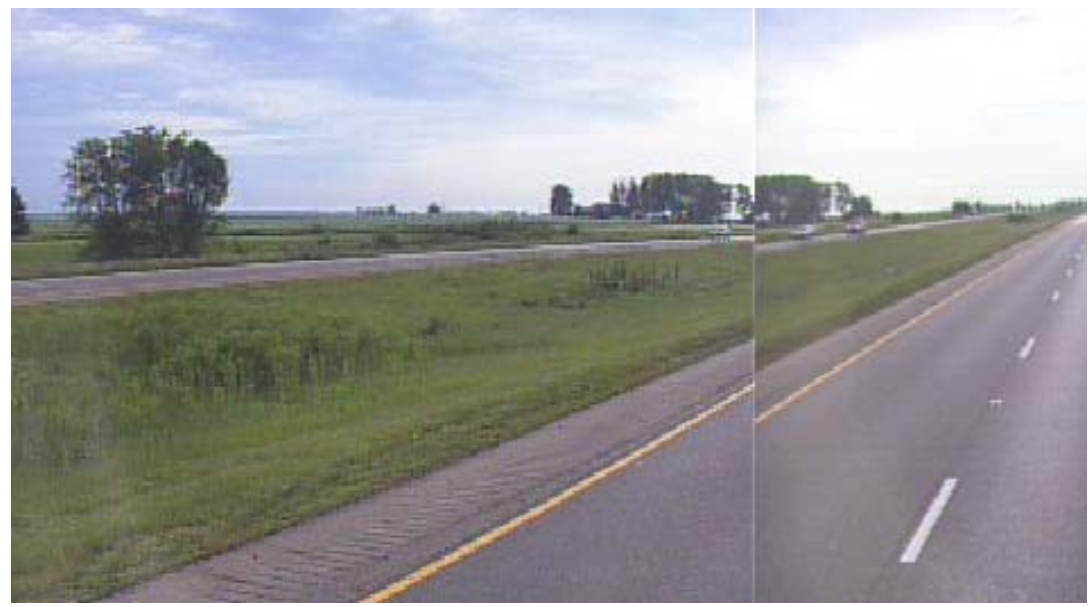

Figure 8.1 Depressed, Intermediate Median, No Median Barrier 


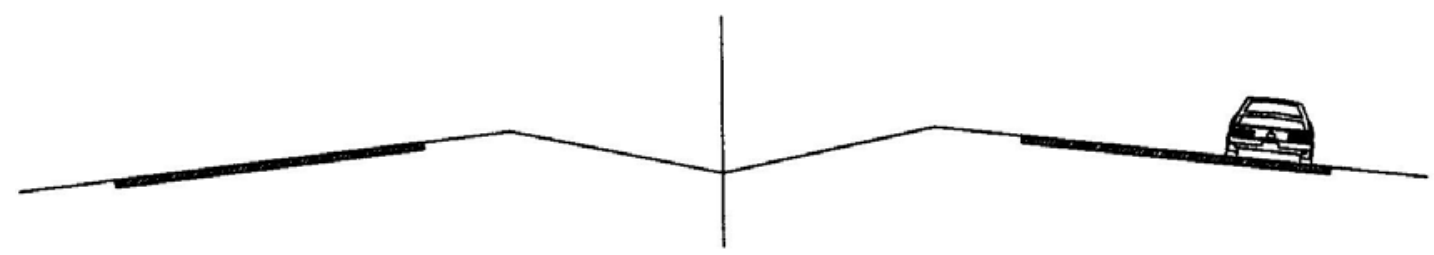

Figure 8.2 Cross-Section of a Depressed Median

\subsubsection{Depressed, Wide Median, No Median Barrier (D3N)}

A depressed wide median ( $\geq 50 \mathrm{ft}$ ) is the most common median treatment found on rural interstates. It is essentially a swale between the two traveled way directions, as seen in Figure 8.4. The swale allows for drainage. Furthermore, the wider median provides a greater degree of separation between the two traveled ways. Similar to Figure 8.2, Figure 8.4 shows what a cross-section of a typical swale would look like, only this time, the distance from the inside shoulder of one traveled way to the inside shoulder of the other traveled way is much wider.

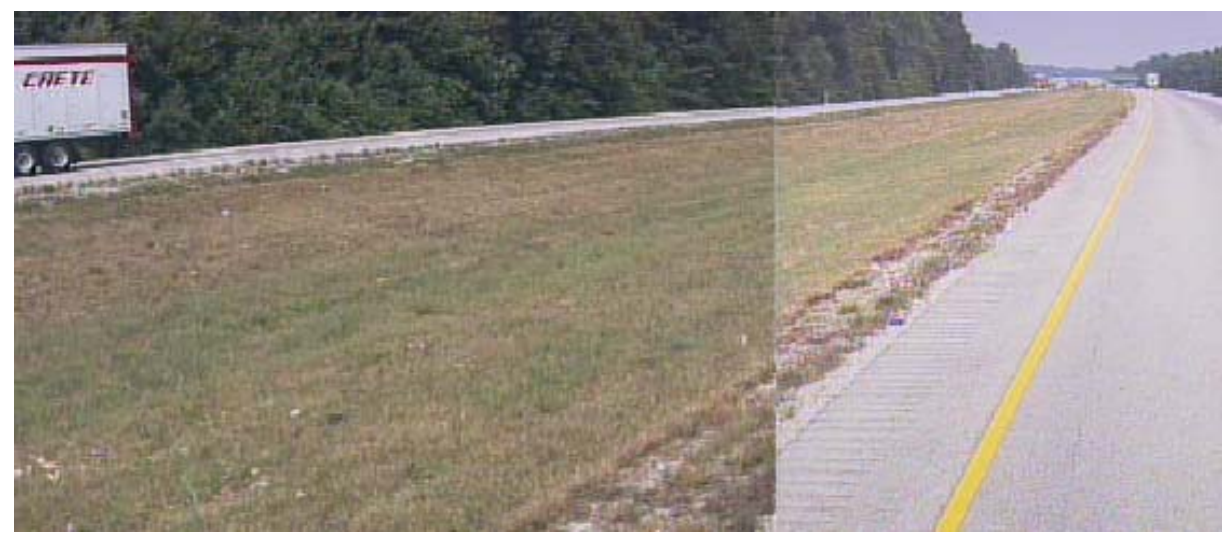

Figure 8.3 Depressed Wide Median, No Median Barrier 


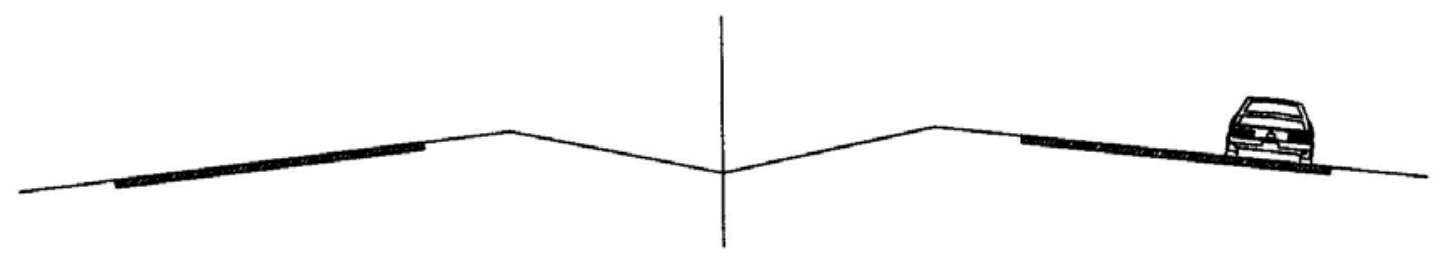

Figure 8.4 Cross-Section of a Depressed Median

\subsubsection{Depressed with Berms, Wide Median, No Median Barrier (C3N)}

A depressed median with berms is essentially a depressed median except that extra material is piled in the center to create a small berm. Figure 8.5 provides an example of such a median treatment, and Figure 8.6 shows an example cross-section of this type of median treatment. Notice the extra material in the center of the swale.

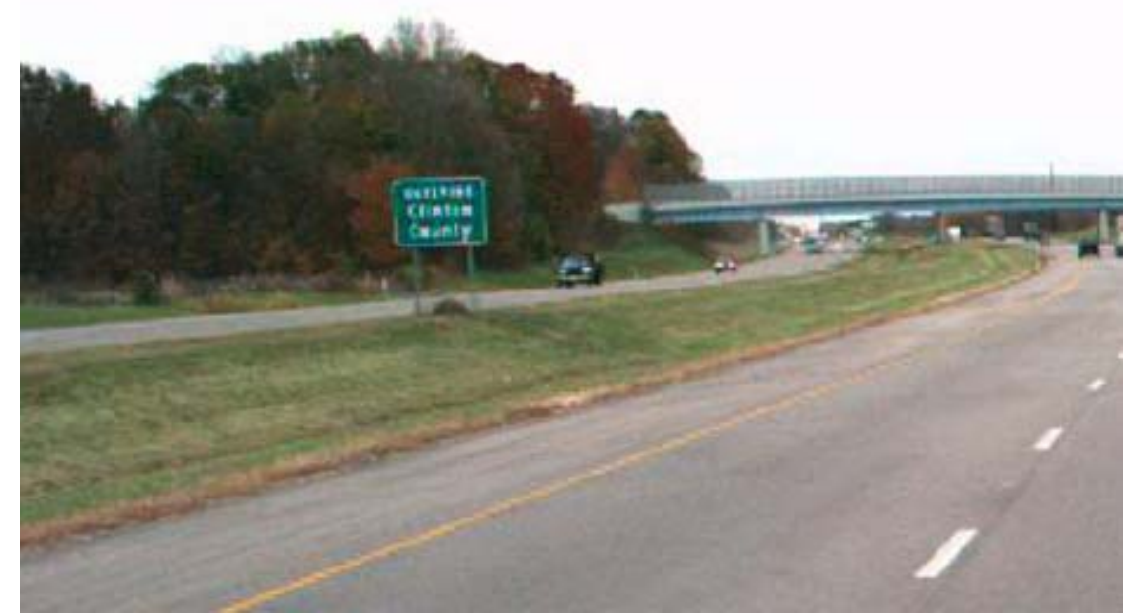

Figure 8.5 Depressed with Berms, Wide Median, No Median Barrier 


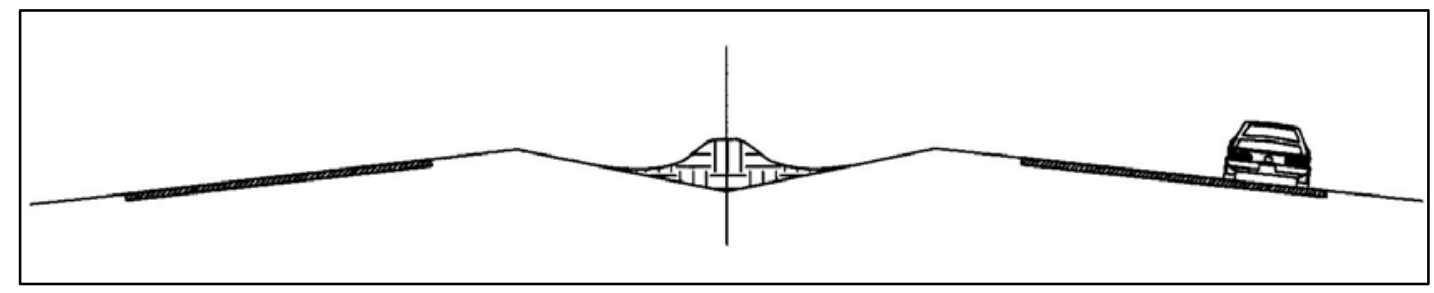

Figure 8.6. Cross-Section of a Depressed with Berms Median Treatment

8.1.4 Berms, Wide Median, No Median Barrier (B3N)

A berm, as shown in Figure 8.7, is made from earthen material and serves as a physical obstruction. One segment of berms may oscillate from a high point to a low point multiple times. Figure 8.8 shows a cross-section of a berm median treatment.

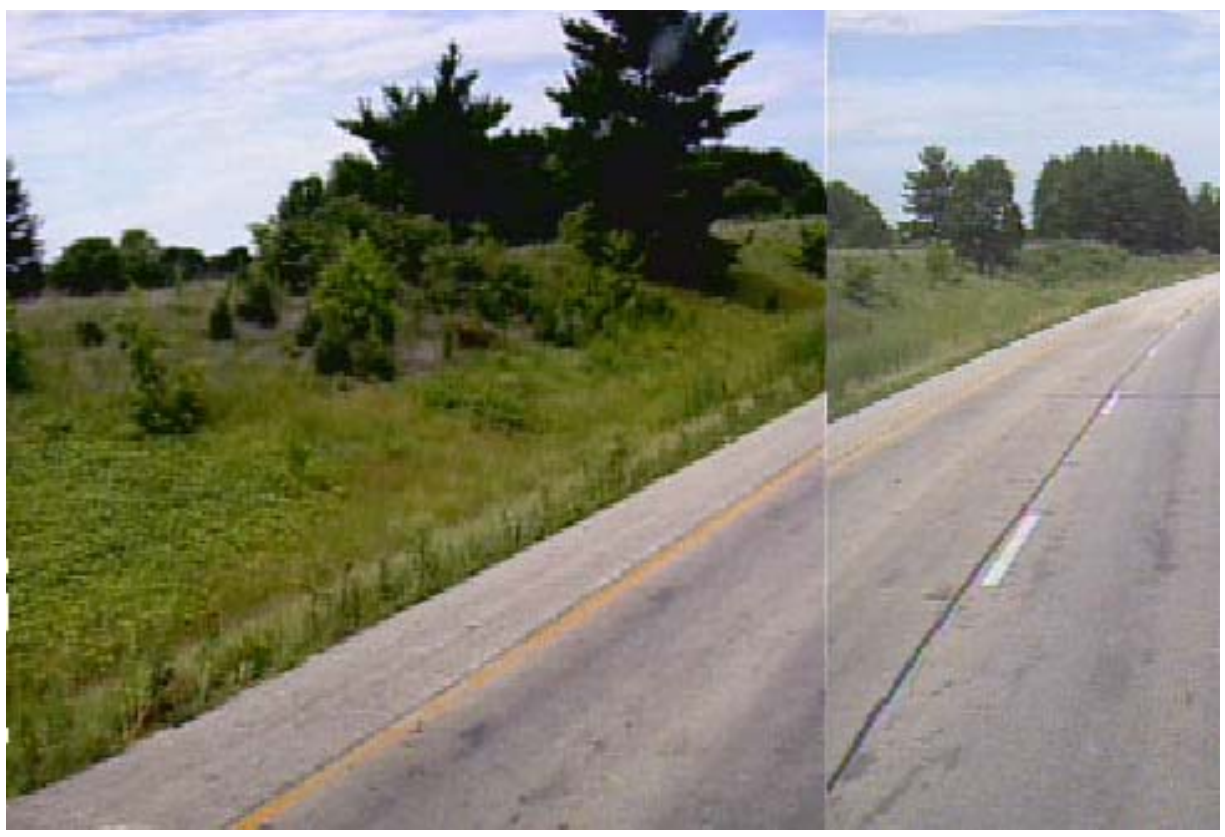

Figure 8.7 Berms, Wide Median, No Median Barrier 


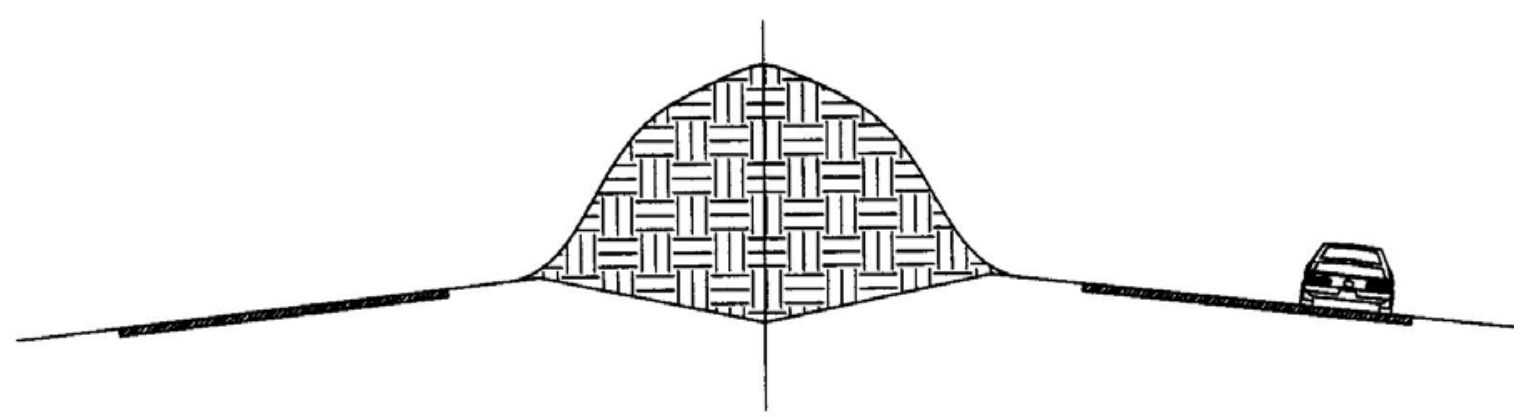

Figure 8.8 Berm Cross-Section

8.1.5 Sloped, Wide Median, No Median Barrier (S3N)

A sloped median, as shown in Figure 8.9, usually occurs when the opposing traveled ways are at different elevations. From the low side, as Figure 8.9 depicts, a sloped median may appear like a berm median, but when viewed from the high side, the median looks like a depressed median. To provide a better understanding of the definition of a sloped median, Figure 8.10 shows a cross-section of this median treatment.

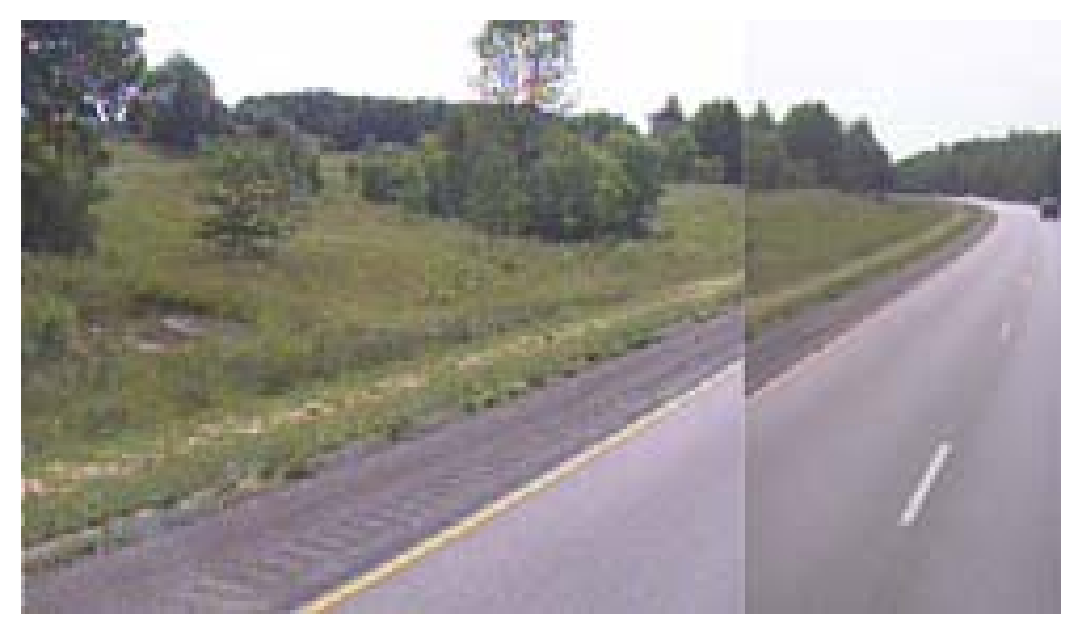

Figure 8.9 Sloped, Wide Median, No Barrier 


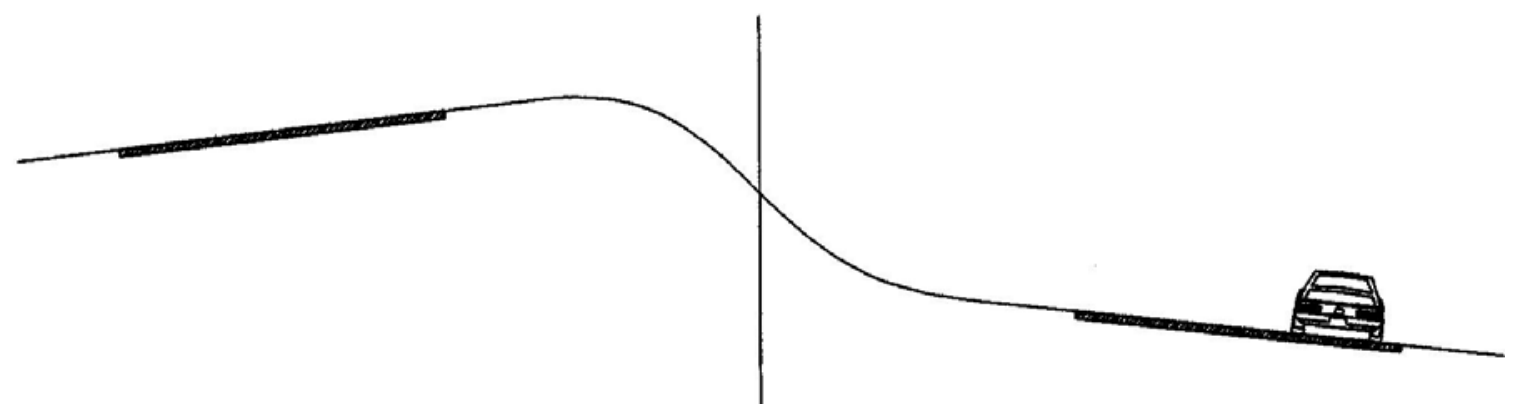

Figure 8.10 Sloped Cross-Section

8.1.6 Depressed, Intermediate Median, Low-Tensioned Cable Median Barrier (D2L)

A depressed intermediate median with low-tensioned cable median barrier, as shown in Figure 8.11, is similar to a depressed median without a median barrier except that the cable barrier was installed. The cable barrier is typically installed close to the shoulder as opposed to the ditch. See Chapter 9 for other state experiences related to the location of installation. 


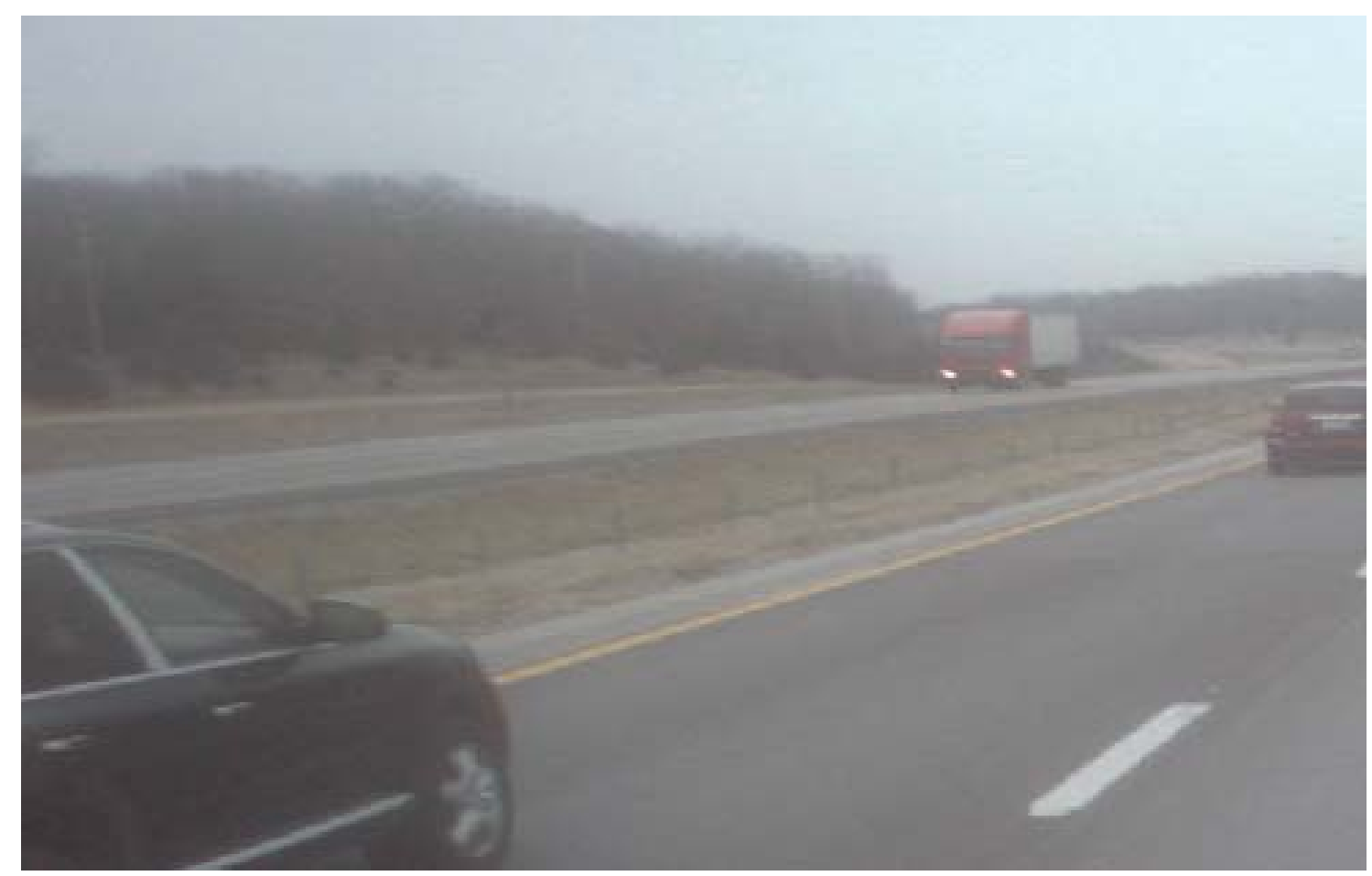

Figure 8.11 Depressed, Intermediate Median, Low-Tensioned Cable Median Barrier

\subsubsection{Depressed, Wide Median, Low-Tensioned Cable Median Barrier (D3L)}

A depressed wide median with low-tensioned cable median barrier, as shown in Figure 8.12 , is similar to a depressed median without a median barrier except that the cable barrier was installed. The cable barrier is typically installed close to the shoulder as opposed to the ditch. See Chapter 9 for other state experiences related to the location of installation. Furthermore, this median treatment is similar to the previously described median treatment with the exception of the additional width allotted in the median. This additional width provides more room for the cable barriers to deflect. 


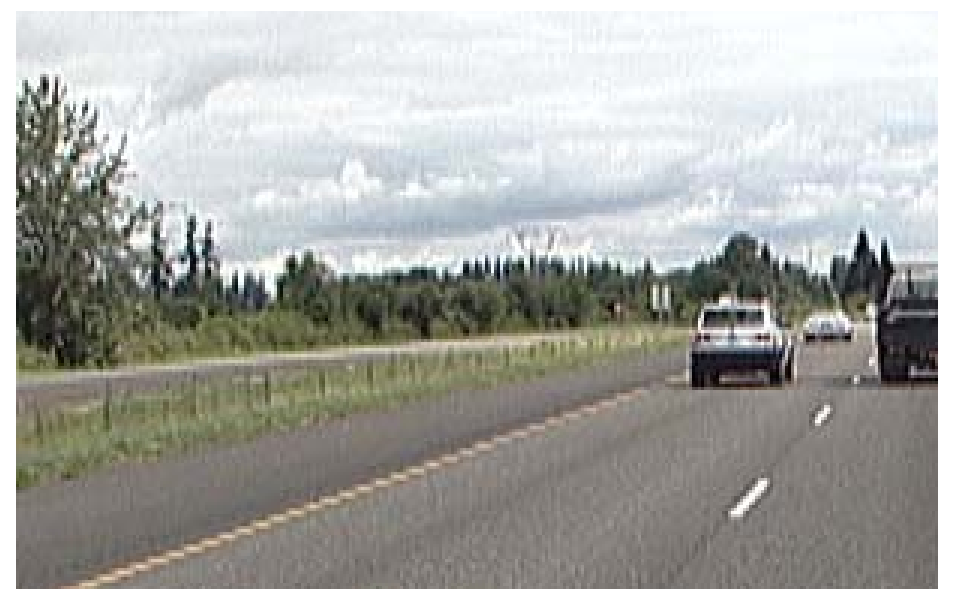

Figure 8.12 Depressed, Wide Median, Low-Tensioned Cable Median Barrier

8.1.8 Depressed, Wide Median, High-Tensioned Cable Median Barrier (D3H)

A depressed wide median with high-tensioned cable median barrier, as shown in Figure 8.13, is similar to a depressed median without a median barrier except that the cable barrier is installed. The cable barrier is typically installed close to the shoulder as opposed to the ditch. See Chapter 9 for other state experiences related to the location of installation. There are several differences between a high-tensioned and low-tensioned cable barrier described in Chapter 9. Most significantly, high-tensioned cable barriers are designed so that ideally they can be hit multiple times if needed. 


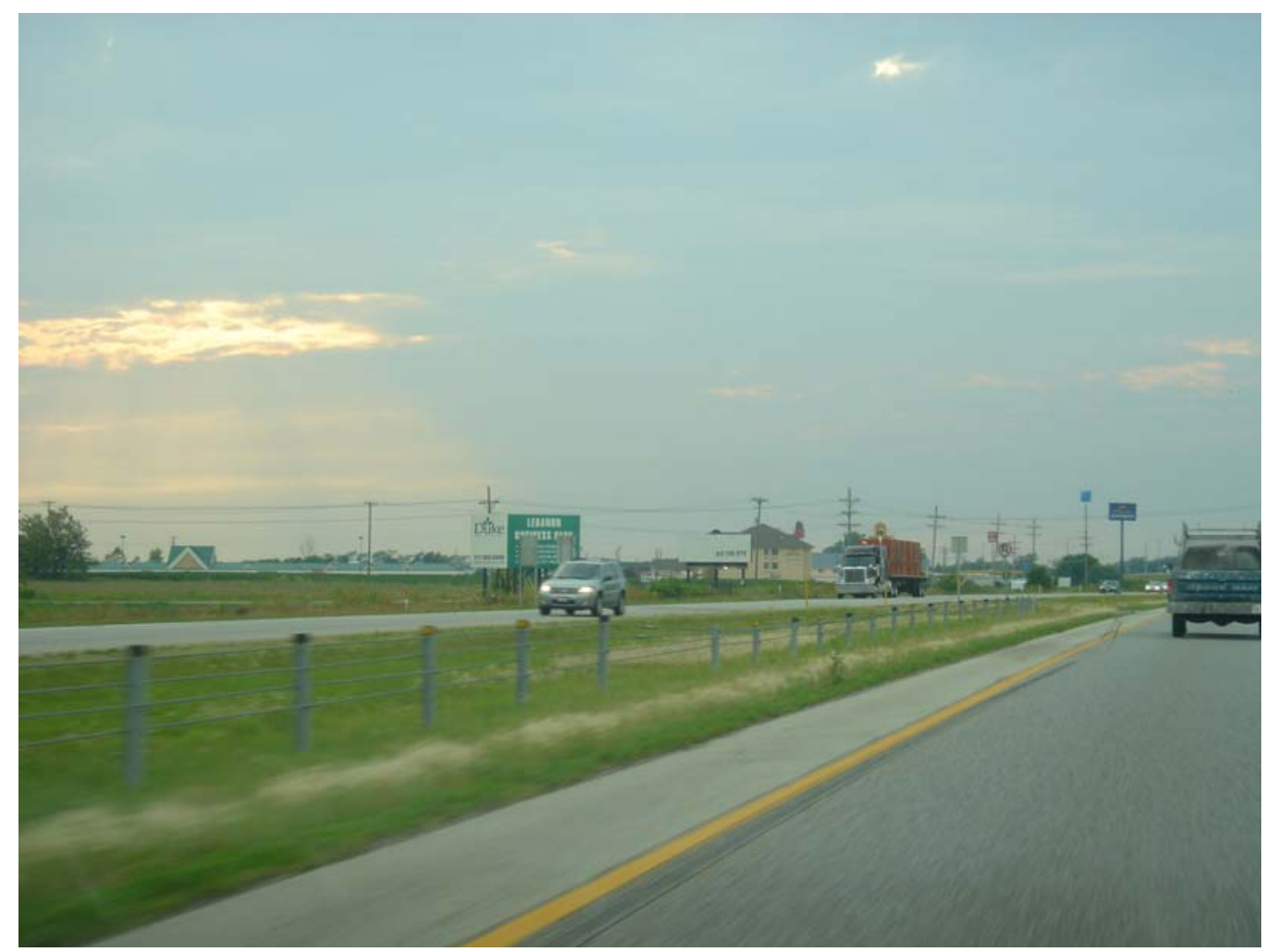

Figure 8.13 Depressed, Wide Median, High-Tensioned Cable Median Barrier 8.1.9 Flush, Narrow Median, Concrete Median Barrier (F1C)

A flush narrow median with a concrete median barrier is shown in Figure 8.14. 


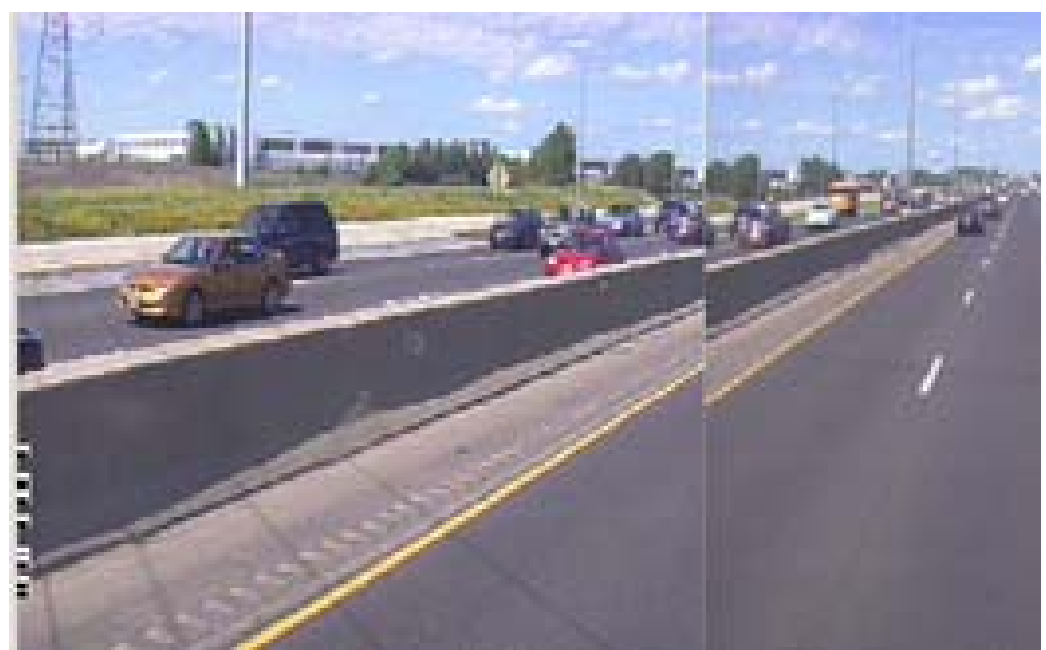

Figure 8.14 Flush, Narrow Median, Concrete Median Barrier

\subsubsection{Flush, Intermediate Median, Concrete Median Barrier (F2C)}

A flush intermediate median with a concrete median barrier is shown in Figure 8.15. This median treatment is very similar to the previous median treatment except that there is more room provided between the barrier and the inside lane line.

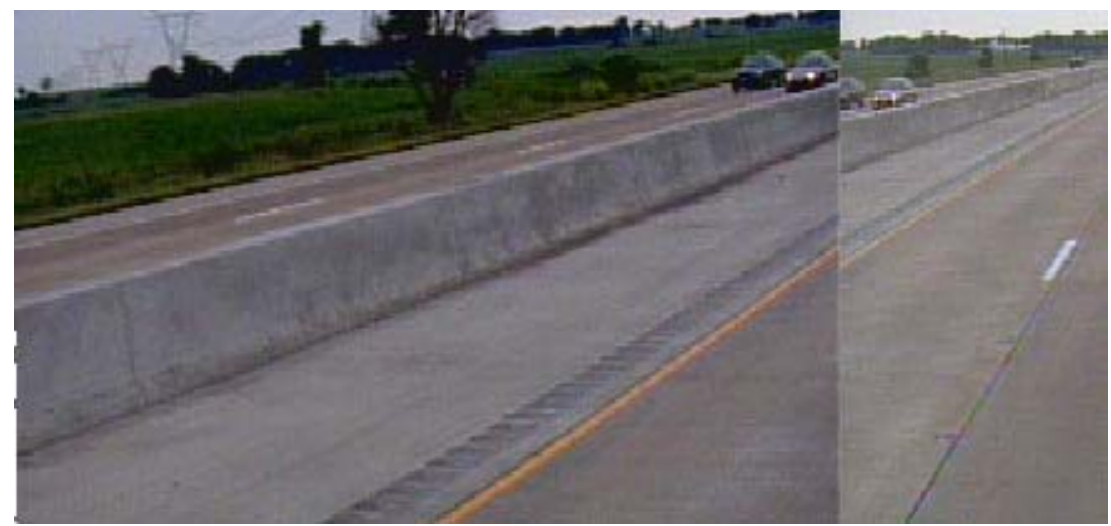

Figure 8.15 Flush, Intermediate, Concrete Median Barrier 


\section{$\underline{8.2 \text { Inputs to Calculations }}$}

\subsubsection{Homogeneous Segments}

An extended freeway section must be divided into homogenous segments were certain roadway and traffic characteristics do not change. Frequencies of crashes are predicted for each of these segments and then accumulate along the studied freeway section. A homogenous segment ends where at least one of the following characteristics changes: median treatment, number of lanes, presence of interior or exterior rumble strips, interior or exterior shoulder width, posted speed limit, the surface type of the median, and the traveled way surface type. Changes of the following characteristics do not require ending the homogenous segment: presence of an exterior barrier, vertical alignment, and horizontal alignment. Horizontal and vertical alignments are represented for each homogenous segment through average values. Calculation of these values is presented in the next section.

\subsubsection{Preparing Input Data}

There are sixteen variables that are present in some of the predictive equations:

$\mathrm{Y}$ - number of years,

$\mathrm{L}$ - length of the segment, AADT - Average Annual Daily Traffic, LNS - total number of lanes in both directions, PSL - posted speed limit, PT - percentage of trucks, $\mathrm{PHC}$ - presence of a horizontal curve, 
HR - average horizontal curvature,

$\mathrm{HF}$ - frequency of horizontal curves,

$\mathrm{PVC}$ - presence of a vertical curve,

$\mathrm{VK}$ - average vertical curvature,

ROF - frequency of off-ramps,

RON - frequency of on-ramps,

RAL - frequency of off and on-ramps,

ISW - inside shoulder width,

$\mathrm{BRG}$ - frequency of bridges.

These variables are defined, described, and when applicable, their computation explained in the following part of the report.

$Y-N u m b e r$ of Years

The number of years is included in the equations for predicting the expected number of crashes. The annual frequency is calculated by setting $\mathrm{Y}$ at one.

\section{$L$ - Length of the Segment}

The segment length is expressed in miles.

\section{AADT - Average Annual Daily Traffic}

The average annual daily traffic should reflect the period for each the expected number of crashes is predicted. Say for example that one wants to compute the number of crashes and the proportion of injury/fatal crashes in the 2005 - 2007 period. The used AADT should be an average of the three values for 2005, 2006, and 2007. A single value for 2006 may be a sufficient approximation. If for some reasons, the segment includes subsegments with different AADT values, then compute a weighted AADT as follows: 


$$
A A D T=\frac{\sum_{i}^{n} L_{i} \bullet A A D T_{i}}{L_{s}},
$$

where,

$\mathrm{AADT}=$ the AADT to be used for predicting the frequency and severity of crashes, $i=$ the sub-segment number, $n=$ the total number of sub-segments, $\mathrm{AADT}_{\mathrm{i}}=$ the AADT for sub-segment $\mathrm{i}$, $\mathrm{L}_{\mathrm{i}}=$ the length of sub-segment $\mathrm{i}$, $\mathrm{L}_{\mathrm{s}}=$ the length of the segment under consideration.

\section{LNS - Total Number of Lanes in Both Directions}

The total number of freeway lanes in both directions does not include speed-change lanes. This value is typically even.

\section{PSL - Posted Speed Limit}

The posted speed limit is the posted speed limit on a segment. A segment cannot have more than one posted speed limit. Otherwise, the segment must be further divided to predict the frequency and severity of crashes on the segment. The posted speed limit is measured in miles per hour.

\section{PT-Percentage of Trucks}

The proportion of trucks is the AADT of trucks divided by the total AADT. This fraction is not multiplied by 100 . If the percentage of trucks is available at multiple locations on the segment a computation similar to that for AADT should be followed. The formula to determine the overall percentage of trucks if there are more than observations is as follows: 


$$
P T=\frac{\sum_{i}^{n} L_{i} \bullet P T_{i}}{L_{s}},
$$

where,

$\mathrm{PT}=$ the PT to be used for predicting the frequency and severity of crashes,

$i=$ the sub segment number,

$n=$ the total number of sub segments,

$\mathrm{PT}_{\mathrm{i}}=$ the $\mathrm{PT}$ for a portion of the segment,

$\mathrm{L}_{\mathrm{i}}=$ the length for which the corresponding PT represents,

$\mathrm{L}_{\mathrm{s}}=$ the total length of the segment under consideration.

PHC-Presence of a Horizontal Curve

The presence of a horizontal curve either takes a value of 0 or 1 . Value of zero is assigned to segment without curves; otherwise value of one is used regardless of the number of horizontal curves. Furthermore, if there any portion of a horizontal curve on the segment, then $\mathrm{PHC}=1$. This variable is used in the equations for predicting the proportion of severe crashes.

HR - Average Horizontal Curvature

The average horizontal curvature is a measure of the sharpness of the curves on a segment. It can be calculated as follows:

$$
H R=\frac{\sum_{i}^{n} \frac{L_{i}}{R_{i}}}{L_{s}} .
$$

where,

$\mathrm{HR}=$ the average horizontal curvature of the segment, $n=$ the number of horizontal curves on the segment,

$\mathrm{R}_{\mathrm{i}}=$ the radius of horizontal curve $\mathrm{i}$,

$\mathrm{L}_{\mathrm{i}}=$ the length of horizontal curve $\mathrm{i}$ or its part included within the segment, $\mathrm{L}_{\mathrm{s}}=$ the length of the segment. 
HF - Frequency of Horizontal Curves

The frequency of horizontal curves is computed as follows:

$$
H F=\frac{\text { Number of Horizontal Curves }}{\text { Segment Length }}
$$

The number of horizontal curves includes horizontal curves that are only partially on the segment.

PVC-Presence of a Vertical Curve

The presence of a vertical curve either takes a value of 0 or 1 . Value of zero is assigned to segment without curves; otherwise value of one is used regardless of the number of vertical curves. Furthermore, if there any portion of a horizontal curve on the segment, then $\mathrm{PVC}=1$. This variable is used in the equations for predicting the proportion of severe crashes.

\section{VK-Average Vertical Curvature}

The average vertical curvature is a measure of the sharpness of the vertical curves on a segment. It can be calculated as follows:

$$
V K=\frac{\sum_{i}^{n} \frac{L_{i}}{K_{i}}}{L_{s}} .
$$

where,

$\mathrm{VK}=$ the average vertical curvature of the segment, $n=$ the number of vertical curves on the segment, $\mathrm{K}_{\mathrm{i}}=$ the $\mathrm{K}$ value of vertical curve $\mathrm{i}$, $\mathrm{L}_{\mathrm{i}}=$ the length of the vertical curve $\mathrm{i}$ or its portion included within the segment, $\mathrm{L}_{\mathrm{s}}=$ the length of the segment. 
ROF - Frequency of Off-Ramps

The frequency of off-ramps is computed as follows:

$$
R O F=\frac{(\text { Number of Off }- \text { Ramps })}{\text { Segment Length }} .
$$

If a segment terminates at a bridge, only the off-ramps that are present within the segment are included in the count. Furthermore, an off-ramp is counted even if only part of it is present in the segment.

RON - Frequency of On-Ramps

The frequency of on-ramps is computed as follows:

$$
R O N=\frac{(\text { Number of On-Ramps) }}{\text { Segment Length }} .
$$

If a segment terminates at a bridge, only the on-ramps that are present within the segment are included in the count. Furthermore, an on-ramp is counted even if only part of it is present in the segment.

\section{RAL - Frequency of Off and On-Ramps}

The frequency of off and on-ramps is computed as follows:

$$
R A L=\frac{(\text { Number of Off }- \text { Ramps })+(\text { Number of On }- \text { Ramps })}{\text { Segment Length }} .
$$

If a segment terminates at a bridge, only the on and off-ramps that are present within the segment are included in the count. Furthermore, a ramp is counted even if only part of it is present in the segment. 
ISW - Inside Shoulder Width

The inside shoulder width is the width between the inside pavement marking of the traveled way and the end of pavement, measured in feet. For medians with concrete barriers where there is no evident distinction of a starting and stopping point for a shoulder, the inside shoulder width is taken as the distance measured from the inside pavement marking of the inside traveled way lane to the edge of the barrier.

$B R G-$ Frequency of Bridges

The frequency of bridges on a segment is computed as follows:

$$
B R G=\frac{\text { Number of Bridges }}{\text { Segment Length }} .
$$

Both overpasses and underpasses are considered bridges. If a segment starts as a bridge that bridge is not included in the count of the number of bridges. Similarly, if the segment ends at a bridge, the bridge is not included in the count for the number of bridges.

\section{$\underline{8.3 \text { Predictive Equations }}$}

Table 8.2 includes all the final equations to use in calculations of the frequency of crashes. The following section describes step by step the process of predicting the frequency and severity of crashes on a segment classified based on the type of median treatment present on that segment. 


\begin{tabular}{|c|c|c|c|}
\hline & MVSD & $M V S D=Y L(A A D T)^{1.619} \exp (-16.015+0.144(R O N))$ & $P(F A T-I N J)=\frac{1}{1+\exp \left(\begin{array}{l}0.565-0.054(L N S)+0.00000243(A A D T)+ \\
0.013(P S L)+0.403(P T)-0.049(B R G)-0.086(R O F)+ \\
0.087(R O N)-0.107(P V C)+0.115(P H C)\end{array}\right.}$ \\
\hline & MVOD & $M V O D=Y L(A A D T)^{0.465} \exp \left(\begin{array}{l}-4.433+0.016(P S L)-0.036(I S W)+ \\
0.060(H R)+0.027(R O N)\end{array}\right)$ & $P(F A T-I N J)=\frac{1}{1+\exp \left(\begin{array}{l}0.669-0.184(L N S)- \\
0.00000679(A A D T)-0.335(P V C)\end{array}\right)}$ \\
\hline \multirow{3}{*}{ S3N } & SV & $S V=Y L(A A D T)^{0.596} \exp (-4.960+0.333(H R))$ & $P(F A T-I N J)=\frac{1}{1+\exp (1.716+0.019(R O F)+0.033(R O N)-0.161(P H C))}$ \\
\hline & MVSD & $M V S D=Y L(A A D T)^{1.329} \exp (-13.201+0.095(R O N))$ & $P(F A T-I N J)=\frac{1}{1+\exp \left(\begin{array}{l}0.365-0.054(L N S)+0.00000243(A A D T)+ \\
0.013(P S L)+0.403(P T)-0.049(B R G)-0.107(P V C)+ \\
0.115(P H C)-0.086(R O F)+0.087(R O N)\end{array}\right)}$ \\
\hline & MVOD & $M V O D=Y L(A A D T)^{0.465} \exp \left(\begin{array}{l}-4.433+0.016(P S L)-0.036(I S W)+ \\
0.060(H R)+0.027(R O N)\end{array}\right)$ & $P(F A T-I N J)=\frac{1}{1+\exp (0.669-0.184(L N S)-0.00000679(A A D T)-0.335(P V C))}$ \\
\hline \multirow{3}{*}{ D2L } & SV & $S V=Y L(A A D T)^{0.577} \exp (-3.794+0.150(H R)+0.070(R O F)-0.166(I S W))$ & $P(F A T-I N J)=\frac{1}{1+\exp (2.100-0.161(P H C)+0.922(R O F)-0.882(R O N))}$ \\
\hline & MVSD & $M V S D=Y L(A A D T)^{1.254} \exp (-12.814+0.020(B R G))$ & $P(F A T-I N J)=\frac{1}{1+\exp \left(\begin{array}{l}0.304-0.054(L N S)+0.00000243(A A D T)+ \\
0.013(P S L)+0.403(P T)+0.936(B R G)+ \\
0.026(R O F)-0.966(P V C)+0.115(P H C)\end{array}\right)}$ \\
\hline & MVOD & $M V O D=\frac{22.63(Y)(L)(A A D T)}{100,000,000}$ & $P(F A T-I N J)=0.304^{1}$ \\
\hline D3L & SV & $S V=Y L(A A D T)^{0.338} \exp (-1.862-0.027(H F))$ & $P(F A T-I N J)=\frac{1}{1+\exp \left(\begin{array}{l}2.000+0.019(R O F)+0.033(R O N)+ \\
-1.438(P H C)-0.694(P V C)\end{array}\right)}$ \\
\hline
\end{tabular}

\footnotetext{
${ }^{1}$ This percentage is based on the number of fatal/injury crash percentage that occurred on the median treatment D2N.
} 


\begin{tabular}{|c|c|c|c|}
\hline & MVSD & $M V S D=Y L(A A D T)^{1.240} \exp (-12.400+0.033(R A L))$ & $P(F A T-I N J)=\frac{1}{1+\exp \left(\begin{array}{l}0.973-0.054(L N S)+0.00000243(A A D T)+ \\
0.013(P S L)+0.403(P T)-0.049(B R G)+ \\
0.026(R O F)-0.107(P V C)+0.115(P H C)\end{array}\right)}$ \\
\hline & MVOD & $M V O D=0$ & N/A \\
\hline \multirow{3}{*}{ D3H } & SV & $S V=Y L(A A D T)^{0.338} \exp (-1.862-0.027(H F))$ & $P(F A T-I N J)=\frac{1}{1+\exp (1.543+0.019(R O F)+0.033(R O N)-0.161(P H C)}$ \\
\hline & MVSD & $M V S D=Y L(A A D T)^{1.240} \exp (-12.400+0.033(R A L))$ & $P(F A T-I N J)=\frac{1}{1+\exp \left(\begin{array}{l}0.723-0.054(L N S)+0.00000243(A A D T)+ \\
0.013(P S L)+0.403(P T)-0.049(B R G)+ \\
0.026(R O F)-0.107(P V C)+0.115(P H C)\end{array}\right)}$ \\
\hline & MVOD & $M V O D=\frac{37.96(Y)(L)(A A D T)}{100,000,000}$ & $P(F A T-I N J)=0.311^{2}$ \\
\hline \multirow{3}{*}{ F1C } & SV & $S V=Y L(A A D T)^{0.577} \exp (-3.794+0.150(H R)+0.070(R O F)-0.166(I S W))$ & $P(F A T-I N J)=\frac{1}{1+\exp (1.212+0.019(R O F)+0.033(R O N)-0.161(P H C))}$ \\
\hline & MVSD & $M V S D=Y L(A A D T)^{1.254} \exp (-12.814+0.020(B R G))$ & $P(F A T-I N J)=\frac{1}{1+\exp \left(\begin{array}{l}0.210-0.054(L N S)+0.00000243(A A D T)+ \\
0.013(P S L)+0.403(P T)-0.049(B R G)+ \\
0.026(R O F)-0.107(P V C)+0.115(P H C)\end{array}\right)}$ \\
\hline & MVOD & MVOD $=0$ & N/A \\
\hline \multirow{3}{*}{$\mathrm{F} 2 \mathrm{C}$} & SV & $S V=Y L(A A D T)^{0.577} \exp (-3.794+0.150(H R)+0.070(R O F)-0.166(I S W))$ & $P(F A T-I N J)=\frac{1}{1+\exp (1.543+0.019(R O F)+0.033(R O N)-0.161(P H C)}$ \\
\hline & MVSD & $M V S D=Y L(A A D T)^{1.254} \exp (-12.814+0.020(B R G))$ & $P(F A T-I N J)=\frac{1}{1+\exp \left(\begin{array}{l}-0.723+0.054(L N S)-0.00000243(A A D T)+ \\
-0.013(P S L)-0.403(P T)+0.049(B R G)+ \\
-0.026(R O F)+0.107(P V C)-0.652(P H C)\end{array}\right)}$ \\
\hline & MVOD & MVOD $=0$ & N/A \\
\hline
\end{tabular}

\footnotetext{
${ }^{2}$ This percentage is based on the number of fatal/injury crashes occurring on median treatments of D3N.
} 


\section{STEP 1: Predict Single Vehicle (SV) Crashes for D2N}

The following equation should be used to predict the frequency of single vehicle crashes for this median treatment:

$$
S V=Y L(A A D T)^{0.577} \exp (-4.134+0.150(H R)+0.070(R O F)-0.166(I S W))
$$

Next, the result of equation (85) is split into severity categories. To do so, first, determine the value of $\beta_{\mathrm{FAT}-\mathrm{INJ}} \mathrm{X}_{\mathrm{FAT}-\mathrm{INJ}}$ using the following equation:

$$
\beta_{F A T-I N J} X_{F A T-I N J}=\left(\begin{array}{l}
-1.463-0.019(R O F)+ \\
-0.033(R O N)+0.161(P H C)
\end{array}\right) .
$$

The result of equation (86) is then inputted into the following equation to determine the probability of fatal-injury crashes, P(FAT-INJ):

$$
P(F A T-I N J)=\frac{1}{1+\exp \left(-\beta_{F A T-I N J} X_{F A T-I N J}\right)} .
$$

The probability of property damage only (PDO) crashes can then be found as follows: 


$$
P(P D O)=1-P(F A T-I N J)
$$

\section{STEP 2: Predict Multiple Vehicle - Same Direction (MVSD) Crashes for D2N}

The following equation should be used to predict the frequency of multiple

vehicle - same direction crashes for this median treatment:

$$
M V S D=Y L(A A D T)^{1.254} \exp (-12.663+0.020(B R G))
$$

Next, the result of equation (89) is split into severity categories. To do so, first, determine the value of $\beta_{\text {FAT-INJ }} \mathrm{X}_{\mathrm{FAT}-\mathrm{INJ}}$ using the following equation:

$$
\beta_{F A T-I N J} X_{F A T-I N J}=\left(\begin{array}{l}
-0.565+0.054(L N S)-0.00000243(A A D T)+ \\
-0.013(P S L)-0.403(P T)+0.049(B R G)+ \\
-0.026(R O F)+0.107(P V C)-0.115(P H C)
\end{array}\right)
$$

The result of equation (90) is then inputted into the following equation to

determine the probability of fatal-injury crashes, $\mathrm{P}(\mathrm{FAT}-\mathrm{INJ})$ :

$$
P(F A T-I N J)=\frac{1}{1+\exp \left(-\beta_{F A T-I N J} X_{F A T-I N J}\right)}
$$

The probability of property damage only (PDO) crashes can then be found as follows: 


$$
P(P D O)=1-P(F A T-I N J) .
$$

\section{STEP 3: Predict Multiple Vehicle - Opposite Direction (MVOD) Crashes for D2N}

The following equation should be used to predict the frequency of multiple vehicle - opposite direction crashes for this median treatment:

$$
M V O D=Y L(A A D T)^{0.465} \exp \left(\begin{array}{l}
-4.034+0.016(P S L)-0.129(I S W)+ \\
0.060(H R)+0.027(R O N)
\end{array}\right)
$$

Next, the result of equation (93) is split into severity categories. To do so, first, determine the value of $\beta_{\mathrm{FAT}-\mathrm{INJ}} \mathrm{X}_{\mathrm{FAT}-\mathrm{INJ}}$ using the following equation:

$$
\beta_{F A T-I N J} X_{F A T-I N J}=\left(\begin{array}{l}
-0.125+0.184(L N S)+0.00000679(A A D T)+ \\
0.335(P V C)-1.081(R O F)+0.968(R O N)
\end{array}\right) .
$$

The result of equation (94) is then inputted into the following equation to determine the probability of fatal-injury crashes, P(FAT-INJ):

$$
P(F A T-I N J)=\frac{1}{1+\exp \left(-\beta_{F A T-I N J} X_{F A T-I N J}\right)} .
$$

The probability of property damage only (PDO) crashes can then be found as follows: 


$$
P(P D O)=1-P(F A T-I N J) .
$$

\subsubsection{Depressed, Wide Median, No Median Barrier (D3N)}

\section{STEP 1: Predict Single Vehicle (SV) Crashes for D3N}

The following equation should be used to predict the frequency of single vehicle crashes for this median treatment:

$$
S V=Y L(A A D T)^{0.338} \exp (-2.202-0.027(H F))
$$

Next, the result of equation (97) is split into severity categories. To do so, first, determine the value of $\beta_{\mathrm{FAT}-\mathrm{INJ}} \mathrm{X}_{\mathrm{FAT}-\mathrm{INJ}}$ using the following equation:

$$
\beta_{F A T-I N J} X_{F A T-I N J}=\left(\begin{array}{l}
-1.543-0.019(R O F)+ \\
-0.033(R O N)+0.161(P H C)
\end{array}\right) .
$$

The result of equation (98) is then inputted into the following equation to determine the probability of fatal-injury crashes, P(FAT-INJ): 


$$
P(F A T-I N J)=\frac{1}{1+\exp \left(-\beta_{F A T-I N J} X_{F A T-I N J}\right)} .
$$

The probability of property damage only (PDO) crashes can then be found as follows:

$$
P(P D O)=1-P(F A T-I N J) .
$$

\section{STEP 2: Predict Multiple Vehicle - Same Direction (MVSD) Crashes for D3N}

The following equation should be used to predict the frequency of multiple vehicle - same direction crashes for this median treatment:

$$
M V S D=Y L(A A D T)^{1.240} \exp (-12.249+0.033(R A L))
$$

Next, the result of equation (101) is split into severity categories. To do so, first, determine the value of $\beta_{\mathrm{FAT}-\mathrm{INJ}} \mathrm{X}_{\mathrm{FAT}-\mathrm{INJ}}$ using the following equation:

$$
\beta_{F A T-I N J} X_{F A T-I N J}=\left(\begin{array}{l}
-0.565+0.054(L N S)-0.00000243(A A D T)+ \\
-0.013(P S L)-0.403(P T)+0.049(B R G)+ \\
-0.026(R O F)+0.107(P V C)-0.115(P H C)
\end{array}\right) .
$$

The result of equation (102) is then inputted into the following equation to determine the probability of fatal-injury crashes, P(FAT-INJ): 


$$
P(F A T-I N J)=\frac{1}{1+\exp \left(-\beta_{F A T-I N J} X_{F A T-I N J}\right)} .
$$

The probability of property damage only (PDO) crashes can then be found as follows:

$$
P(P D O)=1-P(F A T-I N J) .
$$

\section{STEP 3: Predict Multiple Vehicle - Opposite Direction (MVOD) Crashes for D3N}

The following equation should be used to predict the frequency of multiple vehicle - opposite direction crashes for this median treatment:

$$
M V O D=Y L(A A D T)^{0.465} \exp \left(\begin{array}{l}
-4.433+0.016(P S L)-0.036(I S W)+ \\
0.060(H R)+0.027(R O N)
\end{array}\right)
$$

Next, the result of equation (105) is split into severity categories. To do so, first, determine the value of $\beta_{\mathrm{FAT}-\mathrm{INJ}} \mathrm{X}_{\mathrm{FAT}-\mathrm{INJ}}$ using the following equation:

$$
\beta_{F A T-I N J} X_{F A T-I N J}=\left(\begin{array}{l}
-0.669+0.184(L N S)+ \\
0.00000679(A A D T)+0.335(P V C)
\end{array}\right) .
$$

The result of equation (106) is then inputted into the following equation to determine the probability of fatal-injury crashes, P(FAT-INJ): 


$$
P(F A T-I N J)=\frac{1}{1+\exp \left(-\beta_{F A T-I N J} X_{F A T-I N J}\right)} .
$$

The probability of property damage only (PDO) crashes can then be found as follows:

$$
P(P D O)=1-P(F A T-I N J) .
$$

8.3.3 Depressed with Berms, Wide Median, No Median Barrier (C3N)

\section{STEP 1: Predict Single Vehicle (SV) Crashes for C3N}

The following equation should be used to predict the frequency of single vehicle crashes for this median treatment:

$$
S V=Y L(A A D T)^{0.196} \exp (-0.899+0.279(H R))
$$

Next, the result of equation (109) is split into severity categories. To do so, first, determine the value of $\beta_{\mathrm{FAT}-\mathrm{INJ}} \mathrm{X}_{\mathrm{FAT}-\mathrm{INJ}}$ using the following equation:

$$
\beta_{F A T-I N J} X_{F A T-I N J}=\left(\begin{array}{l}
-1.337-0.019(R O F)+ \\
-0.033(R O N)-0.172(P H C)
\end{array}\right) .
$$


The result of equation (110) is then inputted into the following equation to determine the probability of fatal-injury crashes, P(FAT-INJ):

$$
P(F A T-I N J)=\frac{1}{1+\exp \left(-\beta_{F A T-I N J} X_{F A T-I N J}\right)} .
$$

The probability of property damage only (PDO) crashes can then be found as follows:

$$
P(P D O)=1-P(F A T-I N J) .
$$

\section{STEP 2: Predict Multiple Vehicle - Same Direction (MVSD) Crashes}

The following equation should be used to predict the frequency of multiple vehicle - same direction crashes for this median treatment:

$$
M V S D=Y L(A A D T)^{1.194} \exp (-11.996+0.224(R O N)+0.210(H R))
$$

Next, the result of equation (113) is split into severity categories. To do so, first, determine the value of $\beta_{\mathrm{FAT}-\mathrm{INJ}} \mathrm{X}_{\mathrm{FAT}-\mathrm{INJ}}$ using the following equation: 


$$
\beta_{F A T-I N J} X_{F A T-I N J}=\left(\begin{array}{l}
-0.565+0.054(L N S)-0.00000243(A A D T)+ \\
-0.013(P S L)-0.403(P T)+0.049(B R G)+ \\
-0.026(R O F)+0.464(P V C)-0.115(P H C)
\end{array}\right) .
$$

The result of equation (114) is then inputted into the following equation to determine the probability of fatal-injury crashes, P(FAT-INJ):

$$
P(F A T-I N J)=\frac{1}{1+\exp \left(-\beta_{F A T-I N J} X_{F A T-I N J}\right)} .
$$

The probability of property damage only (PDO) crashes can then be found as follows:

$$
P(P D O)=1-P(F A T-I N J) .
$$

\section{STEP 3: Predict Multiple Vehicle - Opposite Direction (MVOD) Crashes for C3N}

The following equation should be used to predict the frequency of multiple vehicle - opposite direction crashes for this median treatment:

$$
M V O D=Y L(A A D T)^{0.465} \exp \left(\begin{array}{l}
-4.433+0.016(P S L)-0.036(I S W)+ \\
0.060(H R)+0.027(R O N)
\end{array}\right)
$$

Next, the result of equation (117) is split into severity categories. To do so, first, determine the value of $\beta_{\mathrm{FAT}-\mathrm{INJ}} \mathrm{X}_{\mathrm{FAT}-\mathrm{INJ}}$ using the following equation: 


$$
\beta_{F A T-I N J} X_{F A T-I N J}=\left(\begin{array}{l}
-0.669+0.184(L N S)+ \\
0.00000679(A A D T)+0.335(P V C)
\end{array}\right) .
$$

The result of equation (118) is then inputted into the following equation to determine the probability of fatal-injury crashes, P(FAT-INJ):

$$
P(F A T-I N J)=\frac{1}{1+\exp \left(-\beta_{F A T-I N J} X_{F A T-I N J}\right)} .
$$

The probability of property damage only (PDO) crashes can then be found as follows:

$$
P(P D O)=1-P(F A T-I N J) .
$$

\subsubsection{Berms, Wide Median, No Median Barrier (B3N)}

\section{STEP 1: Predict Single Vehicle (SV) Crashes for B3N}

The following equation should be used to predict the frequency of single vehicle crashes for this median treatment:

$$
S V=Y L(A A D T)^{0.620} \exp (-5.127+0.062(V K))
$$


Next, the result of equation (121) is split into severity categories. To do so, first, determine the value of $\beta_{\mathrm{FAT}-\mathrm{INJ}} \mathrm{X}_{\mathrm{FAT}-\mathrm{INJ}}$ using the following equation:

$$
\beta_{F A T-I N J} X_{F A T-I N J}=\left(\begin{array}{l}
-1.543-0.019(R O F)+ \\
-0.033(R O N)+0.161(P H C)
\end{array}\right) .
$$

The result of equation (122) is then inputted into the following equation to determine the probability of fatal-injury crashes, P(FAT-INJ):

$$
P(F A T-I N J)=\frac{1}{1+\exp \left(-\beta_{F A T-I N J} X_{F A T-I N J}\right)} .
$$

The probability of property damage only (PDO) crashes can then be found as follows:

$$
P(P D O)=1-P(F A T-I N J) .
$$

\section{STEP 2: Predict Multiple Vehicle - Same Direction (MVSD) Crashes for B3N}

The following equation should be used to predict the frequency of multiple vehicle - same direction crashes for this median treatment:

$$
M V S D=Y L(A A D T)^{1.619} \exp (-16.015+0.144(R O N))
$$


Next, the result of equation (125) is split into severity categories. To do so, first, determine the value of $\beta_{\mathrm{FAT}-\mathrm{INJ}} \mathrm{X}_{\mathrm{FAT}-\mathrm{INJ}}$ using the following equation:

$$
\beta_{F A T-I N J} X_{F A T-I N J}=\left(\begin{array}{l}
-0.566+0.054(L N S)-0.00000243(A A D T)+ \\
-0.013(P S L)-0.403(P T)+0.049(B R G)+ \\
0.086(R O F)-0.087(R O N)+0.107(P V C)+ \\
-0.115(P H C)
\end{array}\right) .
$$

The result of equation (126) is then inputted into the following equation to determine the probability of fatal-injury crashes, P(FAT-INJ):

$$
P(F A T-I N J)=\frac{1}{1+\exp \left(-\beta_{F A T-I N J} X_{F A T-I N J}\right)} .
$$

The probability of property damage only (PDO) crashes can then be found as follows:

$$
P(P D O)=1-P(F A T-I N J) .
$$

\section{STEP 3: Predict Multiple Vehicle - Opposite Direction (MVOD) Crashes for B3N}

The following equation should be used to predict the frequency of multiple vehicle - opposite direction crashes for this median treatment: 


$$
M V O D=Y L(A A D T)^{0.465} \exp \left(\begin{array}{l}
-4.433+0.016(P S L)-0.036(I S W)+ \\
0.060(H R)+0.027(R O N)
\end{array}\right)
$$

Next, the result of equation (129) is split into severity categories. To do so, first, determine the value of $\beta_{\mathrm{FAT}-\mathrm{INJ}} \mathrm{X}_{\mathrm{FAT}-\mathrm{INJ}}$ using the following equation:

$$
\beta_{F A T-I N J} X_{F A T-I N J}=\left(\begin{array}{l}
-0.6691+0.1836(L N S)+ \\
0.00000679(A A D T)+0.3346(P V C)
\end{array}\right)
$$

The result of equation (130) is then inputted into the following equation to determine the probability of fatal-injury crashes, P(FAT-INJ):

$$
P(F A T-I N J)=\frac{1}{1+\exp \left(-\beta_{F A T-I N J} X_{F A T-I N J}\right)}
$$

The probability of property damage only (PDO) crashes can then be found as follows:

$$
P(P D O)=1-P(F A T-I N J)
$$

8.3.5 Sloped, Wide Median, No Median Barrier (S3N)

\section{STEP 1: Predict Single Vehicle (SV) Crashes for S3N}


The following equation should be used to predict the frequency of single vehicle crashes for this median treatment:

$$
S V=Y L(A A D T)^{0.596} \exp (-4.960+0.333(H R))
$$

Next, the result of equation (133) is split into severity categories. To do so, first, determine the value of $\beta_{\mathrm{FAT}-\mathrm{INJ}} \mathrm{X}_{\mathrm{FAT}-\mathrm{INJ}}$ using the following equation:

$$
\beta_{F A T-I N J} X_{F A T-I N J}=\left(\begin{array}{l}
-1.716-0.019(R O F)+ \\
-0.033(R O N)+0.161(P H C)
\end{array}\right) .
$$

The result of equation (134) is then inputted into the following equation to determine the probability of fatal-injury crashes, P(FAT-INJ):

$$
P(F A T-I N J)=\frac{1}{1+\exp \left(-\beta_{F A T-I N J} X_{F A T-I N J}\right)} .
$$

The probability of property damage only (PDO) crashes can then be found as follows:

$$
P(P D O)=1-P(F A T-I N J)
$$




\section{STEP 2: Predict Multiple Vehicle - Same Direction (MVSD) Crashes for S3N}

The following equation should be used to predict the frequency of multiple vehicle - same direction crashes for this median treatment:

$$
M V S D=Y L(A A D T)^{1.329} \exp (-13.201+0.095(R O N))
$$

Next, the result of equation (137) is split into severity categories. To do so, first, determine the value of $\beta_{\mathrm{FAT}-\mathrm{INJ}} \mathrm{X}_{\mathrm{FAT}-\mathrm{INJ}}$ using the following equation:

$$
\beta_{F A T-I N J} X_{F A T-I N J}=\left(\begin{array}{l}
-0.365+0.054(L N S)+ \\
-0.00000243(A A D T)-0.013(P S L)+ \\
-0.403(P T)+0.049(B R G)+ \\
0.107(P V C)-0.115(P H C)+ \\
0.086(R O F)-0.087(R O N)
\end{array}\right) .
$$

The result of equation (138) is then inputted into the following equation to determine the probability of fatal-injury crashes, P(FAT-INJ):

$$
P(F A T-I N J)=\frac{1}{1+\exp \left(-\beta_{F A T-I N J} X_{F A T-I N J}\right)}
$$

The probability of property damage only (PDO) crashes can then be found as follows: 


$$
P(P D O)=1-P(F A T-I N J) .
$$

\section{STEP 3: Predict Multiple Vehicle - Opposite Direction (MVOD) Crashes for S3N}

The following equation should be used to predict the frequency of multiple vehicle - opposite direction crashes for this median treatment:

$$
M V O D=Y L(A A D T)^{0.465} \exp \left(\begin{array}{l}
-4.433+0.016(P S L)-0.036(I S W)+ \\
0.060(H R)+0.027(R O N)
\end{array}\right)
$$

Next, the result of equation (141) is split into severity categories. To do so, first, determine the value of $\beta_{\mathrm{FAT}-\mathrm{INJ}} \mathrm{X}_{\mathrm{FAT}-\mathrm{INJ}}$ using the following equation:

$$
\beta_{F A T-I N J} X_{F A T-I N J}=\left(\begin{array}{l}
-0.669+0.184(L N S)+ \\
0.00000679(A A D T)+0.335(P V C)
\end{array}\right) .
$$

The result of equation (142) is then inputted into the following equation to determine the probability of fatal-injury crashes, P(FAT-INJ):

$$
P(F A T-I N J)=\frac{1}{1+\exp \left(-\beta_{F A T-I N J} X_{F A T-I N J}\right)} .
$$

The probability of property damage only (PDO) crashes can then be found as follows: 


$$
P(P D O)=1-P(F A T-I N J)
$$

8.3.6 Depressed, Intermediate Median, Low-Tensioned Cable Median Barrier (D2L)

\section{STEP 1: Predict Single Vehicle (SV) Crashes for D2L}

The following equation should be used to predict the frequency of single vehicle crashes for this median treatment:

$$
S V=Y L(A A D T)^{0.577} \exp (-3.794+0.150(H R)+0.070(R O F)-0.166(I S W))
$$

Next, the result of equation (145) is split into severity categories. To do so, first, determine the value of $\beta_{\mathrm{FAT}-\mathrm{INJ}} \mathrm{X}_{\mathrm{FAT}-\mathrm{INJ}}$ using the following equation:

$$
\beta_{F A T-I N J} X_{F A T-I N J}=\left(\begin{array}{l}
-2.100+0.161(P H C)+ \\
-0.922(R O F)+0.882(R O N)
\end{array}\right) .
$$

The result of equation (146) is then inputted into the following equation to determine the probability of fatal-injury crashes, P(FAT-INJ):

$$
P(F A T-I N J)=\frac{1}{1+\exp \left(-\beta_{F A T-I N J} X_{F A T-I N J}\right)} .
$$


The probability of property damage only (PDO) crashes can then be found as follows:

$$
P(P D O)=1-P(F A T-I N J)
$$

\section{STEP 2: Predict Multiple Vehicle - Same Direction (MVSD) Crashes for D2L}

The following equation should be used to predict the frequency of multiple vehicle - same direction crashes for this median treatment:

$$
M V S D=Y L(A A D T)^{1.254} \exp (-12.814+0.020(B R G))
$$

Next, the result of equation Error! Reference source not found. is split into severity categories. To do so, first, determine the value of $\beta_{\text {FAT-INJ }} \mathrm{X}_{\mathrm{FAT}-\mathrm{INJ}}$ using the following equation:

$$
\beta_{F A T-I N J} X_{F A T-I N J}=\left(\begin{array}{l}
-0.3043+0.0542(L N S)-0.00000243(A A D T)+ \\
-0.0128(P S L)-0.4034(P T)-0.9362(B R G)+ \\
-0.0264(R O F)+0.9658(P V C)-0.1151(P H C)
\end{array}\right)
$$

The result of equation (150) is then inputted into the following equation to determine the probability of fatal-injury crashes, P(FAT-INJ): 


$$
P(F A T-I N J)=\frac{1}{1+\exp \left(-\beta_{F A T-I N J} X_{F A T-I N J}\right)} .
$$

The probability of property damage only (PDO) crashes can then be found as follows:

$$
P(P D O)=1-P(F A T-I N J) .
$$

\section{STEP 3: Predict Multiple Vehicle - Opposite Direction (MVOD) Crashes for D2L}

The following equation should be used to predict the frequency of multiple vehicle - opposite direction crashes for this median treatment:

$$
M V O D=\frac{22.63(Y)(L)(A A D T)}{100,000,000}
$$

Next, the result of equation (153) is split into severity categories. Individual equations were not developed to predict the severity of crashes for this median treatment due to the low frequency of such crashes. As such, the probability of fatal or injury crashes was determined by dividing the number of fatal or injury crashes for the D2N median treatment by the total number of crashes for the D2N median treatment. This resulted in a $\mathrm{P}(\mathrm{FAT}-\mathrm{INJ})=0.304$. 


\section{STEP 1: Predict Single Vehicle (SV) Crashes for D3L}

The following equation should be used to predict the frequency of single vehicle crashes for this median treatment:

$$
S V=Y L(A A D T)^{0.338} \exp (-1.862-0.027(H F))
$$

Next, the result of equation (154) is split into severity categories. To do so, first, determine the value of $\beta_{\mathrm{FAT}-\mathrm{INJ}} \mathrm{X}_{\mathrm{FAT}-\mathrm{INJ}}$ using the following equation:

$$
\beta_{F A T-I N J} X_{F A T-I N J}=\left(\begin{array}{l}
-2.000-0.019(R O F)-0.033(R O N)+ \\
1.438(P H C)+0.694(P V C)
\end{array}\right) .
$$

The result of equation (155) is then inputted into the following equation to determine the probability of fatal-injury crashes, P(FAT-INJ):

$$
P(F A T-I N J)=\frac{1}{1+\exp \left(-\beta_{F A T-I N J} X_{F A T-I N J}\right)} .
$$

The probability of property damage only (PDO) crashes can then be found as follows:

$$
P(P D O)=1-P(F A T-I N J)
$$




\section{STEP 2: Predict Multiple Vehicle - Same Direction (MVSD) Crashes for D3L}

The following equation should be used to predict the frequency of multiple vehicle - same direction crashes for this median treatment:

$$
M V S D=Y L(A A D T)^{1.240} \exp (-12.400+0.033(R A L))
$$

Next, the result of equation (158) is split into severity categories. To do so, first, determine the value of $\beta_{\mathrm{FAT}-\mathrm{INJ}} \mathrm{X}_{\mathrm{FAT}-\mathrm{INJ}}$ using the following equation:

$$
\beta_{F A T-I N J} X_{F A T-I N J}=\left(\begin{array}{l}
-0.9730+0.0542(L N S)-0.00000243(A A D T)+ \\
-0.0128(P S L)-0.4034(P T)+0.0494(B R G)+ \\
-0.0264(R O F)+0.1070(P V C)-0.1151(P H C)
\end{array}\right)
$$

The result of equation (159) is then inputted into the following equation to determine the probability of fatal-injury crashes, $\mathrm{P}(\mathrm{FAT}-\mathrm{INJ})$ :

$$
P(F A T-I N J)=\frac{1}{1+\exp \left(-\beta_{F A T-I N J} X_{F A T-I N J}\right)}
$$

The probability of property damage only (PDO) crashes can then be found as follows: 


$$
P(P D O)=1-P(F A T-I N J) .
$$

STEP 3: Predict Multiple Vehicle - Opposite Direction (MVOD) Crashes for D3L

There were no multiple vehicle - opposite direction crashes for this median treatment. As a result, the predicted frequency of this type of crash is 0 .

8.3.8 Depressed, Wide Median, High-Tensioned Cable Median Barrier (D3H)

\section{STEP 1: Predict Single Vehicle (SV) Crashes for D3H}

The following equation should be used to predict the frequency of single vehicle crashes for this median treatment:

$$
S V=Y L(A A D T)^{0.338} \exp (-1.862-0.027(H F))
$$

Next, the result of equation (162) is split into severity categories. To do so, first, determine the value of $\beta_{\mathrm{FAT}-\mathrm{INJ}} \mathrm{X}_{\mathrm{FAT}-\mathrm{INJ}}$ using the following equation:

$$
\beta_{F A T-I N J} X_{F A T-I N J}=\left(\begin{array}{l}
-1.543-0.019(R O F)+ \\
-0.033(R O N)+0.161(P H C)
\end{array}\right) .
$$

The result of equation (163) is then inputted into the following equation to determine the probability of fatal-injury crashes, P(FAT-INJ): 


$$
P(F A T-I N J)=\frac{1}{1+\exp \left(-\beta_{F A T-I N J} X_{F A T-I N J}\right)} .
$$

The probability of property damage only (PDO) crashes can then be found as follows:

$$
P(P D O)=1-P(F A T-I N J) .
$$

\section{STEP 2: Predict Multiple Vehicle - Same Direction (MVSD) Crashes for D3H}

The following equation should be used to predict the frequency of multiple vehicle - same direction crashes for this median treatment:

$$
M V S D=Y L(A A D T)^{1.240} \exp (-12.400+0.033(R A L))
$$

Next, the result of equation (166) is split into severity categories. To do so, first, determine the value of $\beta_{\mathrm{FAT}-\mathrm{INJ}} \mathrm{X}_{\mathrm{FAT}-\mathrm{INJ}}$ using the following equation:

$$
\beta_{F A T-I N J} X_{F A T-I N J}=\left(\begin{array}{l}
-0.7230+0.0542(L N S)-0.00000243(A A D T)+ \\
-0.0128(P S L)-0.4034(P T)+0.0494(B R G)+ \\
-0.0264(R O F)+0.1070(P V C)-0.1151(P H C)
\end{array}\right) .
$$


The result of equation (167) is then inputted into the following equation to determine the probability of fatal-injury crashes, P(FAT-INJ):

$$
P(F A T-I N J)=\frac{1}{1+\exp \left(-\beta_{F A T-I N J} X_{F A T-I N J}\right)} .
$$

The probability of property damage only (PDO) crashes can then be found as follows:

$$
P(P D O)=1-P(F A T-I N J) .
$$

\section{STEP 3: Predict Multiple Vehicle - Opposite Direction (MVOD) Crashes for D3H}

The following equation should be used to predict the frequency of multiple vehicle - opposite direction crashes for this median treatment:

$$
M V O D=\frac{37.96(Y)(L)(A A D T)}{100,000,000}
$$

Next, the result of equation (170) is split into severity categories. Individual equations were not developed to predict the severity of crashes for this median treatment due to the low frequency of such crashes. As such, the probability of fatal or injury crashes was determined by dividing the number of fatal or injury crashes for the D2N median treatment by the total number of crashes for the D2N median treatment. This resulted in a $\mathrm{P}(\mathrm{FAT}-\mathrm{INJ})=0.311$. 


\section{STEP 1: Predict Single Vehicle (SV) Crashes for F1C}

The following equation should be used to predict the frequency of single vehicle crashes for this median treatment:

$$
S V=Y L(A A D T)^{0.577} \exp (-3.794+0.150(H R)+0.070(R O F)-0.166(I S W))
$$

Next, the result of equation (171) is split into severity categories. To do so, first, determine the value of $\beta_{\text {FAT-INJ }} \mathrm{X}_{\mathrm{FAT}-\mathrm{INJ}}$ using the following equation:

$$
\beta_{F A T-I N J} X_{F A T-I N J}=\left(\begin{array}{l}
-1.212-0.019(R O F)+ \\
-0.033(R O N)+0.161(P H C)
\end{array}\right) .
$$

The result of equation (172) is then inputted into the following equation to determine the probability of fatal-injury crashes, P(FAT-INJ):

$$
P(F A T-I N J)=\frac{1}{1+\exp \left(-\beta_{F A T-I N J} X_{F A T-I N J}\right)} .
$$

The probability of property damage only (PDO) crashes can then be found as follows: 


$$
P(P D O)=1-P(F A T-I N J) .
$$

STEP 2: Predict Multiple Vehicle - Same Direction (MVSD) Crashes for F1C

The following equation should be used to predict the frequency of multiple vehicle - same direction crashes for this median treatment:

$$
M V S D=Y L(A A D T)^{1.254} \exp (-12.814+0.020(B R G))
$$

Next, the result of equation (175) is split into severity categories. To do so, first, determine the value of $\beta_{\mathrm{FAT}-\mathrm{INJ}} \mathrm{X}_{\mathrm{FAT}-\mathrm{INJ}}$ using the following equation:

$$
\beta_{F A T-I N J} X_{F A T-I N J}=\left(\begin{array}{l}
-0.210+0.054(L N S)-0.00000243(A A D T)+ \\
-0.013(P S L)-0.403(P T)+0.049(B R G)+ \\
-0.026(R O F)+0.107(P V C)-0.115(P H C)
\end{array}\right) .
$$

The result of equation (176) is then inputted into the following equation to determine the probability of fatal-injury crashes, P(FAT-INJ):

$$
P(F A T-I N J)=\frac{1}{1+\exp \left(-\beta_{F A T-I N J} X_{F A T-I N J}\right)} .
$$


The probability of property damage only (PDO) crashes can then be found as follows:

$$
P(P D O)=1-P(F A T-I N J)
$$

\section{STEP 3: Predict Multiple Vehicle - Opposite Direction (MVOD) Crashes for F1C}

No multiple vehicle - opposite direction crashes were found to occur on segments with barriers. As such, the expected frequency for F1C of MVOD crashes is 0.

\subsubsection{Flush, Intermediate Median, Concrete Median Barrier (F2C)}

\section{STEP 1: Predict Single Vehicle (SV) Crashes for F2C}

The following equation should be used to predict the frequency of single vehicle crashes for this median treatment:

$$
S V=Y L(A A D T)^{0.577} \exp (-3.794+0.150(H R)+0.070(R O F)-0.166(I S W))
$$

Next, the result of equation (179) is split into severity categories. To do so, first, determine the value of $\beta_{\mathrm{FAT}-\mathrm{INJ}} \mathrm{X}_{\mathrm{FAT}-\mathrm{INJ}}$ using the following equation:

$$
\beta_{F A T-I N J} X_{F A T-I N J}=\left(\begin{array}{l}
-1.543-0.019(R O F)+ \\
-0.033(R O N)+0.161(P H C)
\end{array}\right) .
$$


The result of equation (180) is then inputted into the following equation to determine the probability of fatal-injury crashes, P(FAT-INJ):

$$
P(F A T-I N J)=\frac{1}{1+\exp \left(-\beta_{F A T-I N J} X_{F A T-I N J}\right)} .
$$

The probability of property damage only (PDO) crashes can then be found as follows:

$$
P(P D O)=1-P(F A T-I N J) .
$$

\section{STEP 2: Predict Multiple Vehicle - Same Direction (MVSD) Crashes for F2C}

The following equation should be used to predict the frequency of multiple vehicle - same direction crashes for this median treatment:

$$
M V S D=Y L(A A D T)^{1.254} \exp (-12.814+0.020(B R G))
$$

Next, the result of equation (183) is split into severity categories. To do so, first, determine the value of $\beta_{\mathrm{FAT}-\mathrm{INJ}} \mathrm{X}_{\mathrm{FAT}-\mathrm{INJ}}$ using the following equation: 


$$
\beta_{F A T-I N J} X_{F A T-I N J}=\left(\begin{array}{l}
-0.723+0.054(L N S)-0.00000243(A A D T)+ \\
-0.013(P S L)-0.403(P T)+0.049(B R G)+ \\
-0.026(R O F)+0.107(P V C)-0.652(P H C)
\end{array}\right) .
$$

The result of equation (184) is then inputted into the following equation to determine the probability of fatal-injury crashes, P(FAT-INJ):

$$
P(F A T-I N J)=\frac{1}{1+\exp \left(-\beta_{F A T-I N J} X_{F A T-I N J}\right)} .
$$

The probability of property damage only (PDO) crashes can then be found as follows:

$$
P(P D O)=1-P(F A T-I N J) .
$$

\section{STEP 3: Predict Multiple Vehicle - Opposite Direction (MVOD) Crashes for F2C}

No multiple vehicle - opposite direction crashes were found to occur on segments with barriers. As such, the expected frequency for F2C of MVOD crashes is 0 .

CHAPTER 9: OTHER STATES EXPERIENCE WITH CABLE BARRIERS

\subsection{Low-Tensioned Cable Barriers}


Prior to when high-tensioned cables gained popularity, low-tensioned cable barriers were primarily used as an alternative to concrete or w-beam barriers. New York was one of the first states to use this type of system in the United States. Other states, such as North Carolina, Oregon, Iowa, Washington and Wisconsin have this type of barrier installed. North Carolina, Washington, Wisconsin and Oregon identified the areas where the low-tensioned cable barrier was originally installed as high-hazard areas. California did install this barrier type at one time, but had since discontinued use of the barrier (Hunter et al., 2001). In fact, they removed this barrier from locations where it was installed. The following are lessons learned when considering the installation and maintenance of these systems.

\subsubsection{Benefits}

Low-tensioned cable barriers have gained popularity based on several attractive features of the barrier system. First, they are more aesthetically pleasing (Sposito et al., 1998; McClanahan et al., 2003). Many drivers do no even notice the presence of cable barrier systems. They are not as imposing as concrete barriers or w-beam. As such, this leads to the next appealing aspect of this barrier type: it does not impede sight distance

(Albin et al., 2001; Sposito et al., 1998). Third, they are considered a low-cost alternative (McClanahan et al., 2003). See the following section a cost comparison between lowtensioned cable barriers and traditional barrier types. Fourth, the installation of these barriers does not increase the impervious area like the installation of concrete barriers does. Therefore, no environmental mitigation is needed (McClanahan et al., 2003). 
Fifth, the force on the occupants is minimal due to the flexible nature of the lowtensioned cable barrier (Albin et al., 2001; Sposito et al., 1998). Finally, most of the system can be extracted and utilized from one site to another (McClanahan et al., 2003).

\subsubsection{Disadvantages}

There are several disadvantages associated with this barrier type. First, the barrier damage is typically increased when compared to other barrier types (Sposito et al., 1998). Second, damaged sections need to be repaired soon after the incident occurred because the area will otherwise remain ineffective (Sposito et al., 1998). This is the considered to be the primary distinction between low-tensioned and high-tensioned cable barriers. Thirdly, a minimum clear zone is required to allow for the cable to deflect (Sposito et al., 1998). Fourthly, this type of barrier is NOT designed to contain large vehicles, such as multi-axle trucks. Finally, periodic retensioning of the cables is required (Sposito et al., 1998).

\subsubsection{Installation}

The installation costs for low-tensioned cable barriers have been shown to be substantially less than that for other barrier alternatives. Table 8.11 below shows the 2003 prices as found in a report by the Washington Department of Transportation. 
Table 9.1 Barrier Installation Costs (McClanahan et al., 2003)

\begin{tabular}{|c|c|c|}
\hline & \multicolumn{2}{|c|}{ State Average Bid Price } \\
\hline Barrier Type & $\$ /$ foot & $\$ /$ mile \\
\hline Low-tensioned cable barrier & 8.33 & 44,000 \\
\hline W-beam guardrail & 13.65 & 72,000 \\
\hline Precast concrete barrier & 24.64 & 130,000 \\
\hline Single Slope concrete barrier & 44.94 & 237,000 \\
\hline Cast in Place concrete barrier & 79.36 & 419,000 \\
\hline
\end{tabular}

The Washington Department of Transportation suggests that barrier runs are limited to 2000 feet between terminals.

The Oregon Department of Transportation suggests that cable guardrails should not be used where sharp curves or curbs exist (Sposito et al., 1998).

It is not recommended that the low-tensioned cable barrier be installed in a location where it will be hit frequently (Sposito et al., 1998).

\subsubsection{Median Grades}

No mention was made in the various reports on low-tensioned cable barriers about the affects of the median grade.

\subsubsection{Median Placement}


A study by the Oregon Department of Transportation advises that low-tensioned cable barriers be installed only in medians where the median width is greater than 23 feet (Sposito et al., 1998).

\subsubsection{Maintenance}

A primary aspect that was highlighted on reports on low-tensioned cable barrier is that an adequate stocking of parts should be maintained (McClanahan et al., 2003). In fact, reports highlighted that several repairs could not be made, although the man-power was available, due to waiting for parts to be delivered. In particular, a stock of bolts, posts, etc. should be maintained.

Highlighted both in a study by the Iowa Department of Transportation with regards to high-tensioned cable barriers, and in a study by the Washington Department of Transportation and in a study by the Oregon Department of Transportation on lowtensioned cable barriers, a wide inside shoulder brings significant benefits to executing repairs needed on the barriers (Sposito et al., 1998; McClanahan et al., 2003). This allows for the maintenance personnel to repair the barriers without having to close lanes.

The following are a list of equipment that is suggested for repair of low-tensioned cable barriers (Sposito et al., 1998):

- One truck-mounted hydraulic crane

- One portable hydraulic hammer

- One four-wheel drive truck with winch (tensioned cables) 
- One truck mounted impact attenuator

- Traffic-cones and proper road work signs, and

- Hand wrenches to tighten the J-bolts that attach the cables to the line posts

The Washington Department of Transportation and Oregon Department of Transportation had two alternative approaches to fixing the cable barriers. The former had the barriers repair in-house. They cited 2 days at the average time to repair damages to the cables (McClanahan et al., 2003). The Oregon Department of Transportation, on the other hand, originally had out-sourced the work. It should be highlighted that they acknowledged the need for a faster repair of damaged barrier segments. They reported an average time between reporting of barrier damage and repair as 30 days. The primary delay to repair time was cited as the contractor that was contracted to repair the work was "very busy with other construction projects" (Sposito et al., 1998).

\subsubsection{Crash Considerations}

Low-tensioned cable barriers are a flexible barrier. As such, it is not surprising that both the Oregon Department of Transportation and the Washington Department of Transportation reported that only $51 \%$ of repairs documented by maintenance personnel could be matched with an accident report (Sposito et al., 1998; McClanahan et al., 2003). 
These values are very consistent with a previous study which found that $54 \%$ of crashes with cable barriers were reported.

One study noted that one of the two crashes which struck a barrier terminal resulted in an injury (McClanahan et al., 2003).

\subsection{High-Tensioned Cable Barriers}

Several states have begun to utilize high-tensioned cable barrier systems as a new median barrier treatment. Colorado, Iowa, Ohio and Utah have created reports that describe each respective state's experience with the high-tensioned cable system. The following are lessons learned when considering the installation and maintenance of these systems.

\subsubsection{Installation}

A concrete socketed foundation is suggested if the high-tensioned cable barriers are to a long-term installation. When installing these foundations, there are several important aspects to consider. First, the top of post and anchor foundations should match the finished grade of the slope. Second, soil compaction requirements and details around the anchor foundations should be clarified in specifications and standard drawings (Sharp, 2005). The Ohio Department of Transportation had an issue with one of its concrete foundations being pulled out of the ground. They noted that it was not built to the manufacturer's specifications of a 12 inch diameter and 36 inch reinforced foundation 
(Ohio DOT, 2005). In locations where frost is a concern, it is suggested that the depth of the concrete be at least 42 inches (Stein, 2005).

A guardrail-drilling rig has been found to be useful for boring the holes for the foundations (Sharp, 2005). The contractor for the Iowa Department of Transportation originally tried to drive the holes and damaged the HMA pavement. Therefore, they chose to drill the holes instead. The consensus seems to be to drill the holes. Even so, the Iowa Department of Transportation found sound difficulties when drilling the holes for the foundations. They installed the cable barrier on the edge of a wide shoulder, and during the drilling, the contractor had difficulty when trying to drill through the angled edge of the HMA shoulder. They also suggest requiring the contractor to use a pan attachment to remove waste material (Stein, 2005).

Be sure to education emergency services on how to deal with the high-tensioned cable barrier systems. Cutting of these systems while in place is undesirable (Sharp, 2005).

\subsubsection{Median Grades}

The grade of the median should be made as flat as possible while at the same time maintaining adequate drainage. It is recommended that the slope be a 6:1 or less (Sharp, $2005 \&$ Stein, 2005). 


\subsubsection{Median Placement}

The Iowa and Utah Departments of Transportation suggest installing the hightensioned cable barrier systems on the high side of the slope, outside of the clear zone if possible. There are several reasons why the ditch is an undesirable location. First, if the soil in the flow line of the ditch stays wet for most of a calendar year, there is a possibility that the post and anchor foundations may come loose (Sharp, 2005).

Secondly, there were concerns that a vehicle could override the barrier if it was installed in the ditch (Stein, 2005). Thirdly, irregularities in the ditch, such as the presence of a drain inlet, may cause problems with the distance from the lowest cable to the ground surface (Outcalt, 2004). Fourthly, obstacles, like sign trusses and bridge piers, may be present in the center of the median, and while trying to jog the cable barrier systems around these objects, maintaining the required high may be compromised (Stein, 2005, Outcalt, 2004).

The Iowa Department of Transportation (IDOT) and the Colorado Department of Transportation had slightly different experiences as compared to the Utah Department of Transportation and ODOT when considering where to install the cable barrier system because the two traveled ways were at different elevations. When this condition occurs, IDOT suggest installing the barrier on the high side (Stein, 2005).

\subsubsection{Maintenance}

High-tensioned cable barriers provide several benefits from a maintenance perspective. First, the system does not have to be fixed immediately after impact (Sharp, 
2005). This is the primary advantage of high-tensioned cable barriers over low-tensioned cable barriers.

The Iowa and Utah Department of Transportation had issues with the tensioning of the cables. The Iowa Department of Transportation suggests that the tensioning be checked at the time of installation and then again 3 weeks after the installation (Stein, 2005). The Utah Department of Transportation suggested either every six months or every thirty hits to ensure tensioning is maintained (Sharp, 2005).

The Iowa Department of Transportation identified one issue as a result of the cold weather: removing the damages posts became difficult. Pry bars, sledge hammers, torches and salt were used to deal with the wedged or frozen post. The salt was applied around the frozen post prior to the day of removal (Stein, 2005). The Colorado Department of Transportation, although not identifying any problems, suggests that using a small amount of expanding foam in the top part of the sockets my help seal them off from water (Outcalt, 2004).

\subsubsection{Cost}

Not much information has been provided on the cost of the high-tensioned cable systems. A study by the Utah Department of Transportation state that one man hour was required per hit. Furthermore, it was estimated that the cost was an average of $\$ 500$ per hit for the tie and cost of repair (Sharp, 2005). A study by the Iowa Department of 
Transportation on high-tensioned cable barriers stated that two workers can replace 7 to 10 posts and reattach the cable in less than half-an-hour (Stein, 2005).

\subsubsection{Causes of Vehicles Breaking Through the Cables}

The Utah Department of Transportation cited two cases in which the vehicle was able to permeate the high-tensioned cable barrier. One was because the barrier was hit at close to a 90 degree angle. The system is not designed to prevent a crossover if a vehicle strikes it at this angle. The second penetration through the barrier was said to be the result of the placement of the barrier (Sharp, 2005).

The Colorado Department of Transportation listed only one case in which an crossover crash occurred. In this instance, the distance from the bottom cable to the ground beneath it was higher than what is suggested by standards (Outcalt, 2004). 


\section{CHAPTER 10: CLOSURE}

\section{$\underline{10.1 \text { Conclusions }}$}

A primary conclusion from this research is that freeway geometry and median treatments affect the frequency and severity of different types of crashes differently. This is most notably demonstrated by differences in the predictive equations developed for the different crash types. A discussion of this is first made from the crash frequency perspective; then a discussion is made from the crash severity perspective. For single vehicle crashes, variables related to curvature, whether horizontal or vertical, were present in each developed model. This was not true for multiple vehicle - same direction crashes. Only the model for the median treatment depressed with berms with a wide median width $(\mathrm{C} 3 \mathrm{~N})$ had a variable representing average horizontal curvature. Interestingly enough, for multiple vehicle - opposite direction crashes, the only variable related to curvature that was present represents average horizontal curvature. Similar to how for single vehicle crashes there was always a variable related to curvature present, for multiple vehicle - same direction crashes, there was always a variable related to the frequency of on-ramps present. In some cases, it was not just the frequency of on-ramps, but the frequency of on and off-ramps (the total frequency of ramps on a segment). For the multiple vehicle - opposite direction model, the variable for the frequency of on- 
ramps was present as well. Only one model for single vehicle crashes had a variable related to the frequency of ramps, but it was for the frequency of off-ramps.

Like frequency, every model includes a variable that represents curvature. The predominant present variable is horizontal curvature, which was the most prevalent variable of curvature present in the frequency models as well. There were two predominant trends for frequency models when considering the natural logarithm of the average annual daily traffic $(\mathrm{Q})$ coefficients: the coefficients were always greater than 1 for multiple vehicle - same direction crashes and the coefficients were always less than 1 for single vehicle crashes. This demonstrates that there are evident differences in behavior with regards to crash type that should be taken into consideration. It is expected that the value for the multiple vehicle - same direction crashes would be greater than 1 because as the number of vehicles increases, the potential for this crash type increases. Furthermore, it can be implied that since there is increased traffic, what may previously have been a single vehicle crash may then be a multiple vehicle - same direction crash.

Binary variables for states are present in most models, which indicates that these states safety differs from Indiana, or the state's method of representing crashes differs from Indiana or both are true. Adding these binary variables was justified and it enables using the developed equations by these states agencies.

This research confirmed results from other studies that indicate that a reduction in median width affects the frequency and severity of crashes. The median treatments depressed without a barrier with a wide median width (D3N) and depressed without a median barrier width an intermediate median width (D2N) are essentially identical median treatment types with the exception of the median width. For both multiple 
vehicle - same direction crashes and multiple vehicle - opposite direction crashes, the rate at which the frequency of crashes increased was greater for the depressed median with an intermediate median width treatment in comparison to the depressed median with a wide median width treatment. In addition, although there seemed to be some variability with the lower values of average annual daily traffic (AADT), as the AADT increased, the frequency of crashes more rapidly increased for the depressed median with an intermediate median width when compared with the depressed median with a wide median width. With regards to severity, the results indicate that a reduction in median width is associated with an increase in severity.

Not all of the median treatments that were identified in practice are defined by the current American Association of State Highway and Transportation Officials (AASHTO) guidelines. The results of this study indicate that the additional median treatments identified, particularly for the median treatment with berms with a wide median width $(\mathrm{B} 3 \mathrm{~N})$ and the median treatment that was sloped with a wide median width $(\mathrm{S} 3 \mathrm{~N})$, do have a safety effect. The median treatment berms and a wide median width was found to significantly increase both the number of single vehicle and multiple vehicle - same direction crashes as the average annual daily traffic increased. Furthermore, the sloped median with a wide median width was found to significantly increase the frequency of single vehicle crashes as the average annual daily traffic increased. On the other hand, the berms median with a wide median width would be considered slightly better in performance as compared to other non-barrier median treatments (depressed without a median barrier with an intermediate median width, depressed with berms with a wide median width and a depressed median without a median barrier with a wide median 
width) for the multiple vehicle - opposite direction crashes, when considering the frequency of crashes. The occurrence of multiple vehicle - opposite direction crashes are possible in this median treatment because not all of the berm medians are continuous; there are gaps between the berms that allow vehicles to pass through.

Although a large amount of data was collected, there was not a sufficient sample size to analyze the severity of fatal crashes separately. As such, originally proposed multinomial model with the three outcomes property damage only (PDO), injury and fatal had to be reduced to a binary model with the two outcomes property damage only and injury/fatal.

Two median treatments related to concrete were addressed in this research: one with a median width less than 30 feet, and one with a median width greater than or equal to 30 feet and less than or equal to 50 feet. It was found that the wider median with a concrete barrier is associated with a higher severity of crashes.

Prior to incorporating the control information, which for the most part seemed to bring more variability, the statistical significance for the depressed with low-tensioned cable barrier with a wide median width (D3L) and flush median with a concrete barrier with a narrow or intermediate median width (CONC, which is a combination of F1C and F2C) median treatments for single vehicle crashes was large, especially for the flush median with a concrete barrier with a narrow or intermediate median with median treatment. After incorporating the control information, the statistical significance was lost. Even so, it is implied that the single vehicle crashes for these two median treatments is increased by more than half when adding these barriers in comparison to medians of the same widths without the barriers. 


\section{$\underline{10.2 \text { Future Research Needs }}$}

Although every attempt was made to obtain information the effects of hightensioned cable barriers on the frequency and severity of crashes, the data sample available did not allow for fully confident conclusions. As such, it would be highly beneficial to revisit the impacts of high-tensioned cable barriers on the frequency and severity of crashes as more data becomes available.

This research attempted to investigate low-tensioned and high-tensioned cable barriers although the pool from which data could be drawn was small. One aspect that was not addressed and should be taken into consideration when considering safety is the affect that such barriers have on specific vehicle types, such as motorcycles and large vehicles.

It was demonstrated that the $\mathrm{B} 3 \mathrm{~N}$ median treatment performs poorly with regards to single vehicle and multiple vehicle - same direction crashes. For multiple vehicle opposite direction crashes, this median treatment performs slightly better in comparison to the other median treatments without median barriers. Unlike the median treatments that had barriers installed, every MVOD crash on this median treatment was not individually scrutinized due to time constraints and other considerations. As such, it would be beneficial to further investigate the safety impacts of this median treatment by inspecting the crash reports. Furthermore, the segments could be further broken down into segments that are continuous berms and those that have slight gaps between berms. This would beneficial to the field of transportation because although they may not be 
identified as median treatments according to the AASHTO guidelines, they were found in almost every state from which data was taken for this study. A likely hurdle in this approach might be the limited accuracy of crash location which becomes an issue when shorter segments are studied.

Many variables were included for investigation in this study, but the time intensive manner of the collection of the geometric data due to the inability of tools and databases made it difficult to consider all information, particularly that with regards to the slopes of depressed medians. It would be suggested that future research investigate how varying slopes on depressed medians affect the frequency and severity of crashes.

Some observations while performing this research indicated that the design of the concrete median barrier should be reanalyzed for several reasons. First, a large percentage of crossover crashes were found to be the result of debris transferring from on traveled way to the opposing traveled way. Most often, these were in locations with concrete barrier. As a large portion of the concrete barriers were low to the ground, the advantages and disadvantages of higher concrete barriers should be investigated. Second, the designs of the vehicles have radically changed over the past few years. Refer to Figure 10.1 below, and Figure 4.2. 


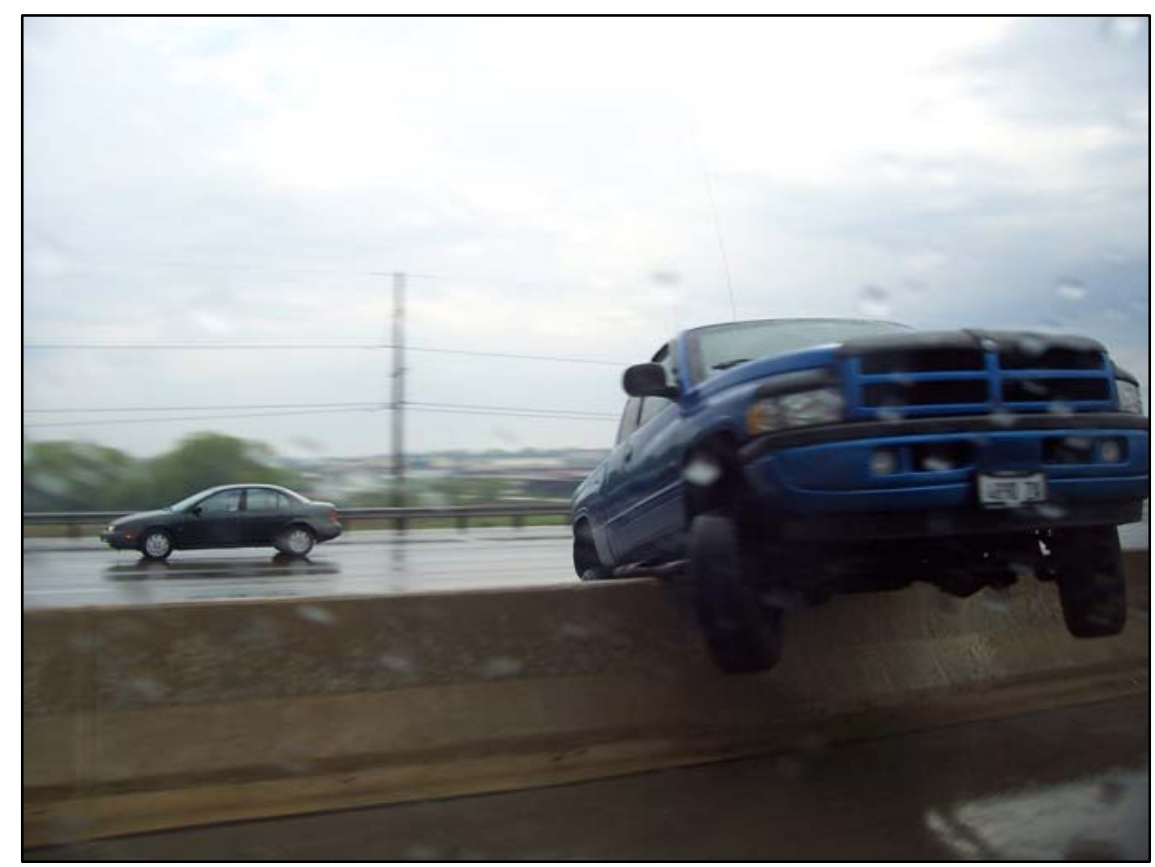

Figure 10.1 Truck on Concrete Barrier

As such it should be investigated whether stronger and possibly taller concrete barriers would be beneficial. Increasing the height of the barriers could also bring benefits with regards to glare created by headlights from vehicles traveling in the opposing direction.

Throughout this study, sample sizes had to be reduced or analyses put on the way sides as a result of insufficient data. A data piece that had a major bearing in the analysis, but which little information was available on is the construction history of the roadways. Particularly, there was little information on the installation dates of barriers unless they were installed very recently. It would be highly beneficial to providing more information from research in transportation if databases could be improved or initiated, as this description highlights. 


\section{LIST OF REFERENCES}

1. Albin, R. B., Bullard, D. L., Jr., Menges, W. L. (2001). Washington State Cable Median Barrier. Transportation Research Record 1743, p.71-79. Transportation Research Board.

2. Allison P.D. (1999). Logistic Regression Using the SAS System - Theory and Application, p.51-57. SAS Institute, Inc.

3. Baxter, J. R. (2006). Acceptance letter Brifen WRSF TL-4 in reply to HAS-10/B82B (03/07/2005) FHWA. Retrieved March 1, 2007, from U.S. Department of Transportation Federal Highway Administration Web Site:

http://safety.fhwa.dot.gov/roadway_dept/road_hardware/barriers/pdf/b82b1.htm.

4. BMI Engineers. (2003). Improved Guidelines for Median Safety: Summary of State Transportation Agency Survey, Draft Report. National Cooperative Highway Research Program, NCHRP Project 17-14(2). National Cooperative Highway Research Program, Washington D.C.

5. Carrasco, O., McFadden, J., and Chandhok, P. (2004). Evaluation of the Effectiveness of Shoulder Rumble Strips on Rural Multi-lane Divided Highways in Minnesota. CD-ROM Compendium of Papers, $83^{\text {rd }}$ Annual Meeting Transportation Research Board (TRB), National Research Council, Washington D.C.

6. Cheng, E. Y., Gonzalez, E., Christensen, M.O. (2000). Application and Evaluation of Rumble Strips on Highways. Retrieved March 1, 2007, from U.S. Department of Transportation Federal Highway Administration Web Site: http://safety.fhwa.dot.gov/roadway_dept/docs/application.pdf.

7. Davis, G. and Pei, J. (2005). Bayesian Reconstruction of Median-Crossing Crashes and Potential Effectiveness of Cable Barriers. CD-ROM Compendium of Papers, $84^{\text {th }}$ Annual Meeting Transportation Research Board (TRB), National Research Council, Washington D.C.

8. Elvik, R. (1995). The Safety Value of Guardrails and Crash Cushions: A MetaAnalysis of Evidence from Evaluation Studies. Accident Analysis and Prevention, 27(4):523-550.

9. Focke, D. (2005). Brifen WRSF In-Service Performance Evaluation: Year 1 Report - For the period from July 2003 to June 2004. Obtained from personal communication with Dean Focke on May 24, 2005. 
10. Foody, T.J. and Culp, T.B. (1974). A Comparison of the Safety Potential of the Raised Versus Depressed Median Design. Transportation Research Record, 514, p.1-15. Transportation Research Board.

11. Hadi, M.A., Aruldhas, J., Chow, L., and Wattleworth, J. (1995). Estimating Safety Effects of Cross-Section Design for Various Highway Types Using Negative Binomial Regression. Transportation Research Record, 1500, p. 169-177. Transportation Research Board.

12. Hauer E. (2000) The Median and Safety. Unpublished Manuscript.

13. Hunter, W. W., Stewart, J.R., Eccles, K. A., Huang, H.F., Council, F.M., and Harkey, D.L. (2001). Three-Strand Cable Median Barrier in North Carolina: In-Service Evaluation. Transportation Research Record, 1743, p. 97-103. Transportation Research Board.

14. Johnson R.T. (1964). Effectiveness of median barriers. Highway Research Record, 105, p. 99-112. Highway Research Board.

15. Khorashadi A., Niemeier D., Shankar V., and Mannering F. (2005). Differences in rural and urban driver-injury severities in accidents involving large-trucks: an exploratory analysis. Accident Analysis and Prevention, 37(5): 910-921.

16. Knuiman, M.W.; Council, F.M.; Reinfurt, D.W. (1993). Association of Median Width and Highway Accident Rates. Transportation Research Record, 1401.

Transportation Research Board, 70-80.

17. Kutner M.H., Nachtsheim C.J., Neter J., and Li W. (2005) Applied Linear Statistical Models - Fifth Edition. New York: Mc Graw-Hill/Irwin.

18. Lee J. and Mannering F. (2000) Impact of roadside features on the frequency and severity of run-off-roadway accidents: an empirical analysis. Accident Analysis and Prevention, 34(2): 149-161.

19. LIMDEP, Version 7.0. (1995). Econometric Software, Inc., Bellport, N.Y.

20. Maximum Posted Speed Limits for Passenger Vehicles. (2006). Retrieved March 1, 2007 from Insurance Institute for Highway Safety (IIHS), Highway Loss data Institute Web Site: http://www.iihs.org/laws/state_laws/speed_limit_laws.html. 
21. McClanahan, D.; Albin, R.B. and Milton, J.C. (2003). Washington State Cable Median Barrier In-Service Study. Retrieved March 1, 2007, from Washington State Department of Transportation Web Site: http://64.233.167.104/search?q=cache:XRv0czfi4AJ:www.wsdot.wa.gov/eesc/design/policy/Documents/CableBarriersubmittalfor TRB.pdf+Washington+State+Cable+Median+Barrier+InService + Study $\& h l=$ en $\& c t=$ lnk $\& c d=1 \& g l=$ us.

22. Noland R.B. and Oh L. (2003) The effect of infrastructure and demographic change on traffic-related fatalities and crashes: a case study of Illinois county-level data. Accident Analysis and Prevention, 36(4):525-532.

23. Nystrom K. et al. (1997). Median Barrier Study Warrant Review - 1997. Rep. No. CALTRANS-TE-97-02. California Department of Transportation, Sacramento, CA.

24. O' Donnell C.J. and Connor C.H. (1996) Predicting the severity of motor vehicle accident injuries using models of ordered multiple choice. Accident Analysis and Prevention, 28(6):739-753.

25. Ohio DOT Field Visits to Cable Median Barrier Projects (4/11/05, summary added 4/13). Obtained from personal communication with Dean Focke on May 24, 2005.

26. Outcalt, William (Skip). (2004). Cable Guardrail. Retrieved March 1, 2007, from Web Site:

http://tig.transportation.org/sites/aashtotig/docs/Colorado\%20cableguardrail\%20Research $\% 20(2004)$.pdf.

27. Report on the $65 \mathrm{mph}$ Speed Limit in New York State. (1999). New York State Department of Transportation (NYSDOT).

28. Roadside Design Guide. (2002). American Association of State Highway and Transportation Officials (AASHTO), Washington D.C.

29. Satellite Images. Retrieved March 6, 2007 from GlobeXplorer: A Digitalglobe Company Web Site: http://www.globexplorer.com.

30. Shankar, V., Mannering, F., Barfield, W. (1995). Effect of Roadway Geometrics And Environmental Factors on Rural Freeway Accident Frequencies. Accident Analysis and Prevention, 27(3):371-389.

31. Sharp, B.; Stewart, R.; Berg, K. (2005). Annual Experimental Features Report: High-Tension Cable Median Barrier (Brifen and Trinity) at UDOT-Final Report. Report No. UT-05.07. Utah Department of Transportation. 
32. Sheeley, D. and Goodloe, K. (2003, June 5). Several trucks collide after one blows a tire. Retrieved March 1, 2007 from JSOnline: Milwaukee Journal Sentinel Web Site: http://www.jsonline.com/story/index.aspx?id=145713.

33. Sposito, B. and Johnston, S. (1998). Three-Cable Median Barrier Final Report. Report No. OR-RD-99-03. Oregon Department of Transportation.

34. Stats and Data. (2007). Retrieved March 6, 2007 from Colorado Department of Transportation Web Site: http://www.dot.state.co.us/\#.

35. Stein, W. (2005). Brifen Wire Rope Safety Fence Final Report. Obtained from personal communication with Jerry Roche on March 28, 2006.

36. Tarko, A. P., Kanodia, M., and Zhou, Y. (2006). Guidelines for Roadway Safety Improvements. JTRP Report SPR-40293. Indiana Department of Transportation.

37. Technical Advisory: Roadway Shoulder Rumble Strips. (2001). T5040.35.

Retrieved March 6, 2007 from U.S. Department of Transportation, Federal Highway Administration Web Site:

http://www.fhwa.dot.gov/legsregs/directives/techadvs/t504035.htm.

38. Telford, E.T. and Israel R.J. (1953). Median study (California). Proceedings of the $32^{\text {nd }}$ Annual Meeting, Highway Research Board, pp.208-231.

39. TransCAD. Caliper Corporation.

40. Ulfarsson, G.F., Mannering, F.L. (2002). Differences in male and female injury severities in sport-utility vehicle, minivan, pickup and passenger car accidents. Accident Analysis and Prevention, 36, 135-147.

41. Wang, J., Hughes, W.E., Stewart, R. (1998). Safety Effects of Cross-Section Design for Rural, Four-Lane, Non-Freeway Highways. Publication No. FHWA-RD-98071, U.S. Department of Transportation, Federal Highway Administration.

42. Washington Department of Transportation (WSDOT). (2006). I-5:

Marysville/Arlington Cable Barrier. Retrieved March 5, 2007, from Washington State Department of Transportation Web Site:

http://www.wsdot.wa.gov/maintenance/barriers/Marysville/default.htm.

43. Washington, S.P., Karlaftis, M.G., Mannering, F. L. (2003). Statistical and Econometric Methods for Transportation Data Analysis. Chapman \& Hall/CRC. 


\section{Appendix A: Data Collected}

Table A.1 Summary of Data Collected, By State

\begin{tabular}{|c|c|c|c|c|c|c|c|c|c|c|}
\hline \multirow{2}{*}{\multicolumn{3}{|c|}{ Data Collected }} & \multicolumn{8}{|c|}{ States } \\
\hline & & & Colorado & Indiana & Illinois & Missouri & New York & Ohio & Oregon & Washington \\
\hline \multicolumn{3}{|c|}{ Segment Length } & $\bar{X}$ & $\bar{X}$ & $\mathrm{X}$ & $\mathrm{X}$ & $\bar{X}$ & $\mathrm{X}$ & $\bar{X}$ & $\mathrm{X}$ \\
\hline \multicolumn{3}{|c|}{ Rural/Urban Indicator } & $\mathrm{X}$ & & & & & $\mathrm{X}$ & $\mathrm{X}$ & $\mathrm{X}$ \\
\hline \multirow{11}{*}{ Vertical Curve } & \multicolumn{2}{|c|}{ Beginning } & $\bar{X}$ & $\bar{X}$ & $\mathrm{X}$ & $\bar{x}$ & $\bar{X}$ & $\bar{x}$ & $\bar{X}$ & $\bar{X}$ \\
\hline & \multicolumn{2}{|c|}{ Middle } & & $\mathrm{X}$ & & & & & & \\
\hline & \multicolumn{2}{|l|}{ End } & $\bar{X}$ & $\bar{X}$ & $\mathrm{X}$ & $\mathrm{X}$ & $\mathrm{X}$ & $\mathrm{X}$ & $\bar{X}$ & $\bar{X}$ \\
\hline & \multicolumn{2}{|c|}{ Beginning Grade } & & $\bar{X}$ & $\mathrm{X}$ & $\mathrm{X}$ & & $\mathrm{X}$ & & $\bar{X}$ \\
\hline & \multicolumn{2}{|c|}{ End Grade } & & $\bar{X}$ & $\mathrm{X}$ & $\mathrm{X}$ & & $\mathrm{X}$ & & $\bar{X}$ \\
\hline & \multicolumn{2}{|c|}{ Length } & $\bar{X}$ & $\bar{X}$ & $\bar{X}$ & $\mathrm{X}$ & $\mathrm{X}$ & $\mathrm{X}$ & & $\bar{X}$ \\
\hline & \multicolumn{2}{|l|}{ Type } & $\mathrm{X}$ & $\mathrm{X}$ & $\mathrm{X}$ & & & $\mathrm{X}$ & $\mathrm{X}$ & $\mathrm{X}$ \\
\hline & \multicolumn{2}{|c|}{ K-Parameter } & & $\bar{X}$ & $\mathrm{X}$ & $\mathrm{X}$ & & $\mathrm{X}$ & $\bar{X}$ & $\bar{X}$ \\
\hline & \multicolumn{2}{|c|}{ Number of Curves } & $\bar{X}$ & $\bar{X}$ & $\bar{X}$ & $\bar{x}$ & $\bar{X}$ & $\bar{X}$ & $\bar{X}$ & $\bar{X}$ \\
\hline & \multicolumn{2}{|c|}{$\%$ Curvature } & & $\mathrm{X}$ & $\mathrm{X}$ & $\mathrm{X}$ & & $\mathrm{X}$ & $\mathrm{X}$ & $\mathrm{X}$ \\
\hline & Average Cur & & & $\mathrm{X}$ & $\mathrm{X}$ & $\mathrm{X}$ & & $\mathrm{X}$ & $\bar{X}$ & $\bar{X}$ \\
\hline & I eft Hand Side & On & $\bar{X}$ & $\mathrm{X}$ & $\mathrm{X}$ & $\bar{x}$ & $\mathrm{X}$ & $\bar{x}$ & $\mathrm{X}$ & $\bar{X}$ \\
\hline Ramp Present in the & Left Hana side & Off & $\bar{X}$ & $\mathrm{X}$ & $\mathrm{X}$ & $\mathrm{X}$ & $\mathrm{X}$ & $\mathrm{X}$ & $\bar{X}$ & $\bar{X}$ \\
\hline Viewing Direction & Riaht Hand Side & On & $\mathrm{X}$ & $x$ & $\mathrm{X}$ & $\mathrm{x}$ & $\mathrm{X}$ & $\mathrm{X}$ & $\mathrm{X}$ & $\mathrm{X}$ \\
\hline & & Off & $\mathrm{X}$ & $x$ & $\mathrm{X}$ & $x$ & $\mathrm{X}$ & $\mathrm{X}$ & $\mathrm{X}$ & $\mathrm{X}$ \\
\hline & & On & $\bar{X}$ & $\mathrm{X}$ & $\mathrm{X}$ & $\mathrm{x}$ & $\mathrm{X}$ & $\mathrm{X}$ & $\mathrm{X}$ & $\bar{X}$ \\
\hline Ramps Present in the & Lett Hand Side & Off & $x$ & $\mathrm{X}$ & $\mathrm{X}$ & $\mathrm{X}$ & $\mathrm{X}$ & $\mathrm{X}$ & $\mathrm{X}$ & $\mathrm{X}$ \\
\hline Opposite Direction & Right Hand Side & On & $\mathrm{X}$ & $\mathrm{X}$ & $\mathrm{X}$ & $\mathrm{X}$ & $\mathrm{X}$ & $\mathrm{X}$ & $\mathrm{X}$ & $\bar{X}$ \\
\hline & Rignt Hand sıde & Off & $\mathrm{X}$ & $\mathrm{X}$ & $\mathrm{X}$ & $\mathrm{X}$ & $X$ & $\mathrm{X}$ & $X$ & $\mathrm{X}$ \\
\hline & Beginnil & & $\bar{X}$ & $\bar{X}$ & $\bar{X}$ & $\bar{x}$ & $\bar{X}$ & $\bar{x}$ & $\bar{X}$ & $\bar{X}$ \\
\hline & End & & $\mathrm{X}$ & $\mathrm{X}$ & $\mathrm{X}$ & $\mathrm{X}$ & $\mathrm{X}$ & $\mathrm{X}$ & $\mathrm{X}$ & $\mathrm{X}$ \\
\hline & Beginning $\mathrm{H}$ & & & $\mathrm{X}$ & $\mathrm{X}$ & & & & & \\
\hline & Ending $\mathrm{He}$ & & & $\mathrm{X}$ & $\mathrm{X}$ & & & & & \\
\hline & Beginning $\mathrm{Coc}$ & tes & & & & $\mathrm{X}$ & & $\mathrm{X}$ & & \\
\hline Horizontal Curve & End Coordi & & & & & $\mathrm{X}$ & & $\mathrm{X}$ & & \\
\hline Horlzontal curve & Length & & $\bar{X}$ & $\bar{x}$ & $\mathrm{X}$ & $\mathrm{X}$ & $\bar{X}$ & $\mathrm{X}$ & $\bar{X}$ & $\bar{X}$ \\
\hline & Radius & & & $X$ & $x$ & $x$ & & $\mathrm{X}$ & $x$ & $X$ \\
\hline & Curve Direction (in & outside) & $\bar{X}$ & $\mathrm{X}$ & $\mathrm{X}$ & $\mathrm{X}$ & & $\mathrm{X}$ & $\mathrm{X}$ & $\bar{X}$ \\
\hline & Number of $C$ & & $\mathrm{X}$ & $\mathrm{X}$ & $\mathrm{X}$ & $\mathrm{X}$ & $\mathrm{X}$ & $\mathrm{X}$ & $\mathrm{X}$ & $\bar{X}$ \\
\hline & $\%$ Curvat & & & $\bar{X}$ & $\mathrm{X}$ & $\mathrm{X}$ & & $\mathrm{X}$ & $\mathrm{X}$ & $\bar{X}$ \\
\hline & Average Cur & & & $\mathrm{X}$ & $\mathrm{X}$ & $\mathrm{x}$ & & $\mathrm{X}$ & $\mathrm{X}$ & $\bar{x}$ \\
\hline Numbe & f Travel Lanes & & $\mathrm{X}$ & $\mathrm{X}$ & $\mathrm{X}$ & $\bar{x}$ & $\mathrm{X}$ & $\bar{X}$ & $x$ & $\bar{X}$ \\
\hline Pavement & pe in Travel Lanes & & $\mathrm{X}$ & $\mathrm{X}$ & $x$ & $\bar{x}$ & $\mathrm{X}$ & $\bar{X}$ & $x$ & $\bar{X}$ \\
\hline & Configura & & $\bar{X}$ & $\mathrm{X}$ & $\mathrm{X}$ & $\mathrm{X}$ & $\bar{X}$ & $\mathrm{X}$ & $\mathrm{X}$ & $\bar{X}$ \\
\hline Median & Surfac & & $\mathrm{X}$ & $\mathrm{X}$ & $\mathrm{X}$ & $\mathrm{X}$ & $\mathrm{X}$ & $\mathrm{X}$ & $\mathrm{X}$ & $\bar{X}$ \\
\hline Median & Width ( & & $\mathrm{X}$ & $\bar{X}$ & $\mathrm{X}$ & $\mathrm{X}$ & $\mathrm{X}$ & $\mathrm{X}$ & $\mathrm{X}$ & $\bar{X}$ \\
\hline & Presence of a & & $\bar{X}$ & $x$ & $x$ & $\mathrm{X}$ & $\mathrm{X}$ & $\mathrm{X}$ & $\mathrm{X}$ & $\bar{X}$ \\
\hline & Type & & $\bar{X}$ & $\bar{X}$ & $\bar{X}$ & $\mathrm{X}$ & $\mathrm{X}$ & $\mathrm{X}$ & $\bar{X}$ & $\bar{X}$ \\
\hline Median Barrier & $\begin{array}{l}\text { Quantitative Locati } \\
\text { of Inside Trave }\end{array}$ & $\begin{array}{l}\text { m Edge } \\
(\mathrm{ft})\end{array}$ & & $x$ & $x$ & $x$ & $X$ & & & \\
\hline & Width ( & & $\bar{X}$ & $\mathrm{X}$ & $\mathrm{X}$ & $\bar{x}$ & $\bar{X}$ & $\bar{X}$ & $\bar{x}$ & $\bar{X}$ \\
\hline Inside Shoulders & Surfac & & $\mathrm{X}$ & $\bar{x}$ & $\mathrm{X}$ & $\mathrm{X}$ & $\mathrm{X}$ & $\mathrm{X}$ & $\bar{X}$ & $\bar{X}$ \\
\hline & Presence of Run & Strips & $\mathrm{X}$ & $X$ & $\mathrm{X}$ & $x$ & $\mathrm{X}$ & $x$ & & \\
\hline & Width ( & & $\bar{x}$ & $\bar{x}$ & $\bar{X}$ & $\mathrm{X}$ & $\mathrm{X}$ & $\mathrm{X}$ & $\mathrm{X}$ & $\bar{x}$ \\
\hline Outside Shoulders & Surfac & & $\mathrm{X}$ & $X$ & $x$ & $x$ & $\mathrm{X}$ & $\mathrm{X}$ & $\mathrm{X}$ & $\mathrm{X}$ \\
\hline & Presence of Run & Strips & $\mathrm{X}$ & $\mathrm{X}$ & $\mathrm{X}$ & $\mathrm{X}$ & $\mathrm{X}$ & $\mathrm{X}$ & $\mathrm{X}$ & $\mathrm{X}$ \\
\hline Outcide Rarrier & Type & & $\bar{x}$ & $\mathrm{X}$ & $\mathrm{X}$ & $\bar{x}$ & $x$ & $\bar{x}$ & $\bar{x}$ & $\bar{X}$ \\
\hline uniside Bamer & Location from Edg & Dutside & & $\mathrm{X}$ & $\mathrm{X}$ & $\mathrm{X}$ & $\mathrm{X}$ & & & \\
\hline & $\overline{A A D T}$ & & $\mathrm{x}$ & $\mathrm{x}$ & $\mathrm{X}$ & $x$ & $\mathrm{X}$ & $\mathrm{X}$ & $\mathrm{X}$ & $\bar{X}$ \\
\hline & Trucks & & $\bar{X}$ & $\mathrm{X}$ & $\mathrm{x}$ & $\mathrm{X}$ & $\mathrm{X}$ & $\mathrm{X}$ & $\mathrm{X}$ & $\bar{X}$ \\
\hline Sneed Limit & As View & & $\bar{X}$ & $\mathrm{X}$ & $\mathrm{X}$ & $\mathrm{X}$ & $\mathrm{X}$ & $\mathrm{X}$ & $\mathrm{X}$ & $\bar{X}$ \\
\hline speed LImIt & Statewic & & $\mathrm{x}$ & $\mathrm{X}$ & $\mathrm{X}$ & $\mathrm{X}$ & $\mathrm{X}$ & $\mathrm{X}$ & $\mathrm{X}$ & $\bar{X}$ \\
\hline & Total Or & & & $\bar{X}$ & $\bar{X}$ & $\mathrm{X}$ & $\mathrm{X}$ & & & \\
\hline Number of Bridges in the & Under & & $\mathrm{X}$ & & & & & $\mathrm{X}$ & $\mathrm{X}$ & $\mathrm{X}$ \\
\hline & Over & & $\mathrm{x}$ & & & & & $\mathrm{X}$ & $\mathrm{X}$ & $\bar{X}$ \\
\hline
\end{tabular}




\section{Appendix B: Geometric Data}

\section{Segment Number}

A segment number was created for the database for each state. In some cases, the segment may be extended to an A and B portion of the original segment number, $1 \mathrm{~A}$ and $1 \mathrm{~B}$ for example. This was often the result of obtaining more information about the segment that was not homogeneous, such as the barrier installation date, and therefore required the subdivision of the segment.

\section{Interstate}

All of the segments included in the final analysis were interstates. The majority of the segments included were collected in rural areas, but sometimes this requirement was relaxed in order to obtain barrier treatments of interest, particularly median treatments that contained concrete barriers.

\section{a. Number}

The interstate number that was given to the roadway was recorded. For example, for I-94, the number 94 was included. For some states, data from several interstates was collected, which may result in overlapping mileposts. As such, it was imperative that the interstate number be collected.

\section{b. Direction}

Typically, to collect data, the video log system was only viewed in one direction. (Please note that in order to obtain information on the on and off-ramps, the video log was viewed in the opposing direction as well.) The data was then assumed to be homogeneous in the other direction, which for interstates is a fairly conservative assumption. As such, the direction that the data was collected in, whether as the mileposts were increasing (I) or decreasing (D), was recorded.

\section{Section}

Each section was defined by the milepost that it began and ended with. Homogenous segments were created.

\section{a. Beginning}

\section{b. End}

The beginning milepost was recorded for each segment.

\section{c. Length}

The end milepost was recorded for each segment.

The absolute value of the length was computed for each homogeneous segment.

\section{Rural/Urban Indicator}

Some states provided information on the type of environment, whether urban or rural, that the roadway was in. Washington State and Oregon are two examples. As such, this information was recorded for several states since the focus of the research was on rural interstates. 


\section{Ramps}

As long as the median treatment and several of the traffic data remained homogeneous, the segment extended beyond over and underpasses. As such, the number of on and off-ramps that were present in a segment were collected.

\section{a. Viewing Direction}

As mentioned previously, data was primarily collected using one direction of the video log. As such, the number of ramps collected in this direction is considered to be in the "viewing direction."

i. Left

Ramps may come connect to the through lanes from the left or right side, as such, this distinction was made when collecting the number of ramps.

\section{On}

It was hypothesized that on-ramps and off-ramps would affect the frequency and severity of crashes in different ways. As such, the distinction between on and off-ramps was made in the data collection.

\section{Off}

\section{ii. Right}

1. On

2. Off

\section{b. Opposite Direction}

As discussed about, the ramps that were collected in the opposite direction are those that were in the direction opposite to that which was used to collect the geometric data. Typically, the video or photo $\log$ in this direction was used to collect this information, but sometimes limitations on data did not allow this.

i. Left

\section{On}

2. Off

\section{ii. Right}

1. On

2. Off

\section{Travel Lanes}

\section{a. Number of Lanes}

The number of traveled way lanes was collected in each direction. As such, when defining a segment, the total number of lanes for the homogenous segment is twice as many lanes as noted under this field.

\section{b. Pavement Type}

General information about the pavement type of the homogenous segment was collected. The pavement type was defined as either concrete or asphalt. The pavement type was visually 


\section{Median Section}

distinguished. Typically, when the pavement type changed, the segment was terminated, and new segment was started.

\section{a. Configuration}

A median configuration can be defined as: depressed, depressed

\section{b. Surface} with berms, berms, sloped, or flush.

The surface type of the median was collected. A slight change, such as the presence of a few trees in an otherwise grass median, would not dictate the end of a segment. If the change of the surface of the median was significant, the segment would be terminated and a new segment started. Surface types identified are as follows: grass, grass with trees, grass with bushes, trees, rock, asphalt, concrete.

c. Width (ft)

The width of a median was determined either from databases provided from the state department of transportation or from the video log system.

\section{d. Presence of a Barrier}

The presence of a barrier was identified using a 0 or no barrier and

\section{Barriers} a 1 for the presence of a barrier.

a. Type

The type of barrier was identified visually. As such, distinctions could not be made between barriers that looked similar. For example, unless construction plans could be obtained, it was hard to distinguish the concrete barriers. Barriers that were identified include: concrete, w-beam, cable barrier, aluminum balanced beam and box-beam.

\section{b. Location}

In some cases, the exact measurement between the inside traveled way lane and the center of the barrier could be determined. This typically required the use of a video log system. Where a video log system was not available, sometimes qualitative barrier locations were recorded.

\section{c. Installation Date}

When it could be determined, the installation date of the barrier was included in the geometric database.

\section{Inside Shoulders}

\section{a. Presence of Interior Shoulder}

Typically, when the median was flush with a concrete barrier, it was difficult to distinguish between an actually shoulder and what was part of the median. As such, a 1 in this field indicates that there is a clear shoulder, and a 0 indicates that there is not a distinction. 


\section{b. Width (ft)}

The width of the inside shoulder is measured in feet.

\section{c. Surface Type}

The surface type of the shoulder was identified as concrete or asphalt.

\section{d. Rumble Strips}

When possible, information about the presence of rumble strips was collected. Segments were terminated and initiated in accordance with the starting and stopping points of rumble strips.

\section{Outside Shoulders}

\section{a. Width (ft)}

The width of the inside shoulder is measured in feet.

\section{b. Surface Type}

The surface type of the shoulder was identified as concrete or asphalt.

\section{c. Rumble Strips}

When possible, information about the presence of rumble strips was collected. Segments were terminated and initiated in accordance with the starting and stopping points of rumble strips. It was much easier to identify whether or not rumble strips were present on the outside shoulder because the vehicles with the cameras that record data for the video log systems are driven in the outside lane, and the camera is typically directed to the right. Some states were in the process of creating databases with this information, but none were available at the time of this research. It would have been useful for the installation dates of this geometric feature to be collected.

\section{Outside Barrier}

Less information was collected on the outside barrier because the focus of this research was the median barriers.

\section{a. Type}

\section{b. Location}

The barrier types that were identified are: cable, concrete, boxbeam, and w-beam barriers.

In some cases, the exact measurement between the outside traveled way lane and the center of the barrier could be determined. This typically required the use of a video log system. Where a video log system was not available, sometimes qualitative barrier locations were recorded.

\section{AADT}

The average annual daily traffic (AADT) was collected for the segments. It was desirable, for the development of the severity models, to obtain the AADT for all of the years for which crash data was collected from the states. Unfortunately, this was not always possible. In several cases, such as for Indiana, a simple equation was developed to predict what the AADT 
would have been for each year for which crash data was collected. It was desirable when creating the safety performance functions (frequency) to determine the median crash year AADT (i.e. if crash data was taken from 2001 to 2005, AADT from 2003 was desired).

\section{Percentage Trucks}

The percentage trucks collected most often corresponds to the year in which the AADT was collected, although this is not always the case.

Sometimes, the percentage trucks are further subdivided into categories.

\section{Speed Limit}

The speed limit is typically determined using the video log, photo log, or a database.

\section{Statewide Speed Limit}

The statewide speed limit was determined from:

\section{Number of Bridges}

http://www.iihs.org/laws/state_laws/speed_limit_laws.html

Originally, the number of brides was collected as a simple total, When it was considered that an overpass may have an alternative affect in comparison to an underpass, for the geometric databases that were still under construction, this subdivided data was collected.

a. Over

b. Under

\section{Vertical Curve}

Vertical curve information was typically collected using the video log systems. For some states, such as Washington State, this information was provided in a database.

\section{a. Beginning Milepost}

\section{b. End Milepost}

The milepost at the beginning of the vertical curve.

\section{c. Length (miles)}

The milepost at the end of the vertical curve.

The absolute difference between the beginning and end milepost.

\section{d. Beginning Grade}

The grade at the milepost that was recorded as the beginning of the curve.

\section{e. End Grade}

\section{f. Type}

The grade at the milepost that was recorded as the end of the curve.

\section{g. K-parameter (miles)}

The K-parameter is calculated as follows:

$$
K-\text { parameter }=\frac{A B S \mid \text { BeginningMP }- \text { EndMP } \mid}{A B S \mid \text { BeginningGrade }- \text { EndGrade } \mid}
$$




\section{Number of Vertical Curves}

This value computes the sum of the number of vertical curves on a segment, even if only part of a curve is on the segment.

\section{Percentage of Vertical Curvature}

The percentage of vertical curvature on a segment is computed as follows:

$$
\% \text { Vertical Curvature }=\frac{\sum \text { Length of vertical curve on segment }}{\text { Length of segment }}
$$

\section{Average Vertical Curvature}

The average vertical curvature on a segment is computed as follows:

$$
\text { Average Vertical Curvature }=\frac{\sum\left(\frac{L}{K}\right)}{\text { Length of Segment }}
$$

\section{Horizontal Curve}

Horizontal curve information was typically collected by recording the headings provided using the video log systems (i.e. Illinois and Indiana). Some video log systems did not provide the heading. In this case, the geometric coordinates were utilized to determine the radius of the horizontal curve (i.e. Missouri and Ohio). For some states, such as Washington State, this information was provided in a database.

\section{a. Inside/Outside}

The direction that the horizontal curve curved in with respect to the direction in which the video or photo log was viewed.

b. Beginning

c. End

The beginning milepost of the horizontal curve.

\section{d. Length (miles)}

The end milepost of the horizontal curve.

e. Radius (miles)

The length of the curve in miles.

The radius of the curve was determined using two different methods dependent upon whether the heading was collected, or information about the longitude was collected.

\section{Number of Horizontal Curves}

This value computes the sum of the number of horizontal curves on a segment, even if only part of a curve is on the segment.

\section{Percentage of Horizontal Curvature}

The percentage of horizontal curvature on a segment is computed as follows:

$$
\% \text { Horizontal Curvature }=\frac{\sum \text { Length of horizontal curve on segment }}{\text { Length of segment }}
$$




\section{Average Horizontal Curvature}

The average horizontal curvature on a segment is computed as follows:

$$
\text { Average Horizontal Curvature }=\frac{\sum\left(\frac{L}{R}\right)}{\text { Length of Segment }}
$$


Appendix C: Images of the Median Treatments

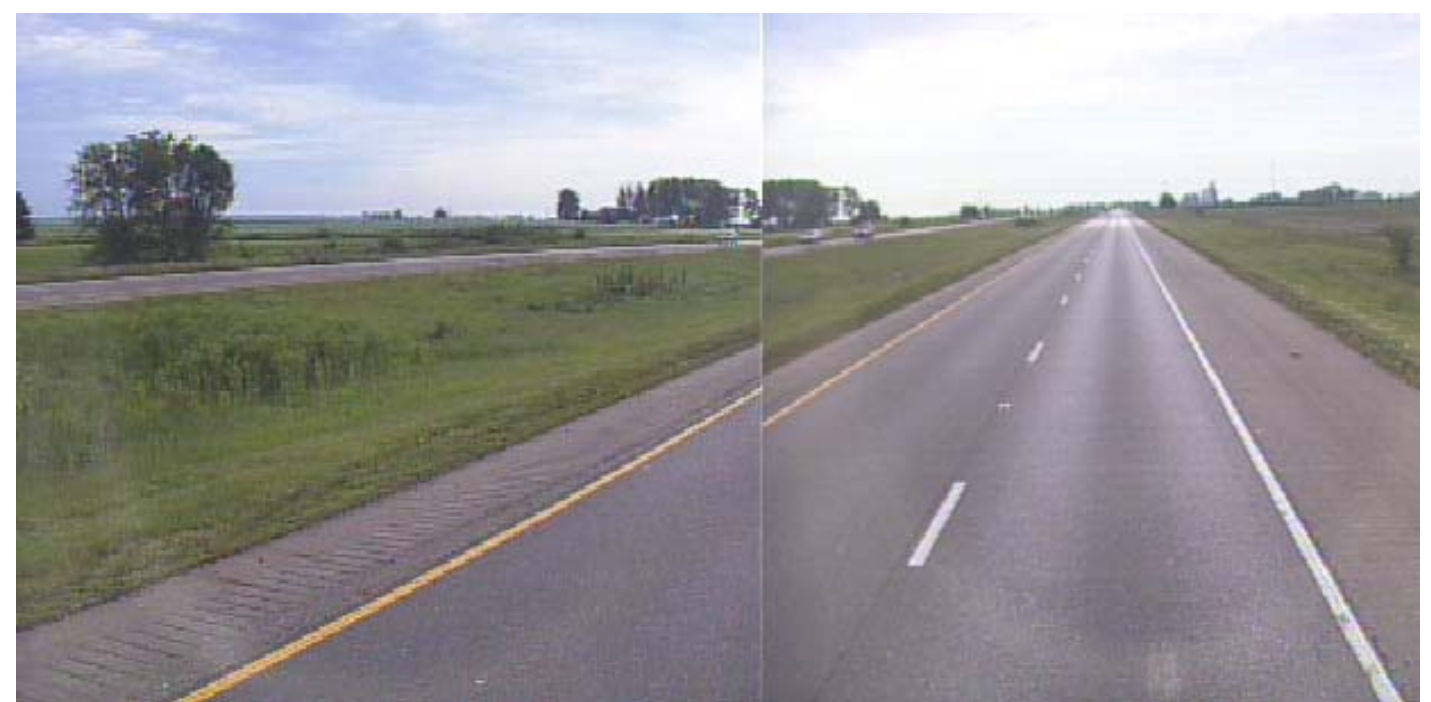

Figure C.1 Depressed Without a Median Barrier, Median Width 30 to 50 feet (D2N)

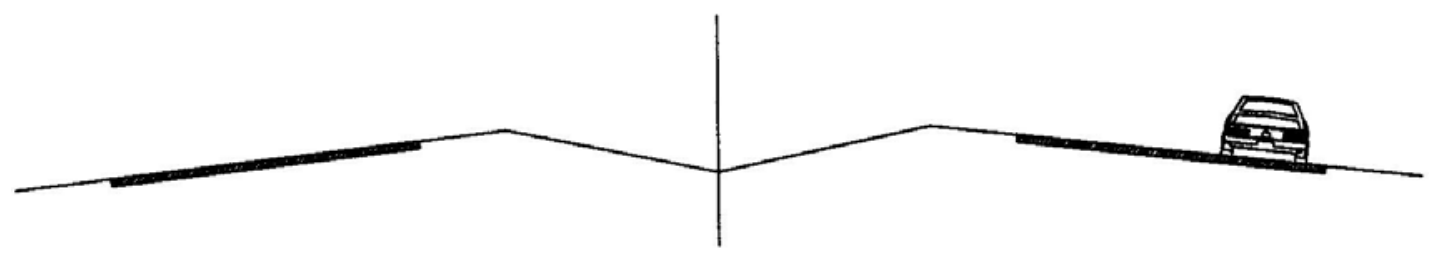

Figure C.2 Cross-Section of A Depressed Median



Figure C.3 Depressed With Berms,

Median Width Greater Than or Equal to 50 feet $(\mathrm{C} 3 \mathrm{~N})$ 




Figure C.4 Cross-Section of A Depressed Median With Berms

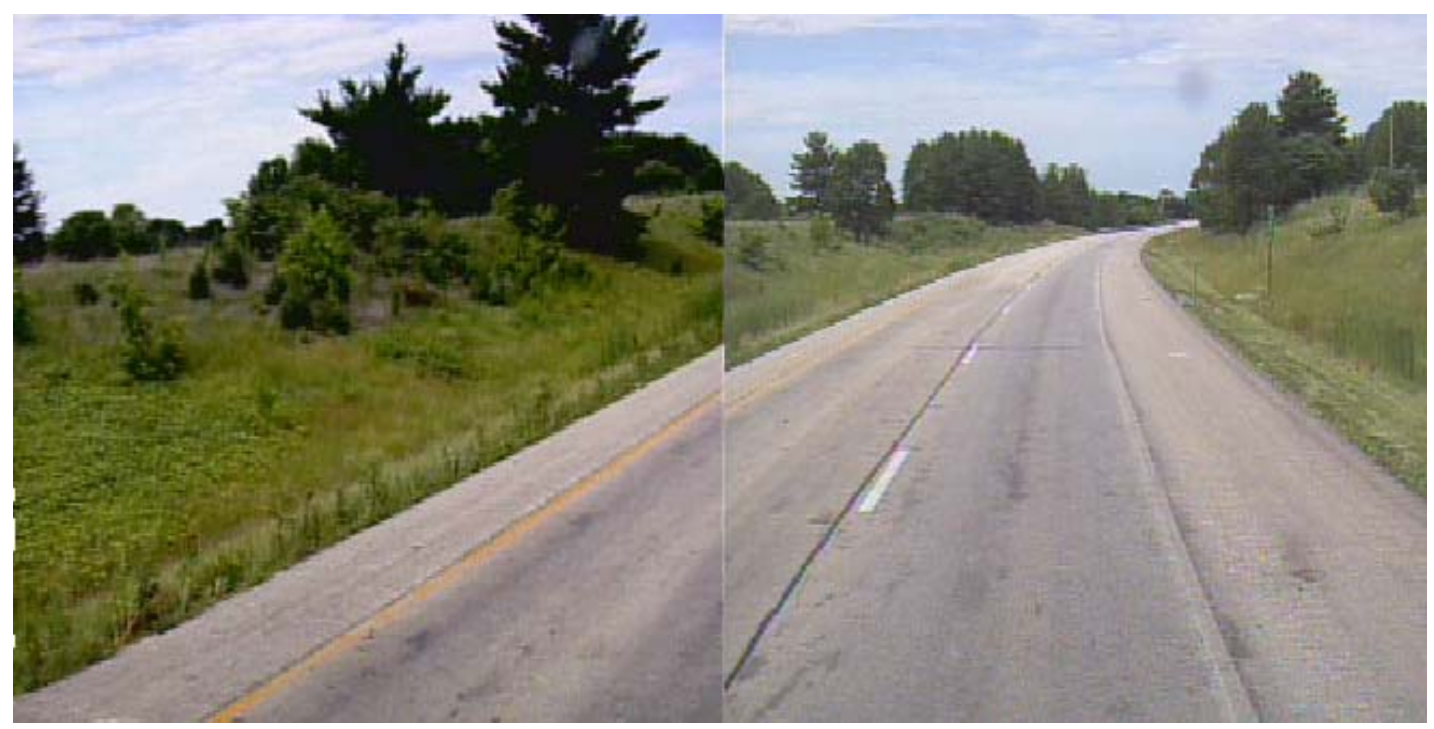

Figure C.5 Berms Without A Median Barrier, Median Width Greater Than or Equal to 50 feet (B3N)

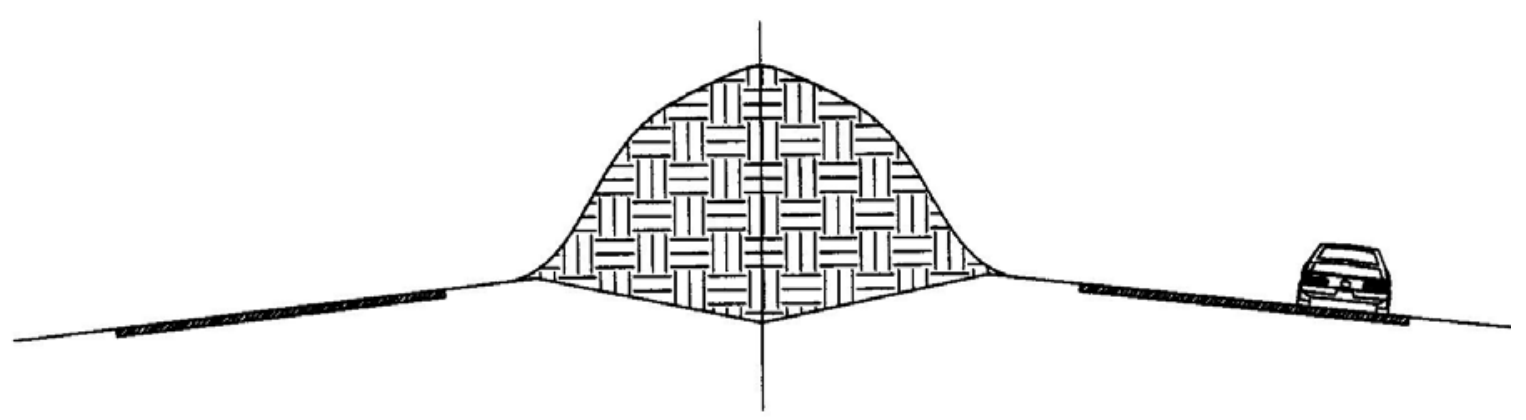

Figure C.6 Cross-Section of Berms Median Without Median Barrier 


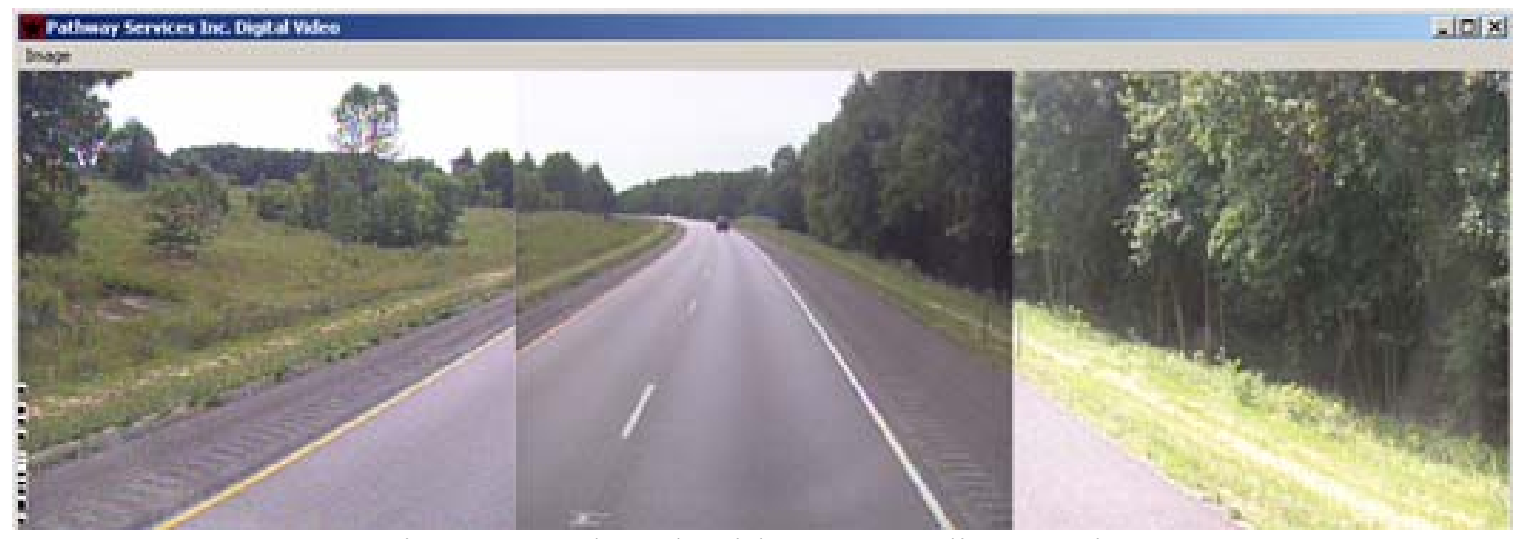

Figure C.7 Sloped Without A Median Barrier,

Median Width Greater Than or Equal to 50 feet (S3N)

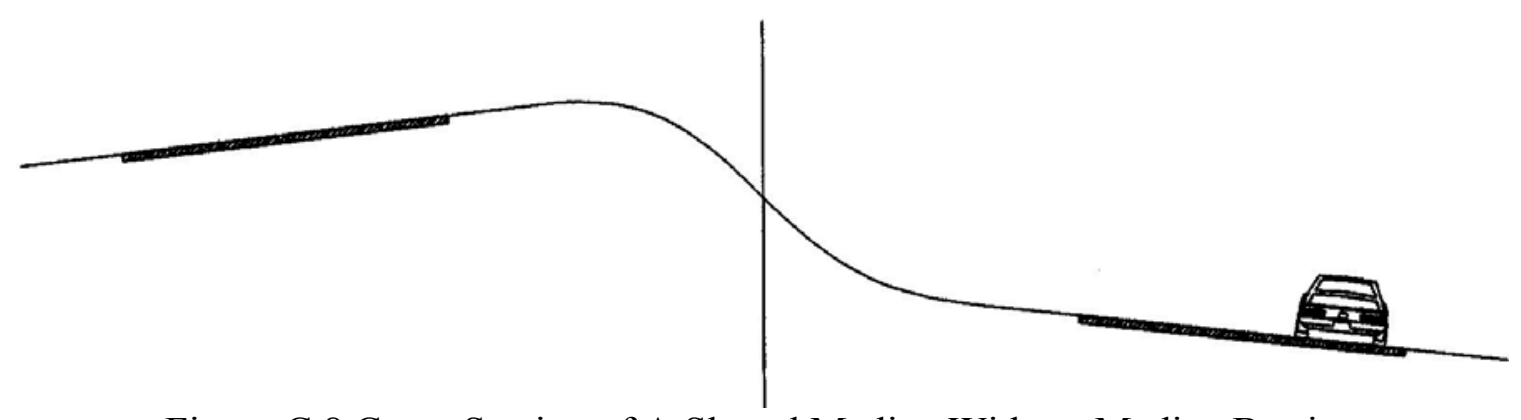

Figure C.8 Cross-Section of A Sloped Median Without Median Barrier 


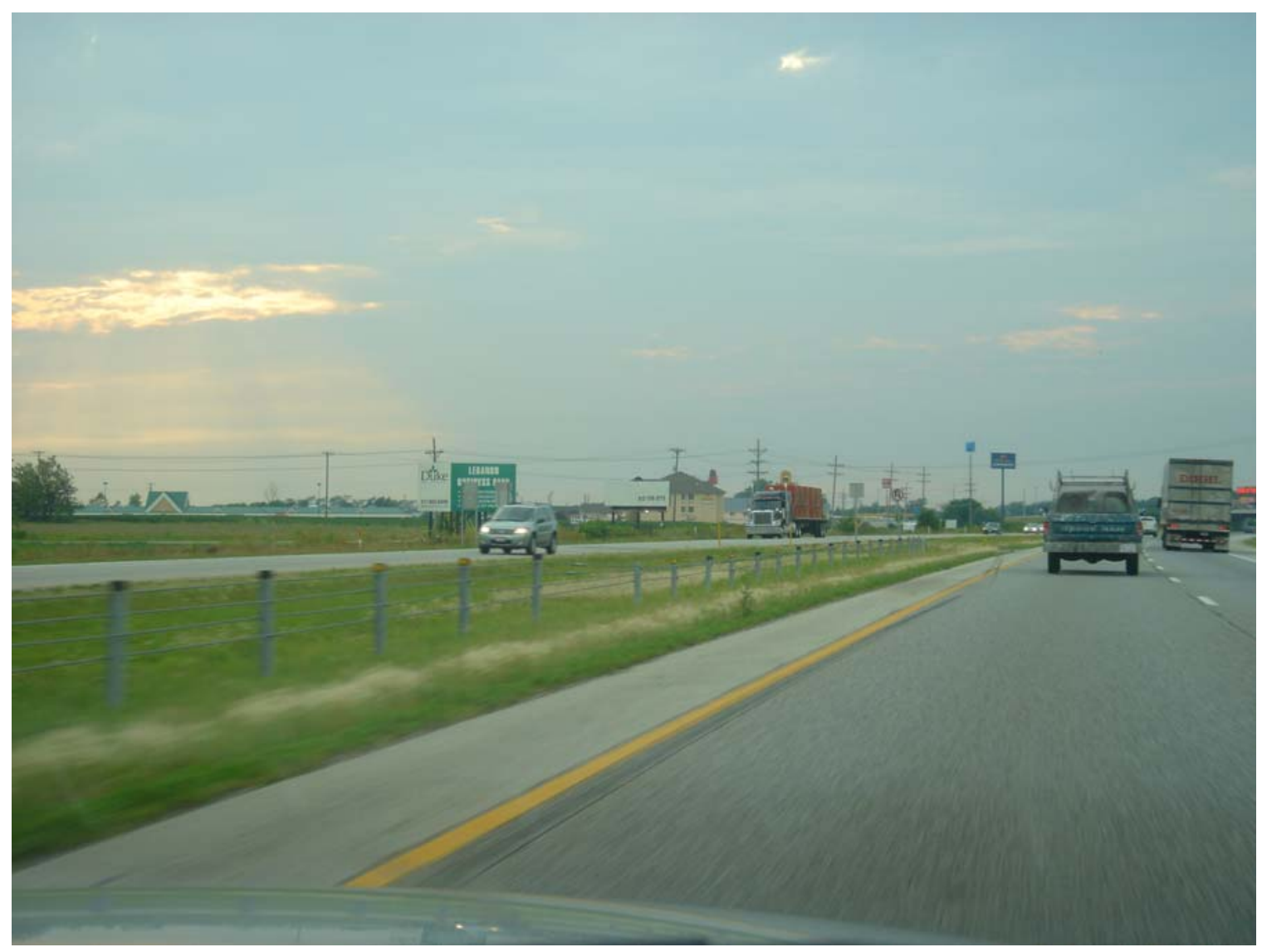

Figure C.9 Depressed Median With High-Tensioned Cable Barrier 


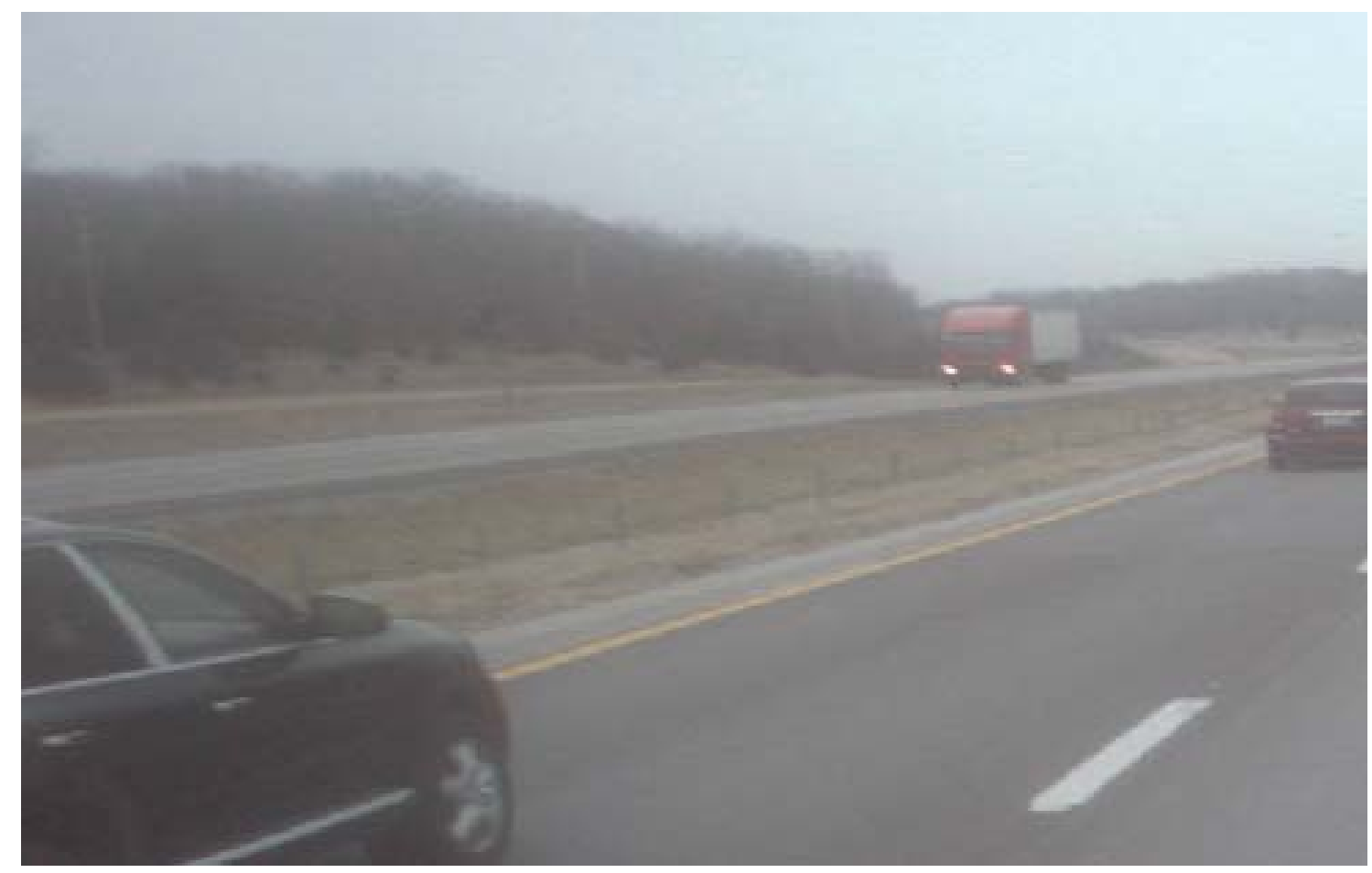

Figure C.10 Depressed Median With Low-Tensioned Cable Barrier

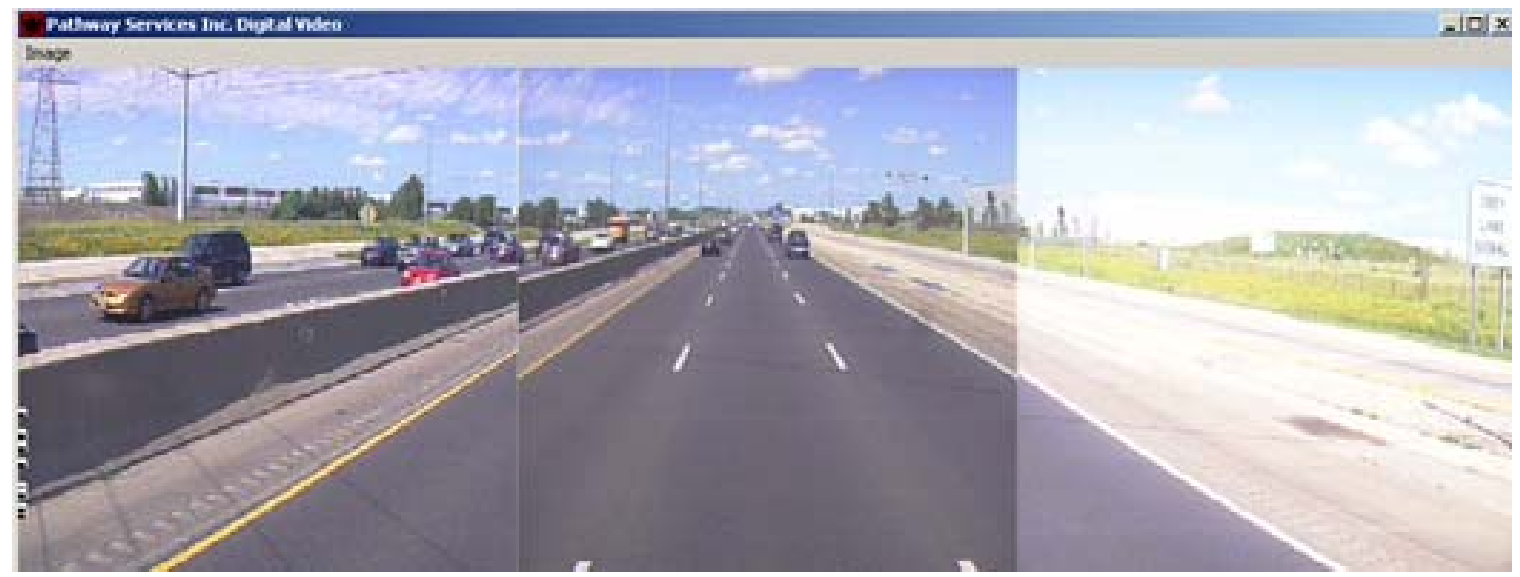

Figure C.11 Flush With A Concrete Median Barrier, Median Width Less Than or Equal to 30 feet (F1C) 


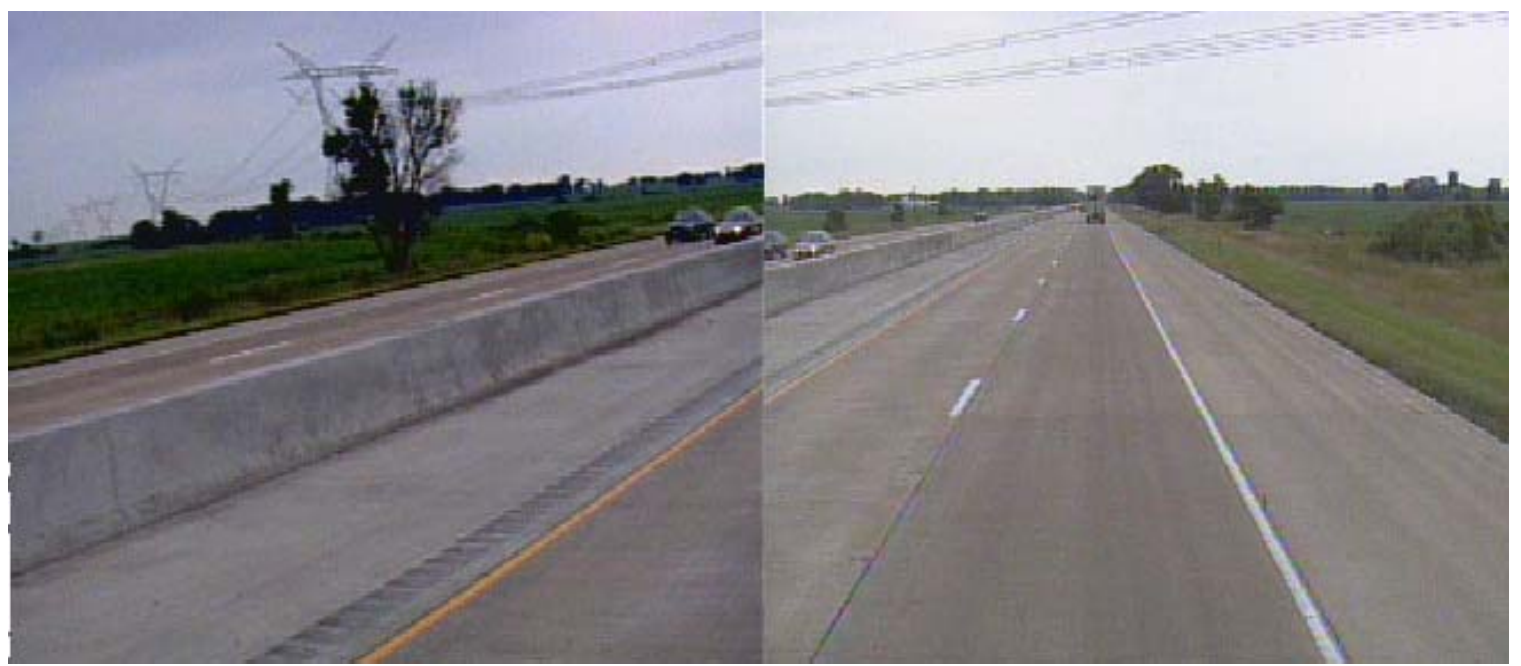

Figure C.12 Flush With A Concrete Median Barrier, Median Width 30 to 50 feet (F2C) 


\section{Appendix D: Crash Classifications}

Table D.1 Accuracy of First Crash Classification

\begin{tabular}{|c|c|c|c|}
\hline Crash ID & From assumptions & From crash reports & Same Coding \\
\hline 99022365003 & Crossover & Stopped in the median & No \\
\hline 97033122004 & Crossover & Crossover & Yes \\
\hline 99091231001 & Crossover & Stopped in the median & No \\
\hline 97012811003 & Crossover & Crossover & Yes \\
\hline 98110855001 & Crossover & Crossover & Yes \\
\hline 97061145017 & Crossover & Crossover & Yes \\
\hline 98080782002 & Crossover & Crossover & Yes \\
\hline 98121445042 & Crossover & Crossover & Yes \\
\hline 98073119002 & Crossover & Stopped in the median & No \\
\hline 99073131001 & Crossover & Stopped in the median & No \\
\hline 98081345035 & Crossover & Crossover & Yes \\
\hline 97111432006 & Crossover & Crossover & Yes \\
\hline 98100445020 & Crossover & Crossover & Yes \\
\hline 98090382001 & Crossover & Redirected crashes & No \\
\hline 97082682012 & Stopped in the median & Crossover & No \\
\hline 97071287005 & Stopped in the median & Stopped in the median & Yes \\
\hline 97021245025 & Stopped in the median & Stopped in the median & Yes \\
\hline 98031174001 & Stopped in the median & Bridge & No \\
\hline 98070422007 & Stopped in the median & Stopped in the median & Yes \\
\hline 98080545018 & Stopped in the median & $\begin{array}{l}\text { Stopped in the median } \\
\text { (redirected inside shoulder) }\end{array}$ & Yes \\
\hline 98090432006 & Stopped in the median & Crossover & No \\
\hline 99010837010 & Stopped in the median & Stopped in the median & Yes \\
\hline 99033137002 & Stopped in the median & Stopped in the median & Yes \\
\hline 99121637006 & Stopped in the median & Stopped in the median & Yes \\
\hline 99022367003 & Stopped in the median & Stopped in the median & Yes \\
\hline 99010323003 & Stopped in the median & Stopped in the median & Yes \\
\hline 99010532016 & Stopped in the median & Stopped in the median & Yes \\
\hline 97020882008 & Redirected crashes & Stopped in the median & No \\
\hline 99102755005 & Redirected crashes & Stopped in the median & No \\
\hline 99011645051 & Redirected crashes & Redirected crashes & Yes \\
\hline 97111311002 & Redirected crashes & Crossover & No \\
\hline 97021145026 & Redirected crashes & Stopped in the median & No \\
\hline 98102849070 & Redirected crashes & Redirected crashes & Yes \\
\hline 98120645029 & Redirected crashes & Redirected crashes & Yes \\
\hline 97011045037 & Redirected crashes & Stopped in the median & No \\
\hline 99031413004 & Redirected crashes & Redirected crashes & Yes \\
\hline 97041356003 & Redirected crashes & Crossover & No \\
\hline 97021245107 & Redirected crashes & Stopped in the median & No \\
\hline 98090737002 & Redirected crashes & Stopped in the median & No \\
\hline 98020482018 & Redirected crashes & $\begin{array}{l}\text { Stopped in the median/cross- } \\
\text { median }\end{array}$ & No \\
\hline
\end{tabular}


Table D.2 Accuracy of Second Crash Classification

\begin{tabular}{|c|c|c|c|c|}
\hline ID crash & From assumptions & From crash reports & Remarks & Good / Bad \\
\hline 97010132005 & Single vehicle & Single vehicle & Crash with a deer & Good \\
\hline 97010454002 & Single vehicle & Single vehicle & & Good \\
\hline 97010713001 & Single vehicle & Single vehicle & & Good \\
\hline 97011032001 & Single vehicle & Single vehicle & & Good \\
\hline 97011065001 & Single vehicle & Single vehicle & & Good \\
\hline 97012637002 & Single vehicle & Single vehicle & & Good \\
\hline 97012823001 & Single vehicle & Single vehicle & & Good \\
\hline 97021037002 & Single vehicle & Single vehicle & & Good \\
\hline 97021156001 & Single vehicle & Single vehicle & & Good \\
\hline 97021245107 & Single vehicle & Single vehicle & & Good \\
\hline 97010322001 & Same direction & Same direction & Description difficult to read & Good \\
\hline 97010331003 & Same direction & Same direction & Police pursuit & Good \\
\hline 97010722001 & Same direction & Same direction & & Good \\
\hline 97010732005 & Same direction & Same direction & & Good \\
\hline 97010954003 & Same direction & Same direction & & Good \\
\hline 97010984003 & Same direction & Same direction & & Good \\
\hline 97011045002 & Same direction & Same direction & & Good \\
\hline 97011045034 & Same direction & Same direction & & Good \\
\hline 97011511001 & Same direction & Same direction & & Good \\
\hline 97011545132 & Same direction & Same direction & $\begin{array}{l}\text { The third car actually responsible for } \\
\text { the crash of the two other ones } \\
\text { crossed the median (opposite } \\
\text { direction but not involved in the } \\
\text { crash) }\end{array}$ & Good \\
\hline 97011545136 & Same direction & Same direction & & Good \\
\hline 97012045007 & Same direction & Same direction & & Good \\
\hline 97012645092 & Same direction & Same direction & & Good \\
\hline 97012667006 & Same direction & Same direction & & Good \\
\hline 97012845049 & Same direction & Same direction & & Good \\
\hline 97021145024 & Same direction & Same direction & & Good \\
\hline 97021245001 & Same direction & Same direction & & Good \\
\hline 97021245111 & Same direction & Same direction & & Good \\
\hline 97010806004 & Opposite direction & Opposite direction & $\begin{array}{l}\text { Opposite and same direction (crash } \\
\text { on both sides with } 2 \text { different cars) }\end{array}$ & Good \\
\hline 97011037002 & Opposite direction & Opposite direction & & Good \\
\hline 97051845001 & Opposite direction & Opposite direction & & Good \\
\hline 97061145017 & Opposite direction & Opposite direction & & Good \\
\hline 97071187002 & Opposite direction & Same direction & & $\mathrm{Bad}$ \\
\hline 97080467001 & Opposite direction & Opposite direction ??? & $\begin{array}{l}1 \text { truck lost his wheel that crossed the } \\
\text { median to hit a car on the other side }\end{array}$ & Good \\
\hline 97092937001 & Opposite direction & Opposite direction & & Good \\
\hline 97101237002 & Opposite direction & Opposite direction & & Good \\
\hline 97110254002 & Opposite direction & Opposite direction & & Good \\
\hline 97111432006 & Opposite direction & Opposite direction & & Good \\
\hline 97112245001 & Opposite direction & Opposite direction & $\begin{array}{l}1 \text { car southbound / 1 car northbound } \\
\text { (but we don't know if the car crossed } \\
\text { the median) }\end{array}$ & Good \\
\hline 97120882015 & Opposite direction & Same direction & $\begin{array}{l}\text { Both vehicles were traveling } \\
\text { southbound but one spinned }\end{array}$ & $\mathrm{Bad}$ \\
\hline 97040722002 & Multiple unknown & Single vehicle & $\begin{array}{l}\text { One of the car left the scene } \\
\text { (direction unknown) - The one } \\
\text { responsible for the accident }\end{array}$ & N/A \\
\hline 97041145065 & Multiple unknown & Same direction & $\begin{array}{l}\text { One of the car left the scene } \\
\text { (direction unknown) }\end{array}$ & N/A \\
\hline 97041145073 & Multiple unknown & Same direction & $\begin{array}{l}\text { One of the car left the scene } \\
\text { (direction unknown) }\end{array}$ & N/A \\
\hline 97051931002 & Multiple unknown & Same direction & $\begin{array}{l}\text { Truck hits by a piece of metal that fell } \\
\text { down from the car he was following. } \\
\text { One of the car left the scene } \\
\text { (direction unknown) }\end{array}$ & N/A \\
\hline
\end{tabular}


Appendix E: Indiana

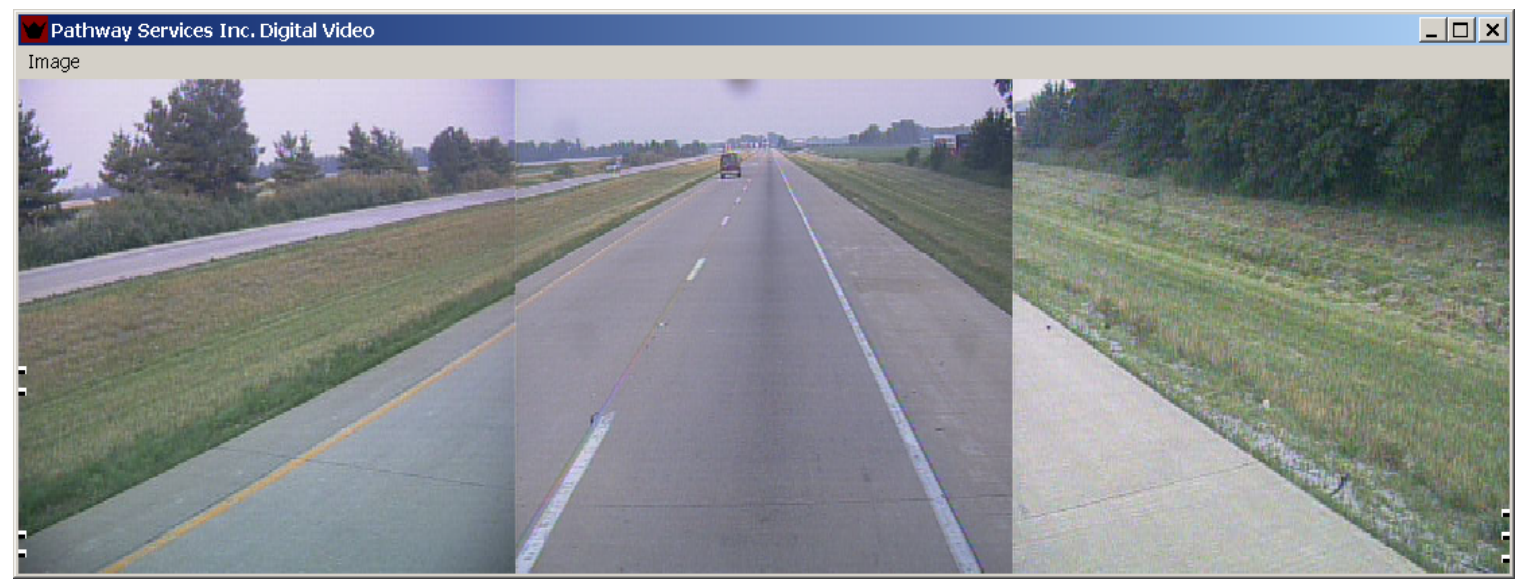

Figure E.1 Indiana Sample Video Log Image

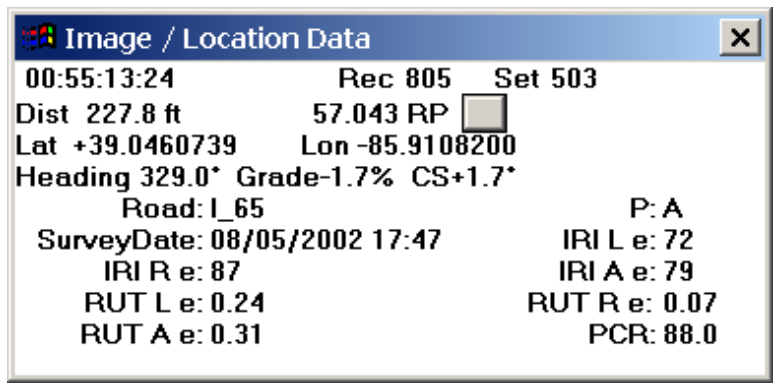

Figure E.2 Indiana Data for An Image 
Table E.1 Indiana Barrier Installation Dates

\begin{tabular}{|c|c|c|c|c|c|c|c|}
\hline \multirow{2}{*}{$\begin{array}{c}\text { New } \\
\text { Numbers }\end{array}$} & \multirow{2}{*}{$\begin{array}{l}\text { Interstate } \\
\text { Number }\end{array}$} & \multicolumn{3}{|c|}{ Section } & \multirow{2}{*}{$\begin{array}{l}\text { Presence } \\
\text { of a barrier }\end{array}$} & \multirow{2}{*}{ Barrier Type } & \multirow{2}{*}{$\begin{array}{c}\text { Barrier } \\
\text { Installation Yea }\end{array}$} \\
\hline & & $\begin{array}{l}\text { Beginning } \\
\text { (Road Post) }\end{array}$ & $\mid \begin{array}{c}\text { End (Road } \\
\text { Post) }\end{array}$ & Length (miles) & & & \\
\hline 52 & I164 & 0.076 & 0.385 & 0.309 & 1 & $\begin{array}{c}\text { aluminum balanced } \\
\text { beam }\end{array}$ & Not determined \\
\hline 53 & 165 & 256.915 & 257.194 & 0.279 & 1 & concrete - high & Not determined \\
\hline 54 & 165 & 256.13 & 256.866 & 0.736 & 1 & concrete - high & 1999 or 2000 \\
\hline 55 & 165 & 255.604 & 256.101 & 0.497 & 1 & concrete - high & 1999 or 2000 \\
\hline 56 & 165 & 255.315 & 255.563 & 0.248 & 1 & concrete - high & 1999 or 2000 \\
\hline 57 & 165 & 254.755 & 255.315 & 0.560 & 1 & concrete - high & 1999 or 2000 \\
\hline 58 & 165 & 253.934 & 254.725 & 0.791 & 1 & concrete - high & 1999 or 2000 \\
\hline 59 & 165 & 253.019 & 253.884 & 0.865 & 1 & concrete - high & 1999 or 2000 \\
\hline 96 & 164 & 21.408 & 21.558 & 0.150 & 1 & w-beam & Not determined \\
\hline 99 & 164 & 21.856 & 21.956 & 0.100 & 1 & w-beam & Not determined \\
\hline 101 & 164 & 22.025 & 22.165 & 0.140 & 1 & w-beam & Not determined \\
\hline 107 & 164 & 31.964 & 32.499 & 0.535 & 1 & w-beam & Not determined \\
\hline 108 & 164 & 32.578 & 32.835 & 0.257 & 1 & w-beam & Not determined \\
\hline 173 & 164 & 68.31 & 68.547 & 0.237 & 1 & w-beam & Not determined \\
\hline 179 & 164 & 69.949 & 70.167 & 0.218 & 1 & w-beam & Not determined \\
\hline 189 & 164 & 81.473 & 82.279 & 0.806 & 1 & w-beam & Not determined \\
\hline 213 & 164 & 92.558 & 92.983 & 0.425 & 1 & reinforced w-beam & Not determined \\
\hline 267 & 164 & 118.086 & 118.136 & 0.050 & 1 & double w-beam & Not determined \\
\hline 270 & 164 & 119.566 & 119.616 & 0.050 & 1 & double w-beam & Not determined \\
\hline 272 & 164 & 119.792 & 119.852 & 0.060 & 1 & rock wall & $\mathrm{N} / \mathrm{A}$ \\
\hline 282 & 164 & 120.688 & 120.891 & 0.203 & 1 & w-beam & Not determined \\
\hline 284 & 164 & 121.05 & 121.716 & 0.666 & 1 & double w-beam & Not determined \\
\hline 288 & 164 & 122.295 & 122.564 & 0.269 & 1 & concrete - low & Not determined \\
\hline 314 & 174 & 73.339 & 74.991 & 1.652 & 1 & concrete - low & Not determined \\
\hline 315 & 174 & 75.011 & 75.1 & 0.089 & 1 & concrete - low & Not determined \\
\hline 316 & 174 & 75.13 & 75.448 & 0.318 & 1 & concrete - low & Not determined \\
\hline 317 & 174 & 75.448 & 76.862 & 1.414 & 1 & concrete - low & Not determined \\
\hline 318 & 174 & 76.862 & 77.588 & 0.726 & 1 & concrete - low & Not determined \\
\hline 319 & 174 & 77.698 & 80.166 & 2.468 & 1 & concrete - low & Not determined \\
\hline 320 & 174 & 80.195 & 80.494 & 0.299 & 1 & concrete - low & Not determined \\
\hline 321 & 174 & 80.554 & 80.862 & 0.308 & 1 & concrete - low & Not determined \\
\hline 322 & 174 & 80.882 & 82.684 & 1.802 & 1 & concrete - low & Not determined \\
\hline 323 & 174 & 82.883 & 83.799 & 0.916 & 1 & concrete - low & Not determined \\
\hline 324 & 174 & 83.858 & 84.615 & 0.757 & 1 & concrete - low & Not determined \\
\hline 325 & 174 & 84.754 & 85.212 & 0.458 & 1 & concrete - low & Not determined \\
\hline 326 & 174 & 85.271 & 85.5 & 0.229 & 1 & concrete - low & Not determined \\
\hline 327 & 174 & 85.65 & 85.938 & 0.288 & 1 & concrete - low & Not determined \\
\hline 328 & 174 & 85.938 & 86.267 & 0.329 & 1 & w-beam & Not determined \\
\hline 329 & 174 & 86.317 & 87.142 & 0.825 & 1 & w-beam & Not determined \\
\hline 331 & 174 & 87.381 & 87.491 & 0.110 & 1 & concrete - low & Not determined \\
\hline 332 & 174 & 87.561 & 88.666 & 1.105 & 1 & concrete - low & Not determined \\
\hline 335 & 174 & 89.292 & 89.581 & 0.289 & 1 & concrete - low & Not determined \\
\hline 336 & 174 & 90.407 & 92.905 & 2.498 & 1 & concrete - low & Not determined \\
\hline
\end{tabular}




\section{Appendix F: Colorado}

This is a brief discussion on the simple linear regression models developed to predict the average vertical curvature for Colorado segments. The first model that was developed was one in which there was a constant. The output is in the table below.

Table F.1 With Constant, Predicting Average Horizontal Curvature

\begin{tabular}{|l|c|c|c|c|c|}
\hline Variable & Coefficient & Standard Error & b/St. Er. & $(|\mathrm{P}| \mathrm{Z}|>\mathrm{z}|)$ & Mean of X \\
\hline Constant & -0.025243 & 0.044540446 & -0.567 & 0.5709 & \\
\hline $\mathrm{PHC}$ & 1.3089842 & 0.09383461 & 13.95 & 0 & 0.31969 \\
\hline
\end{tabular}

$\mathrm{n}=1009$

Log likelihood $=-1475.9063$

Restricted Log likelihood $=-1565.0405$

There are two things that should be observed with respect to the constant: first, it is insignificant, second, the coefficient is very close to 0 , as would be expected. As such, the model was further reduced to the following:

Table F.2 Without Constant, Predicting Average Horizontal Curvature

\begin{tabular}{|l|c|c|c|c|c|}
\hline Variable & Coefficient & Standard Error & b/St. Er. & $(|\mathrm{P}| \mathrm{Z}|>\mathrm{z}|)$ & Mean of X \\
\hline
\end{tabular}

$\mathrm{n}=1009$

\begin{tabular}{|l|c|c|c|c|c|}
\hline PHC & 1.273168 & 0.069337937 & 18.362 & 0 & 0.31969 \\
\hline
\end{tabular}

Log likelihood $=-1476.0672$

Restricted Log likelihood $=-1565.0405$ 
Table F.3 Installation Dates of High-Tensioned Cable Barriers \begin{tabular}{|l|l|}
\hline Segment Number & Barrier Installation Dates \\
\hline
\end{tabular}

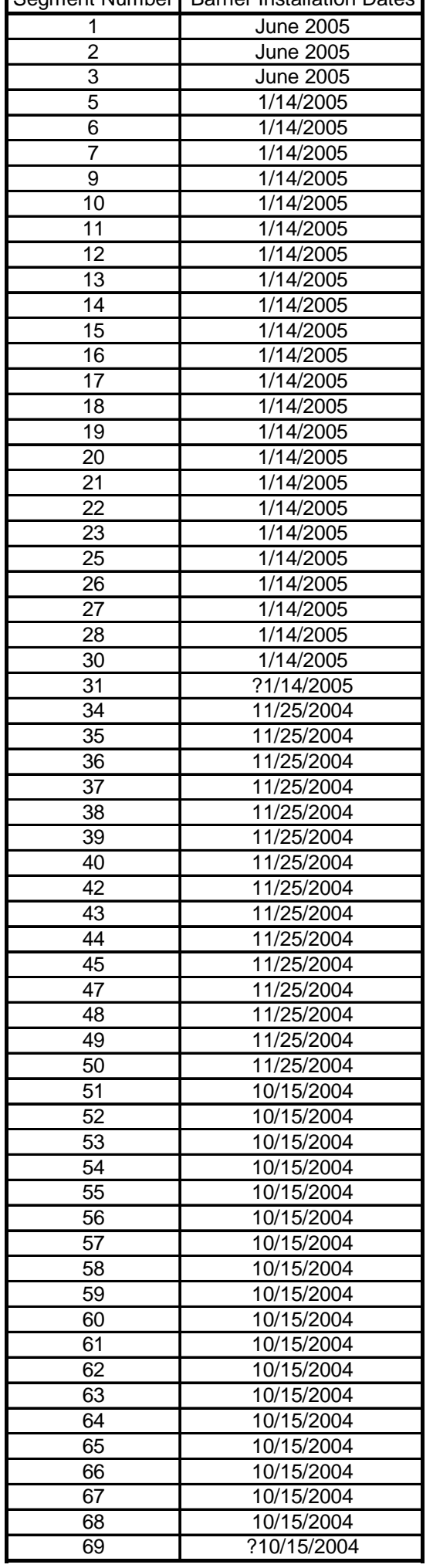


Appendix G: Illinois

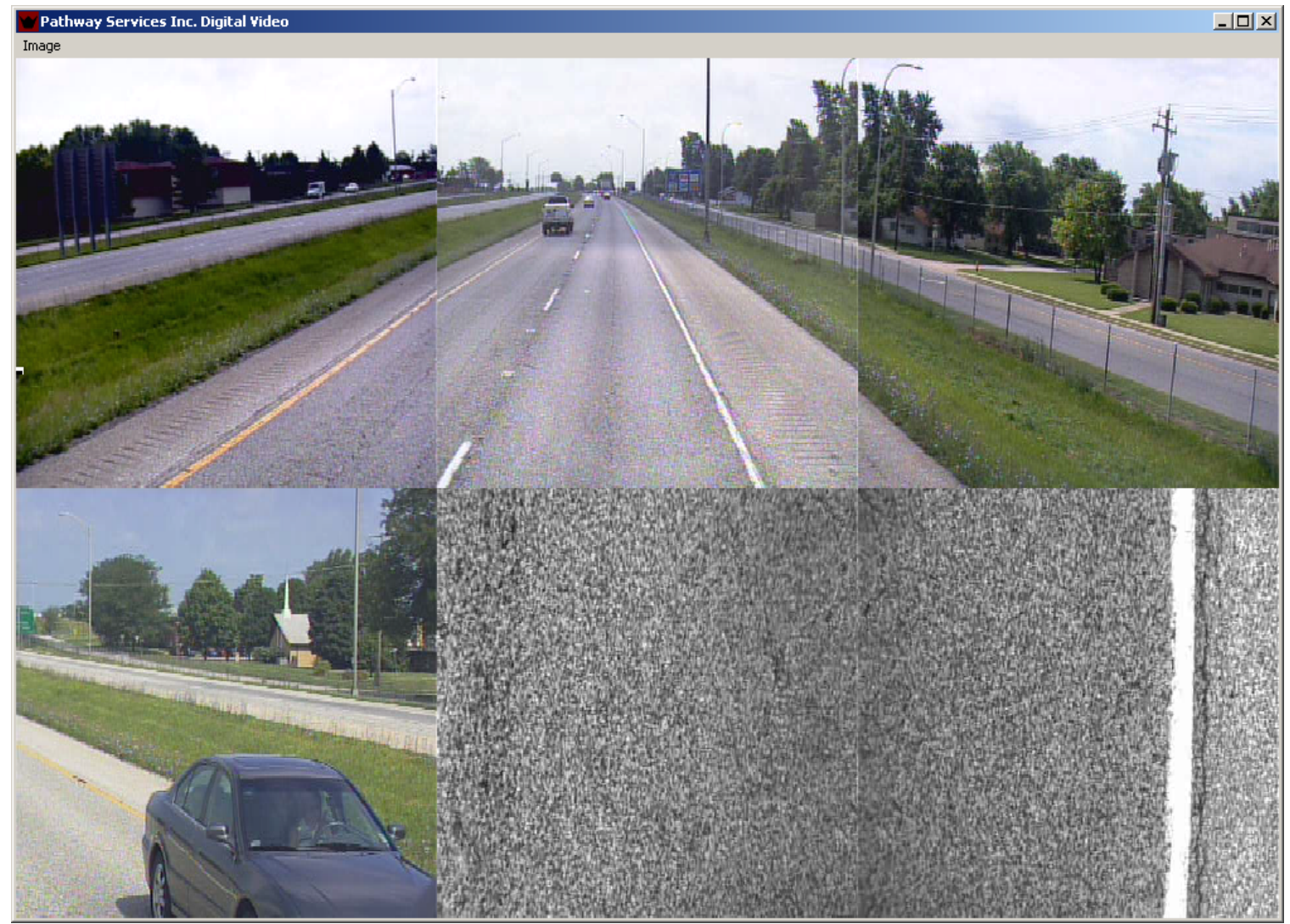

Figure G.1 Illinois Sample Video Log Image



Figure G.2 Illinois Data for An Image 
Interstates

Median Width and Positive Barrier

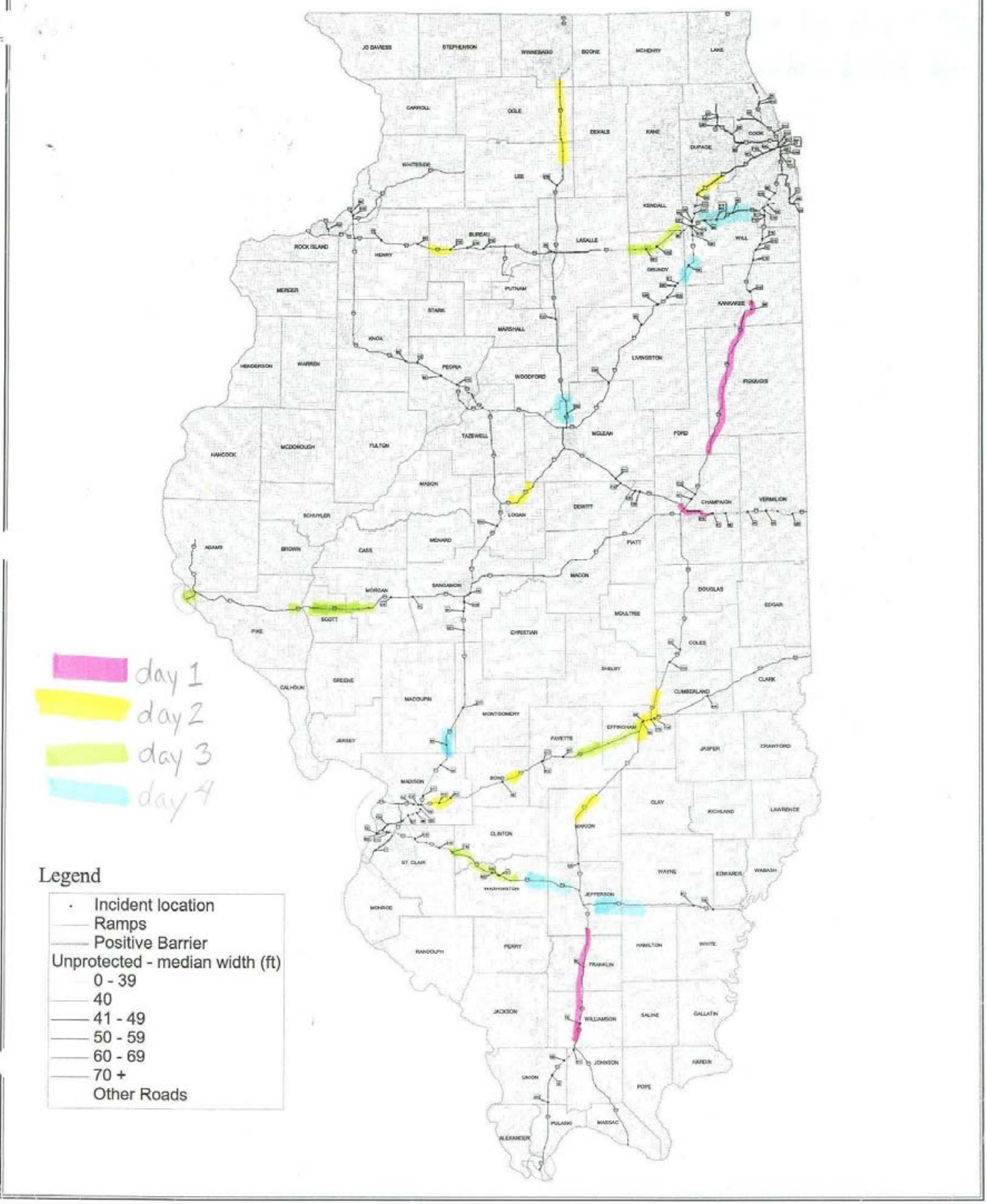

Figure G.3 Illinois Locations of Data Collection 
Table G.1: Multiple Vehicle - Opposite Direction Crash Explanations

\begin{tabular}{|c|c|c|c|c|}
\hline $\begin{array}{l}\text { Crash } \\
\text { Number }\end{array}$ & $\begin{array}{l}\text { Crash } \\
\text { Year }\end{array}$ & Interstate & Explanation & $\begin{array}{c}\text { Caused by } \\
\text { Debris }\end{array}$ \\
\hline 3892932 & 2000 & 55 & Part of trailer from one unit detached went over barrier and struck another unit. & Yes \\
\hline 14198402 & 2001 & 55 & Unit struck by tire that rolled over from unit traveling in opp. direction. & Yes \\
\hline 34173633 & 2003 & 55 & Unit struck by tire from unit traveling in opp. direction. Tire went over center barrier. & Yes \\
\hline 670851 & 2000 & 55 & Unit struck by ice/snow debris kicked over barrier by snow plow. & Yes \\
\hline 1337351 & 2000 & 55 & Unit 1 crossed median and struck unit 2. Alcohol involved. & No \\
\hline 992425206 & 1999 & 55 & Tire detached from unit 1, crossed over and hit Unit 2 & Yes \\
\hline 993004018 & 1999 & 55 & Occurred on frontage road. Mislocated. & No \\
\hline 22843767 & 2002 & 74 & Turning collision at intersection of ramp and local street & No \\
\hline 23541709 & 2002 & 74 & Tire detached from unit 1, crossed over and hit Unit 2 & Yes \\
\hline 25122359 & 2002 & 74 & Tire detached & Yes \\
\hline 990895145 & 1999 & 74 & Unit1 slid into Unit 2's traffic lane. Both headed same direction on a bridge. & No \\
\hline 990808999 & 1999 & 74 & See below & Yes \\
\hline 990809286 & 1999 & 74 & See below & Yes \\
\hline 990891375 & 1999 & 74 & See below & Yes \\
\hline 866905 & 2000 & 80 & Tire detached & Yes \\
\hline 4685202 & 2000 & 80 & Tire detached & Yes \\
\hline 5413604 & 2000 & 80 & Vehicle struck median. Debris thrown over barrier onto oncoming veh windshield & Yes \\
\hline 11775038 & 2001 & 80 & Bedliner from EB unit flew over barrier, struck by WB unit & Yes \\
\hline 21389390 & 2002 & 80 & Vehicle struck median. Debris flew over barrier innto oncoming traffic & Yes \\
\hline 23466089 & 2002 & 80 & Tire detached from unit 1, crossed over and hit Unit 2 & Yes \\
\hline 32068595 & 2003 & 80 & Unit 1 tire detached, Xed over construction median \& hit Unit 2 parked in rest area ramp & Yes \\
\hline 32669160 & 2003 & 80 & Tire detached & Yes \\
\hline 33275579 & 2003 & 80 & Tire detached & Yes \\
\hline 991954222 & 1999 & 80 & Semi lost control, drove through barrier, overturned, spread debris in opposing lanes. & No \\
\hline 4693479 & 2000 & 80 & Tire detached and crossed over barrier. & Yes \\
\hline
\end{tabular}

***Three crashes, all related, but coded separately. These 3 EB crashes took place as a result of a previous westbound crash. A WB truck with a large toolbox and other items in the bed was struck by a semi. The force sent the debris from the truck over the median wall, causing the three crashes listed above. Some vehicles struck debris and others skidded because of the icy conditions. The only crossover was the debris. 
Table G.2 Illinois Barrier Installation Dates

\begin{tabular}{|c|c|c|c|c|c|}
\hline $\begin{array}{l}\text { Segment } \\
\text { Number }\end{array}$ & $\begin{array}{c}\text { Interstate } \\
\text { Number }\end{array}$ & $\begin{array}{l}\text { Beginning } \\
\text { Milepost }\end{array}$ & $\begin{array}{c}\text { End } \\
\text { Milepost }\end{array}$ & Type of Barrier & $\begin{array}{c}\text { Barrier } \\
\text { Installation } \\
\text { Dates }\end{array}$ \\
\hline 2 & 74 & 180.072 & 180.126 & w-beam & Not determined \\
\hline 3 & 74 & 180.126 & 184.391 & Concrete & Not determined \\
\hline 16 & 57 & 310.835 & 311.476 & Concrete & Not determined \\
\hline 17 & 57 & 311.476 & 311.705 & Concrete & Not determined \\
\hline 18 & 57 & 311.882 & 312.061 & Concrete & Not determined \\
\hline 79 & 55 & 260.989 & 261.824 & double w-beam & Not determined \\
\hline 80 & 55 & 261.842 & 263.385 & double w-beam & Not determined \\
\hline 81 & 55 & 264.932 & 266.352 & Concrete-high & Not determined \\
\hline 82 & 55 & 266.352 & 268.615 & Concrete-low & Not determined \\
\hline 122 & 70 & 89.119 & 89.211 & w-beam & Not determined \\
\hline 123 & 70 & 89.211 & 89.295 & w-beam & Not determined \\
\hline 130 & 70 & 90.889 & 90.925 & w-beam & Not determined \\
\hline 145 & 80 & 114.975 & 116.334 & Concrete & 2003 \\
\hline 147 & 80 & 116.654 & 119.258 & Concrete & 2003 \\
\hline 149 & 80 & 119.278 & 120.789 & Concrete & 2003 \\
\hline 150 & 80 & 120.789 & 121.049 & Concrete & 2003 \\
\hline 154 & 72 & 2.873 & 2.911 & w-beam & Not determined \\
\hline 156 & 72 & 40.511 & 40.586 & Concrete & Not determined \\
\hline 232 & 80 & 137.945 & 138.253 & Concrete (discontinuous) & Not determined \\
\hline 233 & 80 & 138.253 & 138.271 & w-beam & Not determined \\
\hline 235 & 80 & 138.29 & 138.299 & w-beam & Not determined \\
\hline 236 & 80 & 138.299 & 138.857 & Concrete (discontinuous) & Not determined \\
\hline 237 & 80 & 138.857 & 138.877 & w-beam & Not determined \\
\hline 239 & 80 & 138.886 & 138.904 & w-beam & Not determined \\
\hline 240 & 80 & 138.904 & 141.107 & Concrete (discontinuous) & Not determined \\
\hline 241 & 80 & 141.716 & 142.375 & Concrete (discontinuous) & Not determined \\
\hline 242 & 80 & 142.375 & 142.393 & w-beam & Not determined \\
\hline 244 & 80 & 142.41 & 142.428 & w-beam & Not determined \\
\hline 245 & 80 & 142.428 & 144.669 & Concrete (discontinuous) & Not determined \\
\hline 246 & 80 & 144.669 & 145.017 & Concrete & Not determined \\
\hline 248 & 80 & 145.029 & 147.088 & Concrete & Not determined \\
\hline 249 & 80 & 147.088 & 147.406 & Concrete - high & Not determined \\
\hline 250 & 80 & 147.406 & 147.504 & Concrete & Not determined \\
\hline 252 & 80 & 147.522 & 148.866 & Concrete & Not determined \\
\hline 265 & 39 & 7.839 & 9.187 & Concrete & Not determined \\
\hline
\end{tabular}


Appendix H: Missouri

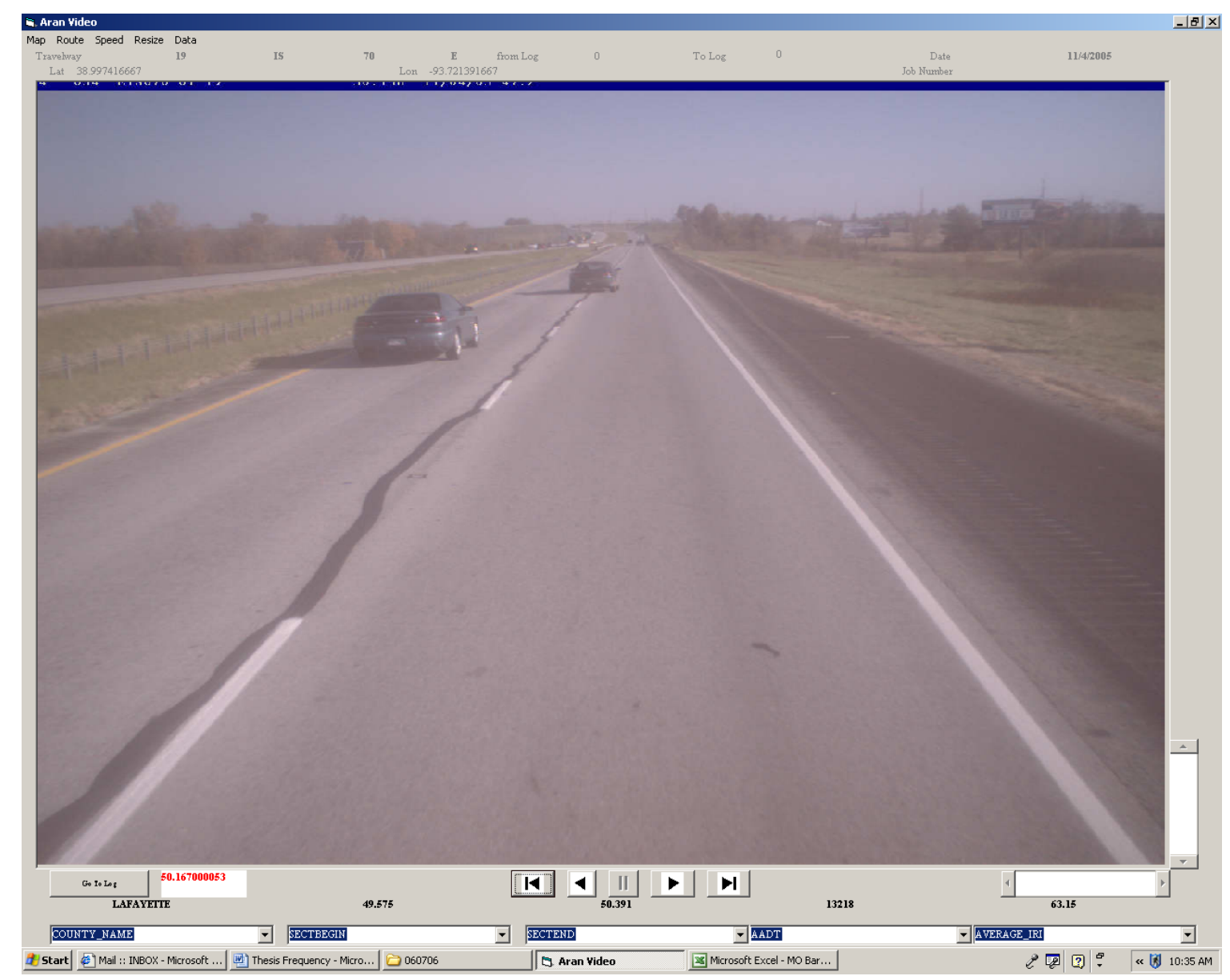

Figure H.1 Missouri Sample Video Log Image 
Table H.1 Missouri Barrier Installation Dates

\begin{tabular}{|c|c|c|c|c|c|}
\hline $\begin{array}{c}\text { Segment } \\
\text { Number }\end{array}$ & $\begin{array}{c}\text { Interstate } \\
\text { Number }\end{array}$ & $\begin{array}{c}\text { Beginning } \\
\text { Milepost }\end{array}$ & $\begin{array}{c}\text { End } \\
\text { Milepost }\end{array}$ & Type of Barrier & $\begin{array}{c}\text { Latest Year } \\
\text { of Barrier } \\
\text { Installation }\end{array}$ \\
\hline 62 & 70 & 124.56 & 128.13 & Concrete & pre-2004 \\
\hline 82 & 70 & 164.935 & 165.657 & Low-tensioned & 2004 \\
\hline 91 & 70 & 169.065 & 170.025 & Low-tensioned & 2004 \\
\hline 92 & 70 & 170.064 & 170.466 & Low-tensioned & 2000 \\
\hline 93 & 70 & 170.502 & 170.932 & Low-tensioned & 2000 \\
\hline 94 & 70 & 171.707 & 174.154 & Low-tensioned & 2002 \\
\hline 95 & 70 & 174.193 & 175.61 & Low-tensioned & 2002 \\
\hline 96 & 70 & 175.629 & 179.452 & Low-tensioned & 2004 \\
\hline 97 & 70 & 179.473 & 180.829 & Low-tensioned & 2004 \\
\hline 99 & 70 & 181.134 & 181.829 & Concrete & pre-2004 \\
\hline 100 & 70 & 181.829 & 183.62 & Low-tensioned & 2004 \\
\hline 101 & 70 & 183.644 & 183.863 & Low-tensioned & 2004 \\
\hline 102 & 70 & 183.974 & 184.331 & Low-tensioned & 2004 \\
\hline 103 & 70 & 184.354 & 185.028 & Low-tensioned & 2004 \\
\hline 104 & 70 & 185.047 & 185.967 & Low-tensioned & 2004 \\
\hline 105 & 70 & 186.294 & 187.316 & Low-tensioned & 2004 \\
\hline 106 & 70 & 187.336 & 188.438 & Low-tensioned & 2000 \\
\hline 107 & 70 & 188.577 & 193.122 & Low-tensioned & 2004 \\
\hline 109 & 70 & 193.41 & 193.826 & Concrete & pre-2004 \\
\hline 110 & 70 & 194.434 & 197.616 & Low-tensioned & 2004 \\
\hline 111 & 70 & 197.636 & 198.011 & Low-tensioned & 2004 \\
\hline 112 & 70 & 198.031 & 198.631 & Low-tensioned & 2000 \\
\hline 113 & 70 & 198.673 & 199.712 & Low-tensioned & 2004 \\
\hline 115 & 70 & 200.843 & 203.508 & Low-tensioned & 2002 \\
\hline 116 & 70 & 203.885 & 205.705 & Low-tensioned & 2002 \\
\hline 117 & 70 & 205.724 & 207.885 & Low-tensioned & 2002 \\
\hline 118 & 70 & 209.792 & 210.426 & Concrete & 2002 \\
\hline
\end{tabular}


Appendix I: Ohio

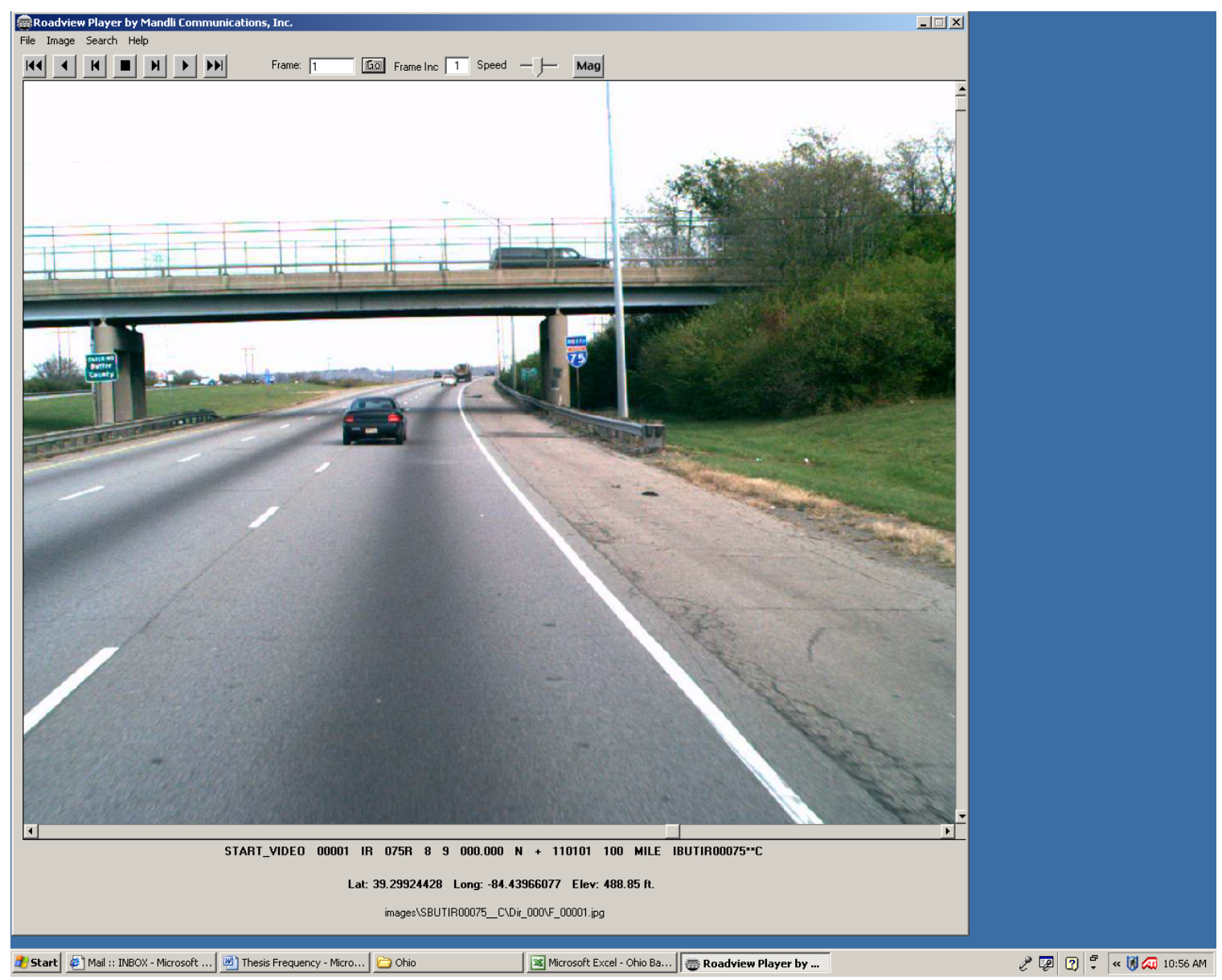

Figure I.1 Ohio Sample Video Log Image 
Table I.1 Ohio Barrier Installation Dates

\begin{tabular}{|c|c|c|c|c|c|}
\hline $\begin{array}{c}\text { Segment } \\
\text { Number }\end{array}$ & $\begin{array}{c}\text { Interstate } \\
\text { Number }\end{array}$ & $\begin{array}{c}\text { Beginning } \\
\text { Milepost }\end{array}$ & $\begin{array}{c}\text { End } \\
\text { Milepost }\end{array}$ & $\begin{array}{c}\text { Type of } \\
\text { Barrier }\end{array}$ & $\begin{array}{c}\text { Year of } \\
\text { Barrier } \\
\text { Installation }\end{array}$ \\
\hline 61 & 75 & 24.467 & 24.928 & Brifen WRSF & 2003 \\
\hline 62 & 75 & 24.958 & 25.448 & Brifen WRSF & 2003 \\
\hline 63 & 75 & 25.468 & 25.989 & Brifen WRSF & 2003 \\
\hline 64 & 75 & 26.019 & 27.07 & Brifen WRSF & 2003 \\
\hline 65 & 75 & 27.09 & 28.221 & Brifen WRSF & 2003 \\
\hline 66 & 75 & 28.581 & 28.721 & Brifen WRSF & 2003 \\
\hline 67 & 75 & 28.906 & 29.262 & Brifen WRSF & 2003 \\
\hline 68 & 75 & 29.31 & 29.782 & Brifen WRSF & 2003 \\
\hline 69 & 75 & 29.859 & 30.532 & Brifen WRSF & 2003 \\
\hline 70 & 75 & 30.571 & 31.254 & Brifen WRSF & 2003 \\
\hline 71 & 75 & 31.292 & 32.033 & Brifen WRSF & 2003 \\
\hline 72 & 75 & 32.071 & 34.987 & Brifen WRSF & 2003 \\
\hline 73 & 75 & 35.025 & 35.833 & Brifen WRSF & 2003 \\
\hline 74 & 75 & 35.872 & 37.719 & Brifen WRSF & 2003 \\
\hline
\end{tabular}

Table I.2: Ohio: Explanation for Crossover Crashes on Segments with Cable Barrier

\begin{tabular}{|c|c|c|c|c|}
\hline Crash Number & $\begin{array}{c}\text { Crash } \\
\text { Year }\end{array}$ & Interstate & Explanation & $\begin{array}{c}\text { Caused } \\
\text { by Debris }\end{array}$ \\
\hline 20048157404 & 2004 & 75 & $\begin{array}{c}\text { Part of a load carried by unit \#1 went across the } \\
\text { median, but not the vehicle }\end{array}$ & Yes \\
\hline 20048179849 & 2004 & 75 & Unit \#1 was backing up on the shoulder. & No \\
\hline 20048290246 & 2004 & 75 & Unit \#1 was backing up on the shoulder. & No \\
\hline 20058117144 & 2005 & 75 & $\begin{array}{c}\text { A brake drum from Unit \#3 went across the } \\
\text { median and struck another vehicle }\end{array}$ & Yes \\
\hline 20048031127 & 2004 & 75 & $\begin{array}{c}\text { The vehicle was traveling in the wrong direction } \\
\text { on the Interstate }\end{array}$ & No \\
\hline 20058015179 & 2005 & 75 & $\begin{array}{c}\text { The vehicle was able to penetrate the cable } \\
\text { barrier. }\end{array}$ & No \\
\hline
\end{tabular}




\section{Appendix J: Washington}

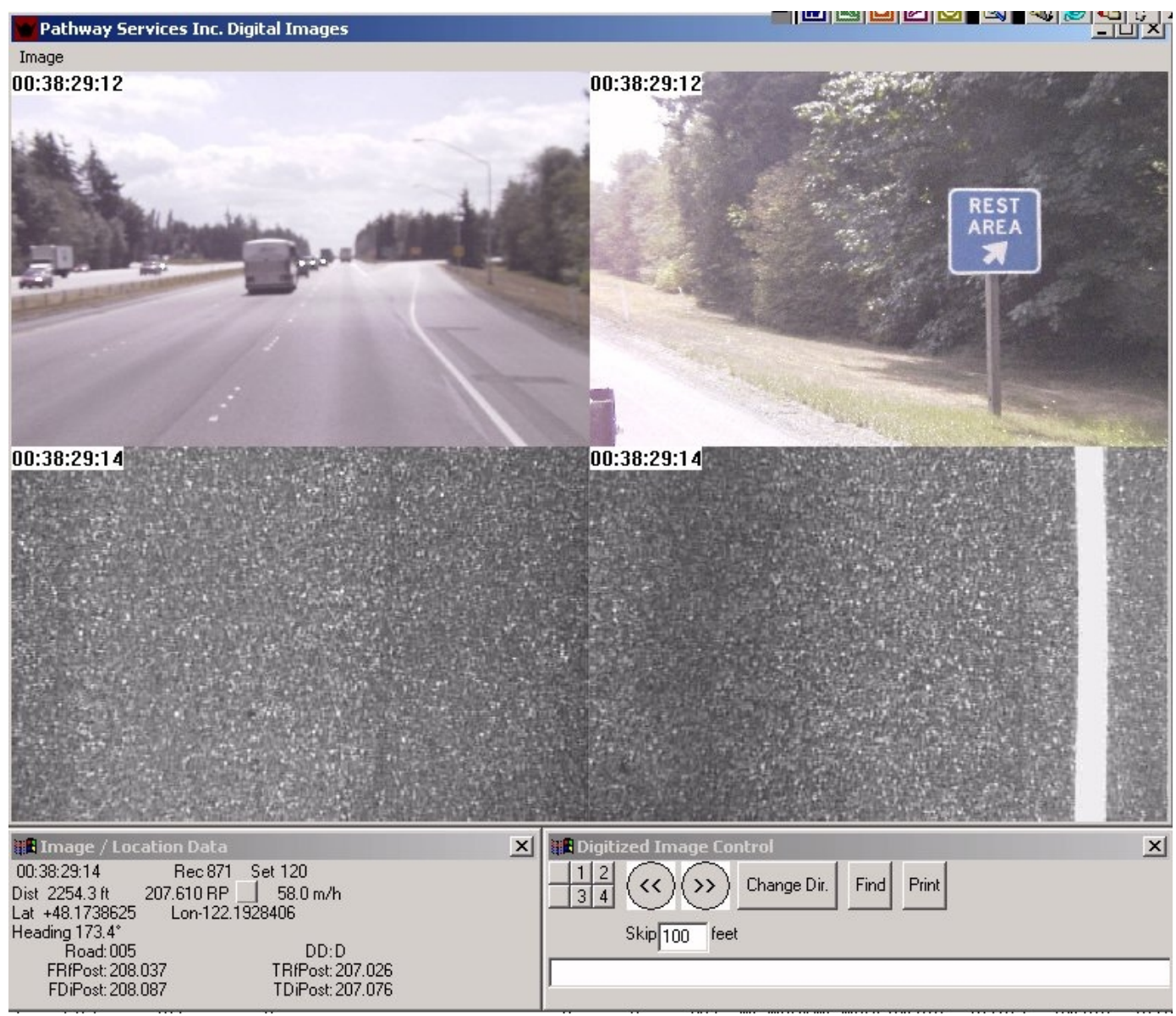

Figure J.1 Sample Washington State Video Log Image 
Appendix K: Pearson Coefficient of Correlation

Table K.1 Pearson Coefficients of Correlation Between the Median Treatments and Traffic and Geometric Variables

\begin{tabular}{|c|c|c|c|c|c|c|c|c|c|c|c|c|}
\hline \multirow{2}{*}{ Variables } & \multicolumn{10}{|c|}{ Median Treatment } \\
\cline { 2 - 11 } & D2H & D3H & D2L & D3L & C3N & B3N & F1W & F1C & F2C & S3N & D1N & D2N \\
\hline LNS & -0.03651 & 0.14699 & 0.04723 & 0.13322 & -0.09739 & 0.07378 & -0.05218 & 0.22844 & -0.04989 & 0.30500 & 0.09460 & -0.17747 \\
POB & -0.01876 & -0.04192 & 0.23429 & -0.02029 & -0.02952 & -0.05133 & -0.02682 & 0.10727 & -0.02476 & -0.00034 & 0.00793 & 0.06552 \\
AADT & 0.06150 & 0.23830 & 0.08629 & 0.01350 & -0.04444 & 0.10608 & -0.03311 & 0.27863 & 0.04259 & 0.23531 & -0.00440 & -0.16525 \\
PT & -0.08592 & -0.10378 & -0.09406 & -0.06782 & 0.25800 & 0.00577 & -0.10638 & -0.13039 & -0.11027 & -0.11440 & -0.04716 & -0.01466 \\
ROF & 0.00661 & 0.02452 & 0.03149 & -0.03425 & -0.05697 & 0.05609 & -0.04296 & 0.11110 & 0.08352 & 0.07502 & -0.03956 & 0.04539 \\
RON & -0.00027 & 0.00581 & 0.00421 & -0.03418 & -0.08354 & 0.03934 & -0.04329 & 0.07353 & 0.08754 & 0.13432 & -0.03724 & 0.03442 \\
BRG & -0.03478 & -0.03950 & -0.00363 & -0.03761 & -0.01784 & 0.02981 & -0.04970 & 0.03849 & 0.07662 & 0.02370 & -0.04024 & 0.00315 \\
PVC & 0.09424 & 0.12130 & 0.00725 & 0.02547 & -0.00154 & 0.02195 & 0.07719 & -0.01806 & 0.00216 & 0.03402 & 0.05041 & -0.09797 \\
PHC & -0.01929 & -0.00086 & 0.01364 & -0.03956 & 0.00018 & 0.07327 & -0.01876 & -0.01309 & -0.01936 & 0.06462 & 0.01496 & -0.08403 \\
PSL & 0.15523 & 0.11031 & 0.09247 & -0.01085 & 0.04653 & -0.00010 & -0.01434 & -0.30069 & 0.03524 & 0.01942 & -0.15249 & -0.22244 \\
\hline
\end{tabular}

Table K.2 Pearson Coefficients of Correlation Between the Median Treatments and the First-Order Interaction Between the Corresponding Median Treatment and the other Traffic and Geometric Variables

\begin{tabular}{|c|c|c|c|c|c|c|c|c|c|c|c|c|}
\hline \multirow{2}{*}{ Variables } & \multicolumn{10}{|c|}{ Median Treatment } \\
\cline { 2 - 11 } & D2H & D3H & D2L & D3L & C3N & B3N & F1W & F1C & F2C & S3N & D1N & D2N \\
\hline Int w/ LNS & 1 & 0.98344 & 0.97966 & 1 & 0.99248 & 0.9781 & 1 & 0.98384 & 0.99337 & 0.94996 & 0.98587 & 0.98735 \\
Int w/ POB & X & X & 0.75075 & X & 0.17716 & 0.07988 & $X$ & 0.39215 & 0.12809 & 0.23569 & 0.24485 & 0.28213 \\
Int w/ AADT & 0.99858 & 0.98392 & 0.88091 & 0.89498 & 0.83843 & 0.73113 & 0.99721 & 0.86518 & 0.97308 & 0.70587 & 0.82443 & 0.91707 \\
Int w/ PT & 0.99615 & 0.96903 & 0.97388 & 0.99858 & 0.95689 & 0.9035 & 1 & 0.88948 & 0.96115 & 0.92879 & 0.89234 & 0.99226 \\
Int w/ ROF & 0.65553 & 0.54603 & 0.73063 & 0.34908 & 0.4274 & 0.5002 & 0.69611 & 0.81246 & 0.83748 & 0.6004 & 0.50011 & 0.42181 \\
Int w/ RON & 0.65553 & 0.55058 & 0.67276 & 0.34908 & 0.53027 & 0.58785 & 0.69611 & 0.7538 & 0.80796 & 0.52951 & 0.48862 & 0.32985 \\
Int w/ BRG & $\mathrm{X}$ & 0.487 & 0.65799 & $\mathrm{X}$ & 0.55091 & 0.39282 & $\mathrm{X}$ & 0.60308 & 0.80973 & 0.40649 & 0.31374 & $\mathrm{X}$ \\
Int W/ PVC & 0.90304 & 0.75845 & 0.53915 & 0.63259 & 0.49702 & 0.5425 & 0.76001 & 0.47008 & 0.51651 & 0.56288 & 0.38408 & 0.71917 \\
Int w/ PHC & 0.32651 & 0.45327 & 0.51116 & 0.11409 & 0.44736 & 0.57401 & 0.37326 & 0.42599 & 0.39056 & 0.56092 & 0.34315 & 0.53002 \\
Int w/ PSL & 1 & 0.99749 & 0.99949 & 1 & 0.999 & 0.99839 & 1 & 0.99602 & 0.99935 & 0.99738 & 0.99608 & 0.99698 \\
\hline
\end{tabular}

Table K.3 Pearson Coefficients of Correlation Between the Traffic and Geometric Variables and the First-order Interaction Between the Corresponding Variable and the Median Treatments

\begin{tabular}{|c|c|c|c|c|c|c|c|c|c|c|}
\hline \multirow{2}{*}{ Variables } & \multicolumn{10}{|c|}{ Median Treatment } \\
\cline { 2 - 10 } & LNS & POB & AADT & PT & ROF & RON & BRG & PVC & PHC & PSL \\
\hline Int w/ D1N & 0.10620 & 0.09823 & 0.01275 & -0.04431 & 0.02104 & 0.03516 & $X$ & 0.10450 & 0.08881 & -0.14542 \\
Int w/ D2N & -0.11722 & 0.63019 & 0.02549 & 0.23355 & 0.53415 & 0.50242 & 0.61237 & 0.41259 & 0.42509 & -0.17118 \\
Int w/ D2H & -0.03651 & $X$ & 0.06184 & -0.08487 & 0.05420 & 0.04065 & $X$ & 0.11339 & 0.04728 & 0.15523 \\
Int w/ D3H & 0.17515 & X & 0.24818 & -0.08228 & 0.18660 & 0.14088 & 0.10334 & 0.21278 & 0.14664 & 0.12240 \\
Int w/ D2L & 0.06907 & 0.32605 & 0.12965 & -0.08291 & 0.08932 & 0.06132 & 0.03728 & 0.09773 & 0.10685 & -0.09410 \\
Int w/ D3L & 0.13322 & $X$ & 0.03610 & -0.06737 & 0.04037 & 0.03090 & $X$ & 0.08590 & 0.01786 & -0.01085 \\
Int w/ C3N & -0.07951 & 0.19780 & 0.05558 & 0.32268 & 0.21065 & 0.07218 & 0.23161 & 0.23161 & 0.24040 & 0.05403 \\
Int w/ B3N & 0.12147 & 0.07424 & 0.30600 & 0.11369 & 0.33210 & 0.21957 & 0.21044 & 0.21044 & 0.25677 & 0.01017 \\
Int w/ F1W & -0.05218 & X & -0.03250 & -0.10638 & -0.00796 & -0.01217 & X & 0.13638 & 0.07724 & -0.01434 \\
Int w/ F1C & 0.26748 & 0.38509 & 0.39627 & -0.01463 & 0.19985 & 0.17886 & 0.17450 & 0.19267 & 0.20134 & -0.27514 \\
Int w/ F2C & -0.04163 & 0.07108 & 0.05242 & -0.08871 & 0.13210 & 0.14455 & 0.12077 & 0.11963 & 0.10431 & 0.03782 \\
Int w/ S3N & 0.42656 & 0.21885 & 0.50821 & -0.04427 & 0.28010 & 0.43327 & 0.26500 & 0.21815 & 0.25069 & 0.03614 \\
\hline
\end{tabular}

